NTP TECHNICAL REPORT ON THE TOXICOLOGY AND CARCINOGENESIS Studies OF

PERFLUOROOCTANOIC ACID (CASRN 335-67-1) ADMINISTERED IN FEED

TO SPRAGUe DAWLEY (HSD:Sprague DaWleY ${ }^{\circledR}$ $S^{\circledR}$ ) RATS (REVISED)

NTP TR 598

MAY 2020

REVISED FEBRUARY 2023 


\section{NTP Technical Report on the Toxicology and Carcinogenesis Studies of Perfluorooctanoic Acid (CASRN 335-67-1) Administered in Feed to Sprague Dawley (Hsd:Sprague Dawley ${ }^{\circledR}$ SD $^{\circledR}$ ) Rats (Revised)}

Technical Report 598

May 2020

Revised February 2023

National Toxicology Program

Public Health Service

U.S. Department of Health and Human Services ISSN: 2378-8925

Research Triangle Park, North Carolina, USA 


\section{Revision Notice}

Errors were identified in the NTP Technical Report on the Toxicology and Carcinogenesis Studies of Perfluorooctanoic Acid (CASRN 335-67-1) Administered in Feed to Sprague Dawley (Hsd:Sprague Dawley ${ }^{\circledR} S D^{\circledR}$ ) Rats (Technical Report 598). For the uterine findings, changes were made to the number of animals in the $0 / 1,000$ ppm group with a neoplasm (overall rates) and the number of litters with animals with a neoplasm (litter rates). One animal with a squamous cell carcinoma in the 0/1,000 ppm group was inadvertently combined in the adenocarcinoma analysis of the extended evaluation. The number of animals examined during the standard, extended, and standard or extended (combined) evaluations was also corrected in the $0 / 300,0 / 1,000$, and 300/1,000 ppm groups. Due to these corrections in the incidence data, statistical analysis was rerun, and the Rao-Scott-adjusted Poly-3 test $p$ values were updated for all exposure groups. As a result, the trend tests for uterine adenocarcinoma are no longer statistically significant $(\mathrm{p}>0.05)$ for the extended and the standard or extended (combined) evaluations. In addition, the pairwise comparisons of adenocarcinoma incidence between the control and the $0 / 1,000 \mathrm{ppm}$ groups are now $\mathrm{p}=0.05$ for the extended and the standard or extended (combined) evaluations. The original conclusion that the higher incidence of uterine adenocarcinoma may have been related to PFOA exposure (equivocal evidence) is not changed. These corrections are described in detail in Appendix F. [February 1, 2023] 


\section{Foreword}

The National Toxicology Program (NTP), established in 1978, is an interagency program within the Public Health Service of the U.S. Department of Health and Human Services. Its activities are executed through a partnership of the National Institute for Occupational Safety and Health (part of the Centers for Disease Control and Prevention), the Food and Drug Administration (primarily at the National Center for Toxicological Research), and the National Institute of Environmental Health Sciences (part of the National Institutes of Health), where the program is administratively located. NTP offers a unique venue for the testing, research, and analysis of agents of concern to identify toxic and biological effects, provide information that strengthens the science base, and inform decisions by health regulatory and research agencies to safeguard public health. NTP also works to develop and apply new and improved methods and approaches that advance toxicology and better assess health effects from environmental exposures.

The Technical Report series began in 1976 with carcinogenesis studies conducted by the National Cancer Institute. In 1981, this bioassay program was transferred to NTP. The studies described in the NTP Technical Report series are designed and conducted to characterize and evaluate the toxicological potential, including carcinogenic activity, of selected substances in laboratory animals (usually two species, rats and mice). Substances (e.g., chemicals, physical agents, and mixtures) selected for NTP toxicity and carcinogenicity studies are chosen primarily on the basis of human exposure, level of commercial production, and chemical structure. The interpretive conclusions presented in NTP Technical Reports are derived solely from the results of these NTP studies, and extrapolation of the results to other species, including characterization of hazards and risks to humans, requires analyses beyond the intent of these reports. Selection for study per se is not an indicator of a substance's carcinogenic potential.

NTP conducts its studies in compliance with its laboratory health and safety guidelines and the Food and Drug Administration Good Laboratory Practice Regulations and meets or exceeds all applicable federal, state, and local health and safety regulations. Animal care and use are in accordance with the Public Health Service Policy on Humane Care and Use of Laboratory Animals. Studies are subjected to retrospective quality assurance audits before they are presented for public review. Draft reports undergo external peer review before they are finalized and published.

The NTP Technical Reports are available free of charge on the NTP website and cataloged in PubMed, a free resource developed and maintained by the National Library of Medicine (part of the National Institutes of Health). Data for these studies are included in NTP's Chemical Effects in Biological Systems database.

For questions about the reports and studies, please email NTP or call 984-287-3211. 


\section{Table of Contents}

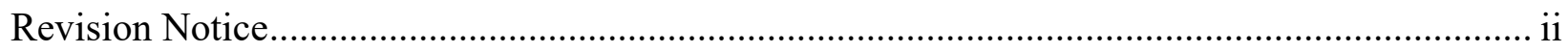

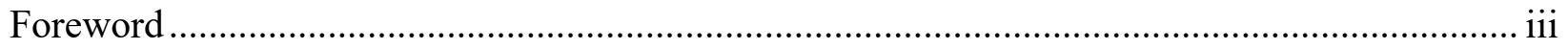

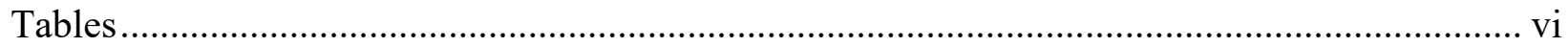

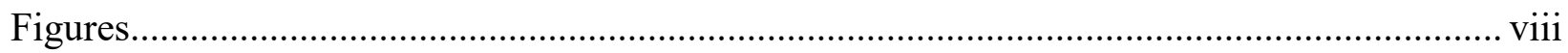

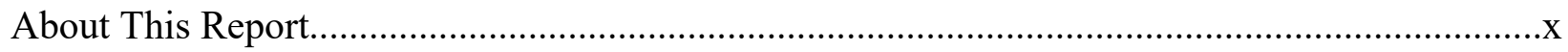

Explanation of Levels of Evidence of Carcinogenic Activity .................................................... xiv

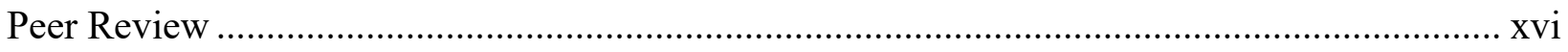

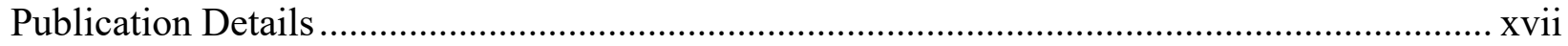

Acknowledgments................................................................................................... Xvii

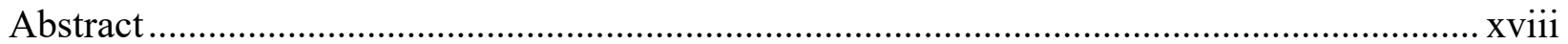

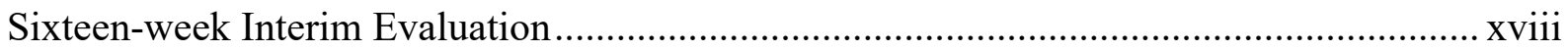

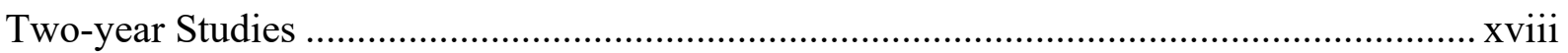

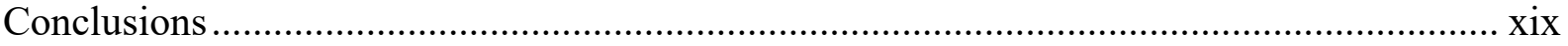

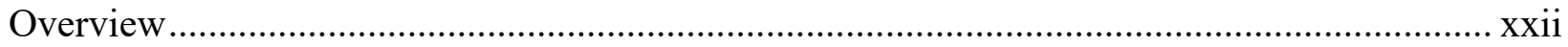

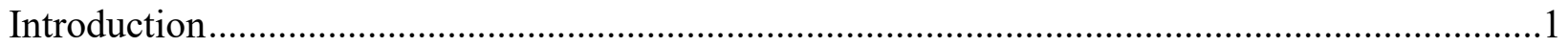

Chemical and Physical Properties...........................................................................................

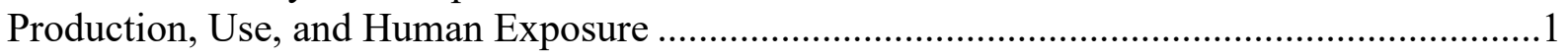

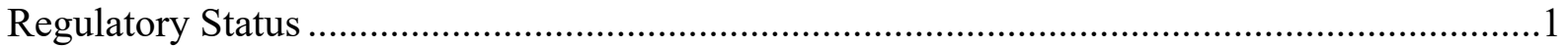

Absorption, Distribution, Metabolism, and Excretion .............................................................

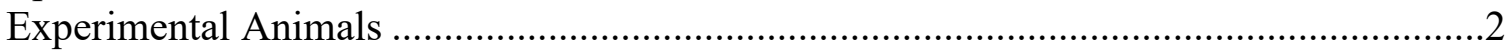

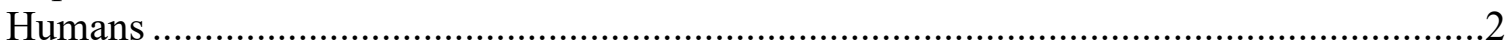

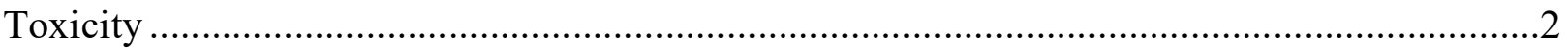

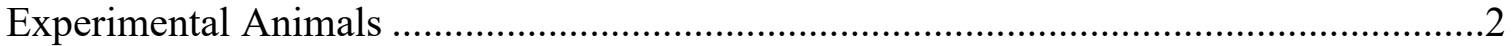

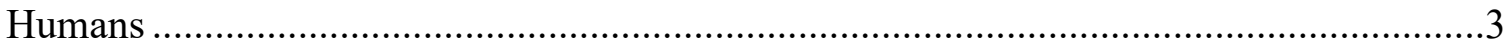

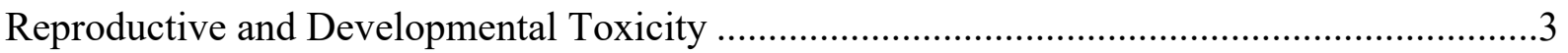

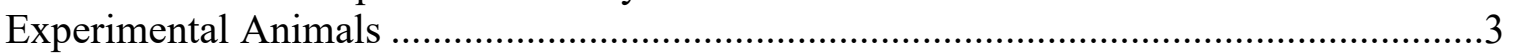

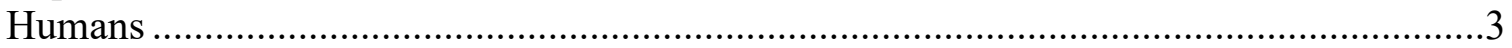

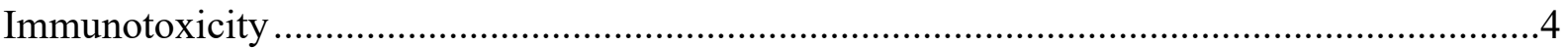

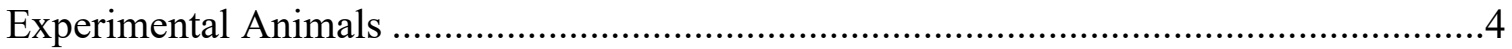

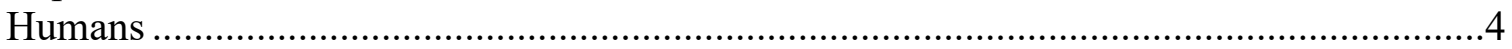

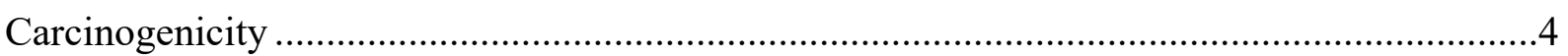

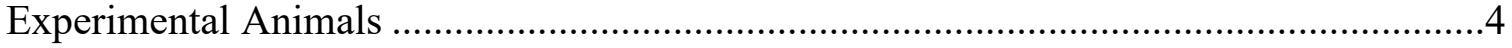

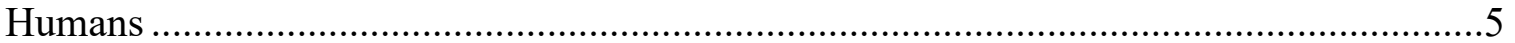

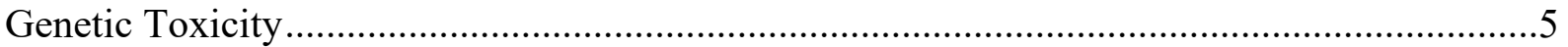

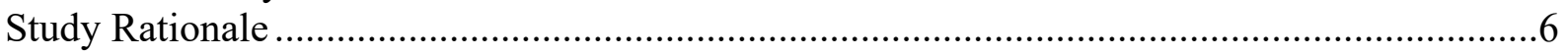

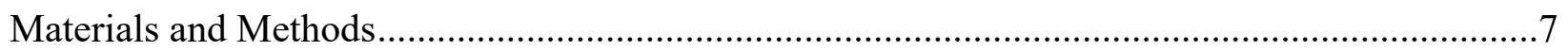

Procurement and Characterization of Perfluorooctanoic Acid ....................................................

Preparation and Analysis of Dose Formulations.................................................................

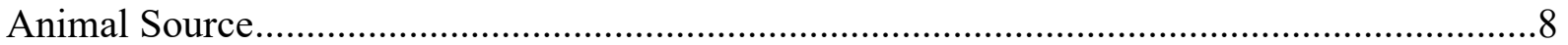


Animal Welfare

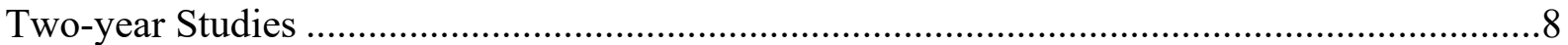

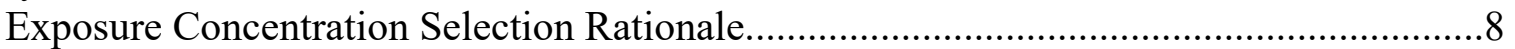

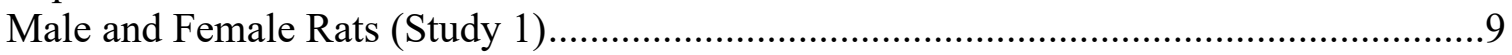

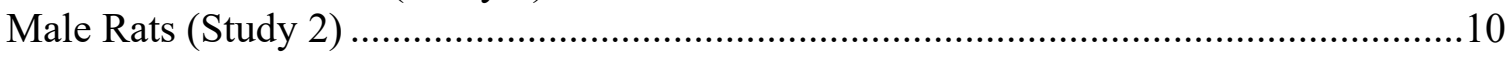

Clinical Examinations and Pathology (Studies 1 and 2)................................................. 11

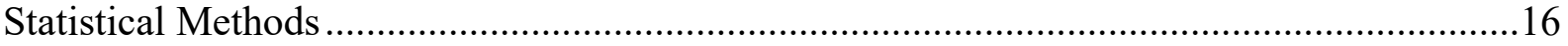

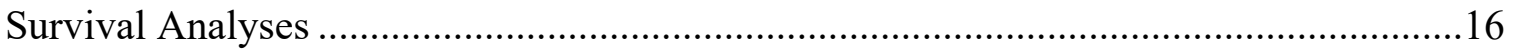

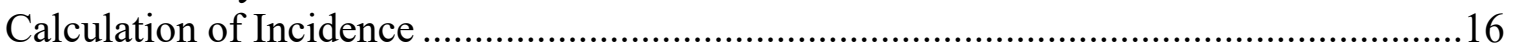

Analysis of Neoplasm and Nonneoplastic Lesion Incidences ..........................................17

Analysis of Continuous Variables ...........................................................................18

Analysis of Gestational and Fertility Indices................................................................18

Body Weight Adjustments........................................................................................18

Testing Effects of Perinatal and Postweaning Exposures...............................................19

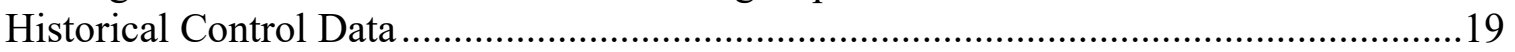

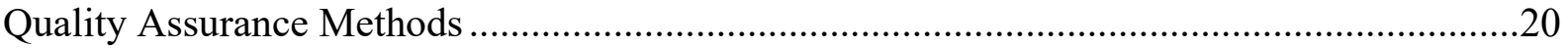

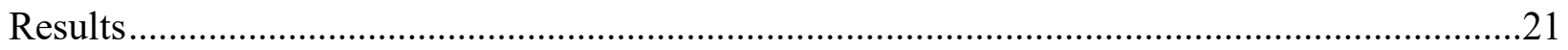

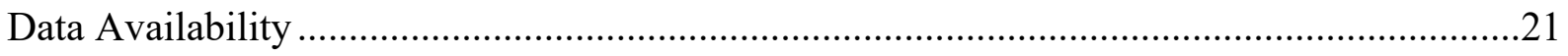

Study 1: Two-year Study in Females and 16-week Interim Evaluation in Males and

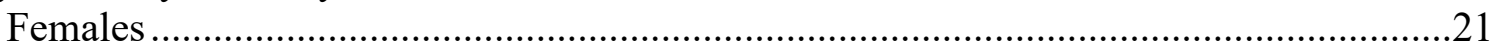

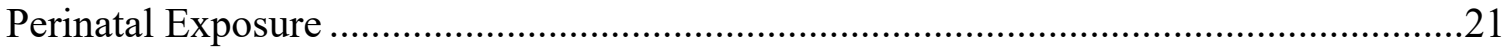

Sixteen-week Interim Evaluation in Males and Females (Study 1)................................24

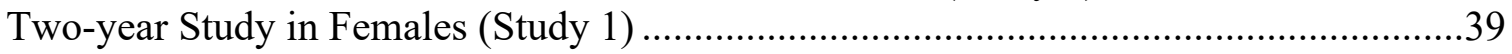

Study 2: Two-year Study in Males with 16-week Interim Evaluation.......................................53

Perinatal Exposure …………………………………..........................................53

Sixteen-week Interim Evaluation in Males (Study 2) ....................................................57

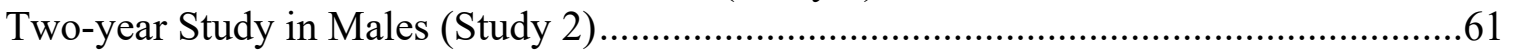

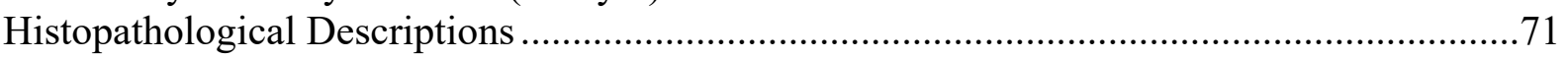

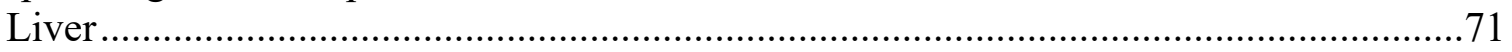

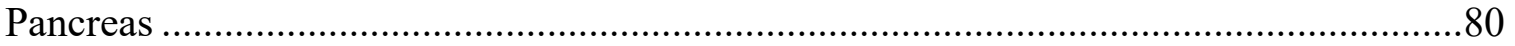

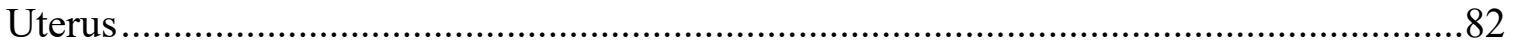

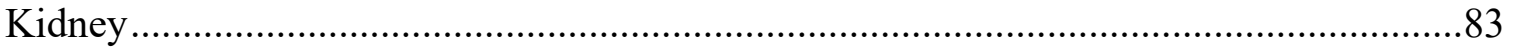

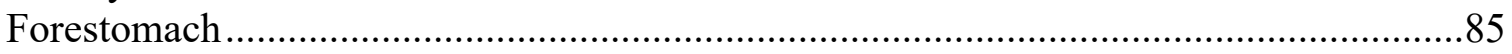

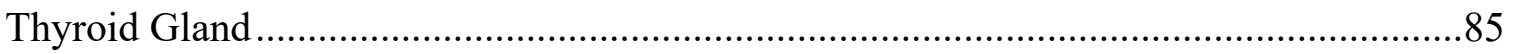

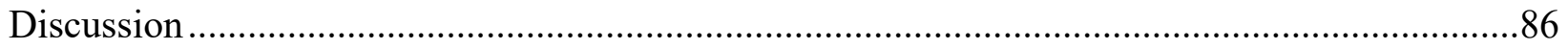

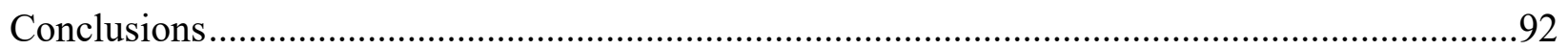

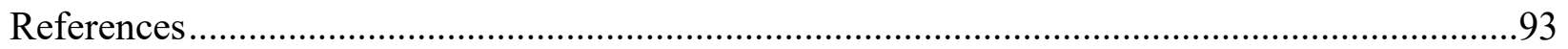

Appendix A. Chemical Characterization and Dose Formulation Studies.................................. A-1

Appendix B. Ingredients, Nutrient Composition, and Contaminant Levels in NTP-2000

Rat and Mouse Ration ....................................................................................

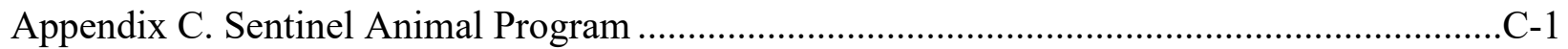

Appendix D. Summary of Peer Review Panel Comments ………………………….............. D-1

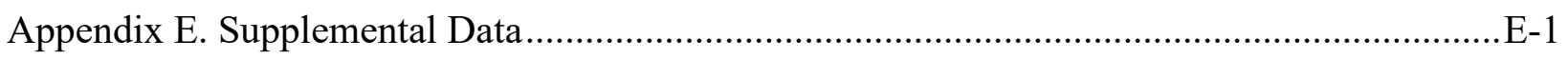




\section{Tables}

Summary of the Two-year Toxicology and Carcinogenesis Studies of Perfluorooctanoic Acid with and without Perinatal Exposure.... XX

Table 1. Exposures during Perinatal and Postweaning Periods in Rats in the First Twoyear Feed Study of Perfluorooctanoic Acid (Study 1)

Table 2. Exposures during Perinatal and Postweaning Periods in Male Rats in the Second Two-year Feed Study of Perfluorooctanoic Acid (Study 2).....

Table 3. Experimental Design and Materials and Methods in the Two-year Feed Studies of Perfluorooctanoic Acid.

Table 4. Summary of Disposition during Perinatal Exposure and $F_{1}$ Allocation in the Two-year Perinatal and Postweaning Study of Perfluorooctanoic Acid (Study 1)

Table 5. Mean Body Weights and Body Weight Gains of $\mathrm{F}_{0}$ Females during Gestation in the Two-year Perinatal and Postweaning Study of Perfluorooctanoic Acid (Study 1)

Table 6. Mean Body Weights and Body Weight Gains of $F_{0}$ Females during Lactation in the Two-year Perinatal and Postweaning Study of Perfluorooctanoic Acid (Study 1)

Table 7. Feed Consumption by $F_{0}$ Females during Gestation and Lactation in the Twoyear Perinatal and Postweaning Study of Perfluorooctanoic Acid (Study 1).

Table 8. Mean Litter Size and Survival Ratio of $F_{1}$ Rats during Lactation in the Two-year Perinatal and Postweaning Study of Perfluorooctanoic Acid (Study 1)

Table 9. Mean Body Weight of $F_{1}$ Rats during Lactation in the Two-year Perinatal and Postweaning Study of Perfluorooctanoic Acid (Study 1).

Table 10. Summary of Plasma and Liver Concentration Data for Male Rats at the 16week Interim of the Two-year Feed Study of Perfluorooctanoic Acid (Study 1) ........25

Table 11. Summary of Plasma and Liver Concentration Data for Female Rats at the 16week Interim of the Two-year Feed Study of Perfluorooctanoic Acid (Study 1) .........26

Table 12. Summary of Hepatic Findings for Male Rats at the 16-week Interim of the Two-year Feed Study of Perfluorooctanoic Acid (Study 1).

Table 13. Summary of Hepatic Findings for Female Rats at the 16-week Interim of the Two-year Feed Study of Perfluorooctanoic Acid (Study 1).

Table 14. Select Organ Weights and Organ-Weight-to-Body-Weight Ratios for Male Rats at the 16-week Interim of the Two-year Feed Study of Perfluorooctanoic Acid (Study 1)

Table 15. Select Clinical Chemistry Data for Male Rats at the 16-week Interim of the Two-year Feed Study of Perfluorooctanoic Acid (Study 1).

Table 16. Select Clinical Chemistry Data for Female Rats at the 16-week Interim of the Two-year Feed Study of Perfluorooctanoic Acid (Study 1).

Table 17. Incidences of Select Nonneoplastic Lesions of the Thyroid Gland, Kidney, and Glandular Stomach in Male Rats at the 16-week Interim of the Two-year Feed Study of Perfluorooctanoic Acid (Study 1) 
Table 18. Incidences of Select Nonneoplastic Lesions of the Thyroid Gland and Kidney in Female Rats at the 16-week Interim of the Two-year Feed Study of Perfluorooctanoic Acid (Study 1)

Table 19. Survival of Female Rats Following Postweaning-only Exposure in the Twoyear Feed Study of Perfluorooctanoic Acid (Study 1)

Table 20. Survival of Female Rats Following Perinatal and Postweaning Exposure in the Two-year Feed Study of Perfluorooctanoic Acid (Study 1)....

Table 21. Mean Body Weights and Survival of Female Rats Following Postweaning-only Exposure in the Two-year Feed Study of Perfluorooctanoic Acid (Study 1)

Table 22. Mean Body Weights and Survival of Female Rats Following Perinatal and Postweaning Exposure in the Two-year Feed Study of Perfluorooctanoic Acid (Study 1)

Table 23. Incidences of Neoplastic and Nonneoplastic Liver Lesions in Female Rats in the Two-year Feed Study of Perfluorooctanoic Acid (Study 1)

Table 24. Incidences of Neoplastic and Nonneoplastic Pancreas Lesions in Female Rats in the Two-year Feed Study of Perfluorooctanoic Acid (Study 1)

Table 25. Incidences of Neoplastic and Nonneoplastic Lesions in the Standard and Extended Evaluations of the Uterus in the Two-year Feed Study of Perfluorooctanoic Acid in Female Rats (Study 1)

Table 26. Incidences of Select Nonneoplastic Lesions in the Kidney, Stomach, and Thyroid Gland of Female Rats in the Two-year Feed Study of Perfluorooctanoic Acid (Study 1).

Table 27. Summary of Disposition during Perinatal Exposure and $F_{1}$ Allocation in the Two-year Perinatal and Postweaning Study of Perfluorooctanoic Acid (Study 2)

Table 28. Perfluorooctanoic Acid Concentrations in $\mathrm{F}_{0}$ and $\mathrm{F}_{1}$ Rats in the Two-year Perinatal and Postweaning Study of Perfluorooctanoic Acid (Study 2)....

Table 29. Mean Body Weights and Body Weight Gains of $F_{0}$ Females during Gestation in the Two-year Perinatal and Postweaning Study of Perfluorooctanoic Acid (Study 2)

Table 30. Mean Body Weights and Body Weight Gains of $\mathrm{F}_{0}$ Females during Lactation in the Two-year Perinatal and Postweaning Study of Perfluorooctanoic Acid (Study 2)

Table 31. Feed Consumption by $F_{0}$ Females during Gestation and Lactation in the Twoyear Perinatal and Postweaning Study of Perfluorooctanoic Acid (Study 2)

Table 32. Mean Litter Size, Survival Ratio, and Mean Body Weights of $F_{1}$ Rats during Lactation in the Two-year Perinatal and Postweaning Study of Perfluorooctanoic Acid (Study 2)....

Table 33. Summary of Plasma and Liver Concentration Data for Male Rats at the 16week Interim of the Two-year Feed Study of Perfluorooctanoic Acid (Study 2) ........57

Table 34. Summary of Hepatic Findings for Male Rats at the 16-week Interim of the Two-year Feed Study of Perfluorooctanoic Acid (Study 2)...

Table 35. Select Organ Weights and Organ-Weight-to-Body-Weight Ratios for Male Rats at the 16-week Interim of the Two-year Feed Study of Perfluorooctanoic Acid (Study 2) 
Table 36. Select Clinical Chemistry Findings for Male Rats at the 16-week Interim of the Two-year Feed Study of Perfluorooctanoic Acid (Study 2).

Table 37. Incidences of Nonneoplastic Liver Lesions in Male Rats at the 16-week Interim of the Two-year Feed Study of Perfluorooctanoic Acid (Study 2)...

Table 38. Survival of Male Rats Following Postweaning-only Exposure in the Two-year Feed Study of Perfluorooctanoic Acid (Study 2)

Table 39. Survival of Male Rats Following Perinatal and Postweaning Exposure in the Two-year Feed Study of Perfluorooctanoic Acid (Study 2)....

Table 40. Mean Body Weights and Survival of Male Rats Following Postweaning-only Exposure in the Two-year Feed Study of Perfluorooctanoic Acid (Study 2).

Table 41. Mean Body Weights and Survival of Male Rats Following Perinatal and Postweaning Exposure in the Two-year Feed Study of Perfluorooctanoic Acid (Study 2)

Table 42. Incidences of Select Neoplastic and Nonneoplastic Liver Lesions in Male Rats in the Two-year Feed Study of Perfluorooctanoic Acid (Study 2)

Table 43. Incidences of Select Neoplastic and Nonneoplastic Pancreas Lesions in Male Rats in the Two-year Feed Study of Perfluorooctanoic Acid (Study 2).

\section{Figures}

Figure 1. Perfluorooctanoic Acid (CASRN 335-67-1; Chemical Formula $\mathrm{C}_{8} \mathrm{HF}_{15} \mathrm{O}_{2}$; Molecular Weight: 414.07)....

Figure 2. Growth Curves for Male Rats with Postweaning-only Exposure to 0/0, 0/150, or 0/300 ppm Perfluorooctanoic Acid in Feed for 21 Weeks.

Figure 3. Growth Curves for Male Rats with Perinatal and Postweaning Exposure to 0/0, 150/150, or 300/300 ppm Perfluorooctanoic Acid in Feed for 21 Weeks .

Figure 4. Kaplan-Meier Survival Curves for Female Rats Exposed to Perfluorooctanoic Acid in Feed for Two Years

Figure 5. Growth Curves for Female Rats with Postweaning-only Exposure to 0/0, 0/300, or 0/1,000 ppm Perfluorooctanoic Acid in Feed for Two Years (Study 1)

Figure 6. Growth Curves for Female Rats with Perinatal and Postweaning Exposure to 0/0, 150/300, or 300/1,000 ppm Perfluorooctanoic Acid in Feed for Two Years (Study 1).

Figure 7. Kaplan-Meier Survival Curves for Male Rats Exposed to Perfluorooctanoic Acid in Feed for Two Years (Study 2).

Figure 8. Growth Curves for Male Rats with Postweaning-only Exposure to 0/0, 0/20, 0/40, or 0/80 ppm Perfluorooctanoic Acid in Feed for Two Years (Study 2)

Figure 9. Growth Curves for Male Rats with Perinatal and Postweaning Exposure to 300/0, 300/20, 300/40, or 300/80 ppm Perfluorooctanoic Acid in Feed for Two Years (Study 2)

Figure 10. Hepatocellular Adenoma in a Male Sprague Dawley Rat Exposed to Perfluorooctanoic Acid in Feed for Two Years (Study 2)

Figure 11. Hepatocellular Carcinoma in a Female Sprague Dawley Rat Exposed to Perfluorooctanoic Acid in Feed for Two Years (Study 1)

Figure 12. Hepatocellular Adenoma in a Male Sprague Dawley Rat Exposed to

Perfluorooctanoic Acid in Feed for Two Years (Study 2) 
Figure 13. Hepatocellular Carcinoma in a Male Sprague Dawley Rat Exposed to Perfluorooctanoic Acid in Feed for Two Years (Study 2)

Figure 14. Mixed-cell Focus of Hepatocytes from the Liver of a Male Sprague Dawley Rat Exposed to Perfluorooctanoic Acid in Feed for Two Years (Study 2).

Figure 15. Hepatocyte Cytoplasmic Alteration and Hypertrophy in a Male Sprague Dawley Rat Exposed to Perfluorooctanoic Acid in Feed for Two Years (Study 2)

Figure 16. Hepatocyte Single Cell Death in a Female Sprague Dawley Rat Exposed to Perfluorooctanoic Acid in Feed for Two Years (Study 1)

Figure 17. Hepatocyte Necrosis in a Female Sprague Dawley Rat Exposed to Perfluorooctanoic Acid in Feed for Two Years (Study 1)....

Figure 18. Hepatocyte Pigment in a Female Sprague Dawley Rat Exposed to Perfluorooctanoic Acid in Feed for Two Years (Study 1) .78

Figure 19. Bile Duct Hyperplasia in a Female Sprague Dawley Rat Exposed to Perfluorooctanoic Acid in Feed for Two Years (Study 1)

Figure 20. Hepatocyte Mitoses in a Female Sprague Dawley Rat Exposed to Perfluorooctanoic Acid in Feed for Two Years (Study 1)

Figure 21. Acinar Cell Hyperplasia and Adenoma of the Pancreas in a Male Sprague Dawley Rat Exposed to Perfluorooctanoic Acid for Two Years (Study 2)

Figure 22. Adenocarcinoma of the Pancreas in a Male Sprague Dawley Rat Exposed to Perfluorooctanoic Acid in Feed for Two Years (Study 2)

Figure 23. Adenocarcinoma of the Uterus in a Female Sprague Dawley Rat Exposed to Perfluorooctanoic Acid in Feed for Two Years (Study 1)

Figure 24. Papilla Urothelial Hyperplasia in the Kidney of a Female Sprague Dawley Rat Exposed to Perfluorooctanoic Acid in Feed for Two Years (Study 1)

Figure 25. Papillary Necrosis in the Kidney of a Female Rat Exposed to Perfluorooctanoic Acid in Feed for Two Years (Study 1)

Figure 26. Forestomach Ulcer in the Stomach of a Female Sprague Dawley Rat Exposed to Perfluorooctanoic Acid in Feed for Two Years (Study 1) 


\section{About This Report}

National Toxicology Program ${ }^{1}$

${ }^{1}$ Division of the National Toxicology Program, National Institute of Environmental Health Sciences, Research Triangle Park, North Carolina, USA

\section{Collaborators}

C.R. Blystone, R.A. Herbert, K.S. Janardhan, E.T. Adams, A.E. Brix, B.L. Burback, C. Co, D.A. Contos, M.C. Cora, T.A. Crabbs, T.A. Cristy, H.C. Cunny, J.M. Fostel, D.K. Gerken, S.W. Graves, M.R. Hejtmancik, J. Hoane, M.J. Hooth, M. Jokinen, J. Pierfelice, A.P. KingHerbert, J. Krause, Y.I. Lu, D.E. Malarkey, S. McBride, B.S. McIntyre, G.K. Roberts, V.G. Robinson, M.J. Ryan, K.R. Shockley, S.L. Smith-Roe, E.M. Snyder, N.L. South, M.D. Stout, G.S. Travlos, D.Y. Vasconcelos, S. Waidyanatha, N.J. Walker, A. Watson, K.L. Witt

Division of the National Toxicology Program, National Institute of Environmental Health Sciences, Research Triangle Park, North Carolina, USA

Evaluated and interpreted results and reported findings

C.R. Blystone, Ph.D., Study Scientist

R.A. Herbert, D.V.M., Ph.D., Co-Study Pathologist

M.C. Cora, D.V.M.

H.C. Cunny, Ph.D.

M.J. Hooth, Ph.D.

A.P. King-Herbert, D.V.M.

D.E. Malarkey, D.V.M., Ph.D.

B.S. McIntyre, Ph.D.

G.K. Roberts, Ph.D.

V.G. Robinson, M.S.

K.R. Shockley, Ph.D.

S.L. Smith-Roe, Ph.D.

M.D. Stout, Ph.D.

G.S. Travlos, D.V.M.

S. Waidyanatha, Ph.D.

N.J. Walker, Ph.D.

A. Watson, Ph.D.

K.L. Witt, M.S.

Provided oversight for data management

J.M. Fostel, Ph.D.

Integrated Laboratory Systems, Inc., Research Triangle Park, North Carolina, USA Evaluated and interpreted results and reported findings

K.S. Janardhan, Ph.D., Co-Study Pathologist

Coordinated NTP Pathology Peer Review for hearts from control Harlan Sprague Dawley rats (April 14, 2016)

M. Jokinen, D.V.M. 
Coordinated NTP Pathology Working Group for 21-week and 2-year rats (June 14, 2017)

E.T. Adams, D.V.M., Ph.D.

Battelle, Columbus, Ohio, USA

Conducted studies and evaluated pathology findings

M.R. Hejtmancik, Ph.D., Principal Investigator

D.A. Contos, M.S.

D.K. Gerken, D.V.M., Ph.D.

M.J. Ryan, D.V.M., Ph.D.

D.Y. Vasconcelos, D.V.M., Ph.D.

Conducted prestart chemistry activities, dose formulations, and biological sample chemistry analyses

S.W. Graves, B.S., Principal Investigator

B.L. Burback, Ph.D.

D.A. Contos, M.S.

T.A. Cristy, B.A.

J. Pierfelice, B.S.

E.M. Snyder, Ph.D.

N.L. South, B.S.

Pathology Associates International, Charles River Laboratories, Inc., Research Triangle Park, North Carolina, USA

Provided pathology review

J. Hoane, D.V.M.

Experimental Pathology Laboratories, Inc., Research Triangle Park, North Carolina, USA Provided pathology review

A.E. Brix, D.V.M., Ph.D.

T.A. Crabbs, D.V.M.

Social \& Scientific Systems, Inc., Research Triangle Park, North Carolina, USA

Provided statistical analyses

S. McBride, Ph.D., Principal Investigator

C. Co, M.S.

J. Krause, Ph.D.

Y.I. Lu, M.S.

\section{Contributors}

Division of the National Toxicology Program, National Institute of Environmental Health Sciences, Research Triangle Park, North Carolina, USA

Provided oversight of external peer review

E.A. Maull, Ph.D.

M.S. Wolfe, Ph.D. 
Experimental Pathology Laboratories, Inc., Research Triangle Park, North Carolina, USA Supervised pathology review

M.H. Hamlin, II, D.V.M., Principal Investigator

NTP Pathology Working Group, National Institute of Environmental Health Sciences, Research Triangle Park, North Carolina, USA

Participated in NTP Pathology Working Group for 21-week and 2-year rats (March 31, 2016)

T.A. Crabbs, D.V.M., Experimental Pathology Laboratories, Inc.

S.A. Elmore, D.V.M., M.S., National Toxicology Program

K.S. Janardhan, Ph.D., ILS, Inc.

R.A. Herbert, D.V.M., Ph.D., National Toxicology Program

D.E. Malarkey, D.V.M., Ph.D., National Toxicology Program

A.R. Pandiri, D.V.M., Ph.D., National Toxicology Program

A. Remick, D.V.M., Ph.D., Charles River Laboratories, Inc.

Participated in NTP Pathology Working Group for uterine lesions in female rats (June 16, 2016)

E.T. Adams, D.V.M., Ph.D., ILS, Inc.

G.A. Boorman, D.V.M., Ph.D., Covance, Inc.

A.E. Brix, D.V.M., Ph.D., Experimental Pathology Laboratories, Inc.

D. Dixon, D.V.M., Ph.D., National Toxicology Program

S.A. Elmore, D.V.M., M.S., National Toxicology Program

R.A. Herbert, D.V.M., Ph.D., National Toxicology Program

K.S. Janardhan, Ph.D., ILS, Inc.

C. Johnson, D.V.M., Charles River Laboratories, Inc.

K.S. Regan, D.V.M., Regan Path/Tox Services, Inc.

NTP Pathology Peer Review, National Institute of Environmental Health Sciences, Research Triangle Park, North Carolina, USA

Participated in NTP Pathology Peer Review for hearts from control Harlan Sprague Dawley

rats (April 14, 2016)

M.F. Cesta, D.V.M., Ph.D., National Toxicology Program

S.A. Elmore, D.V.M., M.S., National Toxicology Program

D.E. Malarkey, D.V.M., Ph.D., National Toxicology Program

C.C. Shackelford, D.V.M., Ph.D., Experimental Pathology Laboratories, Inc.

NTP Pathology Peer Review, National Institute of Environmental Health Sciences, Research Triangle Park, North Carolina, USA

Participated in NTP Pathology Peer Review for brains from control Harlan Sprague Dawley rats (May 19, 2016)

M.F. Cesta, D.V.M., Ph.D., National Toxicology Program

J. Hoane, D.V.M., Pathology Associates International, Charles River Laboratories, Inc.

P. Little, D.V.M., Ph.D., Experimental Pathology Laboratories, Inc.

D.E. Malarkey, D.V.M., Ph.D., National Toxicology Program

CSS Corporation, Research Triangle Park, North Carolina, USA

Prepared quality assessment audits

S. Brecher, Ph.D., Principal Investigator 
S. Iyer, B.S.

V.S. Tharakan, D.V.M.

ICF, Durham, North Carolina, USA

Provided contract oversight

D.F. Burch, M.E.M., Principal Investigator

J.C. Cleland, M.E.M.

J.A. Wignall, M.S.P.H.

Prepared, edited, and formatted report

J. Frye, M.S.

S.R. Gunnels, M.A.

T. Hamilton, M.S.

P.A. Hartman, M.E.M.

B. Ingle, Ph.D.

M. McVey, Ph.D.

K.A. Shipkowski, Ph.D.

Supported external peer review

C.N. Byrd, B.S.

S.A. Hearn, B.S.

S.J. Snow, Ph.D.

Biotechnical Services, Inc., Little Rock, Arkansas, USA

Prepared report

S.R. Gunnels, M.A., Principal Investigator

L.M. Harper, B.S.

J.I. Powers, M.A.P.

D.C. Serbus, Ph.D. 


\section{Explanation of Levels of Evidence of Carcinogenic Activity}

The National Toxicology Program describes the results of individual experiments on a chemical agent and notes the strength of the evidence for conclusions regarding each study. Negative results, in which the study animals do not have a greater incidence of neoplasia than control animals, do not necessarily mean that a chemical is not a carcinogen, inasmuch as the experiments are conducted under a limited set of conditions. Positive results demonstrate that a chemical is carcinogenic for laboratory animals under the conditions of the study and indicate that exposure to the chemical has the potential for hazard to humans. Other organizations, such as the International Agency for Research on Cancer, assign a strength of evidence for conclusions based on an examination of all available evidence, including animal studies such as those conducted by NTP, epidemiologic studies, and estimates of exposure. Thus, the actual determination of risk to humans from chemicals found to be carcinogenic in laboratory animals requires a wider analysis that extends beyond the purview of these studies.

Five categories of evidence of carcinogenic activity are used in the Technical Report series to summarize the strength of evidence observed in each experiment: two categories for positive results (clear evidence and some evidence); one category for uncertain findings (equivocal evidence); one category for no observable effects (no evidence); and one category for experiments that cannot be evaluated because of major flaws (inadequate study). These categories of interpretative conclusions were first adopted in June 1983 and then revised on March 1986 for use in the Technical Report series to incorporate more specifically the concept of actual weight of evidence of carcinogenic activity. For each separate experiment (male rats, female rats, male mice, female mice), one of the following five categories is selected to describe the findings. These categories refer to the strength of the experimental evidence and not to potency or mechanism.

- Clear evidence of carcinogenic activity is demonstrated by studies that are interpreted as showing a dose-related (i) increase of malignant neoplasms, (ii) increase of a combination of malignant and benign neoplasms, or (iii) marked increase of benign neoplasms if there is an indication from this or other studies of the ability of such tumors to progress to malignancy.

- Some evidence of carcinogenic activity is demonstrated by studies that are interpreted as showing a chemical-related increased incidence of neoplasms (malignant, benign, or combined) in which the strength of the response is less than that required for clear evidence.

- Equivocal evidence of carcinogenic activity is demonstrated by studies that are interpreted as showing a marginal increase of neoplasms that may be chemical related.

- No evidence of carcinogenic activity is demonstrated by studies that are interpreted as showing no chemical-related increases in malignant or benign neoplasms.

- Inadequate study of carcinogenic activity is demonstrated by studies that, because of major qualitative or quantitative limitations, cannot be interpreted as valid for showing either the presence or absence of carcinogenic activity.

For studies showing multiple chemical-related neoplastic effects that if considered individually would be assigned to different levels of evidence categories, the following convention has been 
adopted to convey completely the study results. In a study with clear evidence of carcinogenic activity at some tissue sites, other responses that alone might be deemed some evidence are indicated as "were also related" to chemical exposure. In studies with clear or some evidence of carcinogenic activity, other responses that alone might be termed equivocal evidence are indicated as "may have been" related to chemical exposure.

When a conclusion statement for a particular experiment is selected, consideration must be given to key factors that would extend the actual boundary of an individual category of evidence. Such consideration should allow for incorporation of scientific experience and current understanding of long-term carcinogenesis studies in laboratory animals, especially for those evaluations that may be on the borderline between two adjacent levels. These considerations should include:

- adequacy of the experimental design and conduct;

- occurrence of common versus uncommon neoplasia;

- progression (or lack thereof) from benign to malignant neoplasia as well as from preneoplastic to neoplastic lesions;

- some benign neoplasms have the capacity to regress but others (of the same morphologic type) progress. At present, it is impossible to identify the difference. Therefore, where progression is known to be a possibility, the most prudent course is to assume that benign neoplasms of those types have the potential to become malignant;

- combining benign and malignant tumor incidence known or thought to represent stages of progression in the same organ or tissue;

- latency in tumor induction;

- multiplicity in site-specific neoplasia;

- metastases;

- supporting information from proliferative lesions (hyperplasia) in the same site of neoplasia or other experiments (same lesion in another sex or species);

- presence or absence of dose relationships;

- statistical significance of the observed tumor increase;

- concurrent control tumor incidence as well as the historical control rate and variability for a specific neoplasm;

- survival-adjusted analyses and false positive or false negative concerns;

- structure-activity correlations; and

- in some cases, genetic toxicology. 


\section{Peer Review}

The members of the Peer Review Panel who evaluated the draft NTP Technical Report on the Toxicology and Carcinogenesis Studies of Perfluorooctanoic Acid (CASRN 335-67-1) Administered in Feed to Sprague Dawley (Hsd:Sprague Dawley ${ }^{\circledR} S D^{\circledR}$ ) Rats on December 12, 2019, are listed below. Panel members served as independent scientists, not as representatives of any institution, company, or governmental agency. A summary of the Peer Review Panel's comments is provided in Appendix D.

In this capacity, panel members had five major responsibilities in reviewing the NTP studies:

- to ascertain that all relevant literature data have been adequately cited and interpreted,

- to determine if the design and conditions of the NTP studies were appropriate,

- to ensure that the Technical Report presents the experimental results and conclusions fully and clearly,

- to judge the significance of the experimental results by scientific criteria, and

- to assess the evaluation of the evidence of carcinogenic activity and other observed toxic responses.

\section{Peer Reviewers}

\section{Russell Cattley, V.M.D., Ph.D., Chairperson}

Auburn University

Auburn, Alabama, USA

Michael R. Elwell, D.V.M., Ph.D.

APEX TOXPATH, LLC

Apex, North Carolina, USA

Wendy Halpern, D.V.M., Ph.D.

Genentech, Inc.

San Francisco, California, USA

Gabriele Ludewig, Ph.D.

University of Iowa

Iowa City, Iowa, USA

\section{Kristini Miles, Ph.D.}

Venture Chemical Consulting LLC

Atlanta, Georgia, USA 


\section{Publication Details}

Publisher: National Toxicology Program

Publishing Location: Research Triangle Park, NC

ISSN: $2378-8925$

DOI: https://doi.org/10.22427/NTP-TR-598

Report Series: NTP Technical Report Series

Report Series Number: 598

Official citation: National Toxicology Program (NTP). 2023. NTP technical report on the toxicology and carcinogenesis studies of perfluorooctanoic acid (CASRN 335-67-1) administered in feed to Sprague Dawley (Hsd:Sprague Dawley ${ }^{\circledR} \mathrm{SD}^{\circledR}$ ) rats (revised). Research Triangle Park, NC: National Toxicology Program. Technical Report 598.

\section{Acknowledgments}

This work was supported by the Intramural Research Program (ES103316, ES103318, and ES103319) at the National Institute of Environmental Health Sciences, National Institutes of Health and performed for the National Toxicology Program, Public Health Service, U.S. Department of Health and Human Services under contracts HHSN273201800006C, HHSN273201600011C, GS00Q14OADU417 (Order No. HHSN273201600015U), HHSN273201500006C, HHSN273201500012C, HHSN273201500013C, HHSN273201500014C, HHSN316201200054W, HHSN273201000016C, HHS273200900002C, N01-ES-55541, and N01-ES-55551. 


\section{Abstract}

Perfluorooctanoic acid (PFOA) is a perfluorinated alkyl substance (PFAS) with widespread exposure in the environment and human population. Lifetime exposure to this chemical is likely, which includes in utero and postnatal development. Previously conducted chronic carcinogenicity studies of PFOA began exposure after these critical periods of development, so it is unknown whether the carcinogenic response is altered if exposure during gestation and lactation is included. The current PFOA chronic studies were designed to assess the contribution of combined gestational and lactational exposure (herein referred to as perinatal exposure) to the chronic toxicity and carcinogenicity of PFOA. The hypothesis tested was that including exposure during gestation and lactation (perinatal exposure) with postweaning exposure would change the PFOA carcinogenic response quantitatively (more neoplasms) or qualitatively (different neoplasm types) compared to postweaning exposure alone.

This hypothesis was tested using a design of exposing time-mated Sprague Dawley (Hsd:Sprague Dawley ${ }^{\circledR} \mathrm{SD}^{\circledR}$ ) rats to 0,150 , or 300 ppm PFOA during the perinatal period, after which the $F_{1}$ male rats were provided 150 or 300 ppm PFOA (i.e., perinatal/postweaning exposures of $0 / 0,0 / 150,150 / 150,0 / 300$, and $300 / 300 \mathrm{ppm}$ ) and the $\mathrm{F}_{1}$ female rats were provided 300 or 1,000 ppm PFOA (i.e., 0/0, 0/300, 150/300, 0/1,000, and 300/1,000 ppm) during the postweaning period $(\mathrm{n}=50 / \mathrm{sex} /$ dose $)$. Female rats have a lower systemic exposure due to a faster PFOA elimination rate than males, so a higher feed exposure concentration was provided to female rats postweaning. An interim necropsy $(n=10 /$ sex/group) at 16 weeks ( 19 weeks of age) was conducted.

Due to unanticipated toxicity in male rats observed at the 16-week interim time point, males were removed from the first study at week 21 . A second study of males only was started that used lower postweaning feed concentrations. In this second study, the pregnant females were exposed to a single feed concentration of 300 ppm PFOA because this exposure was well tolerated.

\section{Sixteen-week Interim Evaluation}

In general, toxicity was observed in the liver, glandular stomach, kidney, and thyroid gland in males and in the liver, kidney, and thyroid gland in females at the 16-week interim evaluation. Body weights were lower in exposed groups of males and females compared to control groups as exposure concentrations increased. Plasma concentrations of PFOA were consistently higher in males compared to females and consistent between animals that were exposed to PFOA perinatally and postweaning versus postweaning exposure alone. Acyl-CoA oxidase activity in the liver was consistently elevated in males and females (males had higher activity than females) regardless of their exposure during the perinatal period.

\section{Two-year Studies}

Survival was unaffected by PFOA exposure, and there were exposure-related decreases in body weight compared to control groups in both male and female rats. Male rats had increased incidences of hepatocellular adenomas in the $0 / 40,300 / 40,0 / 80$, and 300/80 ppm groups compared to the $0 / 0 \mathrm{ppm}$ control group, and higher incidences of hepatocellular carcinomas were observed in the $300 / 80 \mathrm{ppm}$ group compared to the $0 / 80$ group. Increased pancreatic acinar cell adenomas and adenocarcinomas were observed in all postweaning exposed groups (20,40, and $80 \mathrm{ppm}$ ) with or without perinatal exposure. Although not statistically significant, there were 
occurrences in female rats of pancreatic acinar cell adenomas and adenocarcinomas in the $0 / 1,000$ and 300/1,000 ppm female groups compared to the 0/0 ppm control group. Marginally higher numbers of hepatocellular carcinomas and uterine adenocarcinomas were also observed in the PFOA-exposed groups regardless of perinatal exposure. Nonneoplastic lesions were only observed in the liver and pancreas of male rats, whereas lesions were increased in the liver, kidney, forestomach, and thyroid gland of female rats.

In general, very few significant differences were observed between the responses of groups of animals exposed to PFOA postweaning-only versus groups with both perinatal and postweaning exposures, and most of these differences were considered sporadic. The response to PFOA in female rats was generally less than that of male rats, which was consistent with the lower internal plasma concentrations of PFOA in female rats relative to male rats.

\section{Conclusions}

Under the conditions of these 2-year feed studies, there was clear evidence of carcinogenic activity (see Explanation of Levels of Evidence of Carcinogenic Activity) of PFOA in male Hsd:Sprague Dawley ${ }^{\circledR} \mathrm{SD}^{\circledR}$ rats based on the increased incidence of hepatocellular neoplasms (predominately hepatocellular adenomas) and increased incidence of acinar cell neoplasms (predominately acinar cell adenomas) of the pancreas. The additional effect of perinatal exposure in combination with postnatal exposure was uncertain and limited to the observation of hepatocellular carcinomas.

There was some evidence of carcinogenic activity of PFOA in female Hsd:Sprague Dawley ${ }^{\circledR}$ $\mathrm{SD}^{\circledR}$ rats based on the increased incidences of pancreatic acinar cell adenoma or adenocarcinoma (combined) neoplasms. The higher incidence of hepatocellular carcinomas and adenocarcinomas of the uterus may have been related to exposure. The combined perinatal and postweaning exposure was not observed to change the neoplastic or nonneoplastic response compared to the postweaning exposure alone in female rats.

Exposure to PFOA resulted in increased incidences of nonneoplastic lesions in the liver and pancreas of male rats and in the liver, kidney, forestomach, and thyroid gland of female rats. 


\section{Summary of the Two-year Toxicology and Carcinogenesis Studies of Perfluorooctanoic Acid with} and without Perinatal Exposure

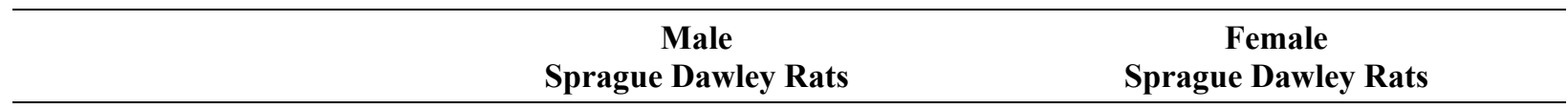

\section{Concentrations in Feed}

Postweaning

Perinatal + Postweaning

\section{Survival Rates}

Postweaning

Perinatal + Postweaning

Body Weights

Postweaning

Perinatal + Postweaning

\section{Nonneoplastic Effects}

Postweaning

Perinatal + Postweaning
0/0, 0/20, 0/40, 0/80 ppm

300/0, 300/20, 300/40, 300/80 ppm

$35 / 50,38 / 50,38 / 50,39 / 50$

0/80 ppm group: $82-90 \%$ of the $0 / 0 \mathrm{ppm}$ control group weight after week 6

300/80 ppm group: $83-90 \%$ of the

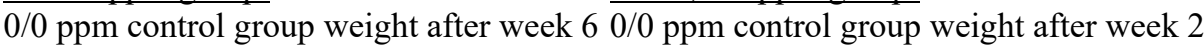

$0 / 0,0 / 300,0 / 1,000 \mathrm{ppm}$

$0 / 0,150 / 300,300 / 1,000 \mathrm{ppm}$

$23 / 50,28 / 50,23 / 50$

$23 / 50,32 / 50,23 / 50$

0/1,000 ppm group: $78-88 \%$ of the 0/0 ppm control group weight after week 2 300/1,000 ppm group: $73-86 \%$ of the
$36 / 50,42 / 50,35 / 50,37 / 50$ Liver: hepatocyte, cytoplasmic alteration $(0 / 50,12 / 50,34 / 50,46 / 50)$; hepatocyte, hypertrophy $(0 / 50,13 / 50,34 / 50,43 / 50)$; hepatocyte, single cell death $(1 / 50,1 / 50$, $11 / 50,24 / 50)$; necrosis $(2 / 50,17 / 50$, $23 / 50,20 / 50)$; pigment $(0 / 50,7 / 50,15 / 50$, $30 / 50)$

Pancreas: acinus, hyperplasia (18/50, $32 / 50,37 / 50,31 / 50$ )

Liver: hepatocyte, cytoplasmic alteration (0/50, 9/50, 49/49); hepatocyte, hypertrophy $(0 / 50,11 / 50,48 / 49)$; hepatocyte, single cell death $(0 / 50,4 / 50$, 29/49); necrosis $(0 / 50,1 / 50,8 / 49)$; pigment $(3 / 50,5 / 50,43 / 49)$; bile duct hyperplasia $(16 / 50,25 / 50,22 / 49)$; hepatocyte, increased mitoses $(2 / 50,3 / 50$, 4/49)

Kidney: papilla, urothelium, hyperplasia (4/50, 21/50, 40/49); papilla, necrosis $(0 / 50,0 / 50,12 / 49)$; renal tubule, mineral $(5 / 50,6 / 50,16 / 49)$

Forestomach: ulcer $(2 / 50,2 / 50,9 / 49)$; epithelium, hyperplasia $(4 / 50,5 / 50$, 22/49); submucosa, inflammation, chronic active $(3 / 50,2 / 50,16 / 49)$

Thyroid gland: follicular cell, hypertrophy $(4 / 50,8 / 50,28 / 49)$

Liver: hepatocyte, cytoplasmic alteration $(0 / 50,17 / 50,49 / 50)$; hepatocyte, hypertrophy $(0 / 50,16 / 50,49 / 50)$; hepatocyte, single cell death $(1 / 50,3 / 50, \quad$ hepatocyte, single cell death $(0 / 50,5 / 50$,
$5 / 50,29 / 50)$; necrosis $(1 / 50,11 / 50,14 / 50,32 / 50)$; necrosis $(0 / 50,4 / 50,5 / 50)$; $21 / 50)$; pigment $(0 / 50,4 / 50,11 / 50,26 / 50)$ pigment $(3 / 50,10 / 50,40 / 50)$; bile duct hyperplasia $(16 / 50,27 / 50,27 / 50)$;

Pancreas: acinus, hyperplasia (23/50, 27/50, 38/50, 33/50) hepatocyte, increased mitoses $(2 / 50,5 / 50$, $10 / 50)$

Kidney: papilla, urothelium, hyperplasia $(4 / 50,8 / 50,45 / 50)$; papilla, necrosis $(0 / 50$, 


\begin{tabular}{|c|c|c|}
\hline & $\begin{array}{c}\text { Male } \\
\text { Sprague Dawley Rats }\end{array}$ & $\begin{array}{l}\text { Female } \\
\text { Sprague Dawley Rats }\end{array}$ \\
\hline & & $\begin{array}{l}0 / 50,22 / 50) ; \text { renal tubule, mineral }(5 / 50, \\
8 / 50,8 / 50)\end{array}$ \\
\hline & & $\begin{array}{l}\text { Forestomach: ulcer }(2 / 50,1 / 50,11 / 50) \text {; } \\
\text { epithelium, hyperplasia }(4 / 50,3 / 50 \text {, } \\
21 / 50) \text {; submucosa, inflammation, chronic } \\
\text { active }(3 / 50,2 / 50,18 / 50)\end{array}$ \\
\hline & & $\frac{\text { Thyroid gland: follicular cell, hypertrophy }}{(4 / 50,9 / 50,19 / 50)}$ \\
\hline \multicolumn{3}{|l|}{ Neoplastic Effects } \\
\hline \multirow[t]{2}{*}{ Liver } & $\begin{array}{l}\text { Postweaning: hepatocellular adenoma } \\
(0 / 50,0 / 50,7 / 50,11 / 50) ; \text { hepatocellular } \\
\text { carcinoma }(0 / 50,0 / 50,0 / 50,0 / 50) ; \\
\text { hepatocellular adenoma or carcinoma } \\
(0 / 50,0 / 50,7 / 50,11 / 50)\end{array}$ & None \\
\hline & $\begin{array}{l}\text { Perinatal + Postweaning: hepatocellular } \\
\text { adenoma }(0 / 50,1 / 50,5 / 50,10 / 50) ; \\
\text { hepatocellular carcinoma }(0 / 50,0 / 50 \text {, } \\
0 / 50,4 / 50) \text {; hepatocellular adenoma or } \\
\text { carcinoma }(0 / 50,1 / 50,5 / 50,12 / 50)\end{array}$ & \\
\hline \multirow[t]{2}{*}{ Pancreas } & $\begin{array}{l}\text { Postweaning: acinar cell adenoma }(3 / 50 \text {, } \\
28 / 50,26 / 50,32 / 50) ; \text { acinar cell } \\
\text { adenocarcinoma }(0 / 50,3 / 50,1 / 50,3 / 50) \text {, } \\
\text { acinar cell adenoma or adenocarcinoma } \\
(3 / 50,29 / 50,26 / 50,32 / 50)\end{array}$ & $\begin{array}{l}\text { Postweaning: acinar cell adenoma }(0 / 50 \text {, } \\
0 / 50,1 / 49) ; \text { acinar cell adenocarcinoma } \\
(0 / 50,0 / 50,1 / 49) ; \text { acinar cell adenoma or } \\
\text { adenocarcinoma }(0 / 50,0 / 50,2 / 49)\end{array}$ \\
\hline & $\begin{array}{l}\text { Perinatal + Postweaning: acinar cell } \\
\text { adenoma }(7 / 50,18 / 50,30 / 50,30 / 50) \text {; } \\
\text { acinar cell adenocarcinoma }(0 / 50,2 / 50 \text {, } \\
1 / 50,3 / 50) \text {, acinar cell adenoma or } \\
\text { adenocarcinoma }(7 / 50,20 / 50,30 / 50 \text {, } \\
30 / 50)\end{array}$ & $\begin{array}{l}\text { Perinatal + Postweaning: acinar cell } \\
\text { adenoma }(0 / 50,0 / 50,3 / 50) ; \text { acinar cell } \\
\text { adenocarcinoma }(0 / 50,0 / 50,2 / 50) \text {; acinar } \\
\text { cell adenoma or adenocarcinoma }(0 / 50 \text {, } \\
0 / 50,5 / 50)\end{array}$ \\
\hline \multicolumn{3}{|l|}{ Equivocal Findings } \\
\hline \multirow[t]{2}{*}{ Liver } & None & $\frac{\text { Postweaning: hepatocellular carcinoma }}{(1 / 50,1 / 50,3 / 49)}$ \\
\hline & & $\begin{array}{l}\text { Perinatal + Postweaning: hepatocellular } \\
\text { carcinoma }(1 / 50,0 / 50,4 / 50)\end{array}$ \\
\hline \multirow[t]{2}{*}{ Uterus } & None & $\frac{\text { Postweaning: adenocarcinoma }}{7 / 49)}(1 / 50,5 / 49$, \\
\hline & & $\frac{\text { Perinatal }+ \text { Postweaning: adenocarcinoma }}{(1 / 50,3 / 50,5 / 50)}$ \\
\hline $\begin{array}{l}\text { Level of Evidence of } \\
\text { Carcinogenic Activity }\end{array}$ & Clear evidence & Some evidence \\
\hline
\end{tabular}




\section{Overview}

The per/polyfluorinated alkyl substances (PFAS) class was nominated to the National Toxicology Program (NTP) by the U.S. Environmental Protection Agency for a variety of in vitro and in vivo toxicity assessments. These included evaluation of the toxicokinetics of seven PFAS chemicals after a single dose in rats; toxicity comparisons of seven PFAS chemicals in 28-day rat studies; and in vitro class evaluations of potential neurotoxicity, mitochondrial toxicity, and immunotoxicity, with a follow-up in vivo immunotoxicity study on perfluorodecanoic acid.

In addition to the above studies, an assessment of perinatal (gestational and lactational) perfluorooctanoic acid exposure on chronic toxicity and carcinogenicity was evaluated in rats. These studies are presented in this Technical Report.

As the PFAS class continues to expand with new uses and replacements, NTP continues to assess the potential toxicity of these chemicals through a variety of methods, including in silico, in vitro, and in vivo studies. 


\section{Introduction}<smiles>O=C(O)C(F)(F)C(F)(F)C(F)(F)C(F)(F)C(F)(F)C(F)(F)C(F)(F)F</smiles>

Figure 1. Perfluorooctanoic Acid (CASRN 335-67-1; Chemical Formula $\mathrm{C}_{8} \mathrm{HF}_{15} \mathrm{O}_{2}$; Molecular Weight: 414.07)

\section{Chemical and Physical Properties}

Perfluorooctanoic acid (PFOA) is a white powder at room temperature and, as a free acid, has a melting point of $54^{\circ} \mathrm{C}$ and a boiling point of $192^{\circ} \mathrm{C}$. At $25^{\circ} \mathrm{C}$, PFOA has a water solubility of 9,500 $\mathrm{mg} / \mathrm{L}$ and a vapor pressure of $0.525 \mathrm{~mm} \mathrm{Hg} .{ }^{1}$ PFOA has an estimated $\log \mathrm{Kow}$ of $4.81 .{ }^{2}$

\section{Production, Use, and Human Exposure}

PFOA was widely used in the manufacturing of a variety of consumer products that included many nonstick applications, such as for clothing and cookware. ${ }^{3}$ However, due to concerns about persistence and potential toxicity, PFOA was removed from commerce through a 2006 agreement between the U.S. Environmental Protection Agency (EPA) and U.S. manufacturers to phase it out of production by $2015 .{ }^{1}$ Although PFOA is no longer produced in the United States, breakdown of other per/polyfluorinated alkyl substances (PFAS) may lead to continued PFOA exposure. ${ }^{4}$ In addition, concentrations of PFAS can persist in the population for a long time due to a slow elimination rate in humans and persistence in the environment.

Many surveys have been conducted of PFOA exposure in humans with general findings of widespread but lower exposure concentrations in the general population, higher concentrations around communities in areas of manufacturing and use, and the highest concentrations in manufacturing plants. The U.S. National Health and Nutrition Examination Survey (NHANES) has been evaluating PFOA concentrations in the U.S. general population for nearly two decades. The geometric mean from the 1999-2000 evaluation was $5.21 \mu \mathrm{g} / \mathrm{L}$ serum, which dropped to $1.56 \mu \mathrm{g} / \mathrm{L}$ in the 2015-2016 assessment. ${ }^{5}$ Near areas of manufacturing or use of PFOA, community concentrations were notably higher than were those in the general population. In members of the community around the Washington Works manufacturing plant in West Virginia, median concentrations were $28.2 \mu \mathrm{g} / \mathrm{L}$, but concentrations were $147.8 \mu \mathrm{g} / \mathrm{L}$ for those working in the plant. ${ }^{6}$ Prior to its discontinued use, mean serum concentrations for workers were as high as 1,030 to $1,090 \mu \mathrm{g} / \mathrm{L}$ in other plants. ${ }^{7}$

\section{Regulatory Status}

As mentioned, PFOA is not currently used in commerce because EPA and U.S. manufacturers came to an agreement to phase out its production. ${ }^{1}$ However, it is still present in many areas of the environment due to its persistence, most notably in drinking water. EPA established a PFOA drinking water health advisory of 70 parts per trillion (ppt) $(70 \mathrm{ng} / \mathrm{L})$ in $2016^{8}$ based on decreased ossification in mice pups and accelerated male puberty. ${ }^{9}$ The Agency for Toxic 
Substances and Disease Registry (ATSDR) recently developed provisional PFOA minimal risk levels of $78 \mathrm{ppt}(78 \mathrm{ng} / \mathrm{L})$ for adults and $21 \mathrm{ppt}(21 \mathrm{ng} / \mathrm{L})$ for children ${ }^{10}$ given research showing increased locomotor activity in adult mouse offspring ${ }^{11}$ and altered mouse bone morphology. ${ }^{12}$ Individual states have also developed PFOA drinking water values in accordance with their assessments; New Jersey developed a drinking water guidance of $14 \mathrm{ppt}(14 \mathrm{ng} / \mathrm{L})$ and Minnesota developed a Health Risk Limit of $35 \mathrm{ppt}(35 \mathrm{ng} / \mathrm{L}) .{ }^{13 ; 14}$ Recently, the European Food Safety Authority developed provisional tolerable weekly intakes of $6 \mathrm{ng} / \mathrm{kg} / \mathrm{week}$ for PFOA based on human endpoints. ${ }^{15}$

\section{Absorption, Distribution, Metabolism, and Excretion}

\section{Experimental Animals}

Several studies have evaluated the absorption, distribution, metabolism, and excretion properties of PFOA. PFOA is generally well absorbed and the highest concentrations are typically observed in the plasma, serum, and liver, followed by the kidney. ${ }^{16} \mathrm{PFOA}$ is water soluble, and most of its elimination occurs via urine without metabolism. Very little to no accumulation has been observed in the brain. ${ }^{17} \mathrm{~A}$ range of elimination rates have been reported and vary across species. In addition, differences in elimination occur between the sexes, most notably in rats. In rats, halflives of 2 to 15 days have been reported in males depending on the dose. ${ }^{18 ; 17 ; 19-23}$ In female rats, much faster half-lives have been observed in the order of 2 to 12 hours. ${ }^{17 ; 22 ; 23}$ In mice, half-lives of 22 days in males and 16 days in females were estimated after a single dose. ${ }^{24}$ In cynomolgus monkeys, a half-life of 14 to 42 days was estimated. ${ }^{25}$

Reuptake via renal absorption has been proposed to explain the differential elimination of the PFAS class across species and sexes. The notable sex difference of PFOA elimination in rats is reduced by castration of males, which increases clearance of PFOA, with evidence suggesting changes in organic anion transporter (OAT) 2 and OAT3 as the mechanism. ${ }^{26}$ In addition, protein binding may be another mechanism. Modeling of PFAS pharmacokinetics has included a saturable renal resorption function. ${ }^{27-31 ; 24}$

\section{Humans}

The half-life of PFOA, determined by measuring blood concentrations in retired workers $(\mathrm{n}=26)$, was estimated to be 3.8 years (arithmetic mean) and 3.5 years (geometric mean). ${ }^{32} \mathrm{~A}$ half-life average of 2.7 years was estimated from a community $(n=106)$ exposed to drinking water contaminated with PFOA..$^{33}$ A small study of ski wax technicians $(n=6)$, who use ski wax and wax-related products that contain PFOA, estimated a half-life average of 2.4 years. ${ }^{34}$

\section{Toxicity}

\section{Experimental Animals}

Extensive literature exists on the toxicity of PFOA in a variety of species. A common target is the liver, with findings ranging from liver hypertrophy or necrosis to alterations in liver enzymes and clinical chemistry changes. Peroxisome proliferator-activated receptor alpha (PPAR $\alpha)$ activation by PFAS in rodents is a mechanistic pathway that is frequently attributed to PFOA exposure, and PPAR $\alpha$ potency across the class varies with chain length. ${ }^{35-40}$ Gene expression 
profiling of the liver also suggests that constitutive androstane receptor (CAR) induction is another factor in liver toxicity and enzyme alterations, ${ }^{41 ; 42}$ with additional studies showing PFOA increases liver PPAR $\alpha$ and CAR/pregnane $\mathrm{X}$ receptor activation leading to increases in cytochrome P450 (Cyp) 2B1/2, Cyp3A1, and Cyp4A1 protein concentrations. ${ }^{43}$ In male Cr1:CD $\mathrm{BR}$ rats exposed to ammonium perfluorooctanoate (APFO) in feed (up to 100 parts per million [ppm]) for 13 weeks, toxicity findings included increased liver weight, hepatocellular hypertrophy, increased liver palmitoyl-CoA oxidase activity, and decreased serum cholesterol. ${ }^{44}$ Exposure of cynomolgus monkeys to APFO for 6 months resulted in increases in triglycerides, decreases in bilirubin, increased liver weight, and decreases in thyroid hormones without histological lesions. ${ }^{45}$

\section{Humans}

Numerous epidemiology studies have evaluated the relationship between health effects or outcomes and exposure to PFOA. These studies include both occupational and environmental exposure, including studies of individuals living in West Virginia's Mid-Ohio Valley that were exposed to high concentrations of PFOA in the drinking water from an industrial plant. An expert panel ${ }^{46}$ and ATSDR ${ }^{47}$ reviewed these studies and concluded that PFOA exposure was associated with liver damage, ${ }^{47}$ increases in serum lipid concentrations, especially cholesterol, pregnancy-induced hypertension and/or pre-eclampsia, immune effects, and thyroid diseases. ${ }^{47 ; 46}$

\section{Reproductive and Developmental Toxicity}

\section{Experimental Animals}

PFOA has been evaluated in several rodent studies for developmental and reproductive toxicity. Gestational exposure to PFOA in mice resulted in developmental and reproductive toxicity ranging from whole litter loss to developmental delays. ${ }^{48 ; 9}$ A two-generation study in Sprague Dawley rats observed a small reduction in pup survival during lactation, decreases in body weights, and delays in pubertal markers at $30 \mathrm{mg} / \mathrm{kg}$, with changes in organ weights and body weights occurring at lower doses. ${ }^{49}$

\section{Humans}

PFOA exposure has been proposed to be associated with reproductive and developmental effects in humans. Reproductive effects include irregular and long menstrual cycles and delayed onset of menarche in adolescent females. Both $\mathrm{ATSDR}^{47}$ and the $\mathrm{C} 8$ panel reports ${ }^{46}$ concluded that PFOA exposure was associated with pregnancy-induced hypertension ${ }^{46}$ or pre-eclampsia. ${ }^{47}$ Several meta-analyses ${ }^{50 ; 51}$ have reported that PFOA is associated with lower infant birth weight; however, ATSDR noted that the decrease in birth weight is small and may not affect the infant's health. The interpretation of these findings is unclear as many studies are cross-sectional and the potential for confounding exists. Low glomerular filtration rate may be a confounding factor because it is related potentially to both lower birth weight and higher levels of PFOA; the potential for confounding is also more likely when maternal samples are taken later in pregnancy. ${ }^{52}$ A recent meta-analysis found that associations with decreased birth weight were mainly limited to studies that sampled maternal blood later in pregnancy and found little evidence of an association in studies sampling blood early in pregnancy. ${ }^{53} \mathrm{~A}$ systematic review identified several human health categories of concern in children with respect to exposure to 
PFAS, including dyslipidemia, immunity (vaccine response and asthma), renal function, and age at menarche. ${ }^{54}$

\section{Immunotoxicity}

\section{Experimental Animals}

Several studies have demonstrated the immunomodulatory effects of PFOA or APFO in mice. Across multiple strains, short-term exposure to PFOA resulted in atrophy of the spleen and thymus, reduction in splenic and thymic lymphocytes, and suppressed the T-cell dependent antibody response (TDAR). These effects occurred in the range of 9.6 to $33 \mathrm{mg} / \mathrm{kg} / \mathrm{day}$ and were consistent across gavage, feed, and drinking water routes of exposure. ${ }^{55-58}$ The most sensitive effects observed were reductions in TDAR and T-cell independent antibody responses at 3.75 and $1.88 \mathrm{mg} / \mathrm{kg} /$ day, respectively, in female C57B16 mice exposed via drinking water for 15 days. ${ }^{59 ; 60}$ Two additional studies report an increased hypersensitivity response in BALB/c mice following PFOA exposure. ${ }^{61 ; 62}$

\section{Humans}

Epidemiological studies provide evidence to suggest a link between PFOA exposure and immunomodulation. Elevated serum PFOA concentrations during development were associated with a reduced antibody response to certain vaccines (e.g., diphtheria and tetanus) in Norwegian and Faroe Island birth cohort studies ${ }^{63-68}$ and in a cross-sectional study of adolescents using NHANES data. ${ }^{69}$ Similar reductions in antibody concentrations were observed following administration of the influenza vaccine in adults in the Mid-Ohio Valley. ${ }^{70}$ Additional immunerelated outcomes associated with PFOA exposure include increased hypersensitivity, reduced resistance to infectious disease, and an increase in autoimmune disease. In addition, the National Toxicology Program (NTP) ${ }^{71}$ conducted a systematic review of immune effects and concluded that PFOA is presumed to be an immune hazard based on evidence from human and animal studies. NTP concluded that there was a moderate level of evidence from studies in humans that PFOA suppresses antibody response, with evidence from developmental, childhood, and adult exposures.

\section{Carcinogenicity}

\section{Experimental Animals}

Two rodent studies have examined the carcinogenic activity of PFOA. The first study, conducted in the early 1980s with Sprague Dawley rats exposed to 0,30, or $300 \mathrm{ppm}$ APFO, showed increased incidences of Leydig cell adenomas of the testis in males and female mammary gland fibroadenomas in the 300 ppm groups. ${ }^{72}$ Further review of the mammary gland fibroadenomas from this study found that they were not in fact increased, as more were observed in the control group than initially reported. ${ }^{73} \mathrm{~A}$ follow-up study in male Sprague Dawley rats exposed to 300 ppm APFO reported increased incidences of hepatocellular adenomas, Leydig cell adenomas, and pancreatic acinar cell neoplasms. ${ }^{74}$ Review of the pancreas from the first study found increased incidences of acinar cell hyperplasia and a single incidence of an acinar cell carcinoma, which was more consistent with the follow-up study. ${ }^{75} \mathrm{~A}$ tumor promotion study in rainbow trout found the high dose of PFOA (1,800 ppm, or $50 \mathrm{mg} / \mathrm{kg}$ per day) increased the 
combined incidence of liver neoplasms in aflatoxin-initiated fish, whereas PFOA alone did not induce liver neoplasms. ${ }^{76}$

\section{Humans}

The carcinogenic activity of PFOA in humans was recently reviewed by the International Agency for Research on Cancer (IARC). ${ }^{77}$ Approximately a dozen epidemiological studies have evaluated the possible carcinogenic effects of PFOA in different exposure scenarios (e.g., occupational, community). IARC concluded that PFOA was possibly carcinogenic to humans (Group 2B) based on limited evidence in humans of associations with cancer of the testis and kidneys and limited evidence in the previously mentioned animal carcinogenicity studies.

\section{Genetic Toxicity}

The genetic toxicity of PFOA has been evaluated in bacterial mutagenicity assays, in vitro tests using human and rodent cells, and one animal study. Whereas bacterial mutagenicity assays using several Salmonella typhimurium test strains were uniformly negative, conflicting results were obtained for PFOA using in vitro tests with mammalian cells. In the single in vivo study, PFOA was reported to induce oxidative damage to DNA obtained from rat liver cells. ${ }^{78}$

PFOA was not mutagenic in S. typhimurium strains TA98, TA100, TA1535, TA1537, and TA1538 in the absence or presence of exogenous rat liver metabolic enzymes (S9 mix) at concentrations up to $5 \mu \mathrm{mol} /$ plate. ${ }^{79}$ PFOA was also negative in $S$. typhimurium test strains TA98, TA100, TA102, and TA104 in the absence or presence of S9 mix when tested up to $500 \mu \mathrm{M}^{80}$

Using the comet assay, significant, dose-dependent increases in DNA damage were observed in human lymphoblastoid TK6 cells exposed to concentrations of PFOA that ranged from 125 to 500 ppm for 2 hours. ${ }^{81}$ Small increases in 8-hydroxy-2'-deoxyguanosine DNA adducts (per $10^{5} \mathrm{dG}$ ) as detected using high-performance liquid chromatography (HPLC)-mass spectrometry (MS) were also reported using the same exposure protocol. In HepG2 cells, PFOA induced significant, dose-dependent increases in DNA damage in the comet assay, in 8-hydroxy$2^{\prime}$-deoxyguanosine as detected by immunostaining, and in micronuclei after 1, 3, or 24 hours of exposure, respectively; the same concentrations, ranging from 50 to $400 \mu \mathrm{M}$, were used for each assay. ${ }^{82}$ Significant increases in DNA damage, as detected using the comet assay, were also observed in HepG2 cells exposed to PFOA at concentrations ranging from 0.2 to $20 \mu \mathrm{M}$ for 24 hours. ${ }^{83}$ PFOA was negative in the comet assay when HepG2 cells were evaluated after 1 or 24 hours of exposure to concentrations ranging from 5 to $400 \mu \mathrm{M}$, and was negative in the micronucleus assay when HepG2 cells were evaluated 24 hours after exposure using the same conditions; however, the percentage of DMSO, a known free radical scavenger that was used for these experiments, was relatively high at $2.5 \%{ }^{84}$ There was no increase in DNA damage in the comet assay in Syrian hamster embryo cells after 5 or 24 hours of exposure to concentrations of PFOA of up to $300 \mu \mathrm{M} .{ }^{85}$ Also, negative results were obtained in the comet assay when freshly isolated Wistar rat testicular cells were exposed to 100 or $300 \mu \mathrm{M}$ PFOA for 24 hours. $^{86}$

One study examined the genotoxicity of PFOA in vivo. Using HPLC and an electrochemical detector (ECD) system, small increases in 8-hydroxy-2'-deoxyguanosine DNA adducts (per $10^{5} \mathrm{dG}$ ) were detected in DNA obtained from the liver, but not the kidney, of male F344 rats exposed to $0.02 \%$ PFOA in feed for 2 weeks, or at 3, 5, or 8 days after a single intraperitoneal 
injection of $100 \mathrm{mg} / \mathrm{kg} \mathrm{PFOA.}{ }^{78}$ Increases in 8-hydroxy-2'-deoxyguanosine (per $10^{5} \mathrm{dG}$ ) in DNA obtained from the liver or kidney were not observed at 1 day after injection. Considering that oxidative damage to DNA typically undergoes rapid repair, the small increases in 8-hydroxy$2^{\prime}$-deoxyguanosine that were detected by Takagi et al. ${ }^{78}$ several days after injection may not necessarily have been due to exposure to PFOA.

In a review of unpublished genetic toxicity test data generated in industry-sponsored studies, PFOA tested as either an ammonium or sodium salt was found to be negative in bacterial mutagenicity assays, the Chinese hamster ovary HGPRT forward mutation assay, the chromosomal aberration assay when performed using Chinese hamster ovary cells or primary human lymphocytes, and in the mouse bone marrow micronucleus assay. ${ }^{87}$

PFOA did not show evidence of genotoxic activity in tests conducted by NTP. ${ }^{88}$ PFOA was negative in bacterial mutagenicity assays in S. typhimurium strain TA100 and E. coli strain WP2 uvrA pKM101, with and without $10 \%$ rat liver S9, and in strain TA98, with S9. In strain TA98 without S9, results with PFOA were equivocal. PFOA was judged to be negative in the peripheral blood micronucleus assay. There were no increases in micronucleated reticulocytes in the peripheral blood of female Sprague Dawley (Hsd:Sprague Dawley ${ }^{\circledR} \mathrm{SD}^{\circledR}$ ) rats administered PFOA for 28 days via gavage. Although a positive response was indicated for male rats, the results were within the laboratory's historical control range, and therefore the biological significance of the increase was questionable. No changes were noted in the percentage of reticulocytes in peripheral blood of either sex, suggesting that PFOA did not induce bone marrow toxicity.

\section{Study Rationale}

The PFAS class was nominated by EPA for toxicity evaluations. Concern that exposure to PFOA could lead to unexpected carcinogenic effects due to exposures during early life development was considered in the nomination. Previous carcinogenicity studies of PFOA ${ }^{74 ; 72}$ began exposure after the critical periods of in utero and early postnatal development, so it is unknown whether the carcinogenic response is altered if exposure during gestation and lactation is included. NTP tested the hypothesis that including exposure during gestation and lactation (perinatal exposure) would change the PFOA carcinogenic response quantitatively (more neoplasms) or qualitatively (different neoplasm types). Feed exposure was selected as it is a common route of exposure in the human population.

Design of this study was based on previous NTP assessments of early developmental exposures influencing carcinogenic activity. ${ }^{89-91}$ This approach uses a matrix-type design that evaluates different gestation/lactation doses. Comparisons were made between groups that received exposure during the perinatal and postweaning periods with groups exposed during the postweaning period only. Exposure concentrations were selected based on available literature and a 16-week interim necropsy was included to assess ongoing toxicity. Due to the identified sex differences in PFOA elimination rates, doses were increased in female rats after weaning to ensure systemic exposure. The male rat portion of this study was stopped and restarted due to observed toxicity occurring at the 16-week interim necropsy. 


\section{Materials and Methods}

\section{Procurement and Characterization of Perfluorooctanoic Acid}

PFOA was obtained from Sigma-Aldrich (St Louis, MO) in a single lot (03427TH). Identity, purity, and stability analyses were conducted under the analytical chemistry laboratory and study laboratory at Battelle (Columbus, $\mathrm{OH}$ ) (Appendix A). Reports on analyses performed in support of the PFOA studies are on file at the National Institute of Environmental Health Sciences (NIEHS).

PFOA lot $03427 \mathrm{TH}$ is a white crystalline solid. The lot was identified using infrared (IR) spectroscopy, ${ }^{19} \mathrm{~F}$ and ${ }^{13} \mathrm{C}$ nuclear magnetic resonance (NMR) spectroscopy, and gas chromatography (GC) with mass spectrometry (MS) detection. The IR and NMR spectra are in good agreement with the structure of PFOA. GC-MS detection confirmed that the primary peak was PFOA.

The purity of lot $03427 \mathrm{TH}$ was evaluated using GC with electron capture detection (ECD) and ion chromatography (IC) with conductivity detection. GC-ECD analysis yielded a purity of $98.3 \%$ and four impurities with areas greater than or equal to $0.1 \%$ of the total peak area. IC with conductivity detection yielded a purity of $98.8 \%$ with three impurities with areas greater than $0.1 \%$ of the total peak area. GC with electron capture detection (ECD) showed that the impurities are likely fluorinated compounds. GC-MS detection showed that two of the impurities representing approximately $1 \%$ of the total area were isomers of PFOA; additional impurities were determined to be perfluorooctenoic acid $(0.51 \%)$ and a structurally dissimilar fluorinated compound $(0.11 \%)$. The purity of PFOA evaluated using differential scanning calorimetry (DSC) was 98.96\%. Karl Fischer titration performed at Pervalere Life Science, Inc. (Whitesboro, NY) yielded a water content of $0.24 \%$. The overall purity of lot $03427 \mathrm{TH}$ was determined to be greater than $98 \%$.

To ensure stability, the test chemical was stored in amber glass bottles at ambient temperature (approximately $25^{\circ} \mathrm{C}$ ). Periodic analyses of lot $03427 \mathrm{TH}$ of the test chemical were performed prior to and during the animal studies by the study laboratory using GC-ECD; no degradation of the test chemical was detected.

\section{Preparation and Analysis of Dose Formulations}

Prior to conducting studies, the homogeneity of PFOA (30 and 300 ppm) in NIH-07 and NTP-2000 formulations was confirmed by the analytical chemistry laboratory using GC-FID. Homogeneity of PFOA in NIH-07 (150 and 300 ppm PFOA) and NTP-2000 (20, 80, 150, 300, and 1,000 ppm PFOA) formulations was also confirmed by the study laboratory using GC-ECD.

Stability studies were performed by the analytical chemistry laboratory at $30 \mathrm{ppm}$ PFOA in NIH-07 and NTP-2000 formulations up to 42 days. On day 42, formulations of NIH-07 were $99 \%$ and $91 \%$ and formulations of NTP-2000 were $104 \%$ and $101 \%$ of day 0 when stored refrigerated (approximately $5^{\circ} \mathrm{C}$ ) or at room temperature (approximately $25^{\circ} \mathrm{C}$ ), respectively. Hence, formulations of $\mathrm{NIH}-07$ were refrigerated (approximately $5^{\circ} \mathrm{C}$ ), whereas formulations of NTP-2000 were stored at room temperature (approximately $25^{\circ} \mathrm{C}$ ). Dosed feed formulations were 
prepared monthly (Table A-1) for both the 21-week and 2-year studies using two types of feed (NIH-07 and NTP-2000).

Analysis of preadministration and postadministration (animal room) dose formulations of PFOA was conducted every 1-3 months over the course of the study (Table A-3, Table A-4). All preadministration formulations in both the 21-week and 2-year studies were within $10 \%$ of the target concentration. All of the postadministration samples collected from feed buckets were within $10 \%$ of the target concentration. Of the few postadministration formulation samples collected from residual animal feed bowls, one sample from the 21-week study, and three samples from the 2-year study were lower than $10 \%$ of the target concentration $(11.5-13.4 \%$ below target).

\section{Animal Source}

Time-mated $\left(\mathrm{F}_{0}\right)$ female Sprague Dawley (Hsd:Sprague Dawley $\left.{ }^{\circledR} \mathrm{SD}^{\circledR}\right)$ rats were obtained from Harlan, Inc. (Madison, WI, or Indianapolis, IN; now Envigo), for the 2-year studies.

\section{Animal Welfare}

Animal care and use are in accordance with the Public Health Service Policy on Humane Care and Use of Animals. All animal studies were conducted in an animal facility accredited by AAALAC International. Studies were approved by the Battelle (Columbus, OH) Animal Care and Use Committee and conducted in accordance with all relevant National Institutes of Health $(\mathrm{NIH})$ and National Toxicology Program (NTP) animal care and use policies and applicable federal, state, and local regulations and guidelines.

\section{Two-year Studies}

\section{Exposure Concentration Selection Rationale}

Initial design of these studies was based on previous NTP assessments of early developmental exposures influencing carcinogenic activity. ${ }^{89-91}$ This approach uses a matrix-type design that evaluates different gestation/lactation doses. PFOA exposure concentrations were selected based on previous chronic studies ${ }^{74 ; 7}$ and reproductive studies ${ }^{49}$ in the literature, in addition to known sex differences in elimination rates. ${ }^{22}$ Exposure concentrations of 150 or 300 ppm during gestation and lactation (these combined developmental periods are referred to as perinatal exposure in this report) were not expected to negatively affect litter size or survival, but still result in significant internal exposure. Note that the rats were exposed during the period of sexual maturation, which occurs postweaning, in both exposure paradigms.

As noted above, two diets were used in this study: (1) NIH-07 was used during the perinatal phase of the study, and (2) NTP-2000 was used during the postweaning phase of the study. The NIH-07 diet is a higher protein diet that supports reproduction and lactation in rodents, whereas the NTP-2000 diet is a lower protein diet that decreases the incidence of chronic nephropathy in rats.

Due to the known differences in kinetics between male and female rats, females were exposed to higher exposure concentrations (300 or $1,000 \mathrm{ppm})$ than were males (150 or $300 \mathrm{ppm})$ in the postweaning period of the first study (Table 1). An interim necropsy at 16 weeks (19 weeks of 
age) was included to assess toxicity and internal exposure in both males and females. A second study was started that focused entirely on males due to observed toxicity at the 16-week interim, and postweaning exposure concentrations were lowered (Table 2). Only a single perinatal exposure concentration was used $(300 \mathrm{ppm})$ to compare to the unexposed rats during that developmental period because this exposure was well tolerated and postweaning comparisons (e.g., 0/80 versus 300/80) were the main objective of the study.

Table 1. Exposures during Perinatal and Postweaning Periods in Rats in the First Two-year Feed Study of Perfluorooctanoic Acid (Study 1)

\begin{tabular}{ccccc}
\hline $\begin{array}{c}\text { Perinatal } \\
\text { Exposure }\end{array}$ & \multicolumn{3}{c}{ Postweaning Exposure } \\
\hline Feed (ppm) & $\mathbf{0}$ & $\mathbf{1 5 0}$ & $\mathbf{3 0 0}$ & $\mathbf{1 , 0 0 0}$ \\
$\mathbf{0}$ & $\mathrm{M} / \mathrm{F}$ & $\mathrm{M}$ & $\mathrm{M} / \mathrm{F}$ & $\mathrm{F}$ \\
$\mathbf{1 5 0}$ & - & $\mathrm{M}$ & $\mathrm{F}$ & - \\
$\mathbf{3 0 0}$ & - & - & $\mathrm{M}$ & $\mathrm{F}$ \\
\hline $\mathrm{M}=$ male; $\mathrm{F}=$ female. & & &
\end{tabular}

Table 2. Exposures during Perinatal and Postweaning Periods in Male Rats in the Second Two-year Feed Study of Perfluorooctanoic Acid (Study 2)

\begin{tabular}{ccccc}
\hline $\begin{array}{c}\text { Perinatal } \\
\text { Exposure }\end{array}$ & \multicolumn{3}{c}{ Postweaning Exposure } \\
\hline Feed (ppm) & $\mathbf{0}$ & $\mathbf{2 0}$ & $\mathbf{4 0}$ & $\mathbf{8 0}$ \\
$\mathbf{0}$ & $\mathrm{M}$ & $\mathrm{M}$ & $\mathrm{M}$ & $\mathrm{M}$ \\
$\mathbf{3 0 0}$ & $\mathrm{M}$ & $\mathrm{M}$ & $\mathrm{M}$ & $\mathrm{M}$ \\
\hline $\mathrm{M}=$ male. & & & &
\end{tabular}

\section{Male and Female Rats (Study 1)}

$F_{0}$ female rats were 12 weeks old upon receipt. Gestation day (GD) 1 was defined as the first day with evidence of mating; $F_{0}$ females were received on GD 2 and held for 4 days. $F_{0}$ females were randomly assigned to three exposure groups on GD 5; 103 to the 0 ppm group and 36 each to the 150 and 300 ppm groups. Randomization was stratified by body weight that produced similar group mean weights using PATH/TOX SYSTEM (Xybion Medical Systems Corporation, Cedar Knolls, NJ). Exposure of $\mathrm{F}_{0}$ females to PFOA in feed began on GD 6.

$\mathrm{F}_{0}$ females were quarantined for 36 days after receipt. Ten nonmated females received in the same shipment as the time-mated dams were designated for disease monitoring and were used for gross necropsies 2 days after arrival; samples were collected for serological analyses, and the animals were terminated, necropsied, and examined for the presence of disease or parasites. The health of the $\mathrm{F}_{1}$ animals was monitored during the study according to the protocols of the NTP Sentinel Animal Program (Appendix C). All results were negative.

$\mathrm{F}_{0}$ females were housed individually during gestation and with their respective litters during lactation. $F_{0}$ females were weighed on GDs 5, 6, 9, 12, 15, 18, and 21 and on postnatal days (PNDs) 1 (with whole litter), 4, 7, 14, and 21. F1 pups were weighed on PNDs 4, 7, 14, and 21. The day of parturition was considered PND $0 . \mathrm{F}_{0}$ females that did not deliver were euthanized on 
GD 27 and the uteri were stained for implantations/resorptions. On PNDs 1 and 4, the numbers of litters and pups and sex ratios for each litter were recorded. On PND 4, litters were standardized to eight pups per litter (four males and four females where possible); litters with fewer than eight pups or two pups per sex were removed from the study. During gestation and lactation, feed consumption per cage was measured continuously over 3- or 4-day intervals.

On the day the last litter reached PND 18, litters were randomly selected and assigned to exposure groups for the 2-year study; $F_{1}$ rats from these litters were then randomly selected for use in the 2-year study. On the day the last litter reached PND 21, dams were removed from the cages, and the pups were weaned (PND 21-23). All $F_{1}$ exposure groups consisted of 60 male or 60 female rats with two pups/sex/litter assigned to postweaning exposure groups.

$F_{1}$ pups were housed up to two per cage (males) or four per cage (females). Feed and water were available ad libitum. Feed consumption was measured weekly for 13 weeks and then for a weeklong period at 4-week intervals, except that feed consumption was also recorded the week following the 16-week interim evaluation. Cages were changed twice weekly and rotated every 2 weeks. Further details of animal maintenance are given in Table 3. Information on feed composition and contaminants is provided in Appendix B.

\section{Male Rats (Study 2)}

$\mathrm{F}_{0}$ female rats were 11 to 13 weeks old upon receipt. GD 1 was defined as the first day with evidence of mating; $F_{0}$ females were received on GD 2 and held for 4 days. $F_{0}$ females were randomly assigned to two exposure groups on GD 5 with 147 going to each of the 0 and 300 ppm groups. Randomization was stratified by body weight that produced similar group mean weights using PATH/TOX SYSTEM. Exposure of $\mathrm{F}_{0}$ females to PFOA in feed began on GD 6.

$\mathrm{F}_{0}$ female rats were quarantined for 37 days after receipt. Ten nonmated females received in the same shipment as the time-mated dams were designated for disease monitoring and were used for gross necropsies 2 days after arrival; samples were collected for serological analyses, and the animals were terminated, necropsied, and examined for the presence of disease or parasites. The health of the $F_{1}$ animals was monitored during the study according to the protocols of the NTP Sentinel Animal Program (Appendix C). All results were negative.

$\mathrm{F}_{0}$ females were housed individually during gestation and with their respective litters during lactation. $\mathrm{F}_{0}$ females were weighed on GDs 5, 6, 9, 12, 15, 18, and 21 and on PND 1 (with whole litter), 4, 7, 14, and 21. F 1 pups were weighed on PNDs 4, 7, 14, and 21 . The day of parturition was considered PND 0. Fo females that did not deliver were euthanized on GD 27 and the uteri were stained for implantations/resorptions. On PNDs 1 and 4, the numbers of litters and pups and sex ratios for each litter were recorded. On PND 4, litters were standardized to eight pups per litter (four males and four females where possible); litters with fewer than eight pups or two pups per sex were removed from the study. During gestation and lactation, feed consumption per cage was measured continuously over 3- or 4-day intervals.

Select litters were removed on GD 18 and PND 4 to quantify PFOA plasma and tissue concentrations. On GD 18, blood was collected from the retroorbital sinus of randomly selected dams ( $n=5$ per exposure group). Blood samples were collected into tubes containing ethylene diamine tetraacetic acid (EDTA), centrifuged, and the plasma harvested. Each dam's fetuses were collected, pooled by litter, and flash frozen in liquid nitrogen. On PND 4, dams with 
unacceptable litters from the $0 \mathrm{ppm}(\mathrm{n}=5)$ and $300 \mathrm{ppm}(\mathrm{n}=4)$ groups were selected for biological sampling. Plasma was collected in the same manner as for GD 18. Up to four pups were collected from each dam (two per sex when possible) and flash frozen in liquid nitrogen. All samples were stored frozen between $-30^{\circ} \mathrm{C}$ and $-15^{\circ} \mathrm{C}$ before shipment on dry ice to Battelle's Chemistry Technical Center (CTC) for analysis.

On the day the last litter reached PND 18, litters were randomly selected and assigned to exposure groups for the 2-year study and then $\mathrm{F}_{1}$ males from these litters were randomly selected for use in the 2-year study. On the day the last litter reached PND 21, dams were removed from the cages, and the pups were weaned (PND 21-23). All $F_{1}$ exposure groups consisted of 60 males.

$F_{1}$ males were housed up to two per cage. Feed and water were available ad libitum. Feed consumption was measured weekly for 13 weeks and then for a week-long period at 4-week intervals, except that feed consumption was also recorded the week following the 16-week interim evaluation. Cages were changed and rotated every 2 weeks. Further details of animal maintenance are given in Table 3. Information on feed composition and contaminants is provided in Appendix B.

\section{Clinical Examinations and Pathology (Studies 1 and 2)}

During the 2-year studies, all animals in both studies were observed twice daily. Individual body weights of $F_{1}$ pups were recorded on day 1 (postweaning), weekly for the first 13 weeks, at 4 -week intervals thereafter, and again prior to termination. Clinical observations were recorded at 4-week intervals beginning during study week 5 and again prior to termination. As an exception to the 4-week intervals, body weights and clinical observations were recorded 2 weeks after the week 16 interim evaluation and data were recorded again 3 weeks later, resulting in one 5-week and one 3-week interval.

Ten rats were selected from each exposure group for interim evaluation at 16 weeks. Body weights were collected, as were blood samples for clinical chemistry determinations and plasma PFOA concentrations. Rats were anesthetized with $70 \% \mathrm{CO}_{2}$ and $30 \% \mathrm{O}_{2}$, and blood was taken from the retroorbital plexus and placed into tubes containing EDTA for plasma or into serum separator tubes for clinical chemistry. Clinical chemistry parameters were analyzed using a Cobas c501 Chemistry Analyzer (Roche Diagnostics, Indianapolis, IN). The clinical chemistry parameters that were measured are listed in Table 3. Plasma, approximately $1 \mathrm{~mL}$, was collected in the morning and stored frozen between $-30^{\circ} \mathrm{C}$ and $-15^{\circ} \mathrm{C}$ until transferred to Battelle's CTC for PFOA concentration analysis. Two, $1 \mathrm{~g}$ sections of liver were collected from 5 males and 5 females (Study 1) and 10 males (Study 2) per exposure group. One sample was immediately homogenized, snap frozen in liquid nitrogen, stored between $-80^{\circ} \mathrm{C}$ and $-60^{\circ} \mathrm{C}$, and analyzed for the determination of acyl-CoA oxidase activity. The second sample was flash frozen in liquid nitrogen, stored, and analyzed for determination of aromatase activity. Acyl-CoA oxidase activity was used as a marker of PPAR $\alpha$ induction, as PFOA is expected to be an inducer. Liver homogenates were centrifuged, and the supernatant added to 96-well plates along with palmitoyl-CoA solution. Kinetic reactions were analyzed by measuring absorbance at $502 \mathrm{~nm}$ for 5 minutes. Liver aromatase activity was evaluated to provide insight into potential endocrine-related lesions such as Leydig cell hyperplasia and/or neoplasia. Microsomal suspensions were prepared from liver samples and were incubated with radiolabeled androst-4- 
ene-3,17-dione and $\beta$-NADPH solutions for 1 hour. Samples were centrifuged, the aqueous layer was mixed with scintillation cocktail, and radioactivity was counted using a liquid scintillation counter (Beckman Coulter, Brea, CA). Another section of liver, approximately $100 \mathrm{mg}$, was collected from 10 males and 10 females (Study 1) and 10 males (Study 2) and stored frozen between $-30^{\circ} \mathrm{C}$ and $-10^{\circ} \mathrm{C}$ until transferred to Battelle's CTC for PFOA concentration analysis. The parameters measured are listed in Table 3.

For determination of internal dose, plasma and liver homogenate samples were analyzed using validated analytical methods that included protein precipitation and liquid chromatography (LC) tandem mass spectrometry (MS/MS) as described in Dzierlenga et al. ${ }^{17}$ The concentration in plasma was expressed as $\mathrm{ng} / \mathrm{mL}$ and in tissues as $\mathrm{ng} / \mathrm{g}$. Fetal and pup homogenate (Study 2 ) were analyzed using methods similar to those for liver analysis.

Complete necropsies were performed on all $\mathrm{F}_{1}$ rats. At the 16 -week interim evaluations, the right adrenal gland, heart, right kidney, liver, lung, pituitary gland, spleen, right testis, thymus, thyroid gland, and uterus (Study 1) were weighed. At necropsy, all organs and tissues were examined for grossly visible lesions, and all major tissues were fixed and preserved in $10 \%$ neutral buffered formalin (except eyes and testes, which were initially fixed in Davidson's solution or modified Davidson's solution, respectively), processed and trimmed, embedded in paraffin, sectioned at a thickness of 4 to $6 \mu \mathrm{m}$, and stained with hematoxylin and eosin (H\&E) for microscopic examination. For all paired organs (e.g., adrenal gland, kidney, ovary), samples from each organ were examined. In the original evaluation of the uterus, a transverse section through each uterine horn, approximately $0.5 \mathrm{~cm}$ cranial to the cervix, was collected for histopathology evaluation. For the extended evaluation of the uterus, all remaining cervical, vaginal, and uterine tissue remnants stored in 10\% neutral buffered formalin were trimmed longitudinally, embedded, sectioned, and stained with H\&E. Tissues examined microscopically are listed in Table 3. Complete microscopic examinations were performed on all $\mathrm{F}_{1}$ females and interim males in Study 1 and on all $\mathrm{F}_{1}$ males at the end of Study 2. At the interim evaluation of Study 2, the liver was the only organ examined in all exposure groups.

Microscopic evaluations were completed by the study laboratory pathologist, and the pathology data were entered into the Toxicology Data Management System. The report, slides, paraffin blocks, residual wet tissues, and pathology data were sent to the NTP Archives for inventory, slide/block match, wet tissue audit, and storage. The slides, individual animal data records, and pathology tables were evaluated by a Quality Assessment (QA) pathologist at a pathology laboratory independent of the study laboratory. The individual animal records and tables were compared for accuracy, the slide and tissue counts were verified, and the histotechnique was evaluated. For the 2-year studies, a QA pathologist evaluated slides from all neoplasms and all potential target organs, which included kidney, liver, pancreas, pancreatic islets, stomach (forestomach and glandular), testes, thyroid gland, and uterus.

The QA report and the reviewed slides were submitted to the NTP Pathology Working Group (PWG) coordinator, who reviewed the selected tissues and addressed any inconsistencies in the diagnoses made by the laboratory and QA pathologists. Representative histopathology slides containing examples of lesions related to chemical administration, examples of disagreements in diagnoses between the laboratory and QA pathologists, or lesions of general interest were presented by the coordinator to the PWG for review. The PWG consisted of the QA pathologist and other pathologists experienced in rodent toxicologic pathology. When the PWG consensus 
diagnosis differed from that of the laboratory pathologist, the diagnosis was changed. Final diagnoses for reviewed lesions represent a consensus between the laboratory pathologist, reviewing pathologist(s), and the PWG. Details of these review procedures have been described, in part, by Maronpot and Boorman ${ }^{92}$ and Boorman et al. ${ }^{93}$ For subsequent analyses of the pathology data, the decision whether or not to evaluate the diagnosed lesions for each tissue type separately or combined was based generally on the guidelines of McConnell et al. ${ }^{94}$

Table 3. Experimental Design and Materials and Methods in the Two-year Feed Studies of Perfluorooctanoic Acid

\begin{tabular}{cc}
\hline Study 1 (Male and Female) & Study 2 (Male) \\
\hline
\end{tabular}

\section{Study Laboratory}

Battelle (Columbus, OH)

Strain and Species

Sprague Dawley (Hsd:Sprague Dawley ${ }^{\circledR} \mathrm{SD}^{\circledR}$ ) rats

\section{Animal Source}

Harlan, Inc. (Madison, WI), now Envigo

Time Held Before Studies

4 days ( $\mathrm{F}_{0}$ females)

\section{Average Age When Studies Began}

12 to 13 weeks ( $F_{0}$ females)

Date of First Exposure

September 19, 2008 ( $\mathrm{F}_{0}$ females)

October 27, 2008 ( $F_{1}$ males $)$

October 28, 2008 ( $\mathrm{F}_{1}$ females)

\section{Duration of Exposure}

GD 6 to PND 21 ( $\mathrm{F}_{0}$ females)

21 weeks $\left(F_{1}\right.$ males - study stopped)

107 weeks $\left(\mathrm{F}_{1}\right.$ females $)$

\section{Date of Last Exposure}

October 27, 2008 ( $\mathrm{F}_{0}$ females)

March 18, 2009 ( $F_{1}$ males)

November 12, 2010 ( $\mathrm{F}_{1}$ females $)$

\section{Necropsy Dates}

Interim evaluation: February 12 ( $F_{1}$ males) or 13 ( $F_{1}$ females), 2009

Core: November 10 through 12, 2010 ( $F_{1}$ females)

\section{Average Age at Necropsy}

Interim evaluation: 19 weeks ( $\mathrm{F}_{1}$ males and females)

Core: 24 weeks ( $F_{1}$ males - euthanized early)

Core: 110 weeks ( $F_{1}$ females)
Same as Study 1

Same as Study 1

Harlan, Inc. (Indianapolis, IN), now Envigo

Same as Study 1

12 to 14 weeks ( $\mathrm{F}_{0}$ females)

June 19, 2009 ( $\mathrm{F}_{0}$ females $)$

July 27, 2009 ( $\mathrm{F}_{1}$ males $)$

GD 6 to PND 21 ( $\mathrm{F}_{0}$ females)

107 weeks $\left(F_{1}\right.$ males $)$

July 27, 2009 ( $\mathrm{F}_{0}$ females)

August 12, 2011 ( $F_{1}$ males)

Interim evaluation: November 11, 2009 ( $\mathrm{F}_{1}$ males) Core: August 8 through 12, 2011 ( $\mathrm{F}_{1}$ males)

Interim evaluation: 19 weeks ( $\mathrm{F}_{1}$ males $)$

Core: 109 to 110 weeks ( $F_{1}$ males)

\section{Size of Study Groups}




\section{Study 1 (Male and Female)}

$\mathrm{F}_{0}$ females: 103 (0 ppm group) or 36 (150 and

$300 \mathrm{ppm}$ groups)

$F_{1}$ rats: 60 males and 60 females

\section{Method of Distribution}

Animals were distributed randomly into groups of approximately equal initial mean body weights

\section{Animals per Cage}

$\mathrm{F}_{0}$ females: One (plus litter)

$F_{1}$ rats: Two (males) or four (females)

\section{Method of Animal Identification}

$\mathrm{F}_{0}$ females: Tail marking with permanent pen

$F_{1}$ rats: Tail tattoo

\section{Diet}

NIH-07 meal feed (perinatal phase) or irradiated NTP-2000 wafer diet (chronic phase) (Zeigler Brothers, Inc., Gardners, PA), available ad libitum, changed every 3 days

\section{Water}

Tap water (Columbus municipal supply) via automatic watering system (Edstrom Industries, Inc., Waterford, WI), available ad libitum

\section{Cages}

Polycarbonate (Lab Products, Inc., Seaford, DE), changed and sanitized at least once weekly (during gestation) or twice weekly; rotated every 2 weeks after weaning

\section{Bedding}

Irradiated Sani-Chips ${ }^{\circledR}$ hardwood chips (P. J. Murphy Forest Products Corp., Montville, NJ), changed once weekly (during gestation) or twice weekly

\section{Rack Filters}

Spun bonded polyester (Snow Filtration Co., Cincinnati, OH), changed every 2 weeks

\section{Racks}

Stainless steel (Lab Products, Inc.), changed and rotated every 2 weeks

\section{Animal Room Environment}

Temperature: $72^{\circ} \pm 3^{\circ} \mathrm{F}$

Relative humidity: $50 \% \pm 15 \%$

Room fluorescent light: 12 hours/day

Room air changes: at least 10/hour

\section{Exposure Concentrations}

\section{Study 2 (Male)}

$F_{0}$ females: 147

$F_{1}$ males: 60

Same as Study 1

$F_{0}$ females: One (plus litter)

$F_{1}$ males: Two

Same as Study 1

Same as Study 1

Same as Study 1

Same as Study 1

Same as Study 1

Same as Study 1

Same as Study 1 


\begin{tabular}{l} 
Study 1 (Male and Female) \\
\hline$F_{0}$ females: 0, 150, or $300 \mathrm{ppm}$ \\
$\mathrm{F}_{1}$ males: $0 / 0,0 / 150,0 / 300,150 / 150$, or $300 / 300 \mathrm{ppm}$ \\
$\mathrm{F}_{1}$ females: 0/0, 0/300, 0/1,000, 150/300, or 300/1,000 ppm \\
Type and Frequency of Observation \\
F $_{0}$ females: Observed twice daily. Body weights were recorded \\
on GDs 5, 6, 9, 12, 15, 18, and 21 and on PNDs 1 (with \\
litters), 4, 7, 14, and 21. Feed consumption was measured from \\
GD 6 to PND 21. \\
$F_{1}$ rats: Observed twice daily. Clinical observations were \\
recorded at 4-week intervals beginning during study week 5 \\
and again prior to termination. Body weights were recorded on \\
PNDs 4, 7, 14, and 21; weekly for 13 weeks, then every \\
4 weeks. Feed consumption was recorded weekly for \\
13 weeks, then for 1 week every 4 weeks. Body weights and \\
clinical observations were also recorded 2 weeks after the \\
interim evaluation and feed consumption was also recorded \\
1 week after the interim evaluation. \\
Method of Euthanasia
\end{tabular}

Carbon dioxide

\section{Necropsy}

Necropsies were performed on all $F_{1}$ rats. Organs weighed at the interim evaluation were right adrenal gland, heart, right kidney, liver, lung, pituitary gland, spleen, right testis, thymus, thyroid gland, and uterus.

\section{Clinical Pathology}

At the 16-week interim, blood was collected from the retroorbital plexus of 10 interim male and female rats per exposure group for clinical chemistry analyses.

Clinical chemistry: albumin, urea nitrogen, creatinine, creatine kinase, glucose, total protein, alanine aminotransferase, alkaline phosphatase, sorbitol dehydrogenase, cholesterol, triglycerides, and bile acids

\section{Histopathology}

Complete histopathology was performed on all $\mathrm{F}_{1}$ female rats and male rats at the 16-week interim and on all remaining $F_{1}$ rats at the end of the study. In addition to gross lesions and tissue masses, the following tissues were examined: adrenal gland, bone with marrow, brain, clitoral gland, esophagus, eyes, Harderian gland, heart, large intestine (cecum, colon, rectum), small intestine (duodenum, jejunum, ileum), kidney, liver, lung, lymph nodes (mandibular and mesenteric), mammary gland, nose, ovary, pancreas, parathyroid gland, pituitary gland, preputial gland, prostate gland, salivary gland, seminal vesicle (interim evaluation only) skin, spleen, stomach (forestomach and glandular), testis with epididymis (interim evaluation only), thymus, thyroid gland, trachea, urinary bladder, and uterus. An additional extended evaluation of the

\author{
$F_{0}$ females: 0 or $300 \mathrm{ppm}$ \\ $F_{1}$ males: $0 / 0,0 / 20,0 / 40,0 / 80,300 / 0,300 / 20$, \\ $300 / 40$, or $300 / 80 \mathrm{ppm}$
}

Study 2 (Male)
$F_{0}$ females: 0 or $300 \mathrm{ppm}$
$\mathrm{F}_{1}$ males: $0 / 0,0 / 20,0 / 40,0 / 80,300 / 0,300 / 20$,
$300 / 40$, or $300 / 80 \mathrm{ppm}$

Same as Study 1 


\begin{tabular}{ll}
\hline \multicolumn{1}{c}{ Study 1 (Male and Female) } & \multicolumn{1}{c}{ Study 2 (Male) } \\
\hline $\begin{array}{l}\text { uterus was performed which included all remaining cervical, } \\
\text { vaginal, and uterine tissue remnants. }\end{array}$ & $\begin{array}{l}\text { glandular), testis with epididymis, thymus, thyroid } \\
\text { gland, trachea, urinary bladder. The liver was } \\
\text { examined in the remaining exposure groups at the } \\
\text { interim evaluation. }\end{array}$ \\
$\begin{array}{ll}\text { Internal Dose Assessment } & \text { Maternal plasma and fetal (pooled by litter) PFOA } \\
\text { At the interim evaluation, PFOA concentrations were } & \text { concentrations were measured at GD 18; maternal } \\
\text { plasma and whole pup PFOA concentrations were } \\
\text { retroorbital plexus and in liver samples collected from 10 } \\
\text { males and 10 females per exposure group. }\end{array}$ & $\begin{array}{l}\text { measured at PND 4. PFOA plasma concentrations } \\
\text { were also measured in 10 males per exposure } \\
\text { group at the interim evaluation. }\end{array}$ \\
$\begin{array}{l}\text { Liver Enzyme Concentrations } \\
\begin{array}{l}\text { Two, 1 g liver samples were collected from five males and five } \\
\text { females per exposure group at the interim evaluation for } \\
\text { determination of acyl-CoA oxidase and aromatase activity. }\end{array}\end{array}$ & $\begin{array}{l}\text { Same as Study 1, except from 10 males per } \\
\text { exposure group }\end{array}$ \\
\hline
\end{tabular}

\section{Statistical Methods}

\section{Survival Analyses}

The probability of survival was estimated by the product-limit procedure of Kaplan and Meier ${ }^{95}$ and is presented graphically. Animals surviving to the end of the observation period are treated as censored observations, as are animals dying from unnatural causes within the observation period. Animals dying from natural causes are included in analyses but are treated as uncensored observations. Dose-related trends and pairwise dose-related effects on survival are assessed using a Cox Proportional Hazards Model $^{96}$ with a random litter effect. All reported $p$ values for the survival analyses are two-sided.

\section{Calculation of Incidence}

Incidences of neoplastic and nonneoplastic lesions are presented as the numbers of animals bearing such lesions at a specific anatomic site and the numbers of animals with that site examined microscopically. For calculation of incidence rates, the denominator for most neoplasms and all nonneoplastic lesions is the number of animals where the site was examined microscopically. However, when macroscopic examination was required to detect neoplasms in certain tissues (e.g., mesentery, pleura, peripheral nerve, skeletal muscle, tongue, tooth, and Zymbal's gland) before microscopic evaluation, the denominators consist of the number of animals that had a gross abnormality. When neoplasms had multiple potential sites of occurrence (e.g., leukemia or lymphoma), the denominators consist of the number of animals on which a necropsy was performed. These statistical analyses also give the survival-adjusted neoplasm rate for each group and each site-specific neoplasm. This survival-adjusted rate (based on the Poly-3 method described below), used in tables presented in this Technical Report, accounts for differential mortality by assigning a reduced risk of neoplasm, proportional to the third power of the fraction of time on study, only to site-specific, lesion-free animals that do not reach terminal euthanasia. 


\section{Analysis of Neoplasm and Nonneoplastic Lesion Incidences}

Statistical analyses of neoplasm and nonneoplastic lesion incidences considered two features of the data. Some animals did not survive the entire 2 years of the study, so survival differences between groups had to be taken into account. Also, up to two animals per sex were randomly selected from each litter to participate in the study. The statistical analysis of lesion incidences used the Poly-3 test to account for survival differences, with a Rao-Scott adjustment for litter effects, as described below.

The Poly-k test ${ }^{97-99}$ was used to assess neoplasm and nonneoplastic lesion prevalence. This test is a survival-adjusted quantal-response procedure that modifies the Cochran-Armitage linear trend test to take survival differences into account. More specifically, this method modifies the denominator in the quantal estimate of lesion incidence to approximate more closely the total number of animal years at risk. For analysis of a given site, each animal is assigned a risk weight. This value is one if the animal had a lesion at that site or if it survived until terminal euthanasia; if the animal died prior to terminal euthanasia and did not have a lesion at that site, its risk weight is the fraction of the entire study time that it survived, raised to the kth power.

This method yields a lesion prevalence rate that depends only on the choice of a shape parameter for a Weibull hazard function describing cumulative lesion incidence over time. ${ }^{97}$ Unless otherwise specified, a value of $\mathrm{k}=3$ was used in the analysis of site-specific lesions. This value was recommended by Bailer and Portier ${ }^{97}$ following an evaluation of neoplasm onset time distributions for a variety of site-specific neoplasms in control F344 rats and B6C3F 1 mice. ${ }^{100}$ Bailer and Portier ${ }^{97}$ showed that the Poly-3 test gave valid results if the true value of $\mathrm{k}$ was anywhere in the range from 1 to 5. A further advantage of the Poly-3 method is that it does not require lesion lethality assumptions. Variation introduced by the use of risk weights, which reflect differential mortality, was accommodated by adjusting the variance of the Poly-3 statistic as recommended by Bieler and Williams. ${ }^{101}$ Poly-3 tests used the continuity correction described by Nam. ${ }^{102}$

Littermates tend to be more like each other than like fetuses/pups in other litters. Failure to account for correlation within litters leads to underestimates of variance in statistical tests, resulting in higher probabilities of Type I errors ("false positives"). Because up to two pups per sex per litter were present in the core study, the Poly-3 test was modified to accommodate litter effects using the Rao-Scott approach. ${ }^{103}$ The Rao-Scott approach accounts for litter effects by estimating the ratio of the variance in the presence of litter effects to the variance in the absence of litter effects. This ratio is then used to adjust the sample size downward to yield the estimated variance in the presence of litter effects. The Rao-Scott approach was implemented in the Poly-3 test as recommended by Fung et al., ${ }^{104}$ formula $\overline{\boldsymbol{T}}_{R S 2}$.

Tests of significance included pairwise comparisons of each dosed group with control groups and a test for an overall dose-related trend. Continuity-corrected Rao-Scott-adjusted Poly-3 tests were used in the analysis of lesion incidence and reported $p$ values are one sided. The significance of lower incidences or decreasing trends in lesions is represented as $1-\mathrm{p}$ with the letter $\mathrm{N}$ added (e.g., $\mathrm{p}=0.99$ is presented as $\mathrm{p}=0.01 \mathrm{~N}$ ). For neoplasms and nonneoplastic lesions observed without litter structure (e.g., at the interim evaluation), Poly-3 tests that included the continuity correction, but without adjustment for potential litter effects, were used for trend and pairwise comparisons to the control group. 
To evaluate incidence rates by litter, the proportions of litters affected by each lesion type were tested among groups. Cochran-Armitage trend tests and Fisher exact tests ${ }^{105}$ were used to test for trends and pairwise differences from the control group, respectively.

\section{Analysis of Continuous Variables}

Prior to statistical analysis, extreme values identified by the outlier test of Dixon and Massey, ${ }^{106}$ for small samples $(n<20)$, and Tukey's outer fences method, ${ }^{107}$ for large samples $(n \geq 20)$, were examined by NTP personnel and implausible values were eliminated from the analysis. Organ and interim sacrifice body weight measurements, which historically have approximately normal distributions, were analyzed with the parametric multiple comparison procedures of Dunnett ${ }^{108}$ and Williams. ${ }^{109 ; 110}$ For sets of pairwise comparisons across perinatal exposure groups at fixed or increasing postweaning exposures, t-tests were used with a Hommel procedure ${ }^{111}$ to adjust for multiple comparisons.

Clinical chemistry, parent compound, liver enzyme data, litter sizes, pup survival, implantations, number of resorptions, and proportions of male pups per litter, which have typically skewed distributions, were analyzed using the nonparametric multiple comparison methods of Shirley ${ }^{112}$ (as modified by Williams ${ }^{113}$ ) and Dunn. ${ }^{114}$ For all quantitative endpoints unaffected by litter structure, Jonckheere's test ${ }^{115}$ was used to assess the significance of the dose-related trends and to determine, at the 0.01 level of significance, whether a trend-sensitive test (Williams' or Shirley's test) was more appropriate for pairwise comparisons than would be a test that does not assume a monotonic dose-related trend (Dunnett's or Dunn's test). For sets of pairwise comparisons across perinatal exposure groups at fixed or increasing postweaning exposures, a Wilcoxon rank-sum test was used with a Hommel procedure ${ }^{111}$ to adjust for multiple comparisons.

Postweaning body weights were measured on two pups per sex per litter in the 2-year study; more than two pups per sex per litter were possible in preweaning body weight measurements. The analyses of pup body weights and body weights adjusted for litter size (described below) of these animals took litter effects into account using a mixed model, where litters were the random effects. To adjust for multiple comparisons in these models, a Dunnett-Hsu adjustment was used. ${ }^{116}$ Dam body weights during gestation, as well as dam body weights during lactation, were analyzed with the parametric multiple comparison procedures of Dunnett ${ }^{108}$ and Williams, ${ }^{109 ;} 110$ depending on whether Jonckheere's test indicated the use of a trend-sensitive test. P values for these analyses are two-sided.

\section{Analysis of Gestational and Fertility Indices}

Dose-related trends in gestational and fertility indices were tested using Cochran-Armitage trend tests. Pairwise comparisons of each dosed group with the control group were conducted using the Fisher exact test. P values for these analyses are two-sided.

\section{Body Weight Adjustments}

Preweaning pup body weights were adjusted for live litter size as follows: A linear model was fit to body weights as a function of dose and litter size. The estimated coefficient of litter size was then used to adjust each pup body weight based on the difference between its litter size and the mean litter size. Prestandardization PND 4 body weights were adjusted for PND 1 litter size, and 
body weights measured between PND 4 poststandardization and PND 21 were adjusted for PND 4 poststandardization litter size. Following adjustment, body weights were analyzed with a linear mixed model with a random litter effect.

\section{Testing Effects of Perinatal and Postweaning Exposures}

Trend and pairwise testing were performed to assess effects of postweaning exposure at given concentrations of perinatal exposure, perinatal exposure effects at given concentrations of postweaning exposure, and combined effects of perinatal and postweaning exposures.

For the 16-week interim evaluation in males and females and the two-year study in females (Study 1), the following comparisons were performed:

- For the groups without perinatal exposure, trend and pairwise comparisons were made to the $0 / 0 \mathrm{ppm}$ control group for postweaning exposures. For males, this involved the $0 / 0,0 / 150$, and $0 / 300 \mathrm{ppm}$ groups. For females, this involved the $0 / 0$, $0 / 300$, and $0 / 1,000$ ppm groups.

- Trend and pairwise comparisons were made to the $0 / 0 \mathrm{ppm}$ control group at increasing concentrations of both the perinatal and postweaning exposures. For males, this involved the $0 / 0,150 / 150$, and $300 / 300$ ppm groups. For females, this involved the $0 / 0,150 / 300$, and $300 / 1,000$ ppm groups.

- For a given postweaning exposure, a series of pairwise comparisons were made between perinatal exposures. For males, this involved comparing the $0 / 150$ to the $150 / 150$ ppm group and the $0 / 300$ to the $300 / 300$ ppm group. For females, this involved comparing the $0 / 300$ to the $150 / 300$ ppm group and the $0 / 1,000$ to the 300/1,000 ppm group.

For the 16-week interim evaluation in males and the two-year study in males (Study 2), the following comparisons were performed:

- For the groups without perinatal exposure, trend and pairwise comparisons were made to the $0 / 0$ ppm control group for postweaning exposures. This involved the $0 / 0$, $0 / 20,0 / 40$, and $0 / 80$ ppm groups.

- For animals with a 300 ppm perinatal exposure, trend and pairwise comparisons were made to the $300 / 0$ ppm group for postweaning exposures. This involved the $300 / 0$, $300 / 20,300 / 40$, and 300/80 ppm groups.

- For a given postweaning exposure, a series of pairwise comparisons were made between perinatal exposures. This involved comparing the $0 / 0$ to the $300 / 0 \mathrm{ppm}$ group, $0 / 20$ to the $300 / 20 \mathrm{ppm}$ group, the $0 / 40$ to the $300 / 40 \mathrm{ppm}$ group, and the $0 / 80$ to the $300 / 80$ group.

- Pairwise comparisons were made of the $0 / 0$ to the $300 / 20 \mathrm{ppm}$ group, $0 / 0$ to the $300 / 40$ ppm group, and $0 / 0$ to the $300 / 80$ ppm group.

\section{Historical Control Data}

The concurrent control group represents the most valid comparison to the treated groups and is the only control group analyzed statistically in NTP bioassays. However, historical control data are often helpful in interpreting potential treatment-related effects, particularly for uncommon or 
rare neoplasm types. For meaningful comparisons, the conditions for studies in the historical control database must be generally similar. Significant factors affecting the background incidences of neoplasms at a variety of sites are diet, sex, strain/stock, and route of exposure. The NTP historical control database contains all 2-year studies for each species, sex, and strain/stock with histopathology findings in control animals completed within the most recent 5-year period $^{117-119}$ including the concurrent control for comparison across multiple technical reports. Due to the sectioning of residual tissues for the uterus, the historical control for this organ consists of three studies at this time: indole-3-carbinol, 2-hydroxy-4-methoxybenzophenone, and this study. In general, the historical control database for a given study includes studies using the same route of administration, and the overall incidence of neoplasms in control groups for all routes of administration are included for comparison, including the current study.

\section{Quality Assurance Methods}

The 2-year studies were conducted in compliance with Food and Drug Administration Good Laboratory Practice Regulations. ${ }^{120}$ In addition, as records from the 2-year studies were submitted to the NTP Archives, these studies were audited retrospectively by an independent QA contractor. Separate audits covered completeness and accuracy of the pathology data, pathology specimens, final pathology tables, and a draft of this NTP Technical Report. Audit procedures and findings are presented in the reports and are on file at NIEHS. The audit findings were reviewed and assessed by NTP staff, and all comments were resolved or otherwise addressed during the preparation of this Technical Report. 


\section{Results}

\section{Data Availability}

The National Toxicology Program (NTP) evaluated all study data. Data relevant for evaluating toxicological findings are presented here. All study data are available in the NTP Chemical Effects in Biological Systems (CEBS) database: https://doi.org/10.22427/NTP-DATA-TR598. ${ }^{\text {a }}$

\section{Study 1: Two-year Study in Females and 16-week Interim Evaluation in Males and Females}

\section{Perinatal Exposure}

No exposure-related effects were observed on the pregnancy status, maternal survival, or number of dams that littered (Table 4). Maternal body weights and body weight gains of exposed dams during gestation were comparable to those of the control group (Table 5). During lactation, there were no consistent effects on maternal weight or maternal body weight gain across time points among exposed groups of dams (Table 6). Feed consumption (g/animal/day) during gestation was marginally ( $3 \%$ to $4 \%$ ) lower in the 150 and $300 \mathrm{ppm}$ groups compared to the control groups at select intervals during gestation (Table 7). Feed consumption was marginally lower (up to 4\%) in the $300 \mathrm{ppm}$ group from lactation days (LDs) 1 to 14, during which primarily the dam, and not the offspring, was consuming the feed (Table 7). Chemical consumption was $10.9 \mathrm{mg} \mathrm{PFOA} / \mathrm{kg}$ body weight/day and $21.7 \mathrm{mg} / \mathrm{kg} /$ day for the 150 and $300 \mathrm{ppm}$ groups during gestation, respectively. Chemical consumption was 23.3 and $45.2 \mathrm{mg} / \mathrm{kg} /$ day for the 150 and $300 \mathrm{ppm}$ groups from LD 1-14, respectively; chemical consumption from LD 14-21 was not calculated due to the entire litter eating feed and an accurate assessment could not be made.

Table 4. Summary of Disposition during Perinatal Exposure and $F_{1}$ Allocation in the Two-year Perinatal and Postweaning Study of Perfluorooctanoic Acid (Study 1)

\begin{tabular}{lccc}
\hline & $\mathbf{0 ~ p p m}$ & $\mathbf{1 5 0} \mathbf{~ p p m}$ & $\mathbf{3 0 0} \mathbf{~ p p m}$ \\
\hline Time-mated Females & 103 & 36 & 36 \\
Nonpregnant Females & 12 & 5 & 4 \\
Pregnant Females Delivering & 91 & 31 & 32 \\
Pregnant Dams Not Delivering & 0 & 0 & 0 \\
Littered/Pregnant on GD 21 & $91 / 91(100 \%)$ & $31 / 31(100 \%)$ & $32 / 32(100 \%)$ \\
Litters Removed (PND 4) & 5 & 1 & 0 \\
Litters Poststandardization (PND 4) & 86 & 30 & 32 \\
Weaned Males/Females & $180 / 180$ & $60 / 60$ & $60 / 60$ \\
\hline
\end{tabular}

aRemoved due to insufficient size.

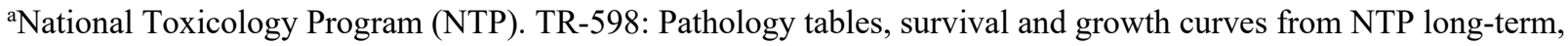
general study information, long-term, genetic toxicology studies. Research Triangle Park, NC. 2020.

https://doi.org/10.22427/NTP-DATA-TR598 
Table 5. Mean Body Weights and Body Weight Gains of $F_{0}$ Females during Gestation in the Two-year Perinatal and Postweaning Study of Perfluorooctanoic Acid (Study 1) ${ }^{\text {a }}$

\begin{tabular}{lccc}
\hline \multicolumn{1}{c}{ Gestation Day } & $\mathbf{0 ~} \mathbf{~ p p m}$ & $\mathbf{1 5 0} \mathbf{~ p p m}$ & $\mathbf{3 0 0} \mathbf{~ p p m}$ \\
\hline Body Weight (g) & & & \\
6 & $240.02 \pm 1.41(91)$ & $241.40 \pm 1.83(31)$ & $240.10 \pm 1.96(32)$ \\
9 & $256.33 \pm 1.37(91)$ & $255.53 \pm 2.04(31)$ & $254.66 \pm 1.98(32)$ \\
12 & $271.57 \pm 1.38(91)$ & $268.85 \pm 1.96(31)$ & $269.44 \pm 2.02(32)$ \\
15 & $291.06 \pm 1.53(91)$ & $288.32 \pm 2.28(31)$ & $287.63 \pm 2.26(32)$ \\
18 & $331.58 \pm 2.00(91)$ & $329.09 \pm 2.81(31)$ & $328.88 \pm 2.72(32)$ \\
21 & $379.39 \pm 2.92(91)$ & $375.53 \pm 3.86(31)$ & $374.91 \pm 3.33(30)$ \\
Body Weight Change (g) & & & \\
6 to 9 & $16.32 \pm 0.57^{*}(91)$ & $14.13 \pm 0.73(31)$ & $14.56 \pm 0.91(32)$ \\
9 to 12 & $15.24 \pm 0.44(91)$ & $13.31 \pm 0.84 *(31)$ & $14.78 \pm 0.59(32)$ \\
12 to 15 & $19.49 \pm 0.51^{*}(91)$ & $19.47 \pm 0.95(31)$ & $18.19 \pm 0.53(32)$ \\
15 to 18 & $40.52 \pm 0.80(91)$ & $40.77 \pm 1.27(31)$ & $41.25 \pm 1.01(32)$ \\
18 to 21 & $47.81 \pm 1.13^{*}(91)$ & $46.44 \pm 1.39(31)$ & $44.83 \pm 1.20(30)$ \\
6 to 21 & $139.37 \pm 2.48^{*}(91)$ & $134.13 \pm 3.32(31)$ & $133.39 \pm 2.79(30)$ \\
\hline
\end{tabular}

Statistical significance for a treatment group indicates a significant pairwise test compared to the vehicle control group. Statistical significance for the control group indicates a significant trend test.

*Statistically significant at $\mathrm{p} \leq 0.05$.

'Mean \pm standard error (number of dams). Each exposed group was compared to the control group using Williams' test when a significant trend $(\mathrm{p} \leq 0.01)$ was present by Jonckheere's test or with Dunnett's test when no significant trend was present.

Table 6. Mean Body Weights and Body Weight Gains of $F_{0}$ Females during Lactation in the Two-year Perinatal and Postweaning Study of Perfluorooctanoic Acid (Study 1) ${ }^{\mathrm{a}}$

\begin{tabular}{lccc}
\hline \multicolumn{1}{c}{ Lactation Day } & $\mathbf{0 ~ p p m}$ & $\mathbf{1 5 0} \mathbf{~ p p m}$ & $\mathbf{3 0 0} \mathbf{~ p p m}$ \\
\hline Body Weight (g) & & & \\
1 & $281.59 \pm 1.60(91)$ & $279.45 \pm 2.04(31)$ & $277.89 \pm 2.47(32)$ \\
4 & $298.08 \pm 1.51^{*}(86)$ & $295.41 \pm 2.13(30)$ & $289.97 \pm 3.18^{*}(32)$ \\
7 & $304.13 \pm 1.48^{*}(86)$ & $298.58 \pm 2.32(30)$ & $299.36 \pm 2.53(32)$ \\
14 & $321.16 \pm 1.65(86)$ & $316.43 \pm 2.21(30)$ & $316.98 \pm 2.22(32)$ \\
21 & $306.22 \pm 1.52(86)$ & $306.24 \pm 1.84(30)$ & $305.80 \pm 2.69(32)$ \\
Body Weight Change (g) & & & \\
1 to 4 & $15.75 \pm 0.81(86)$ & $16.06 \pm 1.20(30)$ & $12.07 \pm 2.30(32)$ \\
4 to 7 & $6.05 \pm 0.84(86)$ & $3.17 \pm 1.41(30)$ & $9.39 \pm 1.90(32)$ \\
7 to 14 & $17.03 \pm 0.95(86)$ & $17.85 \pm 1.24(30)$ & $17.63 \pm 1.47(32)$ \\
14 to 21 & $-14.94 \pm 1.19^{*}(86)$ & $-10.19 \pm 1.22 *(30)$ & $-11.18 \pm 1.60(32)$ \\
1 to 21 & $23.89 \pm 1.14^{* *}(86)$ & $26.89 \pm 1.74(30)$ & $27.91 \pm 2.07(32)$ \\
\hline
\end{tabular}

Statistical significance for a treatment group indicates a significant pairwise test compared to the vehicle control group. Statistical significance for the control group indicates a significant trend test.

$*$ Statistically significant at $\mathrm{p} \leq 0.05 ; * * \mathrm{p} \leq 0.01$.

aMean \pm standard error (number of dams). Each exposed group was compared to the control using Williams' test when a significant $(\mathrm{p} \leq 0.01)$ trend was present by Jonckheere's test or with Dunnett's test when no significant trend was present. 
Table 7. Feed Consumption by $F_{0}$ Females during Gestation and Lactation in the Two-year Perinatal and Postweaning Study of Perfluorooctanoic Acid (Study 1) ${ }^{\mathrm{a}}$

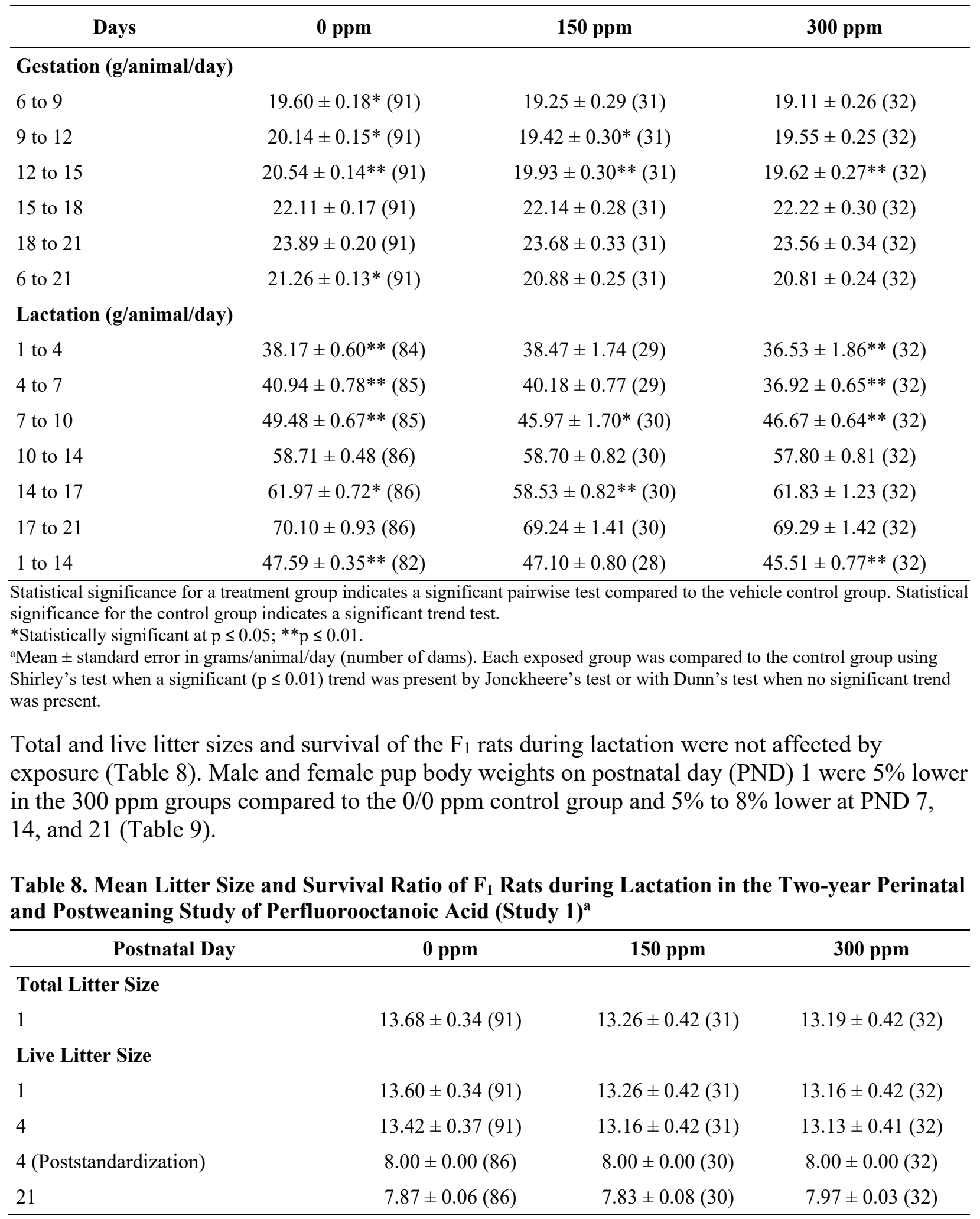




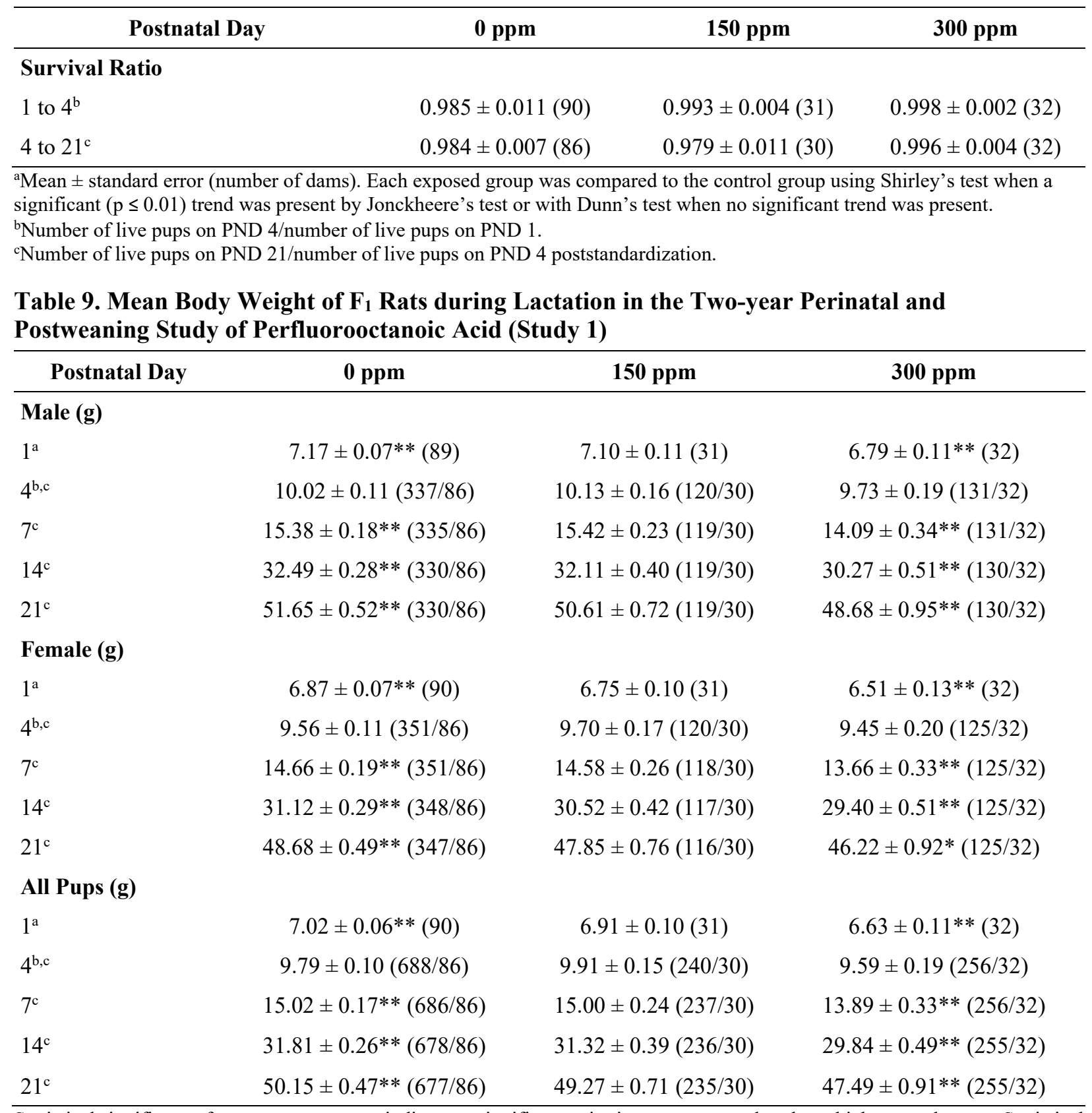

Statistical significance for a treatment group indicates a significant pairwise test compared to the vehicle control group. Statistical significance for the control group indicates a significant trend test.

*Statistically significant at $\mathrm{p} \leq 0.05 ; * \mathrm{p} \leq 0.01$.

${ }^{a}$ Mean \pm standard error (number of dams). Each exposed group was compared to the control group using Williams' test when a significant $(\mathrm{p} \leq 0.01)$ trend was present by Jonckheere's test or with Dunnett's test when no significant trend was present. bPND 4 poststandardization.

${ }^{\mathrm{c}}$ Mean \pm standard error (number of pups/number of dams). Individual pup weights first adjusted for litter size on PND 4 poststandardization. Each exposed group was compared to the control group using a mixed model with a Dunnett-Hsu adjustment.

\section{Sixteen-week Interim Evaluation in Males and Females (Study 1)}

No early deaths occurred among rats designated for interim evaluation at 16 weeks (19 weeks of age). Due to the concern of overt toxicity in males, the male portion of the 2-year study was 
terminated at 21 weeks ( 24 weeks of age). The overt toxicity in the male rats presented low body weights and the presence of liver necrosis. There were no exposure-related clinical observations (Appendix E). No other evaluation was performed on the males removed from study at 21 weeks.

Group mean feed (g/animal/day) and compound consumption ( $\mathrm{mg} / \mathrm{kg} / \mathrm{day})$ for male rats through 21 weeks are available in Appendix E. Compared to the $0 / 0 \mathrm{ppm}$ control group, mean feed consumption by exposed males was lower through week 13 of the study. Mean feed consumption (g/animal/day) by $0 / 150,150 / 150,0 / 300$, and $300 / 300$ ppm groups was $13 \%, 11 \%, 23 \%$, and $19 \%$ less than the $0 / 0 \mathrm{ppm}$ control group, respectively, at 13 weeks. This reduction in feed consumption may be due in part to the smaller size of the animals (described below) compared to the $0 / 0$ ppm control group. This difference would be captured in feed consumption expressed in $\mathrm{g} / \mathrm{kg}$ body weight/day, but these values were not calculated. Compound consumption for the 0/150 and 150/150 ppm groups through week 13 averaged 15.6 and $15.8 \mathrm{mg} / \mathrm{kg} / \mathrm{day}$, respectively, and for the 0/300 and 300/300 ppm groups, 31.7 and $32.1 \mathrm{mg} / \mathrm{kg} /$ day, respectively.

Mean feed consumption (g/animal/day) for $\mathrm{F}_{1}$ females is available in Appendix E. Feed consumption for females in the $0 / 300$ and $150 / 300$ ppm groups was within $10 \%$ of the $0 / 0 \mathrm{ppm}$ control group throughout the study. Mean feed consumption for the $0 / 1,000$ and 300/1,000 ppm female groups was reduced through the first 4 weeks postweaning. However, by the fifth week, mean feed consumption for these two groups was within $10 \%$ of the $0 / 0$ ppm control group and remained so through the end of the study. Compound consumption averaged $29.6 \mathrm{mg} / \mathrm{kg} / \mathrm{day}$ for the $0 / 300$ and $150 / 300 \mathrm{ppm}$ groups and 98.6 and $104.4 \mathrm{mg} / \mathrm{kg} / \mathrm{day}$ for the $0 / 1,000$ and 300/1,000 ppm groups, respectively.

Plasma PFOA concentrations in males were consistent between groups with and without exposure during the perinatal period and were within $10 \%$ of each other between the $0 / 150$ and $150 / 150$ ppm groups and between the $0 / 300$ and 300/300 ppm groups (Table 10). Liver concentrations showed a similar pattern. Plasma concentrations in females showed a similar pattern to the males (e.g., minor differences between perinatal exposures and liver patterns); however, PFOA concentrations were much lower compared to males even though female exposure (mg/kg/day) was 2 to 3 times higher compared to males (Table 11). Plasma concentrations were approximately 12 -fold lower in the $0 / 300 \mathrm{ppm}$ female group compared to the $0 / 300$ ppm male group.

Table 10. Summary of Plasma and Liver Concentration Data for Male Rats at the 16-week Interim of the Two-year Feed Study of Perfluorooctanoic Acid (Study 1) ${ }^{\mathrm{a}, \mathrm{b}}$

\begin{tabular}{lcccc}
\hline & \multicolumn{3}{c}{ Postweaning Exposure } \\
\cline { 2 - 5 } & $\begin{array}{c}\text { Perinatal } \\
\text { Exposure }\end{array}$ & $\mathbf{0 ~ p p m}$ & $\mathbf{1 5 0} \mathbf{~ p p m}$ & $\mathbf{3 0 0} \mathbf{~ p p m}$ \\
\hline $\mathbf{n}$ & $0 \mathrm{ppm}$ & $\mathrm{BD}^{\mathrm{c}}$ & $193,000 \pm 11,325$ & $242,500 \pm 12,731$ \\
\hline Plasma Concentration $(\mathrm{ng} / \mathrm{mL})$ & $150 \mathrm{ppm}$ & - & $175,390 \pm 14,956$ & - \\
& $300 \mathrm{ppm}$ & - & - & $223,400 \pm 8,422$ \\
& $0 \mathrm{ppm}$ & $\mathrm{BD}^{\mathrm{c}}$ & $466.1 \pm 27.4$ & $585.7 \pm 30.7$ \\
\hline
\end{tabular}




\begin{tabular}{|c|c|c|c|c|}
\hline & \multicolumn{4}{|c|}{ Postweaning Exposure } \\
\hline & $\begin{array}{l}\text { Perinatal } \\
\text { Exposure }\end{array}$ & 0 ppm & 150 ppm & 300 ppm \\
\hline & $150 \mathrm{ppm}$ & - & $423.6 \pm 36.1$ & - \\
\hline & 300 ppm & - & - & $539.5 \pm 20.3$ \\
\hline \multirow[t]{3}{*}{ Liver Concentration (ng/g) } & 0 ppm & $\mathrm{BD}$ & $157,400 \pm 5,418$ & $171,000 \pm 7,578$ \\
\hline & 150 ppm & - & $144,300 \pm 5,752$ & - \\
\hline & 300 ppm & - & - & $193,800 \pm 9,704$ \\
\hline \multirow[t]{3}{*}{ Liver Concentration $(\mu \mathrm{M})$} & $0 \mathrm{ppm}$ & $\mathrm{BD}$ & $380.1 \pm 13.1$ & $413.0 \pm 18.3$ \\
\hline & 150 ppm & - & $348.5 \pm 13.9$ & - \\
\hline & 300 ppm & - & - & $468.0 \pm 23.4$ \\
\hline \multirow[t]{3}{*}{ Liver/Plasma Ratio } & $0 \mathrm{ppm}$ & $\mathrm{BD}$ & $0.84 \pm 0.05$ & $0.73 \pm 0.06$ \\
\hline & 150 ppm & - & $0.86 \pm 0.06$ & - \\
\hline & $300 \mathrm{ppm}$ & - & - & $0.88 \pm 0.05$ \\
\hline
\end{tabular}

Pairwise comparisons across perinatal exposures (0/150 vs. $150 / 150 \mathrm{ppm}$ and 0/300 vs. $300 / 300 \mathrm{ppm})$ did not show any statistically significant differences.

Values adjusted for molar concentration were calculated by dividing by the molecular weight of 414.06 .

$\mathrm{BD}=$ below detection; group did not have over $20 \%$ of its values above the limit of quantification. In these cases, no statistical analyses were performed.

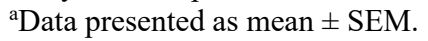

bStatistical analysis performed by Jonckheere's (trend) and Shirley's or Dunn's (pairwise) tests (unless otherwise noted). ${ }^{\mathrm{c}} \mathrm{N}=9$; decrease in $\mathrm{N}$ in the $0 / 0 \mathrm{ppm}$ control group is due to the exclusion of an implausible plasma concentration value.

Table 11. Summary of Plasma and Liver Concentration Data for Female Rats at the 16-week Interim of the Two-year Feed Study of Perfluorooctanoic Acid (Study 1) ${ }^{a, b}$

\begin{tabular}{lcccc}
\hline & & \multicolumn{3}{c}{ Postweaning Exposure } \\
\cline { 2 - 5 } & $\begin{array}{c}\text { Perinatal } \\
\text { Exposure }\end{array}$ & $\mathbf{0 ~ p p m}$ & $\mathbf{3 0 0} \mathbf{~ p p m}$ & $\mathbf{1 , 0 0 0} \mathbf{~ p p m}$ \\
\hline $\mathbf{n}$ & & 10 & 10 & 10 \\
\hline Plasma Concentration $(\mathrm{ng} / \mathrm{mL})$ & $0 \mathrm{ppm}$ & $\mathrm{BD}$ & $20,420 \pm 1,212$ & $72,250 \pm 4,351$ \\
& $150 \mathrm{ppm}$ & - & $20,800 \pm 1,043$ & - \\
& $300 \mathrm{ppm}$ & - & - & $70,160 \pm 6,895$ \\
Plasma Concentration $(\mu \mathrm{M})$ & $0 \mathrm{ppm}$ & $\mathrm{BD}$ & $49.3 \pm 2.9$ & $174.5 \pm 10.5$ \\
& $150 \mathrm{ppm}$ & - & $50.2 \pm 2.5$ & - \\
& $300 \mathrm{ppm}$ & - & - & $169.4 \pm 16.7$ \\
Liver Concentration $(\mathrm{ng} / \mathrm{g})$ & $0 \mathrm{ppm}$ & $\mathrm{BD}$ & $16,420 \pm 787$ & $69,040 \pm 3,942$ \\
& $150 \mathrm{ppm}$ & - & $16,660 \pm 750$ & - \\
& $300 \mathrm{ppm}$ & - & - & $67,840 \pm 5,681$ \\
Liver Concentration $(\mu \mathrm{M})$ & $0 \mathrm{ppm}$ & $\mathrm{BD}$ & $39.7 \pm 1.9$ & $166.7 \pm 9.5$ \\
& $150 \mathrm{ppm}$ & - & $40.2 \pm 1.8$ & - \\
& $300 \mathrm{ppm}$ & - & - & $163.8 \pm 13.7$ \\
\hline
\end{tabular}




\begin{tabular}{lcccc}
\hline & & \multicolumn{3}{c}{ Postweaning Exposure } \\
\cline { 2 - 5 } & $\begin{array}{c}\text { Perinatal } \\
\text { Exposure }\end{array}$ & $\mathbf{0 ~ p p m}$ & $\mathbf{3 0 0} \mathbf{~ p p m}$ & $\mathbf{1 , 0 0 0} \mathbf{~ p p m}$ \\
Liver/Plasma Ratio & $0 \mathrm{ppm}$ & BD & $0.82 \pm 0.03$ & $0.96 \pm 0.04$ \\
& $150 \mathrm{ppm}$ & - & $0.81 \pm 0.03$ & - \\
& $300 \mathrm{ppm}$ & - & - & $0.99 \pm 0.05$ \\
\hline
\end{tabular}

Pairwise comparisons across perinatal exposures (0/300 vs. 150/300 ppm and 0/1,000 vs. 300/1,000 ppm) did not show any statistically significant differences.

Values adjusted for molar concentration were calculated by dividing by the molecular weight of 414.06.

$\mathrm{BD}=$ below detection; group did not have over $20 \%$ of its values above the limit of quantification. In these cases, no statistical analyses were performed.

a Data presented as mean \pm SEM.

'Statistical analysis performed by Jonckheere's (trend) and Shirley's or Dunn's (pairwise) tests (unless otherwise noted).

Males in all exposure groups gained weight through the interim study evaluation at week 16 (Figure 2, Figure 3; Appendix E). However, exposed males did not gain weight at the same rate as the $0 / 0$ ppm control group; this reduced weight gain was related to exposure. Body weights of males in the $0 / 150$ and $150 / 150$ ppm groups evaluated at 16 weeks were $79 \%$ and $76 \%$ of the $0 / 0 \mathrm{ppm}$ control group weight, respectively, and body weights of males in the $0 / 300$ and $300 / 300$ ppm groups were $55 \%$ of the $0 / 0$ ppm control group weight.

Group mean body weights of females are reported in Appendix E. Mean body weights for females in the $0 / 300$ and $150 / 300 \mathrm{ppm}$ groups were within $10 \%$ of the $0 / 0 \mathrm{ppm}$ control group. Mean body weights for the $0 / 1,000$ and 300/1,000 ppm female groups were approximately $10-15 \%$ less than the $0 / 0$ ppm control group throughout most of the postweaning period. For the females evaluated at 16 weeks, mean body weights for the 0/1,000 and 300/1,000 ppm groups were $12 \%$ less than that of the $0 / 0 \mathrm{ppm}$ control group. 


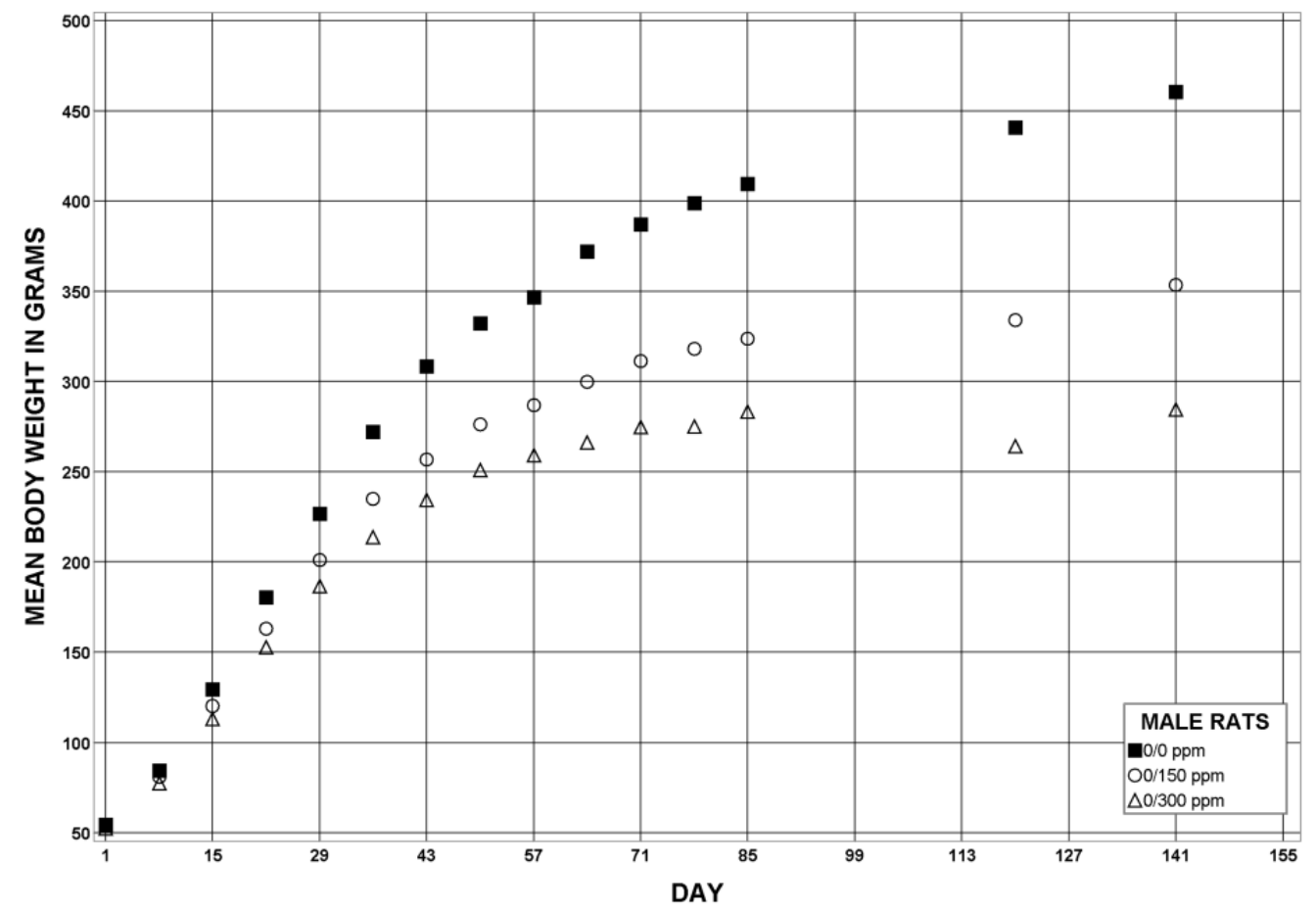

Figure 2. Growth Curves for Male Rats with Postweaning-only Exposure to 0/0, 0/150, or $0 / 300$ ppm Perfluorooctanoic Acid in Feed for 21 Weeks

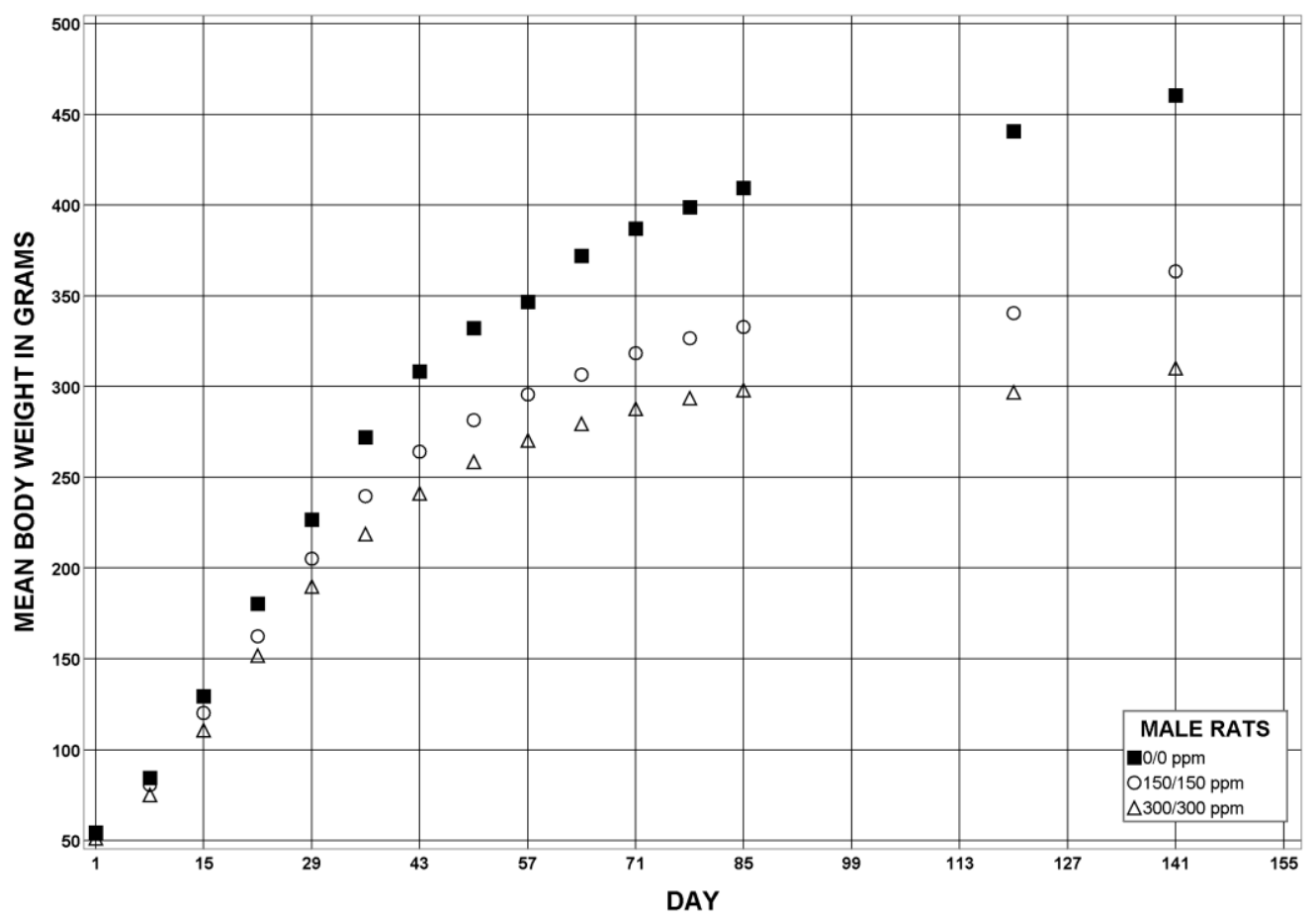

Figure 3. Growth Curves for Male Rats with Perinatal and Postweaning Exposure to 0/0, 150/150, or 300/300 ppm Perfluorooctanoic Acid in Feed for 21 Weeks 
The group mean absolute and relative liver weights of all exposed groups of males and of $0 / 1,000$ and $300 / 1,000 \mathrm{ppm}$ female groups were significantly greater than those of the $0 / 0 \mathrm{ppm}$ control group (Table 12, Table 13). Absolute liver weights were increased up to $42 \%$ (males) and $36 \%$ (females) of the $0 / 0 \mathrm{ppm}$ control group. Histological correlates (hepatocyte hypertrophy, cytoplasmic alteration, and pigment) were present in all groups that had liver weight changes (Table 12, Table 13). Groups with both perinatal and postweaning exposure did not differ from groups with postweaning-only exposure.

Acyl-CoA oxidase enzyme activity, a marker of PPAR $\alpha$ activity, was increased in all male and female PFOA-exposed groups. Activity increased in males in the $0 / 150$ and $150 / 150$ ppm groups by 10 -fold and increased in the $0 / 300$ and $300 / 300$ ppm groups by 11 - to 12 -fold compared to the $0 / 0 \mathrm{ppm}$ control group. The magnitude of the effect was smaller in females with a 1.4-fold increase in the mid-doses of 0/300 and 150/300 ppm groups and a 5.5- and 6.5-fold increase in the $300 / 1,000$ and $0 / 1,000 \mathrm{ppm}$ groups, respectively, compared to the $0 / 0 \mathrm{ppm}$ control group. No changes were observed in liver aromatase activity in males or females (Table 12, Table 13). 
Table 12. Summary of Hepatic Findings for Male Rats at the 16-week Interim of the Two-year Feed Study of Perfluorooctanoic Acid (Study 1)

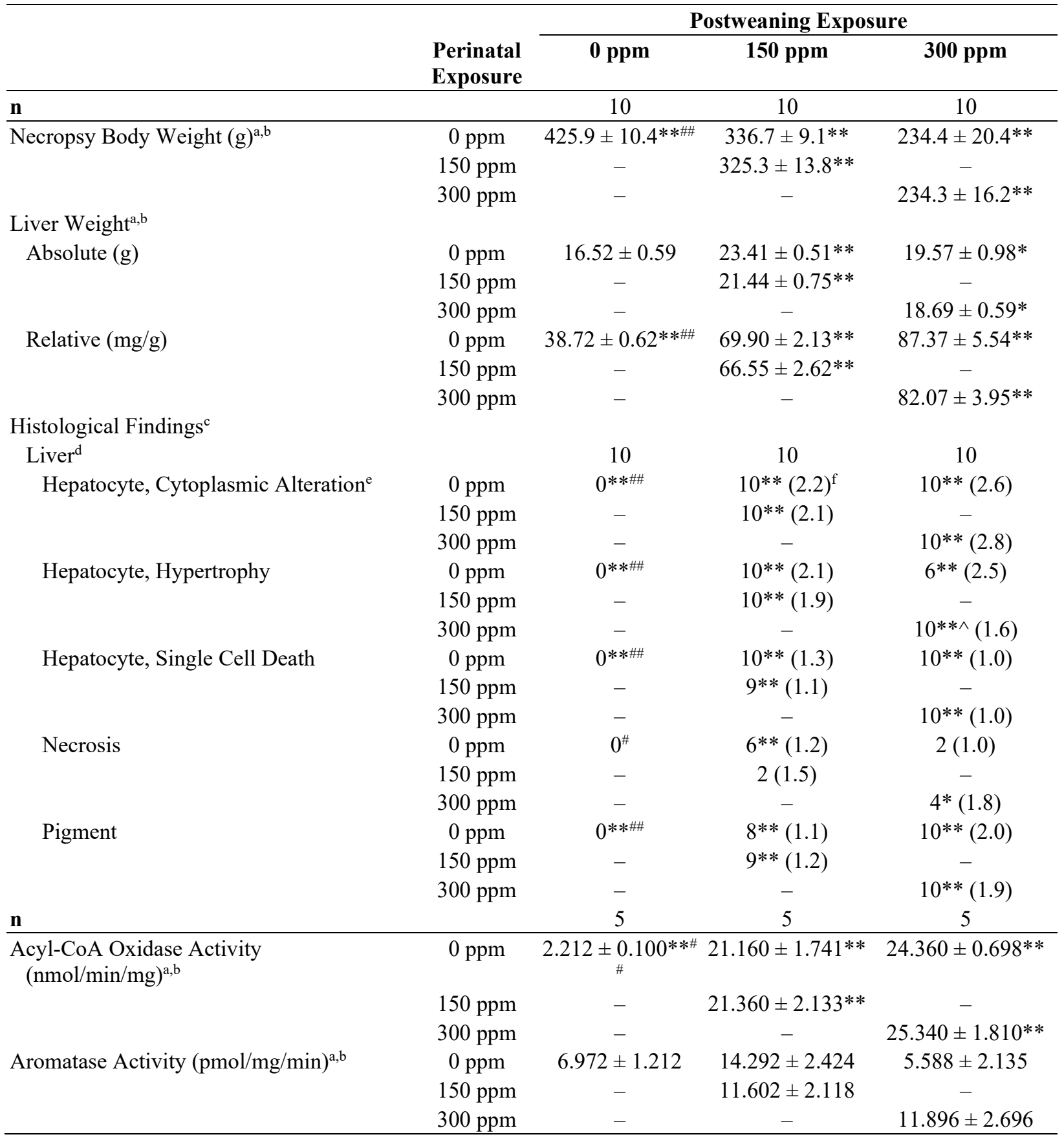

Statistical significance for a treatment group indicates a significant pairwise test compared to the $0 / 0$ ppm control group.

Statistical significance for the $0 / 0 \mathrm{ppm}$ control group indicates a significant trend test.

*Statistically significant at $\mathrm{p} \leq 0.05 ; * * \mathrm{p} \leq 0.01$.

${ }^{\#}$ Statistically significant trend at $\mathrm{p} \leq 0.05$ when comparing across the $0 / 0,150 / 150$, and $300 / 300 \mathrm{ppm}$ groups; ${ }^{\#} \mathrm{p} \leq 0.01$.

${ }^{\wedge}$ Statistically significant at $p \leq 0.05$ when comparing $0 / 300$ vs. $300 / 300 \mathrm{ppm}$.

${ }^{\text {aD }}$ ata presented as mean \pm SEM.

'Statistical analysis performed by Jonckheere's (trend) and Shirley's or Dunn's (pairwise) tests.

'Statistical analysis performed by the Poly-3 test.

${ }^{\mathrm{d}}$ Number of animals examined microscopically.

${ }^{\mathrm{e} N u m b e r}$ of animals with lesion.

${ }_{\mathrm{f}}^{\mathrm{f}}$ Average severity grade of lesion in affected animals: $1=$ minimal; $2=$ mild; $3=$ moderate; $4=$ marked. 
Table 13. Summary of Hepatic Findings for Female Rats at the 16-week Interim of the Two-year Feed Study of Perfluorooctanoic Acid (Study 1)

\begin{tabular}{|c|c|c|c|c|}
\hline & \multirow[b]{2}{*}{$\begin{array}{l}\text { Perinatal } \\
\text { Exposure }\end{array}$} & \multicolumn{3}{|c|}{ Postweaning Exposure } \\
\hline & & 0 ppm & 300 ppm & 1,000 ppm \\
\hline $\mathbf{n}$ & & 10 & 10 & 10 \\
\hline \multirow[t]{3}{*}{ Necropsy Body Weight (g) } & $0 \mathrm{ppm}$ & $255.2 \pm 4.5^{* * \# \#}$ & $248.9 \pm 8.5$ & $223.7 \pm 3.9 * *$ \\
\hline & $150 \mathrm{ppm}$ & - & $242.3 \pm 7.1$ & - \\
\hline & $300 \mathrm{ppm}$ & - & - & $223.4 \pm 8.4 * *$ \\
\hline \multicolumn{5}{|l|}{ Liver Weight $t^{\mathrm{a}, \mathrm{b}}$} \\
\hline \multirow[t]{3}{*}{ Absolute (g) } & $0 \mathrm{ppm}$ & $9.35 \pm 0.40^{* * \# \#}$ & $9.78 \pm 0.32$ & $12.70 \pm 0.36^{* *}$ \\
\hline & $150 \mathrm{ppm}$ & - & $9.36 \pm 0.23$ & - \\
\hline & 300 ppm & - & - & $12.71 \pm 0.56^{* *}$ \\
\hline \multirow[t]{3}{*}{ Relative (mg/g) } & $0 \mathrm{ppm}$ & $36.55 \pm 1.08^{* * \# \#}$ & $39.34 \pm 0.61$ & $56.78 \pm 1.33^{* *}$ \\
\hline & $150 \mathrm{ppm}$ & - & $38.70 \pm 0.70$ & - \\
\hline & 300 ppm & - & - & $56.86 \pm 1.19 * *$ \\
\hline \multicolumn{5}{|l|}{ Histological Findings ${ }^{\mathrm{c}}$} \\
\hline Liver $^{\mathrm{d}}$ & & 10 & 10 & 10 \\
\hline \multirow[t]{3}{*}{ Hepatocyte, Cytoplasmic Alteration ${ }^{\mathrm{e}}$} & $0 \mathrm{ppm}$ & $0 * * \#$ & 0 & $10 * *(1.3)^{\mathrm{f}}$ \\
\hline & $150 \mathrm{ppm}$ & - & 0 & - \\
\hline & $300 \mathrm{ppm}$ & - & - & $10^{* *}(2.0)$ \\
\hline \multirow[t]{3}{*}{ Hepatocyte, Hypertrophy } & $0 \mathrm{ppm}$ & $0 * * \#$ & 0 & $10^{* *}(1.4)$ \\
\hline & $150 \mathrm{ppm}$ & - & 0 & - \\
\hline & $300 \mathrm{ppm}$ & - & - & $10 * *(2.0)$ \\
\hline \multirow[t]{3}{*}{ Hepatocyte, Single Cell Death } & 0 ppm & 0 & 0 & $1(1.0)$ \\
\hline & $150 \mathrm{ppm}$ & - & 0 & - \\
\hline & 300 ppm & - & - & 0 \\
\hline \multirow[t]{3}{*}{ Necrosis } & $0 \mathrm{ppm}$ & 0 & 0 & $2(2.5)$ \\
\hline & $150 \mathrm{ppm}$ & - & 0 & - \\
\hline & $300 \mathrm{ppm}$ & - & - & 0 \\
\hline \multirow[t]{3}{*}{ Pigment } & $0 \mathrm{ppm}$ & $0^{\# \#}$ & 0 & $2(1.0)$ \\
\hline & $150 \mathrm{ppm}$ & - & 0 & - \\
\hline & 300 ppm & - & - & $6 * *(1.0)$ \\
\hline
\end{tabular}




\section{Perfluorooctanoic Acid, NTP TR 598}

\begin{tabular}{lcccc}
\hline & & \multicolumn{3}{c}{ Postweaning Exposure } \\
\cline { 3 - 5 } & $\begin{array}{c}\text { Perinatal } \\
\text { Exposure }\end{array}$ & $\mathbf{0 ~ p p m}$ & $\mathbf{3 0 0} \mathbf{~ p p m}$ & $\mathbf{1 , 0 0 0} \mathbf{~ p p m}$ \\
\hline $\mathbf{n}$ & $0 \mathrm{ppm}$ & $2.366 \pm 0.106^{* * * \#}$ & $3.402 \pm 0.300^{* *}$ & $15.360 \pm 0.375^{* *}$ \\
\hline $\begin{array}{c}\text { Acyl-CoA Oxidase Activity } \\
(\mathrm{nmol} / \mathrm{min} / \mathrm{mg})^{\mathrm{a}, \mathrm{b}}\end{array}$ & $150 \mathrm{ppm}$ & - & $3.300 \pm 0.213^{* *}$ & - \\
& $300 \mathrm{ppm}$ & - & - & $12.980 \pm 0.712^{* *}$ \\
& $0 \mathrm{ppm}$ & $1.590 \pm 0.404$ & $1.762 \pm 0.302$ & $1.710 \pm 0.433$ \\
Aromatase Activity (pmol/mg/min) $)^{\mathrm{a}, \mathrm{b}}$ & $150 \mathrm{ppm}$ & - & $2.672 \pm 0.881$ & - \\
& $300 \mathrm{ppm}$ & - & - & $2.616 \pm 0.572$ \\
\hline
\end{tabular}

Statistical significance for a treatment group indicates a significant pairwise test compared to the $0 / 0$ ppm control group. Statistical significance for the $0 / 0 \mathrm{ppm}$ control group indicates a significant trend test.

Pairwise comparisons across perinatal exposures (0/300 vs. $150 / 300 \mathrm{ppm}$ and 0/1,000 vs. 300/1,000 ppm) did not show any statistically significant differences.

*Statistically significant at $\mathrm{p} \leq 0.05 ; * * \mathrm{p} \leq 0.01$.

"Statistically significant trend at $\mathrm{p} \leq 0.05$ when comparing across the $0 / 0,150 / 300$, and 300/1,000 ppm groups; ${ }^{\# \#} \leq 0.01$.

${ }^{a}$ Data presented as mean \pm SEM.

'Statistical analysis performed by Jonckheere's (trend) and Shirley's or Dunn's (pairwise) tests.

'Statistical analysis performed by the Poly-3 test.

${ }^{\mathrm{d}}$ Number of animals examined microscopically.

eNumber of animals with lesion.

${ }^{\mathrm{f}}$ Average severity grade of lesion in affected animals: $1=$ minimal; $2=$ mild; $3=$ moderate; $4=$ marked.

The mean absolute and relative spleen and absolute thymus weights of all exposed male groups were significantly less than those of the $0 / 0 \mathrm{ppm}$ control group (Table 14; Appendix E). The decrease in absolute spleen and thymus weights was up to $54 \%$ and $49 \%$, respectively, in the $0 / 300 \mathrm{ppm}$ group compared to the $0 / 0 \mathrm{ppm}$ control group; however, there were no correlated histological findings.

Statistically significant differences between exposed and $0 / 0 \mathrm{ppm}$ control group males in absolute and relative heart, lung, right kidney, testis, thyroid gland, pituitary gland, and adrenal gland mean weights were considered related to the significantly decreased body weights, and there were no correlated histological findings (Appendix E).

Significantly decreased mean absolute right kidney and lung weights of the 0/1,000 and $300 / 1,000 \mathrm{ppm}$ female groups, mean absolute heart weight of the 0/1,000 ppm female group, and mean absolute pituitary gland weight of the 300/1,000 ppm female group were also considered related to reduced body weights. 
Table 14. Select Organ Weights and Organ-Weight-to-Body-Weight Ratios for Male Rats at the 16-week Interim of the Two-year Feed Study of Perfluorooctanoic Acid (Study 1)

\begin{tabular}{|c|c|c|c|c|}
\hline & \multirow[b]{2}{*}{$\begin{array}{l}\text { Perinatal } \\
\text { Exposure }\end{array}$} & \multicolumn{3}{|c|}{ Postweaning Exposure } \\
\hline & & 0 ppm & 150 ppm & 300 ppm \\
\hline n & & 10 & 10 & 10 \\
\hline \multirow[t]{3}{*}{ Necropsy Body Weight (g) } & $0 \mathrm{ppm}$ & $425.9 \pm 10.4 * * \#$ & $336.7 \pm 9.1 * *$ & $234.4 \pm 20.4^{* *}$ \\
\hline & $150 \mathrm{ppm}$ & - & $325.3 \pm 13.8 * *$ & - \\
\hline & 300 ppm & - & - & $234.3 \pm 16.2 * *$ \\
\hline \multicolumn{5}{|l|}{ Spleen Weight } \\
\hline \multirow[t]{3}{*}{ Absolute (g) } & $0 \mathrm{ppm}$ & $0.805 \pm 0.031^{* * \# \#}$ & $0.551 \pm 0.022 * *$ & $0.373 \pm 0.038^{* *}$ \\
\hline & $150 \mathrm{ppm}$ & - & $0.543 \pm 0.036^{* *}$ & - \\
\hline & $300 \mathrm{ppm}$ & - & - & $0.395 \pm 0.038^{* *}$ \\
\hline \multirow[t]{3}{*}{ Relative (mg/g) } & $0 \mathrm{ppm}$ & $1.89 \pm 0.05^{* * \#}$ & $1.63 \pm 0.03 * *$ & $1.58 \pm 0.06^{* *}$ \\
\hline & $150 \mathrm{ppm}$ & - & $1.66 \pm 0.07^{*}$ & - \\
\hline & 300 ppm & - & - & $1.66 \pm 0.07^{*}$ \\
\hline \multicolumn{5}{|l|}{ Thymus Weight } \\
\hline \multirow[t]{3}{*}{ Absolute (g) } & $0 \mathrm{ppm}$ & $0.369 \pm 0.015^{* * \# \#}$ & $0.277 \pm 0.017^{* *}$ & $0.187 \pm 0.027^{* *}$ \\
\hline & $150 \mathrm{ppm}$ & - & $0.284 \pm 0.014^{* *}$ & - \\
\hline & 300 ppm & - & - & $0.208 \pm 0.026^{* *}$ \\
\hline \multirow[t]{3}{*}{ Relative (mg/g) } & $0 \mathrm{ppm}$ & $0.87 \pm 0.04$ & $0.83 \pm 0.05$ & $0.77 \pm 0.06$ \\
\hline & $150 \mathrm{ppm}$ & - & $0.88 \pm 0.04$ & - \\
\hline & 300 ppm & - & - & $0.86 \pm 0.07$ \\
\hline
\end{tabular}

Statistical significance for a treatment group indicates a significant pairwise test compared to the 0/0 ppm control group. Statistical significance for the $0 / 0 \mathrm{ppm}$ control group indicates a significant trend test.

Pairwise comparisons across perinatal exposures (0/150 vs. $150 / 150 \mathrm{ppm}$ and $0 / 300 \mathrm{vs.} 300 / 300 \mathrm{ppm})$ did not show any statistically significant differences.

$*$ Statistically significant at $\mathrm{p} \leq 0.05 ; * * \mathrm{p} \leq 0.01$.

${ }^{\#}$ Statistically significant trend at $\mathrm{p} \leq 0.05$ when comparing across the $0 / 0,150 / 150$, and $300 / 300$ ppm groups; ${ }^{\# \#} \mathrm{p} \leq 0.01$.

${ }^{\text {aData }}$ presented as mean \pm SEM.

'Statistical analysis performed by Jonckheere's (trend) and Shirley's or Dunn's (pairwise) tests (unless otherwise noted). 
Select clinical chemistry data are presented in Table 15 (males) and Table 16 (females). Urea nitrogen concentrations were significantly increased in all exposed male groups; this was most likely due to a decrease in water consumption (i.e., mild dehydration), which is supported by the observed decreases in feed consumption. Triglyceride concentrations were significantly decreased in all exposed male groups.

Globulin concentrations were significantly decreased in all exposed groups of males and females. In exposed male groups, the degree of decrease in the globulin concentration resulted in a significant decrease in total protein concentration. Albumin concentrations were significantly increased in the $0 / 150$ and $150 / 150 \mathrm{ppm}$ male groups and in the $0 / 1,000$, and $300 / 1,000 \mathrm{ppm}$ female groups compared to the $0 / 0 \mathrm{ppm}$ control group. The combination of these protein changes resulted in significant increases in the albumin:globulin ratios in all exposed groups.

With and without perinatal exposure, alanine aminotransferase (ALT), alkaline phosphatase (ALP), and sorbitol dehydrogenase (SDH) enzyme activities were significantly increased in all exposed male groups. In females, ALT activity was significantly increased in the $0 / 1,000$ and $300 / 1,000$ ppm groups, whereas SDH activity was increased in the 300/1,000 ppm group and ALP activity increased in the $0 / 1,000 \mathrm{ppm}$ group compared to the $0 / 0 \mathrm{ppm}$ control group. Additionally, bile acid concentrations were significantly increased in all exposed male groups with and without perinatal exposure.

Table 15. Select Clinical Chemistry Data for Male Rats at the 16-week Interim of the Two-year Feed Study of Perfluorooctanoic Acid (Study 1) ${ }^{\mathrm{a}, \mathrm{b}}$

\begin{tabular}{|c|c|c|c|c|}
\hline & & & weaning Expos & \\
\hline & $\begin{array}{l}\text { Perinatal } \\
\text { Exposure }\end{array}$ & 0 ppm & 150 ppm & 300 ppm \\
\hline $\mathbf{n}$ & & 10 & 10 & 10 \\
\hline Urea Nitrogen $(\mathrm{mg} / \mathrm{dL})$ & $0 \mathrm{ppm}$ & $15.3 \pm 0.6^{* * \# \#}$ & $21.2 \pm 0.7 * *$ & $21.3 \pm 0.8^{* *}$ \\
\hline & $150 \mathrm{ppm}$ & - & $20.6 \pm 1.0^{* *}$ & - \\
\hline & $300 \mathrm{ppm}$ & - & - & $24.1 \pm 1.0^{* *}$ \\
\hline Total Protein $(\mathrm{g} / \mathrm{dL})$ & $0 \mathrm{ppm}$ & $6.59 \pm 0.07 * * \#$ & $6.17 \pm 0.09 * *$ & $5.18 \pm 0.15^{* *}$ \\
\hline & $150 \mathrm{ppm}$ & - & $5.87 \pm 0.13^{* *}$ & - \\
\hline & $300 \mathrm{ppm}$ & - & - & $5.35 \pm 0.22 * *$ \\
\hline Albumin (g/dL) & $0 \mathrm{ppm}$ & $4.13 \pm 0.04$ & $4.69 \pm 0.07 * *$ & $4.00 \pm 0.14$ \\
\hline & $150 \mathrm{ppm}$ & - & $4.48 \pm 0.09^{*}$ & - \\
\hline & $300 \mathrm{ppm}$ & - & - & $4.09 \pm 0.16$ \\
\hline Globulin (g/dL) & $0 \mathrm{ppm}$ & $2.46 \pm 0.06^{* * \# \#}$ & $1.48 \pm 0.07 * *$ & $1.18 \pm 0.03 * *$ \\
\hline & $150 \mathrm{ppm}$ & - & $1.39 \pm 0.06^{* *}$ & - \\
\hline & 300 ppm & - & - & $1.26 \pm 0.08 * *$ \\
\hline A/G Ratio & $0 \mathrm{ppm}$ & $1.69 \pm 0.05^{* * \# \#}$ & $3.24 \pm 0.18^{* *}$ & $3.40 \pm 0.12 * *$ \\
\hline & $150 \mathrm{ppm}$ & - & $3.27 \pm 0.15^{* *}$ & - \\
\hline & $300 \mathrm{ppm}$ & - & - & $3.31 \pm 0.16^{* *}$ \\
\hline Triglycerides (mg/dL) & 0 ppm & $115.1 \pm 6.2 * * \# \#$ & $61.5 \pm 6.5^{* *}$ & $52.4 \pm 6.4^{* *}$ \\
\hline & $150 \mathrm{ppm}$ & - & $58.4 \pm 3.6^{* *}$ & - \\
\hline
\end{tabular}




\begin{tabular}{|c|c|c|c|c|}
\hline & \multirow[b]{2}{*}{$\begin{array}{l}\text { Perinatal } \\
\text { Exposure }\end{array}$} & \multicolumn{3}{|c|}{ Postweaning Exposure } \\
\hline & & 0 ppm & 150 ppm & 300 ppm \\
\hline & $300 \mathrm{ppm}$ & - & - & $52.3 \pm 2.0^{* *}$ \\
\hline \multirow[t]{3}{*}{ Alanine Aminotransferase (IU/L) } & 0 ppm & $50.70 \pm 1.80 * \#$ & $71.20 \pm 4.05^{* *}$ & $66.70 \pm 6.71 *$ \\
\hline & $150 \mathrm{ppm}$ & - & $70.20 \pm 3.09 * *$ & - \\
\hline & $300 \mathrm{ppm}$ & - & - & $65.10 \pm 4.49^{* *}$ \\
\hline \multirow[t]{3}{*}{ Alkaline Phosphatase (IU/L) } & 0 ppm & $174.1 \pm 9.3^{* * \# \#}$ & $412.6 \pm 38.1^{* *}$ & $399.1 \pm 27.0 * *$ \\
\hline & $150 \mathrm{ppm}$ & - & $398.7 \pm 25.0^{* *}$ & - \\
\hline & 300 ppm & - & - & $410.8 \pm 33.1^{* *}$ \\
\hline \multirow[t]{3}{*}{ Sorbitol Dehydrogenase (IU/L) } & 0 ppm & $8.2 \pm 0.7 * * \#$ & $16.7 \pm 1.8 * *$ & $20.6 \pm 7.7 * *$ \\
\hline & $150 \mathrm{ppm}$ & - & $15.9 \pm 1.3 * *$ & - \\
\hline & $300 \mathrm{ppm}$ & - & - & $16.3 \pm 1.8^{* *}$ \\
\hline \multirow[t]{3}{*}{ Bile salt/acids $(\mu \mathrm{mol} / \mathrm{L})$} & 0 ppm & $25.4 \pm 1.6^{* * \# \#}$ & $45.7 \pm 3.6^{* *}$ & $127.0 \pm 26.5^{* *}$ \\
\hline & $150 \mathrm{ppm}$ & - & $46.2 \pm 6.4^{* *}$ & - \\
\hline & 300 ppm & - & - & $69.8 \pm 15.2 * *$ \\
\hline
\end{tabular}

Statistical significance for a treatment group indicates a significant pairwise test compared to the $0 / 0$ ppm control group. Statistical significance for the $0 / 0 \mathrm{ppm}$ control group indicates a significant trend test.

Pairwise comparisons across perinatal exposures (0/150 vs. $150 / 150 \mathrm{ppm}$ and 0/300 vs. 300/300 ppm) did not show any statistically significant differences.

*Statistically significant at $\mathrm{p} \leq 0.05 ; * * \mathrm{p} \leq 0.01$.

\#Statistically significant trend at $\mathrm{p} \leq 0.05$ when comparing across the $0 / 0,150 / 150$, and $300 / 300 \mathrm{ppm}$ groups; ${ }^{\#} \mathrm{p} \leq 0.01$.

${ }^{a}$ Data presented as mean \pm SEM.

'Statistical analysis performed by Jonckheere's (trend) and Shirley's or Dunn's (pairwise) tests (unless otherwise noted).

Table 16. Select Clinical Chemistry Data for Female Rats at the 16-week Interim of the Two-year Feed Study of Perfluorooctanoic Acid (Study 1) , $^{\text {,b }}$

\begin{tabular}{|c|c|c|c|c|}
\hline & \multirow[b]{2}{*}{$\begin{array}{l}\text { Perinatal } \\
\text { Exposure }\end{array}$} & \multicolumn{3}{|c|}{ Postweaning Exposure } \\
\hline & & O ppm & 300 ppm & 1,000 ppm \\
\hline $\mathbf{n}$ & & 10 & 10 & 10 \\
\hline \multirow[t]{3}{*}{ Total Protein (g/dL) } & $0 \mathrm{ppm}$ & $6.87 \pm 0.04^{\#}$ & $6.80 \pm 0.10$ & $7.09 \pm 0.11$ \\
\hline & $150 \mathrm{ppm}$ & - & $6.70 \pm 0.08$ & - \\
\hline & $300 \mathrm{ppm}$ & - & - & $7.19 \pm 0.08^{*}$ \\
\hline \multirow[t]{3}{*}{ Albumin (g/dL) } & $0 \mathrm{ppm}$ & $4.65 \pm 0.05^{* * \# \#}$ & $4.85 \pm 0.08$ & $5.25 \pm 0.09^{* *}$ \\
\hline & 150 ppm & - & $4.74 \pm 0.04$ & - \\
\hline & $300 \mathrm{ppm}$ & - & - & $5.33 \pm 0.07 * *$ \\
\hline \multirow[t]{3}{*}{ Globulin (g/dL) } & $0 \mathrm{ppm}$ & $2.22 \pm 0.04 * * \#$ & $1.95 \pm 0.04 * *$ & $1.84 \pm 0.04 * *$ \\
\hline & $150 \mathrm{ppm}$ & - & $1.96 \pm 0.07 * *$ & - \\
\hline & $300 \mathrm{ppm}$ & - & - & $1.86 \pm 0.05^{* *}$ \\
\hline \multirow[t]{2}{*}{ A/G Ratio } & $0 \mathrm{ppm}$ & $2.10 \pm 0.05^{* * \# \#}$ & $2.49 \pm 0.06^{* *}$ & $2.86 \pm 0.05^{* *}$ \\
\hline & 150 ppm & - & $2.44 \pm 0.09 * *$ & - \\
\hline
\end{tabular}




\begin{tabular}{lcccc}
\hline & & \multicolumn{3}{c}{ Postweaning Exposure } \\
\cline { 3 - 5 } & Perinatal & $\mathbf{0 ~ p p m}$ & $\mathbf{3 0 0} \mathbf{~ p p m}$ & $\mathbf{1 , 0 0 0} \mathbf{~ p p m}$ \\
\hline \multirow{2}{*}{ Exposure } & $300 \mathrm{ppm}$ & - & - & $2.88 \pm 0.08^{* *}$ \\
Alanine Aminotransferase (IU/L) & $0 \mathrm{ppm}$ & $43.70 \pm 2.18^{* * \# \#}$ & $50.50 \pm 3.08$ & $56.00 \pm 3.06^{* *}$ \\
& $150 \mathrm{ppm}$ & - & $51.00 \pm 2.75$ & - \\
Alkaline Phosphatase (IU/L) & $300 \mathrm{ppm}$ & - & - & $54.90 \pm 2.07^{* *}$ \\
& $0 \mathrm{ppm}$ & $129.8 \pm 9.0^{*}$ & $122.4 \pm 7.8$ & $166.3 \pm 6.9^{*}$ \\
& $150 \mathrm{ppm}$ & - & $154.8 \pm 11.3$ & - \\
Sorbitol Dehydrogenase (IU/L) & $300 \mathrm{ppm}$ & - & - & $144.5 \pm 11.6$ \\
& $0 \mathrm{ppm}$ & $8.1 \pm 0.6^{\#}$ & $9.2 \pm 0.9$ & $10.3 \pm 1.1$ \\
& $150 \mathrm{ppm}$ & - & $9.8 \pm 0.9$ & - \\
& $300 \mathrm{ppm}$ & - & - & $10.9 \pm 0.7^{*}$ \\
\hline
\end{tabular}

Statistical significance for a treatment group indicates a significant pairwise test compared to the $0 / 0 \mathrm{ppm}$ control group. Statistical significance for the $0 / 0 \mathrm{ppm}$ control group indicates a significant trend test.

Pairwise comparisons across perinatal exposures ( $0 / 300$ vs. $150 / 300 \mathrm{ppm}$ and $0 / 1,000$ vs. $300 / 1,000)$ did not show any statistically significant differences.

*Statistically significant at $\mathrm{p} \leq 0.05 ; * * \mathrm{p} \leq 0.01$.

\#Statistically significant trend at $\mathrm{p} \leq 0.05$ when comparing across the $0 / 0,150 / 300$, and $300 / 1,000$ ppm groups; \# $p \leq 0.01$.

${ }^{a}$ Data presented as mean \pm SEM.

'Statistical analysis performed by Jonckheere's (trend) and Shirley's or Dunn's (pairwise) tests (unless otherwise noted).

Data for nonneoplastic lesions in male and female rats at the 16-week interim evaluation are presented in Appendix E.

The histopathological descriptions of the nonneoplastic and neoplastic data for the 16-week interim and 2-year studies in males and females discussed in this section are presented in the Histopathological Descriptions section following the presentation of the 2-year study in males.

Liver: Compared to the $0 / 0$ ppm control group, the incidences of hepatocyte hypertrophy, hepatocyte cytoplasmic alteration, hepatocyte single cell death, and pigment were significantly increased in all exposed male groups (Table 12). The incidences of hepatocyte necrosis were significantly increased in the $0 / 150$ and $300 / 300$ ppm groups; two incidences of necrosis also occurred in the $0 / 300$ and $150 / 150$ ppm groups. No differences between groups with perinatal and without perinatal exposures were observed.

In females, the incidences of hepatocyte hypertrophy and hepatocyte cytoplasmic alteration were significantly increased in the $0 / 1,000$ and 300/1,000 ppm groups compared to the $0 / 0 \mathrm{ppm}$ control group (Table 13). The incidence of pigment was significantly increased in the $300 / 1,000$ ppm group relative to the $0 / 0$ ppm control group.

Thyroid Gland: In males, the incidence of follicular cell hypertrophy was significantly increased in the $0 / 300 \mathrm{ppm}$ group compared to the $00 / 0 \mathrm{ppm}$ control group (Table 17). In females, the incidence of follicular cell hypertrophy was significantly increased in the 300/1,000 ppm group compared to the $0 / 0$ ppm control (Table 18). No differences between groups with perinatal and without perinatal exposures were observed. 
Kidney: In males, the incidences of renal tubule mineral were significantly increased in the 0/150, 0/300, and 300/300 ppm groups compared to the 0/0 ppm control group (Table 17).

In females, the incidences of papilla urothelium hyperplasia were significantly increased in the $0 / 1,000$ and 300/1,000 ppm groups compared to the $0 / 0 \mathrm{ppm}$ control (Table 18). The incidence of renal tubule mineral in the $0 / 1,000 \mathrm{ppm}$ group was significantly greater than that of the $0 / 0 \mathrm{ppm}$ control group. No differences between groups with perinatal and without perinatal exposures were observed.

Glandular Stomach: The incidences of chronic active inflammation of the submucosa were increased in all exposed male groups compared to the $0 / 0$ ppm control group, but the increases were statistically significant only in the $0 / 300$ ppm group (Table 17). No differences between groups with perinatal and without perinatal exposures were observed.

Table 17. Incidences of Select Nonneoplastic Lesions of the Thyroid Gland, Kidney, and Glandular Stomach in Male Rats at the 16-week Interim of the Two-year Feed Study of Perfluorooctanoic Acid (Study 1) ${ }^{\mathrm{a}}$

\begin{tabular}{|c|c|c|c|c|}
\hline & \multirow[b]{2}{*}{$\begin{array}{l}\text { Perinatal } \\
\text { Exposure }\end{array}$} & \multicolumn{3}{|c|}{ Postweaning Exposure } \\
\hline & & O ppm & 150 ppm & 300 ppm \\
\hline $\mathbf{n}$ & & $10^{\mathrm{b}}$ & 10 & 10 \\
\hline \multicolumn{5}{|l|}{ Thyroid Gland } \\
\hline \multirow[t]{3}{*}{ Follicular Cell, Hypertrophy ${ }^{\mathrm{c}}$} & 0 ppm & $0^{* *}$ & $2(1.0)^{\mathrm{d}}$ & $6^{* *}(1.0)$ \\
\hline & $150 \mathrm{ppm}$ & - & 0 & - \\
\hline & $300 \mathrm{ppm}$ & - & - & $2(1.0)$ \\
\hline \multicolumn{5}{|l|}{ Kidney } \\
\hline \multirow[t]{3}{*}{ Renal Tubule, Mineral } & $0 \mathrm{ppm}$ & $0 * * \#$ & $4 *(1.0)$ & $5^{* *}(1.0)$ \\
\hline & $150 \mathrm{ppm}$ & - & $1(1.0)$ & - \\
\hline & $300 \mathrm{ppm}$ & - & - & $6 * *(1.0)$ \\
\hline \multicolumn{5}{|l|}{ Glandular Stomach } \\
\hline \multirow{3}{*}{$\begin{array}{l}\text { Submucosa, Inflammation, } \\
\text { Chronic Active }\end{array}$} & $0 \mathrm{ppm}$ & $0^{* *}$ & $2(1.0)$ & $5^{* *}(1.0)$ \\
\hline & $150 \mathrm{ppm}$ & - & $2(1.0)$ & - \\
\hline & 300 ppm & - & - & $2(1.0)$ \\
\hline
\end{tabular}

Statistical significance for a treatment group indicates a significant pairwise test compared to the $0 / 0$ ppm control group. Statistical significance for the $0 / 0 \mathrm{ppm}$ control group indicates a significant trend test.

Pairwise comparisons across perinatal exposures (0/150 vs. $150 / 150 \mathrm{ppm}$ and $0 / 300$ vs. $300 / 300 \mathrm{ppm})$ did not show any statistically significant differences.

$*$ Statistically significant at $\mathrm{p} \leq 0.05 ; * \mathrm{p} \leq 0.01$

\# Statistically significant trend at $\mathrm{p} \leq 0.01$ when comparing across the $0 / 0,150 / 150$, and $300 / 300$ ppm groups.

aStatistical analysis performed by the Poly-3 test.

bumber of animals examined microscopically.

${ }^{\mathrm{c}}$ Number of animals with lesion.

${ }^{\mathrm{d} A v e r a g e ~ s e v e r i t y ~ g r a d e ~ o f ~ l e s i o n ~ i n ~ a f f e c t e d ~ a n i m a l s: ~} 1=$ minimal; $2=$ mild; $3=$ moderate; $4=$ marked. 
Table 18. Incidences of Select Nonneoplastic Lesions of the Thyroid Gland and Kidney in Female Rats at the 16-week Interim of the Two-year Feed Study of Perfluorooctanoic Acid (Study 1) ${ }^{\mathbf{a}}$

\begin{tabular}{|c|c|c|c|c|}
\hline & \multirow[b]{2}{*}{$\begin{array}{l}\text { Perinatal } \\
\text { Exposure }\end{array}$} & \multicolumn{3}{|c|}{ Postweaning Exposure } \\
\hline & & O ppm & 300 ppm & 1,000 ppm \\
\hline $\mathbf{n}$ & & $10^{\mathrm{b}}$ & 10 & 10 \\
\hline \multicolumn{5}{|l|}{ Thyroid Gland } \\
\hline \multirow[t]{3}{*}{ Follicular Cell, Hypertrophy ${ }^{\mathrm{c}}$} & 0 ppm & $0^{\# \#}$ & 0 & $1(1.0)^{\mathrm{d}}$ \\
\hline & $150 \mathrm{ppm}$ & - & 0 & - \\
\hline & $300 \mathrm{ppm}$ & - & - & $4 *(1.3)$ \\
\hline \multicolumn{5}{|l|}{ Kidney } \\
\hline \multirow[t]{3}{*}{ Renal Tubule, Mineral } & $0 \mathrm{ppm}$ & $2 * *(1.0)$ & $1(1.0)$ & $7 *(1.0)$ \\
\hline & $150 \mathrm{ppm}$ & - & $2(1.0)$ & - \\
\hline & 300 ppm & - & - & $5(1.2)$ \\
\hline \multirow[t]{3}{*}{ Papilla, Urothelium, Hyperplasia } & 0 ppm & $0 * * \#$ & 0 & $4 *(1.3)$ \\
\hline & $150 \mathrm{ppm}$ & - & 0 & - \\
\hline & $300 \mathrm{ppm}$ & - & - & $4 *(1.0)$ \\
\hline
\end{tabular}

Statistical significance for a treatment group indicates a significant pairwise test compared to the $0 / 0$ ppm control group. Statistical significance for the $0 / 0 \mathrm{ppm}$ control group indicates a significant trend test.

Pairwise comparisons across perinatal exposures (0/300 vs. $150 / 300$ ppm and 0/1,000 vs. 300/1,000 ppm) did not show any statistically significant differences.

*Statistically significant at $\mathrm{p} \leq 0.05 ; * \mathrm{p} \leq 0.01$.

\# Statistically significant trend at $\mathrm{p} \leq 0.01$ when comparing across the $0 / 0,150 / 300$, and $300 / 1,000$ ppm groups.

aStatistical analysis performed by the Poly-3 test.

bNumber of animals examined microscopically.

${ }^{c}$ Number of animals with lesion.

${ }^{\mathrm{d}}$ Average severity grade of lesion in affected animals: $1=$ minimal; $2=$ mild; $3=$ moderate; $4=$ marked. 


\section{Two-year Study in Females (Study 1)}

Survival of exposed groups of females was similar to that of the $0 / 0 \mathrm{ppm}$ control group (Table 19, Table 20; Figure 4). There were no exposure-related clinical observations (Appendix E).

Table 19. Survival of Female Rats Following Postweaning-only Exposure in the Two-year Feed Study of Perfluorooctanoic Acid (Study 1)

\begin{tabular}{lccc}
\hline & $\mathbf{0 / 0} \mathbf{~ p p m}$ & $\mathbf{0 / 3 0 0} \mathbf{~ p p m}$ & $\mathbf{0 / 1 , 0 0 0} \mathbf{~ p p m}$ \\
\hline Animals Initially in Study & 50 & 50 & 50 \\
Moribund & 15 & 16 & 20 \\
Natural Deaths & 12 & 6 & 7 \\
Animals Surviving to & 23 & $28^{\mathrm{a}}$ & 23 \\
Study Termination & & 56.0 & 46.0 \\
Percent Probability of & 46.0 & & 626.1 \\
Survival at End of Study & & 695.3 & $\mathrm{p}=0.777 \mathrm{~N}$ \\
Mean Survival (days) $^{\mathrm{c}}$ & 646.6 & $\mathrm{p}=0.126 \mathrm{~N}$ & \\
Survival Analysis $^{\mathrm{d}}$ & $\mathrm{p}=0.901$ & &
\end{tabular}

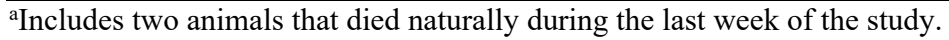

${ }^{b}$ Kaplan-Meier determinations.

${ }^{\mathrm{c}}$ Mean of litter means of all deaths (uncensored, censored, and study termination).

dThe result of the trend test is in the $0 / 0 \mathrm{ppm}$ column, and the results of the pairwise comparisons with the $0 / 0$ ppm control group are in the exposed group columns. Negative trends are indicated by N. Analyses were performed using a Cox Proportional Hazards Model with dam ID as a random effect.

Table 20. Survival of Female Rats Following Perinatal and Postweaning Exposure in the Two-year Feed Study of Perfluorooctanoic Acid (Study 1)

\begin{tabular}{lccc}
\hline & $\mathbf{0 / 0} \mathbf{~ p p m}$ & $\mathbf{1 5 0 / 3 0 0} \mathbf{~ p p m}$ & $\mathbf{3 0 0 / 1 , 0 0 0 ~} \mathbf{~ p p m}$ \\
\hline Animals Initially in Study & 50 & 50 & 50 \\
Moribund & 15 & 11 & 17 \\
Natural Deaths & 12 & 7 & 10 \\
Animals Surviving to & 23 & 32 & $23^{\mathrm{a}}$ \\
Study Termination & 46.0 & 64.0 & 46.0 \\
Percent Probability of & & & \\
Survival at End of Study & & 681.1 & 660.0 \\
Mean Survival (days) $^{\mathrm{c}}$ & 646.6 & $\mathrm{p}=0.080 \mathrm{~N}$ & $\mathrm{p}=0.831 \mathrm{~N}$ \\
Survival Analysis $^{\mathrm{d}}$ & $\mathrm{p}=0.831$ & &
\end{tabular}

ancludes one animal that died naturally during the last week of the study.

${ }^{b}$ Kaplan-Meier determinations.

${ }^{\mathrm{c}}$ Mean of litter means of all deaths (uncensored, censored, and study termination).

${ }^{\mathrm{d}}$ The result of the trend test is in the $0 / 0 \mathrm{ppm}$ column, and the results of the pairwise comparisons with the $0 / 0 \mathrm{ppm}$ control group are in the exposed group columns. Negative trends are indicated by N. Analyses were performed using a Cox Proportional Hazards Model with dam ID as a random effect. 


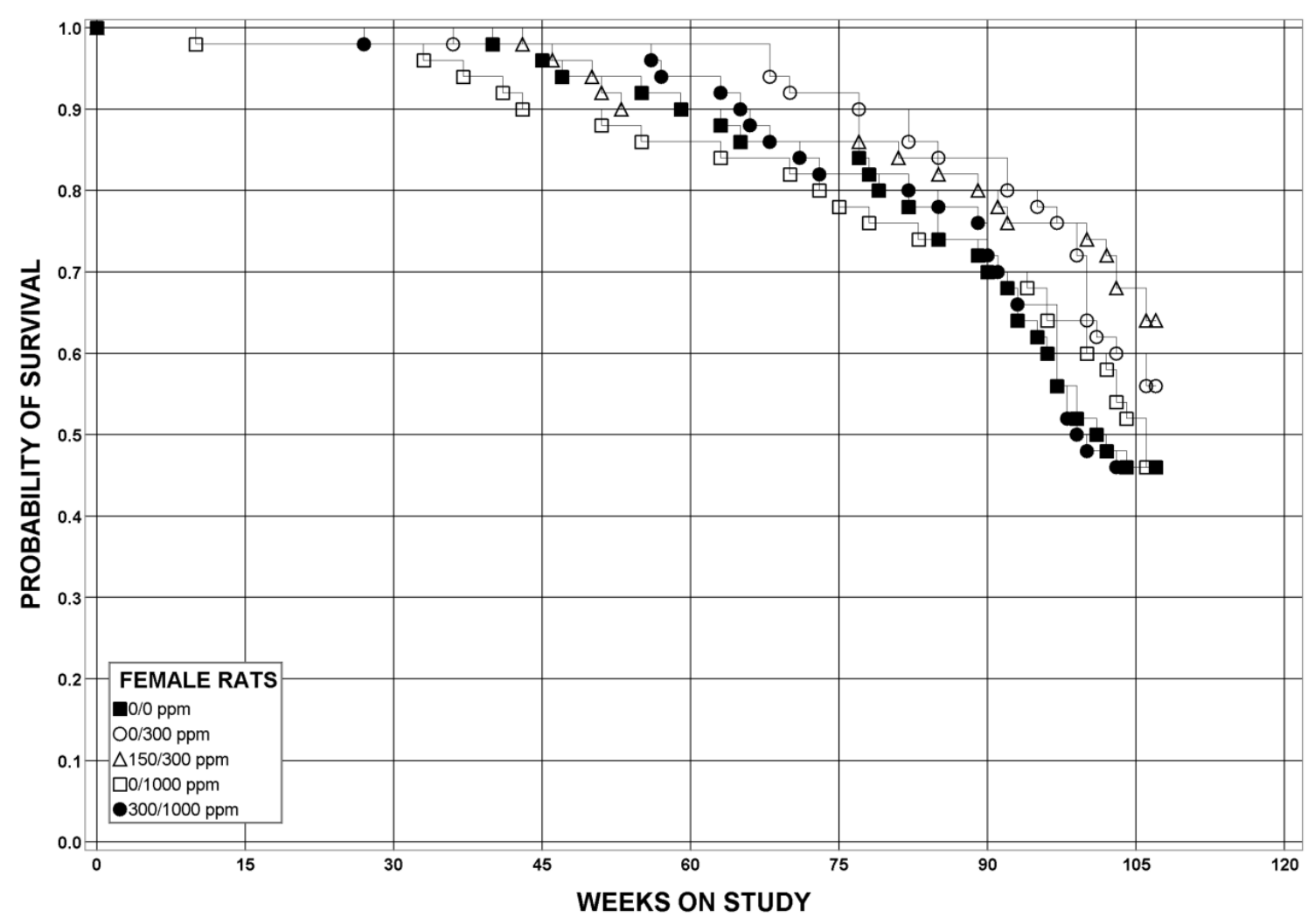

Figure 4. Kaplan-Meier Survival Curves for Female Rats Exposed to Perfluorooctanoic Acid in Feed for Two Years

Exposure-related decreases in group mean body weights were observed for exposed females throughout the study (Table 21, Table 22; Figure 5; Figure 6). At study termination, group mean body weights for the $0 / 1,000$ and $300 / 1,000$ ppm groups were lower $(19 \%$ and $27 \%$, respectively) than those of the $0 / 0 \mathrm{ppm}$ control group. 
Table 21. Mean Body Weights and Survival of Female Rats Following Postweaning-only Exposure in the Two-year Feed Study of Perfluorooctanoic Acid (Study 1)

\begin{tabular}{|c|c|c|c|c|c|c|c|c|}
\hline \multirow[b]{2}{*}{ Day } & \multicolumn{2}{|c|}{ 0/0 ppm } & \multicolumn{3}{|c|}{ 0/300 ppm } & \multicolumn{3}{|c|}{ 0/1,000 ppm } \\
\hline & Av. Wt. (g) & $\begin{array}{l}\text { No. of } \\
\text { Litters }\end{array}$ & Av. Wt. (g) & $\begin{array}{l}\text { Wt. (\% of } \\
\text { Controls) }\end{array}$ & $\begin{array}{l}\text { No. of } \\
\text { Litters }\end{array}$ & Av. Wt. (g) & $\begin{array}{l}\text { Wt. (\% of } \\
\text { Controls) }\end{array}$ & $\begin{array}{l}\text { No. of } \\
\text { Litters }\end{array}$ \\
\hline 1 & 55.4 & 32 & 53.3 & 96.2 & 29 & 53.3 & 96.3 & 31 \\
\hline 8 & 82.3 & 32 & 77.7 & 94.4 & 29 & 67.8 & 82.4 & 31 \\
\hline 15 & 111.6 & 32 & 109.3 & 97.9 & 29 & 89.4 & 80.1 & 31 \\
\hline 22 & 146.3 & 32 & 143.7 & 98.3 & 29 & 118.0 & 80.7 & 31 \\
\hline 29 & 168.8 & 32 & 167.9 & 99.4 & 29 & 141.5 & 83.8 & 31 \\
\hline 36 & 188.5 & 32 & 185.4 & 98.3 & 29 & 159.1 & 84.4 & 31 \\
\hline 43 & 202.2 & 32 & 201.3 & 99.5 & 29 & 174.4 & 86.2 & 31 \\
\hline 50 & 213.2 & 32 & 209.3 & 98.2 & 29 & 185.9 & 87.2 & 31 \\
\hline 57 & 224.4 & 32 & 219.7 & 97.9 & 29 & 194.9 & 86.9 & 31 \\
\hline 64 & 231.4 & 32 & 226.1 & 97.7 & 29 & 201.0 & 86.8 & 31 \\
\hline 71 & 236.8 & 32 & 231.4 & 97.7 & 29 & 208.7 & 88.1 & 31 \\
\hline 78 & 241.2 & 32 & 237.3 & 98.3 & 29 & 213.6 & 88.5 & 31 \\
\hline 85 & 245.7 & 32 & 241.8 & 98.4 & 29 & 216.0 & 87.9 & 31 \\
\hline 120 & 256.6 & 32 & 255.2 & 99.4 & 29 & 227.3 & 88.6 & 31 \\
\hline 141 & 269.1 & 32 & 263.2 & 97.8 & 29 & 238.4 & 88.6 & 31 \\
\hline 169 & 279.3 & 32 & 273.2 & 97.8 & 29 & 243.5 & 87.2 & 31 \\
\hline 197 & 287.1 & 32 & 279.8 & 97.4 & 29 & 249.2 & 86.8 & 31 \\
\hline 225 & 291.9 & 32 & 285.1 & 97.7 & 29 & 255.2 & 87.4 & 30 \\
\hline 253 & 299.6 & 32 & 291.0 & 97.1 & 29 & 261.3 & 87.2 & 29 \\
\hline 281 & 302.9 & 32 & 296.3 & 97.8 & 29 & 261.1 & 86.2 & 29 \\
\hline 309 & 313.0 & 32 & 302.0 & 96.5 & 29 & 268.5 & 85.8 & 28 \\
\hline 337 & 317.3 & 31 & 305.6 & 96.3 & 29 & 268.5 & 84.6 & 28 \\
\hline 365 & 324.2 & 31 & 313.2 & 96.6 & 29 & 275.1 & 84.9 & 28 \\
\hline 393 & 331.2 & 30 & 320.2 & 96.7 & 29 & 276.0 & 83.3 & 28 \\
\hline 421 & 339.7 & 29 & 329.0 & 96.9 & 29 & 279.6 & 82.3 & 28 \\
\hline 449 & 339.8 & 29 & 332.9 & 98.0 & 29 & 276.6 & 81.4 & 28 \\
\hline 477 & 346.4 & 29 & 336.7 & 97.2 & 29 & 286.8 & 82.8 & 28 \\
\hline 505 & 356.3 & 29 & 342.2 & 96.0 & 29 & 291.1 & 81.7 & 28 \\
\hline 533 & 364.0 & 28 & 347.3 & 95.4 & 29 & 300.6 & 82.6 & 28 \\
\hline 561 & 366.0 & 27 & 353.5 & 96.6 & 29 & 296.0 & 80.9 & 27 \\
\hline 589 & 369.8 & 26 & 351.5 & 95.1 & 27 & 301.1 & 81.4 & 27 \\
\hline 617 & 372.9 & 26 & 351.9 & 94.4 & 27 & 300.6 & 80.6 & 27 \\
\hline 645 & 376.8 & 24 & 356.7 & 94.7 & 27 & 300.1 & 79.7 & 26 \\
\hline 673 & 383.1 & 23 & 359.9 & 94.0 & 27 & 300.2 & 78.4 & 25 \\
\hline 701 & 378.2 & 21 & 375.6 & 99.3 & 23 & 305.1 & 80.7 & 23 \\
\hline 729 & 383.9 & 19 & 369.3 & 96.2 & 21 & 303.5 & 79.0 & 20 \\
\hline EOS & 387.0 & 19 & 369.7 & 95.5 & 19 & 314.6 & 81.3 & 18 \\
\hline
\end{tabular}

$\mathrm{EOS}=$ end of study. 
Table 22. Mean Body Weights and Survival of Female Rats Following Perinatal and Postweaning Exposure in the Two-year Feed Study of Perfluorooctanoic Acid (Study 1)

\begin{tabular}{|c|c|c|c|c|c|c|c|c|}
\hline \multirow[b]{2}{*}{ Day } & \multicolumn{2}{|c|}{ 0/0 ppm } & \multicolumn{3}{|c|}{$150 / 300 \mathrm{ppm}$} & \multicolumn{3}{|c|}{$300 / 1,000$ ppm } \\
\hline & Av. Wt. (g) & $\begin{array}{l}\text { No. of } \\
\text { Litters }\end{array}$ & Av. Wt. (g) & $\begin{array}{l}\text { Wt. (\% of } \\
\text { Controls) }\end{array}$ & $\begin{array}{l}\text { No. of } \\
\text { Litters }\end{array}$ & Av. Wt. (g) & $\begin{array}{l}\text { Wt. (\% of } \\
\text { Controls) }\end{array}$ & $\begin{array}{l}\text { No. of } \\
\text { Litters }\end{array}$ \\
\hline 1 & 55.4 & 32 & 54.9 & 99.0 & 29 & 51.6 & 93.1 & 30 \\
\hline 8 & 82.3 & 32 & 79.2 & 96.3 & 29 & 62.9 & 76.5 & 30 \\
\hline 15 & 111.6 & 32 & 106.4 & 95.3 & 29 & 82.6 & 74.0 & 30 \\
\hline 22 & 146.3 & 32 & 143.8 & 98.3 & 29 & 109.7 & 75.0 & 30 \\
\hline 29 & 168.8 & 32 & 166.7 & 98.7 & 29 & 133.3 & 79.0 & 30 \\
\hline 36 & 188.5 & 32 & 183.3 & 97.2 & 29 & 152.7 & 81.0 & 30 \\
\hline 43 & 202.2 & 32 & 197.6 & 97.7 & 29 & 166.3 & 82.2 & 30 \\
\hline 50 & 213.2 & 32 & 208.6 & 97.8 & 29 & 179.9 & 84.4 & 30 \\
\hline 57 & 224.4 & 32 & 217.7 & 97.0 & 29 & 189.1 & 84.3 & 30 \\
\hline 64 & 231.4 & 32 & 223.2 & 96.4 & 29 & 196.6 & 84.9 & 30 \\
\hline 71 & 236.8 & 32 & 228.7 & 96.6 & 29 & 202.5 & 85.5 & 30 \\
\hline 78 & 241.2 & 32 & 234.4 & 97.2 & 29 & 206.8 & 85.7 & 30 \\
\hline 85 & 245.7 & 32 & 237.6 & 96.7 & 29 & 210.9 & 85.8 & 30 \\
\hline 120 & 256.6 & 32 & 254.0 & 99.0 & 29 & 221.0 & 86.1 & 30 \\
\hline 141 & 269.1 & 32 & 260.5 & 96.8 & 29 & 229.4 & 85.3 & 30 \\
\hline 169 & 279.3 & 32 & 269.9 & 96.6 & 29 & 237.4 & 85.0 & 30 \\
\hline 197 & 287.1 & 32 & 277.8 & 96.8 & 29 & 243.0 & 84.6 & 30 \\
\hline 225 & 291.9 & 32 & 282.1 & 96.7 & 29 & 247.9 & 84.9 & 30 \\
\hline 253 & 299.6 & 32 & 287.0 & 95.8 & 29 & 253.8 & 84.7 & 30 \\
\hline 281 & 302.9 & 32 & 294.2 & 97.1 & 29 & 250.8 & 82.8 & 30 \\
\hline 309 & 313.0 & 32 & 298.2 & 95.2 & 29 & 257.2 & 82.2 & 30 \\
\hline 337 & 317.3 & 31 & 302.8 & 95.4 & 29 & 261.0 & 82.3 & 30 \\
\hline 365 & 324.2 & 31 & 310.4 & 95.8 & 29 & 264.0 & 81.4 & 30 \\
\hline 393 & 331.2 & 30 & 305.3 & 92.2 & 28 & 266.0 & 80.3 & 30 \\
\hline 421 & 339.7 & 29 & 311.6 & 91.7 & 28 & 268.4 & 79.0 & 30 \\
\hline 449 & 339.8 & 29 & 317.6 & 93.5 & 28 & 267.4 & 78.7 & 30 \\
\hline 477 & 346.4 & 29 & 322.1 & 93.0 & 28 & 272.3 & 78.6 & 29 \\
\hline 505 & 356.3 & 29 & 327.3 & 91.8 & 28 & 279.0 & 78.3 & 29 \\
\hline 533 & 364.0 & 28 & 333.7 & 91.7 & 28 & 285.3 & 78.4 & 28 \\
\hline 561 & 366.0 & 27 & 335.8 & 91.7 & 28 & 287.2 & 78.5 & 28 \\
\hline 589 & 369.8 & 26 & 339.0 & 91.7 & 27 & 291.1 & 78.7 & 27 \\
\hline 617 & 372.9 & 26 & 339.0 & 90.9 & 27 & 291.2 & 78.1 & 27 \\
\hline 645 & 376.8 & 24 & 340.0 & 90.2 & 24 & 291.3 & 77.3 & 25 \\
\hline 673 & 383.1 & 23 & 338.2 & 88.3 & 24 & 294.2 & 76.8 & 23 \\
\hline 701 & 378.2 & 21 & 344.4 & 91.1 & 24 & 286.6 & 75.8 & 20 \\
\hline 729 & 383.9 & 19 & 342.2 & 89.1 & 22 & 289.0 & 75.3 & 20 \\
\hline EOS & 387.0 & 19 & 346.5 & 89.5 & 22 & 283.7 & 73.3 & 19 \\
\hline
\end{tabular}

$\overline{\mathrm{EOS}}=$ end of study. 


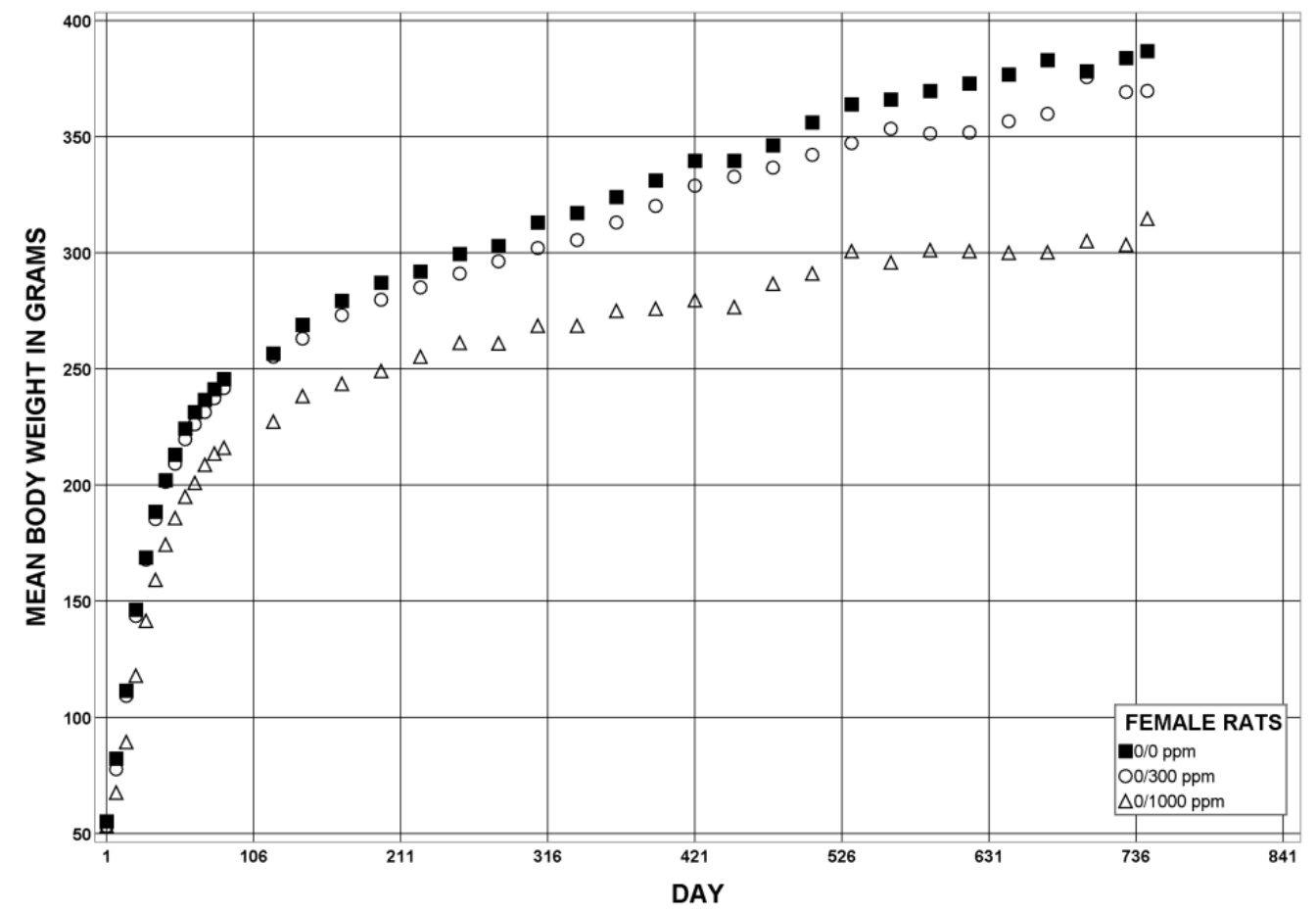

Figure 5. Growth Curves for Female Rats with Postweaning-only Exposure to 0/0, 0/300, or 0/1,000 ppm Perfluorooctanoic Acid in Feed for Two Years (Study 1)

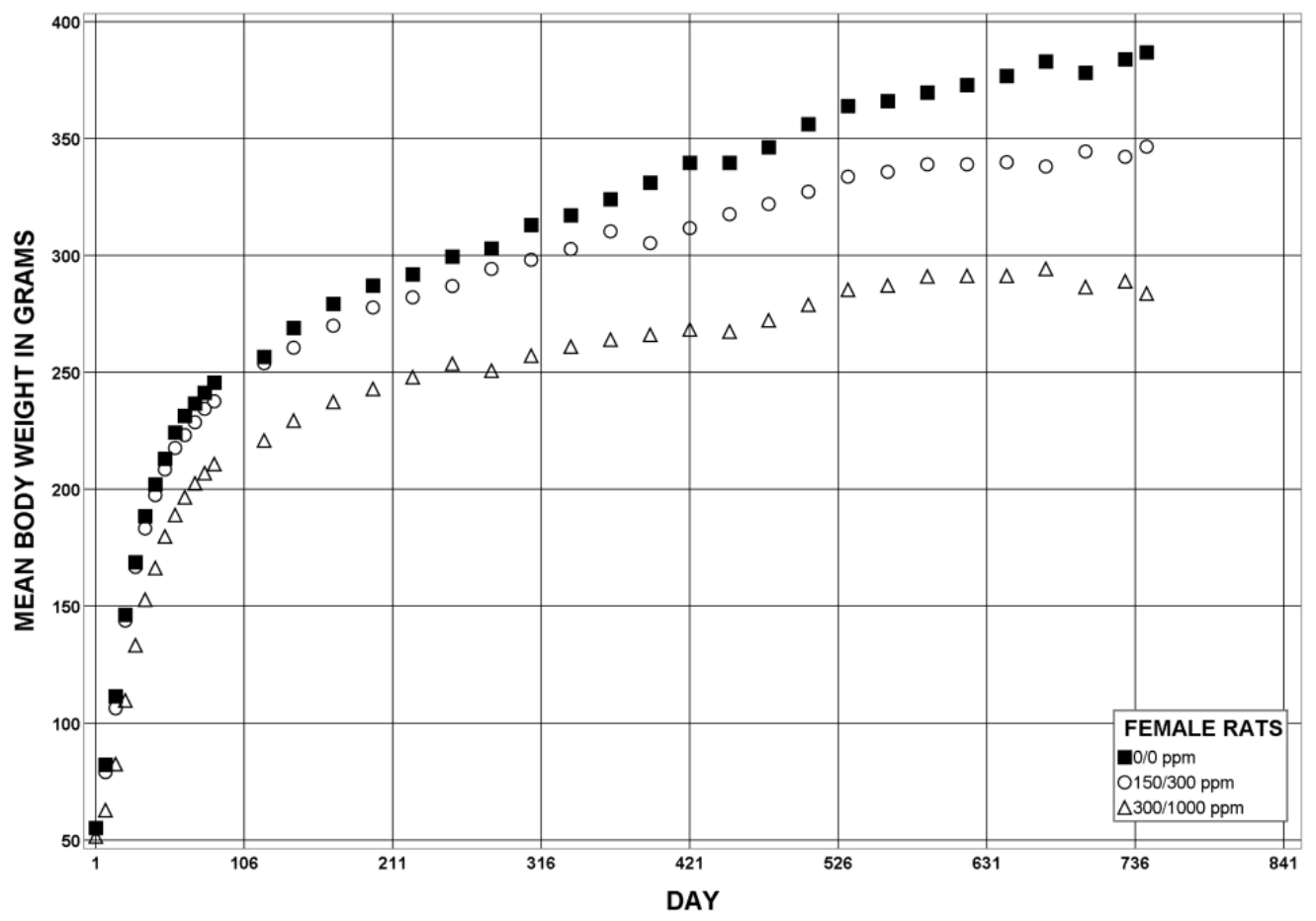

Figure 6. Growth Curves for Female Rats with Perinatal and Postweaning Exposure to 0/0, 150/300, or 300/1,000 ppm Perfluorooctanoic Acid in Feed for Two Years (Study 1) 
Group mean feed consumption over the course of the study averaged $93 \%, 99 \%, 96 \%$, and $88 \%$ of the $0 / 0$ ppm control group for the $0 / 300,150 / 300,0 / 1,000$, and 300/1,000 ppm groups, respectively (Appendix E). After weaning, compound consumption for females in the 0/300 and $150 / 300 \mathrm{ppm}$ groups averaged 18.2 and $18.4 \mathrm{mg} / \mathrm{kg} /$ day, respectively. Compound consumption averaged 63.4 and $63.5 \mathrm{mg} / \mathrm{kg} /$ day for the 0/1,000 and 300/1,000 ppm groups, respectively.

\section{Pathology and Statistical Analyses}

The morphologic features of the lesions discussed in this section are presented in the Histopathological Descriptions section following the Study 2 results.

Liver: Chronic exposure with and without perinatal exposure resulted in slight increases in the incidences of hepatocellular carcinoma in the 0/1,000 and 300/1,000 ppm groups, respectively; however, the increases were not significantly different from the incidence in the $0 / 0 \mathrm{ppm}$ control group (Table 23). The occurrences of hepatocellular adenomas did not differ among the groups. The combined incidence of adenomas and carcinomas was marginally higher in the 1,000 ppm postweaning groups, which was primarily due to the higher incidence of carcinomas in these groups (Table 23). The one hepatocellular carcinoma present in the historical control is from this study. No differences between groups with perinatal and without perinatal exposures were observed.

Chronic exposure with and without perinatal exposure resulted in exposure concentration-related increases in the incidences of a spectrum of nonneoplastic hepatocellular lesions (Table 23; Appendix E). Compared to the incidences in the 0/0 ppm control group, the incidences of hepatocyte cytoplasmic alteration and hepatocyte hypertrophy were significantly increased in all exposed female groups in the 2-year study. In general, the severity of these lesions tended to be minimal to moderate and were more severe in groups receiving the highest exposure concentrations. Hepatocyte hypertrophy and cytoplasmic alteration were generally colocalized hepatocellular changes.

The incidences of hepatocyte single cell death were significantly increased in the 150/300, 0/1,000, and 300/1,000 ppm groups compared to the 0/0 ppm control group (Table 23; Appendix E).

The incidences of necrosis were increased in all exposed groups; however, only the increase in the $0 / 1,000 \mathrm{ppm}$ group reached statistical significance compared to the $0 / 0 \mathrm{ppm}$ control group (Table 23; Appendix E).

The incidences of pigment were significantly increased in the $150 / 300,0 / 1,000$, and $300 / 1,000$ ppm groups compared to the 0/0 ppm control group (Table 23; Appendix E).

The incidences of bile duct hyperplasia were increased in all exposed groups compared to the $0 / 0$ ppm control group; the increase was significant only in the 300/1,000 ppm group (Table 23; Appendix E).

The incidences of hepatocyte mitoses were significantly increased in the 300/1,000 ppm group compared to the $0 / 0$ ppm control group (Table 23; Appendix E). 
Table 23. Incidences of Neoplastic and Nonneoplastic Liver Lesions in Female Rats in the Two-year Feed Study of Perfluorooctanoic Acid (Study 1)

\begin{tabular}{|c|c|c|c|c|}
\hline & & & weaning $\mathbf{E x}$ & \\
\hline & $\begin{array}{l}\text { Perinatal } \\
\text { Exposure }\end{array}$ & O ppm & 300 ppm & 1,000 ppm \\
\hline $\mathbf{n}$ & & $50^{\mathrm{a}}$ & 50 & $50^{\mathrm{b}}$ \\
\hline Hepatocyte, Cytoplasmic Alteration ${ }^{\mathrm{c}}$ & 0 ppm & $0 * * \#$ & $9 * *(1.4)^{\mathrm{d}}$ & $49 * *(2.3)$ \\
\hline & $150 \mathrm{ppm}$ & - & $17 * *(1.1)$ & - \\
\hline & $300 \mathrm{ppm}$ & - & - & $49 * *(2.2)$ \\
\hline Hepatocyte, Hypertrophy & 0 ppm & $0 * * \#$ & $11 * *(1.7)$ & $48^{* *}(2.4)$ \\
\hline & $150 \mathrm{ppm}$ & - & $16^{* *}(1.6)$ & - \\
\hline & $300 \mathrm{ppm}$ & - & - & $49 * *(2.4)$ \\
\hline Hepatocyte, Single Cell Death & 0 ppm & $0 * * \#$ & $4(1.0)$ & $29 * *(1.3)$ \\
\hline & $150 \mathrm{ppm}$ & - & $5 *(1.0)$ & - \\
\hline & $300 \mathrm{ppm}$ & - & - & $32 * *(1.2)$ \\
\hline Necrosis & 0 ppm & $0 * *$ & $1(1.0)$ & $8 *(1.5)$ \\
\hline & $150 \mathrm{ppm}$ & - & $4(1.3)$ & - \\
\hline & $300 \mathrm{ppm}$ & - & - & $5(2.4)$ \\
\hline Pigment & 0 ppm & $3^{* * \# \#}(1.3)$ & $5(1.4)$ & $43^{* *}(1.7)$ \\
\hline & $150 \mathrm{ppm}$ & - & $10 *(1.1)$ & - \\
\hline & 300 ppm & - & - & $40 * *(1.8)$ \\
\hline Bile Duct, Hyperplasia & 0 ppm & $16^{\#}(1.3)$ & $25(1.2)$ & $22(1.2)$ \\
\hline & $150 \mathrm{ppm}$ & - & $27(1.1)$ & - \\
\hline & $300 \mathrm{ppm}$ & - & - & $27 *(1.3)$ \\
\hline Hepatocyte, Increased Mitoses & $0 \mathrm{ppm}$ & $2^{\#}(1.0)$ & $3(1.0)$ & $4(1.5)$ \\
\hline & $150 \mathrm{ppm}$ & - & $5(1.6)$ & - \\
\hline & $300 \mathrm{ppm}$ & - & - & $10 *(1.3)$ \\
\hline Hepatocellular Adenoma ${ }^{\mathrm{e}}$ & & & & \\
\hline $\begin{array}{l}\text { Overall Rate }^{\mathrm{f}} \\
\text { Litters Rate }^{\mathrm{g}} \\
\text { Rao-Scott Adjusted Poly-3 Test }{ }^{\mathrm{h}, \mathrm{i}}\end{array}$ & $0 \mathrm{ppm}$ & $\begin{aligned} & 2 / 50(4 \%) \\
& 2 / 32(6 \%) \\
\mathrm{p}= & 0.543 \mathrm{~N} / 0.322\end{aligned}$ & $\begin{array}{l}0 / 50(0 \%) \\
0 / 29(0 \%) \\
\mathrm{p}=0.262 \mathrm{~N}\end{array}$ & $\begin{array}{l}1 / 49(2 \%) \\
1 / 31(3 \%) \\
p=0.506 \mathrm{~N}\end{array}$ \\
\hline $\begin{array}{l}\text { Overall Rate } \\
\text { Litters Rate } \\
\text { Rao-Scott Adjusted Poly-3 Test }\end{array}$ & $150 \mathrm{ppm}$ & - & $\begin{array}{c}0 / 50(0 \%) \\
0 / 29(0 \%) \\
p=0.251 N\end{array}$ & - \\
\hline $\begin{array}{l}\text { Overall Rate } \\
\text { Litters Rate } \\
\text { Rao-Scott Adjusted Poly-3 Test }\end{array}$ & $300 \mathrm{ppm}$ & - & - & $\begin{array}{c}3 / 50(6 \%) \\
3 / 30(10 \%) \\
p=0.508\end{array}$ \\
\hline Hepatocellular Carcinoma $^{\mathrm{j}}$ & & & & \\
\hline $\begin{array}{l}\text { Overall Rate } \\
\text { Litters Rate } \\
\text { Rao-Scott Adjusted Poly-3 Test }\end{array}$ & $0 \mathrm{ppm}$ & $\begin{array}{c}1 / 50(2 \%) \\
1 / 32(3 \%) \\
\mathrm{p}=0.211 / 0.089\end{array}$ & $\begin{array}{l}1 / 50(2 \%) \\
1 / 29(3 \%) \\
\mathrm{p}=0.709 \mathrm{~N}\end{array}$ & $\begin{array}{c}3 / 49(6 \%) \\
3 / 31(10 \%) \\
p=0.318\end{array}$ \\
\hline $\begin{array}{l}\text { Overall Rate } \\
\text { Litters Rate } \\
\text { Rao-Scott Adjusted Poly-3 Test }\end{array}$ & $150 \mathrm{ppm}$ & - & $\begin{array}{c}0 / 50(0 \%) \\
0 / 29(0 \%) \\
\mathrm{p}=0.524 \mathrm{~N}\end{array}$ & - \\
\hline $\begin{array}{l}\text { Overall Rate } \\
\text { Litters Rate } \\
\text { Rao-Scott Adjusted Poly-3 Test }\end{array}$ & $300 \mathrm{ppm}$ & - & - & $\begin{array}{c}4 / 50(8 \%) \\
4 / 30(13 \%) \\
p=0.233\end{array}$ \\
\hline
\end{tabular}




\begin{tabular}{lcccc}
\hline & & \multicolumn{3}{c}{ Postweaning Exposure } \\
\cline { 3 - 4 } & $\begin{array}{c}\text { Perinatal } \\
\text { Exposure }\end{array}$ & $\mathbf{0 ~ p p m}$ & $\mathbf{3 0 0} \mathbf{~ p p m}$ & $\mathbf{1 , 0 0 0} \mathbf{~ p p m}$ \\
\hline Hepatocellular Adenoma or Carcinoma, (Combined) & & & \\
Overall Rate & $0 \mathrm{ppm}$ & $3 / 50(6 \%)$ & $1 / 50(2 \%)$ & $4 / 49(8 \%)$ \\
Litters Rate & & $3 / 32(9 \%)$ & $1 / 29(3 \%)$ & $4 / 31(13 \%)$ \\
Rao-Scott Adjusted Poly-3 Test & & $\mathrm{p}=0.332 / 0.093$ & $\mathrm{p}=0.275 \mathrm{~N}$ & $\mathrm{p}=0.491$ \\
Overall Rate & $150 \mathrm{ppm}$ & & $0 / 50(0 \%)$ & \\
Litters Rate & & $0 / 29(0 \%)$ & - \\
Rao-Scott Adjusted Poly-3 Test & $300 \mathrm{ppm}$ & & $\mathrm{p}=0.126 \mathrm{~N}$ & \\
Overall Rate & & & - & $6 / 50(12 \%)$ \\
Litters Rate & - & & $\mathrm{p}=0.269$ \\
Rao-Scott Adjusted Poly-3 Test & & & & $-20 \%)$ \\
\hline
\end{tabular}

Statistical significance for a treatment group indicates a significant pairwise test compared to the $0 / 0$ ppm control group. Statistical significance for the $0 / 0 \mathrm{ppm}$ control group indicates a significant trend test.

Pairwise comparisons across perinatal exposures (0/300 vs. $150 / 300 \mathrm{ppm}$ and 0/1,000 vs. 300/1,000 ppm) did not show any statistically significant differences.

*Significantly different $(\mathrm{p} \leq 0.05)$ from the $0 / 0 \mathrm{ppm}$ control group by the Rao-Scott test.; **p $\leq 0.01$.

${ }^{\#}$ Statistically significant trend at $\mathrm{p} \leq 0.05$ when comparing across the $0 / 0,150 / 300$, and $300 / 1,000 \mathrm{ppm}$ groups; ${ }^{\# \#} \mathrm{p} \leq 0.01$.

${ }^{a}$ Number of animals with tissue examined microscopically.

${ }^{\mathrm{b}} \mathrm{N}=49$ for the $0 / 1,000$ ppm group.

'Number of animals with lesion.

${ }^{\mathrm{d}}$ Average severity grade of lesions in affected animals: $1=$ minimal, $2=$ mild, $3=$ moderate, $4=$ marked.

${ }^{\mathrm{e}}$ Historical control incidence for all routes of 2-year studies (mean \pm standard deviation): $14 / 340$ (3.63\% $\pm 2.59 \%$ ); range: $0 \%$ to $8 \%$.

f Number of animals with neoplasm per number of animals necropsied.

gNumber of litters with animals with neoplasm per number of litters necropsied.

heneath the control incidence is the $\mathrm{p}$ value associated with the trend test. Beneath the exposed group incidences are the $\mathrm{p}$ values corresponding to pairwise comparisons between the respective control and that exposed group. The Rao-Scott test adjusts the Poly-3 test for within-litter correlation. A negative trend or a lower incidence in an exposure group is indicated by $\mathrm{N}$.

${ }^{i}$ Rao-Scott trend values presented as: $\mathrm{p}$ value (postweaning-only exposure groups)/p value (perinatal and postweaning exposure groups).

${ }^{\mathrm{j}}$ Historical control incidence: $1 / 340(0.33 \% \pm 0.82 \%)$; range: $0 \%$ to $2 \%$.

kHistorical control incidence: $15 / 340(3.96 \% \pm 2.77 \%)$; range: $0 \%$ to $8 \%$.

Pancreas: In the 300/1,000 ppm group, slight increases were observed in the incidences of acinar cell adenoma, acinar cell adenocarcinoma and adenoma or adenocarcinoma combined that did not reach statistical significance compared to the $0 / 0 \mathrm{ppm}$ control group (Table 24). One duct adenocarcinoma occurred in the 300/1,000 ppm group. (See 2-year study in males for description of the pancreatic lesions.) There were occurrences of hyperplasia, but they were not statistically significant. No differences between groups with perinatal and without perinatal exposures were observed.

Table 24. Incidences of Neoplastic and Nonneoplastic Pancreas Lesions in Female Rats in the Two-year Feed Study of Perfluorooctanoic Acid (Study 1)

\begin{tabular}{lcccc}
\hline & & \multicolumn{3}{c}{ Postweaning Exposure } \\
\cline { 3 - 5 } & $\begin{array}{c}\text { Perinatal } \\
\text { Exposure }\end{array}$ & $\mathbf{0 ~ p p m}$ & $\mathbf{3 0 0} \mathbf{~ p p m}$ & $\mathbf{1 , 0 0 0} \mathbf{~ p p m}$ \\
\hline $\mathbf{n}$ & & $50^{\mathrm{a}}$ & 50 & $50^{\mathrm{b}}$ \\
\hline Acinus, Hyperplasia $^{\mathrm{c}}$ & $0 \mathrm{ppm}$ & 0 & $1(2.0)^{\mathrm{d}}$ & $1(2.0)$ \\
& $150 \mathrm{ppm}$ & - & 0 & - \\
& $300 \mathrm{ppm}$ & - & - & $1(4.0)$ \\
\hline
\end{tabular}


Perfluorooctanoic Acid, NTP TR 598

\begin{tabular}{|c|c|c|c|c|}
\hline & \multirow[b]{2}{*}{$\begin{array}{l}\text { Perinatal } \\
\text { Exposure }\end{array}$} & \multicolumn{3}{|c|}{ Postweaning Exposure } \\
\hline & & 0 ppm & 300 ppm & 1,000 ppm \\
\hline \multicolumn{5}{|l|}{ Acinar Cell Adenoma ${ }^{\mathrm{e}}$} \\
\hline $\begin{array}{l}\text { Overall Rate }^{\mathrm{f}} \\
\text { Litters Rate } \\
\text { Rao-Scott Adjusted Poly-3 Test }{ }^{\mathrm{h}}\end{array}$ & $0 \mathrm{ppm}$ & $\begin{array}{l}0 / 50(0 \%) \\
0 / 32(0 \%) \\
p=0.084^{i}\end{array}$ & $\begin{array}{l}0 / 50 \\
0 / 29 \\
j\end{array}$ & $\begin{array}{l}1 / 49(2 \%) \\
1 / 31(3 \%) \\
\quad(\mathrm{e})\end{array}$ \\
\hline $\begin{array}{l}\text { Overall Rate } \\
\text { Litters Rate } \\
\text { Rao-Scott Adjusted Poly-3 Test }\end{array}$ & $150 \mathrm{ppm}$ & - & $\begin{array}{l}0 / 50(0 \%) \\
0 / 29(0 \%) \\
\quad(\mathrm{e})\end{array}$ & - \\
\hline $\begin{array}{l}\text { Overall Rate } \\
\text { Litters Rate } \\
\text { Rao-Scott Adjusted Poly-3 Test }\end{array}$ & $300 \mathrm{ppm}$ & - & - & $\begin{array}{c}3 / 50(6 \%) \\
3 / 30(10 \%) \\
p=0.215\end{array}$ \\
\hline \multicolumn{5}{|l|}{ Acinar Cell Adenocarcinoma ${ }^{\mathrm{k}}$} \\
\hline $\begin{array}{l}\text { Overall Rate } \\
\text { Litters Rate } \\
\text { Rao-Scott Adjusted Poly-3 Test }\end{array}$ & $0 \mathrm{ppm}$ & $\begin{array}{l}0 / 50(0 \%) \\
0 / 32(0 \%) \\
p=0.178^{i}\end{array}$ & $\begin{array}{l}0 / 50 \\
0 / 29 \\
-\end{array}$ & $\begin{array}{l}1 / 49(2 \%) \\
1 / 31(3 \%) \\
\quad(\mathrm{e})\end{array}$ \\
\hline $\begin{array}{l}\text { Overall Rate } \\
\text { Litters Rate } \\
\text { Rao-Scott Adjusted Poly-3 Test }\end{array}$ & $150 \mathrm{ppm}$ & - & $\begin{array}{l}0 / 50(0 \%) \\
0 / 29(0 \%) \\
\quad(\mathrm{e})\end{array}$ & - \\
\hline $\begin{array}{l}\text { Overall Rate } \\
\text { Litters Rate } \\
\text { Rao-Scott Adjusted Poly-3 Test }\end{array}$ & $300 \mathrm{ppm}$ & - & - & $\begin{array}{l}2 / 50(4 \%) \\
2 / 30(7 \%) \\
p=0.340\end{array}$ \\
\hline \multicolumn{5}{|c|}{ Acinar Cell Adenoma or Adenocarcinoma, (Combined) $)^{1}$} \\
\hline $\begin{array}{l}\text { Overall Rate } \\
\text { Litters Rate } \\
\text { Rao-Scott Adjusted Poly-3 Test }\end{array}$ & 0 ppm & $\begin{aligned} & 0 / 50(0 \%) \\
& 0 / 32(0 \%) \\
& \mathrm{p}= 0.174 / 0.018^{\mathrm{m}}\end{aligned}$ & $\begin{array}{l}0 / 50(0 \%) \\
0 / 29(0 \%) \\
\text { (e) }\end{array}$ & $\begin{array}{l}2 / 49(4 \%) \\
2 / 31(6 \%) \\
p=0.337\end{array}$ \\
\hline $\begin{array}{l}\text { Overall Rate } \\
\text { Litters Rate } \\
\text { Rao-Scott Adjusted Poly-3 Test }\end{array}$ & $150 \mathrm{ppm}$ & - & $\begin{array}{l}0 / 50(0 \%) \\
0 / 29(0 \%) \\
\quad(\mathrm{e})\end{array}$ & - \\
\hline $\begin{array}{l}\text { Overall Rate } \\
\text { Litters Rate } \\
\text { Rao-Scott Adjusted Poly-3 Test }\end{array}$ & $300 \mathrm{ppm}$ & - & - & $\begin{array}{c}5 / 50(10 \%) \\
5 / 30(17 \%) \\
p=0.086\end{array}$ \\
\hline
\end{tabular}

Pairwise comparisons across perinatal exposures (0/300 vs. 150/300 ppm and 0/1,000 vs. 300/1,000 ppm) did not show any statistically significant differences.

(e) = value of statistic could not be computed.

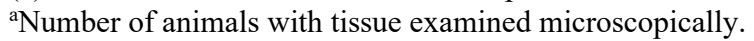

${ }^{\mathrm{b}} \mathrm{N}=49$ for the $0 / 1,000$ ppm group.

${ }^{\mathrm{c}}$ Number of animals with lesion.

${ }^{\mathrm{d} A v e r a g e ~ s e v e r i t y ~ g r a d e ~ o f ~ l e s i o n s ~ i n ~ a f f e c t e d ~ a n i m a l s: ~} 1=$ minimal, $2=$ mild, $3=$ moderate, $4=$ marked.

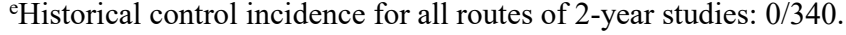

f Number of animals with neoplasm per number of animals necropsied.

gNumber of litters with animals with neoplasm per number of litters necropsied.

${ }^{h}$ Beneath the control incidence is the $p$ value associated with the trend test. Beneath the exposed group incidences are the $p$ values corresponding to pairwise comparisons between the respective control and that exposed group. The Rao-Scott test adjusts the Poly-3 test for within-litter correlation. A negative trend or a lower incidence in an exposure group is indicated by $\mathrm{N}$.

iP value represents the trend for the $0 / 0,150 / 300$, and $300 / 1,000 \mathrm{ppm}$ groups.

${ }^{\mathrm{j} N o t}$ applicable; no neoplasms in group.

${ }^{k}$ Historical control incidence: $0 / 340$.

${ }^{1}$ Historical control incidence: 0/340.

mao-Scott trend values presented as: $\mathrm{p}$ value (postweaning-only exposure groups)/p value (perinatal and postweaning exposure groups). 
Uterus: In the standard evaluation of the perinatal and/or postweaning exposures, increased incidences of adenocarcinomas of the uterus, compared to the $0 / 0 \mathrm{ppm}$ control group, occurred in the $0 / 300,0 / 1,000,150 / 300$, and 300/1,000 ppm groups (Table 25).

In the extended evaluation, additional adenocarcinomas were diagnosed in the uteri of exposed groups (Table 25). The incidences of adenocarcinoma were increased in the 0/300 and $0 / 1,000$ ppm groups; the increase in the $0 / 1,000$ ppm group was significant.

In the combined standard and extended evaluations, the incidences of adenocarcinoma were increased in the $0 / 300,0 / 1,000,150 / 300$, and 300/1,000 ppm groups; however, the increase was significant only in the $0 / 1,000$ ppm group (Table 25). No differences between groups with perinatal and without perinatal exposures were observed.

Table 25. Incidences of Neoplastic and Nonneoplastic Lesions in the Standard and Extended Evaluations of the Uterus in the Two-year Feed Study of Perfluorooctanoic Acid in Female Rats (Study 1)

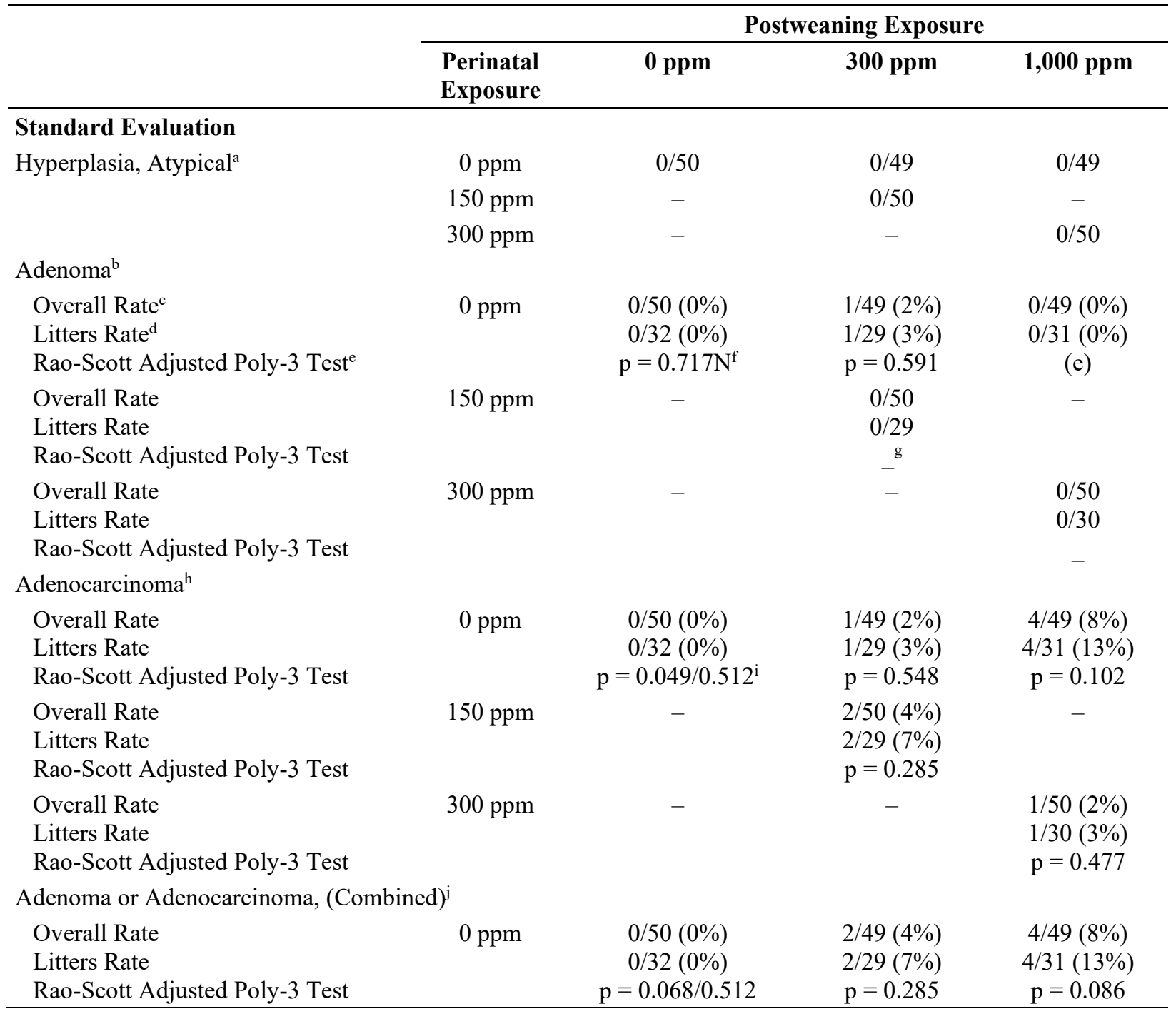


Perfluorooctanoic Acid, NTP TR 598

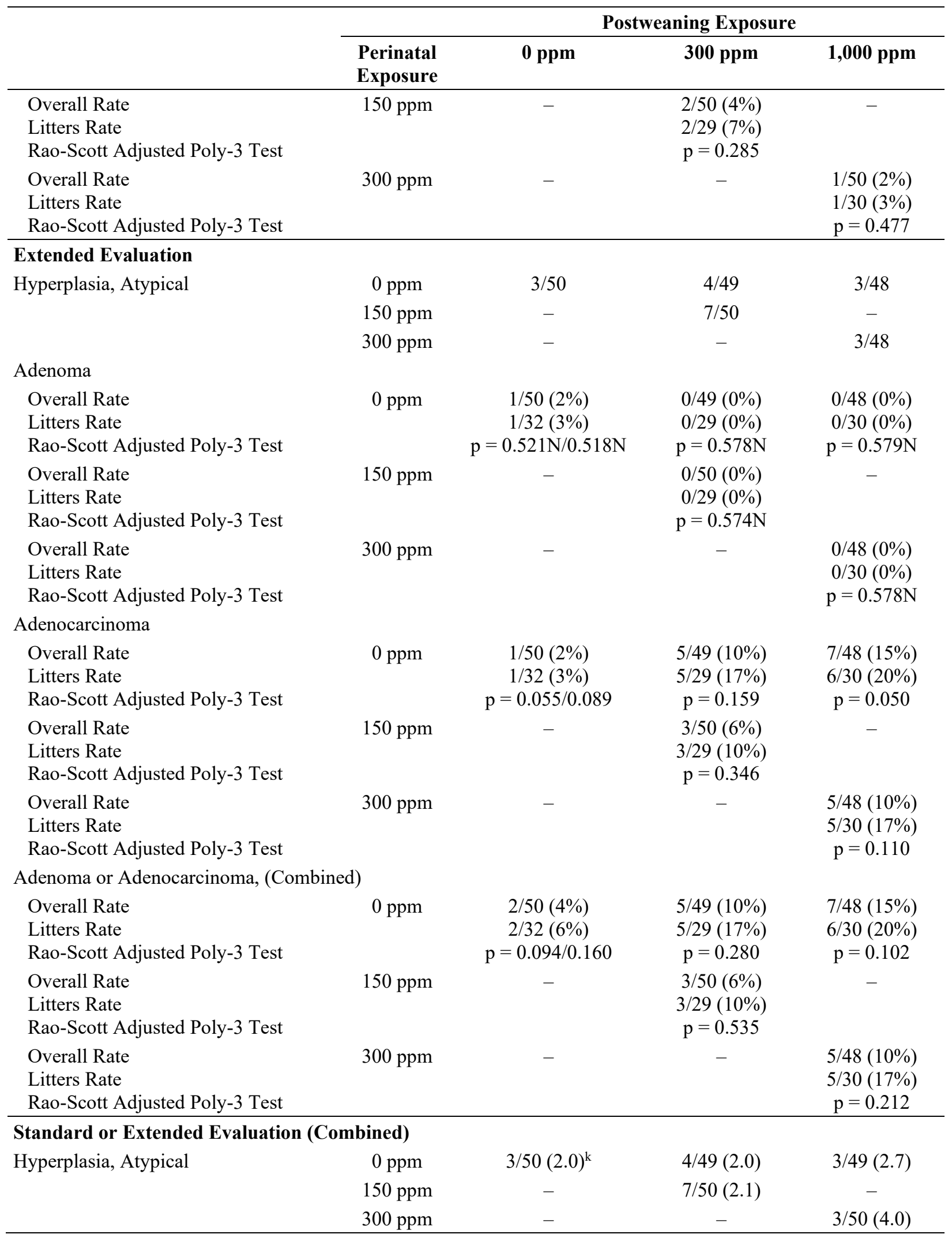


Perfluorooctanoic Acid, NTP TR 598

\begin{tabular}{|c|c|c|c|c|}
\hline & \multirow[b]{2}{*}{$\begin{array}{l}\text { Perinatal } \\
\text { Exposure }\end{array}$} & \multicolumn{3}{|c|}{ Postweaning Exposure } \\
\hline & & O ppm & 300 ppm & $1,000 \mathrm{ppm}$ \\
\hline \multicolumn{5}{|l|}{ Adenoma } \\
\hline $\begin{array}{l}\text { Overall Rate } \\
\text { Litters Rate } \\
\text { Rao-Scott Adjusted Poly-3 Test }\end{array}$ & $0 \mathrm{ppm}$ & $\begin{array}{c}1 / 50(2 \%) \\
1 / 32(3 \%) \\
\mathrm{p}=0.376 \mathrm{~N} / 0.513 \mathrm{~N}\end{array}$ & $\begin{array}{c}1 / 49(2 \%) \\
1 / 29(3 \%) \\
p=0.717 \mathrm{~N}\end{array}$ & $\begin{array}{c}0 / 49(0 \%) \\
0 / 31(0 \%) \\
p=0.489 \mathrm{~N}\end{array}$ \\
\hline $\begin{array}{l}\text { Overall Rate } \\
\text { Litters Rate } \\
\text { Rao-Scott Adjusted Poly-3 Test }\end{array}$ & $150 \mathrm{ppm}$ & - & $\begin{array}{c}0 / 50(0 \%) \\
0 / 29(0 \%) \\
\mathrm{p}=0.576 \mathrm{~N}\end{array}$ & - \\
\hline $\begin{array}{l}\text { Overall Rate } \\
\text { Litters Rate } \\
\text { Rao-Scott Adjusted Poly-3 Test }\end{array}$ & $300 \mathrm{ppm}$ & - & - & $\begin{array}{c}0 / 50(0 \%) \\
0 / 30(0 \%) \\
p=0.573 \mathrm{~N}\end{array}$ \\
\hline \multicolumn{5}{|l|}{ Adenocarcinoma } \\
\hline $\begin{array}{l}\text { Overall Rate } \\
\text { Litters Rate } \\
\text { Rao-Scott Adjusted Poly-3 Test }\end{array}$ & $0 \mathrm{ppm}$ & $\begin{array}{c}1 / 50(2 \%) \\
1 / 32(3 \%) \\
\mathrm{p}=0.054 / 0.094\end{array}$ & $\begin{array}{c}5 / 49(10 \%) \\
5 / 29(17 \%) \\
p=0.159\end{array}$ & $\begin{array}{c}7 / 49(14 \%) \\
6 / 31(19 \%) \\
p=0.050\end{array}$ \\
\hline $\begin{array}{l}\text { Overall Rate } \\
\text { Litters Rate } \\
\text { Rao-Scott Adjusted Poly-3 Test }\end{array}$ & $150 \mathrm{ppm}$ & - & $\begin{array}{c}3 / 50(6 \%) \\
3 / 29(10 \%) \\
p=0.345\end{array}$ & - \\
\hline $\begin{array}{l}\text { Overall Rate } \\
\text { Litters Rate } \\
\text { Rao-Scott Adjusted Poly-3 Test }\end{array}$ & 300 ppm & - & - & $\begin{array}{c}5 / 50(10 \%) \\
5 / 30(17 \%) \\
p=0.115\end{array}$ \\
\hline \multicolumn{5}{|c|}{ Adenoma or Adenocarcinoma, (Combined) } \\
\hline $\begin{array}{l}\text { Overall Rate } \\
\text { Litters Rate } \\
\text { Rao-Scott Adjusted Poly-3 Test }\end{array}$ & $0 \mathrm{ppm}$ & $\begin{array}{c}2 / 50(4 \%) \\
2 / 32(6 \%) \\
\mathrm{p}=0.094 / 0.169\end{array}$ & $\begin{array}{c}5 / 49(10 \%) \\
5 / 29(17 \%) \\
p=0.280\end{array}$ & $\begin{array}{c}7 / 49(14 \%) \\
6 / 31(19 \%) \\
p=0.101\end{array}$ \\
\hline $\begin{array}{l}\text { Overall Rate } \\
\text { Litters Rate } \\
\text { Rao-Scott Adjusted Poly-3 Test }\end{array}$ & $150 \mathrm{ppm}$ & - & $\begin{array}{c}3 / 50(6 \%) \\
3 / 29(10 \%) \\
p=0.535\end{array}$ & - \\
\hline $\begin{array}{l}\text { Overall Rate } \\
\text { Litters Rate } \\
\text { Rao-Scott Adjusted Poly-3 Test }\end{array}$ & $300 \mathrm{ppm}$ & - & - & $\begin{array}{c}5 / 50(10 \%) \\
5 / 30(17 \%) \\
p=0.220\end{array}$ \\
\hline
\end{tabular}

Pairwise comparisons across perinatal exposures (0/300 vs. 150/300 ppm and 0/1,000 vs. 300/1,000 ppm) did not show any statistically significant differences.

(e) = value of statistic could not be computed.

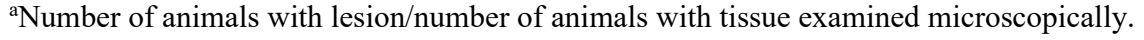

${ }^{b}$ Historical control incidence for all routes of 2-year studies (mean \pm standard deviation): $1 / 150(0.67 \% \pm 1.15 \%)$; range: $0 \%$ to $2 \%$.

${ }^{\mathrm{c}}$ Number of animals with neoplasm per number of animals necropsied.

dNumber of litters with animals with neoplasm per number of litters necropsied.

${ }^{\mathrm{e} B e n e a t h}$ the control incidence is the $\mathrm{p}$ value associated with the trend test. Beneath the exposed group incidences are the $\mathrm{p}$ values corresponding to pairwise comparisons between the respective control and that exposed group. The Rao-Scott test adjusts the Poly-3 test for within-litter correlation. A negative trend or a lower incidence in an exposure group is indicated by $\mathrm{N}$.

fP value represents the trend for the $0 / 0,0 / 300$, and $0 / 1,000$ ppm groups.

gNot applicable; no neoplasms in group.

hHistorical control incidence: $11 / 150(7.33 \% \pm 4.62 \%)$; range: $2 \%$ to $10 \%$.

${ }^{\mathrm{i}}$ Rao-Scott trend values presented as: $\mathrm{p}$ value (postweaning-only exposure groups)/p value (perinatal and postweaning exposure groups).

${ }^{\mathrm{j} H i s t o r i c a l}$ control incidence: $12 / 150(8 \% \pm 3.46 \%)$; range: $4 \%$ to $10 \%$.

${ }^{\mathrm{k}}$ Average severity grade of lesions in affected animals: $1=$ minimal, $2=$ mild, $3=$ moderate, $4=$ marked. 
Kidney: Compared to the $0 / 0 \mathrm{ppm}$ control group, the incidences of hyperplasia of the renal papillary epithelium were significantly increased in the 0/300,0/1,000, and 300/1,000 ppm groups (Table 26). The incidences of papilla necrosis were significantly increased in the $0 / 1,000$ and 300/1,000 ppm groups. The incidence of renal tubule mineral was significantly increased in the $0 / 1,000$ ppm group. In general, the incidences of these kidney lesions increased with increasing exposure concentration. There were some statistical differences observed in groups with and without perinatal exposure. The incidence of hyperplasia of the renal papillary epithelium in the $150 / 300$ ppm group was significantly decreased compared to the $0 / 300 \mathrm{ppm}$ group. It is not clear if this was related to perinatal exposure as this only occurred with the $150 \mathrm{ppm}$ perinatal exposure and not the $300 \mathrm{ppm}$ perinatal exposure. In addition, there was a decrease of renal tubule mineral in the $300 / 1,000 \mathrm{ppm}$ group compared to the $0 / 1,000 \mathrm{ppm}$ group. Similarly, it is unclear if this is related to perinatal exposure.

Table 26. Incidences of Select Nonneoplastic Lesions in the Kidney, Stomach, and Thyroid Gland of Female Rats in the Two-year Feed Study of Perfluorooctanoic Acid (Study 1)

\begin{tabular}{|c|c|c|c|c|}
\hline & \multirow[b]{2}{*}{$\begin{array}{l}\text { Perinatal } \\
\text { Exposure }\end{array}$} & \multicolumn{3}{|c|}{ Postweaning Exposure } \\
\hline & & 0 ppm & 300 ppm & $1,000 \mathrm{ppm}$ \\
\hline $\mathbf{n}$ & & $50^{\mathrm{a}}$ & 50 & $50^{\mathrm{b}}$ \\
\hline \multicolumn{5}{|l|}{ Kidney } \\
\hline \multirow[t]{3}{*}{ Papilla, Urothelium, Hyperplasia ${ }^{c}$} & $0 \mathrm{ppm}$ & $4^{* * \# \#}(1.0)^{\mathrm{d}}$ & $21 * *(1.0)$ & $40 * *(1.9)$ \\
\hline & $150 \mathrm{ppm}$ & - & $8^{\wedge \wedge}(1.0)$ & - \\
\hline & $300 \mathrm{ppm}$ & - & - & $45 * *(1.8)$ \\
\hline \multirow[t]{3}{*}{ Papilla, Necrosis } & $0 \mathrm{ppm}$ & $0^{* * \# \#}$ & 0 & $12 * *(2.3)$ \\
\hline & $150 \mathrm{ppm}$ & - & 0 & - \\
\hline & 300 ppm & - & - & $22 * *(2.1)$ \\
\hline \multirow[t]{3}{*}{ Renal Tubule, Mineral } & $0 \mathrm{ppm}$ & $5 * *(1.2)$ & $6(1.3)$ & $16^{* *}(1.0)$ \\
\hline & $150 \mathrm{ppm}$ & - & $8(1.0)$ & - \\
\hline & $300 \mathrm{ppm}$ & - & - & $8^{\wedge}(1.5)$ \\
\hline \multicolumn{5}{|l|}{ Forestomach } \\
\hline \multirow[t]{3}{*}{ Ulcer } & $0 \mathrm{ppm}$ & $2 * * \#(1.5)$ & $2(1.5)$ & $9 *(1.6)$ \\
\hline & $150 \mathrm{ppm}$ & - & $1(1.0)$ & - \\
\hline & 300 ppm & - & - & $11 *(2.1)$ \\
\hline \multirow[t]{3}{*}{ Epithelium, Hyperplasia } & $0 \mathrm{ppm}$ & $4 * * \#(2.3)$ & $5(1.8)$ & $22 * *(2.8)$ \\
\hline & $150 \mathrm{ppm}$ & - & $3(2.3)$ & - \\
\hline & $300 \mathrm{ppm}$ & - & - & $21 * *(2.5)$ \\
\hline \multirow{3}{*}{$\begin{array}{l}\text { Submucosa, Inflammation, } \\
\text { Chronic Active }\end{array}$} & $0 \mathrm{ppm}$ & $3 * * \#$ (2.3) & $2(2.5)$ & $16^{* *}(2.6)$ \\
\hline & $150 \mathrm{ppm}$ & - & $2(2.0)$ & - \\
\hline & $300 \mathrm{ppm}$ & - & - & $18 * *(2.5)$ \\
\hline
\end{tabular}




\begin{tabular}{lcccc}
\hline & & \multicolumn{3}{c}{ Postweaning Exposure } \\
\cline { 3 - 5 } & $\begin{array}{c}\text { Perinatal } \\
\text { Exposure }\end{array}$ & $\mathbf{0 ~ p p m}$ & $\mathbf{3 0 0} \mathbf{~ p p m}$ & $\mathbf{1 , 0 0 0} \mathbf{~ p p m}$ \\
\hline Thyroid Gland & $0 \mathrm{ppm}$ & $4^{* * \# *}(2.3)$ & $8(2.1)$ & $28^{* *}(2.0)$ \\
Follicular Cell, Hypertrophy & $150 \mathrm{ppm}$ & - & $9(1.6)$ & - \\
& $300 \mathrm{ppm}$ & - & - & $19^{* *}(1.7)$ \\
\hline
\end{tabular}

Statistical significance for a treatment group indicates a significant pairwise test compared to the $0 / 0$ ppm control group.

Statistical significance for the $0 / 0 \mathrm{ppm}$ control group indicates a significant trend test.

*Significantly different $(\mathrm{p} \leq 0.05)$ from the $0 / 0 \mathrm{ppm}$ control by the Rao-Scott test; ${ }^{*} \mathrm{p} \leq 0.01$.

\#\#tatistically significant trend at $\mathrm{p} \leq 0.01$ when comparing across the $0 / 0,150 / 300$, and $300 / 1,000$ ppm groups.

${ }^{\wedge}$ Statistically different $(\mathrm{p} \leq 0.05)$ when comparing the $0 / 300 \mathrm{vs} .150 / 300 \mathrm{ppm}$ groups or $0 / 1,000 \mathrm{vs} .300 / 1,000$ groups; ${ }^{\wedge} \mathrm{p} \leq 0.01$.

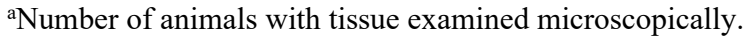

${ }^{\mathrm{b}} \mathrm{N}=49$ for the $0 / 1,000$ ppm group.

${ }^{c}$ Number of animals with lesion.

${ }^{\mathrm{d}}$ Average severity grade of lesions in affected animals: $1=$ minimal, $2=$ mild, $3=$ moderate, $4=$ marked.

Forestomach: The incidences of ulcer, epithelium hyperplasia, and chronic active inflammation of the submucosa in the 0/1,000 and 300/1,000 ppm groups were significantly greater than those in the $0 / 0$ ppm control group (Table 26). Both exposed groups had a single case of a squamous cell papilloma (Appendix E).

Thyroid Gland: The incidences of follicular cell hypertrophy in the 0/1,000 and 300/1,000 ppm groups were significantly greater than those in the $0 / 0 \mathrm{ppm}$ control group (Table 26). No differences between groups with perinatal and without perinatal exposures were observed. 


\section{Study 2: Two-year Study in Males with 16-week Interim Evaluation}

\section{Perinatal Exposure}

No exposure-related effects were observed on the pregnancy status, maternal survival, or number of dams that littered (Table 27). PFOA fetal and lactational transfer was assessed at GD 18 and PND 4, respectively (Table 28). Maternal plasma concentrations of the $300 \mathrm{ppm}$ group were $75.1 \mu \mathrm{M}$ on GD 18 and $74.2 \mu \mathrm{M}$ on PND 4. Concentrations of PFOA from fetuses pooled by litter on GD 18 were $23 \mu \mathrm{M}$, indicating some maternal transfer with maternal plasma concentrations at $75 \mu \mathrm{M}$. On PND 4, concentrations from whole male and female pups were comparable at $11 \mu \mathrm{M}$ and $10 \mu \mathrm{M}$, respectively, indicating some lactational transfer (Table 28). Concentrations of PFOA were below detection in the control group.

Table 27. Summary of Disposition during Perinatal Exposure and $F_{1}$ Allocation in the Two-year Perinatal and Postweaning Study of Perfluorooctanoic Acid (Study 2)

\begin{tabular}{lcc}
\hline & $\mathbf{0 ~ p p m}$ & $\mathbf{3 0 0} \mathbf{~ p p m}$ \\
\hline Time-mated Females & 147 & 147 \\
Pregnant Females & 129 & 123 \\
Nonpregnant Females & 18 & 24 \\
Biological Sample Analysis (GD 18) & $6^{\mathrm{a}}$ & 5 \\
Pregnant Dams Not Delivering & 4 & 6 \\
Moribund (Dystocia) & 1 & 0 \\
Littered/Pregnant on GD 21 & $119 / 123(97 \%)$ & $112 / 118(95 \%)$ \\
Litters Removed (PND 4) & 11 & 5 \\
Litters Poststandardization (PND 4) & 108 & 107 \\
Weaned Males & 240 & 240 \\
\hline
\end{tabular}

ancludes one dam that was not pregnant.

${ }^{b}$ Removed due to insufficient size.

Table 28. Perfluorooctanoic Acid Concentrations in $F_{0}$ and $F_{1}$ Rats in the Two-year Perinatal and Postweaning Study of Perfluorooctanoic Acid (Study 2)

\begin{tabular}{lcc}
\hline & $\mathbf{0 ~ p p m}$ & $\mathbf{3 0 0} \mathbf{p p m}$ \\
\hline Gestation Day 18 & & \\
$\mathrm{F}_{0}$ Plasma Concentration $(\mathrm{ng} / \mathrm{mL})$ & $\mathrm{BD}$ & $31,080 \pm 1,227(5)$ \\
$\mathrm{F}_{0}$ Plasma Concentration $(\mu \mathrm{M})$ & $\mathrm{BD}$ & $75.1 \pm 3.0(5)$ \\
$\mathrm{F}_{1}$ Pooled Whole Fetus $(\mathrm{ng} / \mathrm{g})$ & $\mathrm{BD}$ & $9,374 \pm 1,785(5)$ \\
$\mathrm{F}_{1}$ Pooled Whole Fetus $(\mu \mathrm{M})$ & $\mathrm{BD}$ & $23 \pm 4(5)$ \\
\hline
\end{tabular}




\begin{tabular}{lcc}
\hline & 0 ppm & 300 ppm \\
\hline Postnatal Day 4 & & \\
F $_{0}$ Plasma Concentration $(\mathrm{ng} / \mathrm{mL})$ & BD & $30,725 \pm 2,782(4)$ \\
$\mathrm{F}_{0}$ Plasma Concentration $(\mu \mathrm{M})$ & BD & $74.2 \pm 6.74(4)$ \\
$\mathrm{F}_{1}$ Pooled Whole Male Pup $(\mathrm{ng} / \mathrm{g})$ & BD & $4,539 \pm 320(4)$ \\
$\mathrm{F}_{1}$ Pooled Whole Male Pup $(\mu \mathrm{M})$ & BD & $11 \pm 1(4)$ \\
$\mathrm{F}_{1}$ Pooled Whole Female Pup $(\mathrm{ng} / \mathrm{g})$ & BD & $4,132 \pm 517(3)$ \\
$\mathrm{F}_{1}$ Pooled Whole Female Pup $(\mu \mathrm{M})$ & BD & $10 \pm 1(3)$ \\
\hline
\end{tabular}

$\mathrm{BD}=$ below detection.

${ }^{\mathrm{a}}$ Mean \pm standard error (number of dams, fetuses, or pups). No statistical analysis was performed.

Maternal body weights of the $300 \mathrm{ppm}$ group during gestation were similar to those of the control group (Table 29). A slight decrease in body weight gain was observed at the first interval of GD 6 to 9, but overall weight gain from GD 6 to 21 was not affected by exposure (Table 29). During lactation, there was a marginal decrease $(2 \%$ to $3 \%)$ in maternal weight compared to the control group and a decrease in body weight gain over this time period (Table 30 ).

Table 29. Mean Body Weights and Body Weight Gains of $F_{0}$ Females during Gestation in the Two-year Perinatal and Postweaning Study of Perfluorooctanoic Acid (Study 2) ${ }^{\mathrm{a}}$

\begin{tabular}{lcc}
\hline \multicolumn{1}{c}{ Gestation Day } & $\mathbf{0 ~} \mathbf{~ p p m}$ & $\mathbf{3 0 0} \mathbf{~ p p m}$ \\
\hline Body Weight $(\mathbf{g})$ & & \\
6 & $214.14 \pm 1.11(129)$ & $213.74 \pm 1.18(123)$ \\
9 & $229.97 \pm 1.33(129)$ & $227.52 \pm 1.40(123)$ \\
12 & $247.19 \pm 1.20(129)$ & $245.27 \pm 1.21(123)$ \\
15 & $264.53 \pm 1.34(129)$ & $262.78 \pm 1.30(123)$ \\
18 & $298.93 \pm 1.97(129)$ & $299.40 \pm 1.83(123)$ \\
21 & $341.68 \pm 2.88(124)$ & $341.25 \pm 2.71(118)$ \\
Body Weight Change (g) & & \\
6 to 9 & $15.83 \pm 0.68(129)$ & $13.77 \pm 0.66 *(123)$ \\
9 to 12 & $17.22 \pm 0.57(129)$ & $17.75 \pm 0.70(123)$ \\
12 to 15 & $17.34 \pm 0.51(129)$ & $17.51 \pm 0.43(123)$ \\
15 to 18 & $34.40 \pm 0.89(129)$ & $36.62 \pm 0.90(123)$ \\
18 to 21 & $43.04 \pm 1.07(124)$ & $42.24 \pm 1.16(118)$ \\
6 to 21 & $127.70 \pm 2.49(124)$ & $127.68 \pm 2.46(118)$ \\
\hline
\end{tabular}

Statistical significance for a treatment group indicates a significant pairwise test compared to the vehicle control group. *Statistically significant at $\mathrm{p} \leq 0.05$.

${ }^{\mathrm{a}}$ Mean \pm standard error (number of dams). The exposed group was compared to the control group using a t-test. 
Table 30. Mean Body Weights and Body Weight Gains of $F_{0}$ Females during Lactation in the Two-year Perinatal and Postweaning Study of Perfluorooctanoic Acid (Study 2) ${ }^{\mathbf{a}}$

\begin{tabular}{lcc}
\hline \multicolumn{1}{c}{ Lactation Day } & $\mathbf{0 ~} \mathbf{~ p p m}$ & $\mathbf{3 0 0} \mathbf{~ p p m}$ \\
\hline Body Weight $(\mathbf{g})$ & & \\
1 & $259.90 \pm 1.35(119)$ & $257.71 \pm 1.35(112)$ \\
4 & $271.11 \pm 1.41(119)$ & $267.13 \pm 1.36^{*}(112)$ \\
7 & $281.72 \pm 1.37(108)$ & $276.49 \pm 1.36^{* *}(107)$ \\
14 & $296.06 \pm 1.64(107)$ & $290.23 \pm 1.35^{* *}(107)$ \\
21 & $283.21 \pm 1.60(107)$ & $274.49 \pm 1.40^{* *}(107)$ \\
Body Weight Change (g) & & \\
1 to 4 & $11.21 \pm 0.60(119)$ & $9.42 \pm 0.52^{*}(112)$ \\
4 to 7 & $9.63 \pm 0.65(108)$ & $9.72 \pm 0.69(107)$ \\
7 to 14 & $14.25 \pm 1.09(107)$ & $13.74 \pm 0.73(107)$ \\
14 to 21 & $-12.85 \pm 1.10(107)$ & $-15.74 \pm 0.74 *(107)$ \\
1 to 21 & $22.61 \pm 1.10(107)$ & $16.99 \pm 0.91 * *(107)$ \\
\hline
\end{tabular}

Statistical significance for a treatment group indicates a significant pairwise test compared to the vehicle control group. *Statistically significant at $\mathrm{p} \leq 0.05 ; * \mathrm{p} \leq 0.01$.

${ }^{a}$ Mean \pm standard error (number of dams). The exposed group was compared to the control group using a t-test.

Feed consumption (g/animal/day) was marginally lower $(\leq 3 \%)$ in the $300 \mathrm{ppm}$ group compared to the control group at two intervals during gestation, but overall GD 6 to 21 feed consumption was unaffected (Table 31). Feed consumption by the $300 \mathrm{ppm}$ female group during lactation was marginally less (approximately 5\%) than that of the control group from LD 1 to 14 (Table 31). Chemical consumption was $21.8 \mathrm{mg} / \mathrm{kg} /$ day during gestation and $48.3 \mathrm{mg} / \mathrm{kg} /$ day during days 1 to 14 of the lactational period.

Table 31. Feed Consumption by $F_{0}$ Females during Gestation and Lactation in the Two-year Perinatal and Postweaning Study of Perfluorooctanoic Acid (Study 2) ${ }^{\mathbf{a}}$

\begin{tabular}{lcc}
\hline \multicolumn{1}{c}{ Days } & $\mathbf{0 ~} \mathbf{~ p p m}$ & $\mathbf{3 0 0} \mathbf{~ p p m}$ \\
\hline Gestation (g/animal/day) & \\
6 to 9 & $17.03 \pm 0.20(129)$ & $16.52 \pm 0.20^{* *}(123)$ \\
9 to 12 & $17.34 \pm 0.13(129)$ & $17.58 \pm 0.11(123)$ \\
12 to 15 & $18.77 \pm 0.15(129)$ & $18.27 \pm 0.18^{* *}(123)$ \\
15 to 18 & $21.02 \pm 0.21(129)$ & $21.50 \pm 0.29123)$ \\
18 to 21 & $21.24 \pm 0.22(124)$ & $21.15 \pm 0.26(118)$ \\
6 to 21 & $19.11 \pm 0.14(124)$ & $18.99 \pm 0.12(118)$ \\
Lactation (g/animal/day) & & \\
1 to 4 & $41.24 \pm 1.47(115)$ & $38.18 \pm 1.11^{* *}(112)$ \\
4 to 7 & $40.00 \pm 0.37(108)$ & $38.66 \pm 0.30^{*}(107)$ \\
7 to 10 & $47.89 \pm 0.43(107)$ & $45.14 \pm 0.34^{* *}(107)$ \\
\hline
\end{tabular}




\begin{tabular}{|c|c|c|}
\hline Days & 0 ppm & 300 ppm \\
\hline 10 to 14 & $54.50 \pm 0.41(106)$ & $53.25 \pm 0.39 *(107)$ \\
\hline 14 to 17 & $57.58 \pm 0.60(107)$ & $55.66 \pm 0.37 * *(107)$ \\
\hline 17 to 21 & $67.70 \pm 0.81(107)$ & $66.83 \pm 0.59(107)$ \\
\hline 1 to 14 & $46.81 \pm 0.42(102)$ & $44.62 \pm 0.34 * *(107)$ \\
\hline
\end{tabular}

Statistical significance for a treatment group indicates a significant pairwise test compared to the vehicle control group. *Statistically significant at $\mathrm{p} \leq 0.05 ; * \mathrm{p} \leq 0.01$.

${ }^{a}$ Mean \pm standard error in grams/cage per day (number of dams). The exposed group was compared to the control group using the Wilcoxon rank-sum test.

Live litter sizes on PNDs 1 and 21 were not affected by exposure, and survival of $\mathrm{F}_{1}$ pups was not affected between PNDs 4 poststandardization and 21 (Table 32). The mean pup body weight of the $300 \mathrm{ppm}$ group was $4 \%$ less than that of the controls on PND 1. $F_{1} 300 \mathrm{ppm}$ male weights were less than control group weights throughout lactation, ranging from $3 \%$ lower at PND 1 to $7 \%$ lower at PND 21.

Table 32. Mean Litter Size, Survival Ratio, and Mean Body Weights of $F_{1}$ Rats during Lactation in the Two-year Perinatal and Postweaning Study of Perfluorooctanoic Acid (Study 2)

\begin{tabular}{lcc}
\hline \multicolumn{1}{c}{ Postnatal Day } & 0 ppm & 300 ppm \\
\hline Live Litter Size $^{\mathbf{a}}$ & & \\
1 & $11.72 \pm 0.26(118)$ & $11.52 \pm 0.24(112)$ \\
4 (Poststandardization) & $8.00 \pm 0.00(118)$ & $7.99 \pm 0.01(112)$ \\
21 & $7.81 \pm 0.07(118)$ & $7.89 \pm 0.03(112)$ \\
Survival Ratio & \\
4 to 21 & $0.98 \pm 0.01(118)$ & $0.99 \pm 0.00(112)$ \\
Body Weight & & \\
All Pups & & \\
$1^{\mathrm{a}, \mathrm{c}}$ & & $7.07 \pm 0.05^{* *}(112)$ \\
Male Pups & $7.37 \pm 0.06(118)$ & \\
$1^{\text {c }}$ & & $7.26 \pm 0.06^{* *}(111)$ \\
$4^{\mathrm{d}}$ & $7.50 \pm 0.06(116)$ & $10.14 \pm 0.10^{* *}(435 / 107)$ \\
$7^{\mathrm{d}}$ & $10.57 \pm 0.12(436 / 108)$ & $15.03 \pm 0.15^{* *}(435 / 107)$ \\
$14^{\mathrm{d}}$ & $15.90 \pm 0.18(435 / 108)$ & $30.19 \pm 0.24^{* *}(431 / 107)$ \\
$21^{\mathrm{d}}$ & $31.64 \pm 0.30(427 / 107)$ & $48.84 \pm 0.43^{* *}(428 / 107)$ \\
\hline
\end{tabular}

Statistical significance for a treatment group indicates a significant pairwise test compared to the vehicle control group.

$* *$ Statistically significant at $\mathrm{p} \leq 0.01$.

${ }^{a}$ Mean \pm standard error (number of dams). The exposed group was compared to the control group using the Wilcoxon rank-sum test.

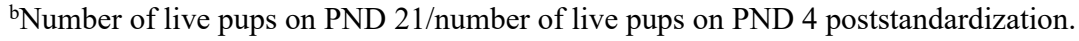

${ }^{c}$ Mean \pm standard error (number of dams). The exposed group was compared to the control group using a t-test.

${ }^{\mathrm{d}}$ Mean \pm standard error (number of pups/number of dams). Values were adjusted for live litter size at PND 4 poststandardization; a mixed-litter effects model was used to compare the exposed group to the control group. 
Group mean body weights are provided in Appendix E. Group mean body weights for the 0/20, $300 / 0$, and $300 / 20 \mathrm{ppm}$ groups were within $10 \%$ of the $0 / 0 \mathrm{ppm}$ control group until the interim evaluation. At 16 weeks, group mean body weights for the $0 / 40,300 / 40,0 / 80$, and 300/80 ppm groups were $18 \%, 14 \%, 19 \%$, and $21 \%$ less than that of the $0 / 0 \mathrm{ppm}$ control group, respectively (Table 34).

With the exception of the 300/0 ppm group, the group mean absolute and relative liver weights of all exposed groups were significantly greater than those of the $0 / 0 \mathrm{ppm}$ control group (Table 34). Histological correlates were present in all groups that had liver weight changes (Appendix E). No differences were observed between groups with and without perinatal exposures.

Acyl-CoA oxidase enzyme activity within the liver was increased in all postweaning exposed groups compared to the $0 / 0 \mathrm{ppm}$ control group (Table 34). The magnitude of the increase was similar between groups that were perinatally exposed or not (e.g., 0/20 vs. 300/20 ppm).

Aromatase activity within the liver was increased marginally in all postweaning exposed groups with roughly a doubling in activity compared to the $0 / 0 \mathrm{ppm}$ control group (Table 34 ). Note that the $0 / 0$ ppm control group and 300/0 ppm groups had similar acyl-CoA oxidase and aromatase activity. No differences were observed between groups with and without perinatal exposures.

Table 34. Summary of Hepatic Findings for Male Rats at the 16-week Interim of the Two-year Feed Study of Perfluorooctanoic Acid (Study 2)

\begin{tabular}{|c|c|c|c|c|c|}
\hline & \multirow[b]{2}{*}{$\begin{array}{l}\text { Perinatal } \\
\text { Exposure }\end{array}$} & \multicolumn{4}{|c|}{ Postweaning Exposure } \\
\hline & & 0 ppm & 20 ppm & $40 \mathrm{ppm}$ & 80 ppm \\
\hline $\mathbf{n}$ & & $10^{\mathrm{c}}$ & 10 & 10 & 10 \\
\hline \multirow[t]{2}{*}{ Necropsy Body Wt. (g) } & $0 \mathrm{ppm}$ & $429.8 \pm 12.1 * *$ & $389.5 \pm 7.9 * *$ & $351.8 \pm 8.7 * *$ & $348.4 \pm 10.2 * *$ \\
\hline & $300 \mathrm{ppm}$ & $414.6 \pm 7.5^{* *}$ & $390.5 \pm 7.7 \dagger$ & $367.5 \pm 7.2 * * \dagger \dagger$ & $338.4 \pm 13.7 * *+\dagger$ \\
\hline \multicolumn{6}{|l|}{ Liver Weight } \\
\hline \multirow[t]{2}{*}{ Absolute (g) } & $0 \mathrm{ppm}$ & $14.62 \pm 0.43 * *$ & $17.99 \pm 0.42 * *$ & $18.80 \pm 0.76^{* *}$ & $19.74 \pm 0.90 * *$ \\
\hline & $300 \mathrm{ppm}$ & $13.57 \pm 0.30^{* *}$ & $17.33 \pm 0.66^{* * \dagger \dagger}$ & $18.49 \pm 0.47 * * \dagger \dagger$ & $18.64 \pm 1.04 * * \dagger \dagger$ \\
\hline \multirow[t]{2}{*}{ Relative (mg/g) } & 0 ppm & $34.10 \pm 0.81^{* *}$ & $46.24 \pm 0.90^{* *}$ & $53.38 \pm 1.49 * *$ & $56.56 \pm 1.71 * *$ \\
\hline & 300 ppm & $32.73 \pm 0.43^{* *}$ & $44.27 \pm 1.02 * * \dagger \dagger$ & $50.30 \pm 0.76^{* * \dagger \dagger}$ & $55.07 \pm 2.18^{* * \dagger \dagger}$ \\
\hline$\underline{\mathbf{n}}$ & & 10 & 10 & 10 & 10 \\
\hline \multirow{2}{*}{$\begin{array}{l}\text { Acyl-CoA Oxidase } \\
\text { Activity }(\mathrm{nmol} / \mathrm{min} / \mathrm{mg})\end{array}$} & $0 \mathrm{ppm}$ & $2.636 \pm 0.107 * *$ & $11.436 \pm 0.660^{* *}$ & $19.360 \pm 1.170^{* *}$ & $25.010 \pm 1.973 * *$ \\
\hline & $300 \mathrm{ppm}$ & $2.754 \pm 0.073 * *$ & $13.779 \pm 1.484 * * \dagger \dagger$ & $18.420 \pm 1.061 * * \dagger \dagger$ & $25.320 \pm 2.438 * * \dagger \dagger$ \\
\hline \multirow{2}{*}{$\begin{array}{l}\text { Aromatase Activity } \\
(\mathrm{pmol} / \mathrm{mg} / \mathrm{min})\end{array}$} & 0 ppm & $7.658 \pm 0.718 * *$ & $15.910 \pm 0.842^{* *}$ & $14.539 \pm 1.075^{* *}$ & $16.630 \pm 0.766^{* *}$ \\
\hline & $300 \mathrm{ppm}$ & $8.837 \pm 0.782 * *$ & $15.951 \pm 1.059 * * \dagger \dagger$ & $17.560 \pm 1.477 * *+\dagger$ & $16.640 \pm 1.083 * * \dagger \dagger$ \\
\hline
\end{tabular}

Statistical significance for a treatment group indicates a significant pairwise test compared to the respective control group $(0 / 0$ or $300 / 0 \mathrm{ppm})$. Statistical significance for the $0 / 0 \mathrm{ppm}$ or $300 / 0 \mathrm{ppm}$ control group indicates a significant trend test.

Pairwise comparisons across perinatal exposures ( $0 / 20$ vs. $300 / 20,0 / 40$ vs. $300 / 40$, and $0 / 80$ vs. $300 / 80$ ppm) did not show any statistically significant differences.

*Statistically significant at $\mathrm{p} \leq 0.05 ; * \mathrm{p} \leq 0.01$.

$\dagger$ Statistically significant at $\mathrm{p} \leq 0.05$ for pairwise comparisons of $0 / 0$ to $300 / 20 \mathrm{ppm}, 0 / 0$ to $300 / 40 \mathrm{ppm}$, and $0 / 0$ to $300 / 80 \mathrm{ppm}$ using a Wilcoxon rank-sum test with a Hommel adjustment (enzyme activity) or a t-test with a Hommel adjustment (body and organ weights); $\dagger \dagger \mathrm{p} \leq 0.01$.

${ }^{a}$ Data presented as mean \pm SEM.

'Statistical analysis of body and organ weights performed using Jonckheere's (trend) and Williams' or Dunnett's (pairwise) tests. Statistical analysis of enzyme activity performed using Jonckheere's (trend) and Shirley's or Dunn's (pairwise) tests.

${ }^{\mathrm{c}}$ Number of animals examined. 
With the exception of the relative weight of the $0 / 80 \mathrm{ppm}$ group, the group mean absolute and relative spleen weights of all exposed groups were significantly less than those of the $0 / 0 \mathrm{ppm}$ control group (Table 35; Appendix E). Absolute weights were decreased up to 29\% compared to the $0 / 0$ ppm control group without a histological correlate.

With the exception of the 300/0 ppm group, the group mean relative right kidney weights of all exposed groups were significantly greater than that of the $0 / 0 \mathrm{ppm}$ control group (Table 35 ; Appendix E). The absolute right kidney weight of the $0 / 20 \mathrm{ppm}$ group was significantly greater than that of the $0 / 0$ ppm control groups. There were no correlated histological findings to explain the increases in kidney weights. Overall, organ weight changes in the adrenal, heart, pituitary gland, lung, testis, thymus, and thyroid gland were considered secondary to body weight changes (Appendix E).

Table 35. Select Organ Weights and Organ-Weight-to-Body-Weight Ratios for Male Rats at the 16-week Interim of the Two-year Feed Study of Perfluorooctanoic Acid (Study 2),

\begin{tabular}{|c|c|c|c|c|c|}
\hline & \multirow[b]{2}{*}{$\begin{array}{l}\text { Perinatal } \\
\text { Exposure }\end{array}$} & \multicolumn{4}{|c|}{ Postweaning Exposure } \\
\hline & & 0 ppm & 20 ppm & 40 ppm & 80 ppm \\
\hline $\mathbf{n}$ & & $10^{\mathrm{c}}$ & 10 & 10 & 10 \\
\hline \multicolumn{6}{|l|}{ Spleen Weight } \\
\hline \multirow[t]{2}{*}{ Absolute (g) } & 0 ppm & $0.793 \pm 0.029 * *$ & $0.634 \pm 0.025 * *$ & $0.564 \pm 0.014^{* *}$ & $0.577 \pm 0.031 * *$ \\
\hline & $300 \mathrm{ppm}$ & $0.648 \pm 0.016^{* * \# \#}$ & $0.643 \pm 0.025 \dagger \dagger$ & $0.589 \pm 0.015 \dagger \dagger$ & $0.540 \pm 0.035^{* * \dagger \dagger}$ \\
\hline \multirow[t]{2}{*}{ Relative (mg/g) } & 0 ppm & $1.85 \pm 0.08^{*}$ & $1.63 \pm 0.05^{*}$ & $1.61 \pm 0.05^{*}$ & $1.66 \pm 0.07$ \\
\hline & $300 \mathrm{ppm}$ & $1.57 \pm 0.04^{\#}$ & $1.64 \pm 0.04 \dagger$ & $1.60 \pm 0.02 \dagger$ & $1.59 \pm 0.06 \dagger$ \\
\hline \multicolumn{6}{|c|}{ Right Kidney Weight } \\
\hline \multirow[t]{2}{*}{ Absolute (g) } & $0 \mathrm{ppm}$ & $1.14 \pm 0.04$ & $1.31 \pm 0.03 * *$ & $1.26 \pm 0.04$ & $1.19 \pm 0.04$ \\
\hline & 300 ppm & $1.17 \pm 0.02$ & $1.27 \pm 0.02 \dagger$ & $1.23 \pm 0.03$ & $1.18 \pm 0.05$ \\
\hline \multirow[t]{2}{*}{ Relative (mg/g) } & $0 \mathrm{ppm}$ & $2.66 \pm 0.06^{* *}$ & $3.36 \pm 0.07 * *$ & $3.59 \pm 0.04 * *$ & $3.42 \pm 0.06^{* *}$ \\
\hline & $300 \mathrm{ppm}$ & $2.83 \pm 0.04 * *$ & $3.26 \pm 0.05 * * \dagger \dagger$ & $3.35 \pm 0.05 * * \dagger \dagger$ & $3.47 \pm 0.05 * * \dagger \dagger$ \\
\hline
\end{tabular}

Statistical significance for a treatment group indicates a significant pairwise test compared to the respective control group $(0 / 0$ or $300 / 0 \mathrm{ppm}$ ). Statistical significance for the $0 / 0 \mathrm{ppm}$ or $300 / 0 \mathrm{ppm}$ control group indicates a significant trend test.

*Statistically significant at $\mathrm{p} \leq 0.05 ; * * \mathrm{p} \leq 0.01$.

$\uparrow$ Statistically significant at $\mathrm{p} \leq 0.05$ for pairwise comparisons of $0 / 0$ to $300 / 20 \mathrm{ppm}, 0 / 0$ to $300 / 40 \mathrm{ppm}$, and $0 / 0$ to $300 / 80 \mathrm{ppm}$ using a t-test with a Hommel $\mathrm{p}$ value adjustment (body and organ weights); $\dagger \dagger \mathrm{p} \leq 0.01$.

\#Statistically significant at $\mathrm{p} \leq 0.05$ for pairwise comparisons of $0 / 0$ to $300 / 0 \mathrm{ppm}, 0 / 20$ to $300 / 20 \mathrm{ppm}, 0 / 40$ to $300 / 40 \mathrm{ppm}$, and $0 / 80$ to $300 / 80 \mathrm{pm}$ using a t-test with a Hommel $\mathrm{p}$ value adjustment; ${ }^{\# \#} \mathrm{p} \leq 0.01$.

${ }^{\mathrm{a}}$ Data presented as mean \pm SEM.

'Statistical analysis of body and organ weights performed using Jonckheere's (trend) and Williams' or Dunnett's (pairwise) tests. 'Number of animals examined.

Clinical chemistry data are presented in Table 36 . Compared to the $0 / 0 \mathrm{ppm}$ control group, urea nitrogen concentrations were significantly increased in the $0 / 40,0 / 80,300 / 40$, and 300/80 ppm groups. Mild increases in urea nitrogen without concomitant increases in creatinine concentration usually indicate decreased water consumption (i.e., mild dehydration). Triglyceride concentrations were significantly decreased in the $0 / 20,0 / 40,300 / 20,300 / 40$, and $300 / 80 \mathrm{ppm}$ groups. Cholesterol concentrations were significantly decreased in the $300 / 20$ and $300 / 80 \mathrm{ppm}$ groups. No differences were observed between groups with and without perinatal exposures. 
In all exposed groups except the $300 / 0$ ppm group, the globulin concentrations were significantly decreased compared to the $0 / 0 \mathrm{ppm}$ control group; the degree of decrease in the globulin concentration resulted in significant decreases in total protein concentration in these groups. Albumin concentrations were significantly increased in all male groups, except the $0 / 20$ and $300 / 0$ ppm groups. The combination of these protein changes resulted in significant increases in the albumin:globulin $(\mathrm{A} / \mathrm{G})$ ratios in all groups except the $300 / 0$ ppm group.

ALT, ALP, and SDH activities were significantly increased in all exposed groups except the $300 / 0$ ppm group, and bile acid concentrations were significantly increased in the 300/20 and $300 / 40$ ppm groups, compared to the $0 / 0$ ppm control group.

Table 36. Select Clinical Chemistry Findings for Male Rats at the 16-week Interim of the Two-year Feed Study of Perfluorooctanoic Acid (Study 2) ${ }^{\mathrm{a}, \mathrm{b}}$

\begin{tabular}{|c|c|c|c|c|c|}
\hline & \multirow[b]{2}{*}{$\begin{array}{l}\text { Perinatal } \\
\text { Exposure }\end{array}$} & \multicolumn{4}{|c|}{ Postweaning Exposure } \\
\hline & & O ppm & 20 ppm & 40 ppm & 80 ppm \\
\hline $\mathbf{n}$ & & $10^{\mathrm{c}}$ & 10 & 10 & 10 \\
\hline \multirow[t]{2}{*}{ Urea Nitrogen $(\mathrm{mg} / \mathrm{dL})$} & $0 \mathrm{ppm}$ & $17.0 \pm 0.3 * *$ & $18.6 \pm 0.7$ & $20.4 \pm 0.7 * *$ & $19.8 \pm 0.8^{* *}$ \\
\hline & $300 \mathrm{ppm}$ & $16.4 \pm 0.5^{* *}$ & $18.0 \pm 0.4^{*}$ & $20.3 \pm 0.7 * * \dagger \dagger$ & $22.4 \pm 1.4^{* * \dagger \dagger}$ \\
\hline \multirow[t]{2}{*}{ Total Protein (g/dL) } & $0 \mathrm{ppm}$ & $6.58 \pm 0.06^{* *}$ & $6.13 \pm 0.10 * *$ & $5.92 \pm 0.07^{* *}$ & $5.98 \pm 0.07^{* *}$ \\
\hline & $300 \mathrm{ppm}$ & $6.45 \pm 0.07$ & $6.15 \pm 0.07 * \dagger \dagger$ & $5.96 \pm 0.06 * * \dagger \dagger$ & $6.32 \pm 0.09^{\# \dagger}$ \\
\hline \multirow[t]{2}{*}{ Albumin (g/dL) } & $0 \mathrm{ppm}$ & $4.24 \pm 0.06^{* *}$ & $4.53 \pm 0.10$ & $4.61 \pm 0.06^{* *}$ & $4.65 \pm 0.06^{* *}$ \\
\hline & $300 \mathrm{ppm}$ & $4.31 \pm 0.04 * *$ & $4.60 \pm 0.07 * *+\dagger$ & $4.51 \pm 0.07 * \dagger$ & $4.91 \pm 0.06^{* * *+\dagger \dagger}$ \\
\hline \multirow[t]{2}{*}{ Globulin (g/dL) } & $0 \mathrm{ppm}$ & $2.34 \pm 0.05^{* *}$ & $1.60 \pm 0.06^{* *}$ & $1.31 \pm 0.07^{* *}$ & $1.33 \pm 0.06^{* *}$ \\
\hline & $300 \mathrm{ppm}$ & $2.14 \pm 0.06^{* *}$ & $1.55 \pm 0.07 * * \dagger \dagger$ & $1.45 \pm 0.05^{* * \dagger \dagger}$ & $1.41 \pm 0.10^{* *+\dagger}$ \\
\hline \multirow[t]{2}{*}{ A/G Ratio } & $0 \mathrm{ppm}$ & $1.82 \pm 0.06^{* *}$ & $2.87 \pm 0.13^{* *}$ & $3.60 \pm 0.18^{* *}$ & $3.55 \pm 0.16^{* *}$ \\
\hline & $300 \mathrm{ppm}$ & $2.03 \pm 0.05^{* *}$ & $3.02 \pm 0.13^{* * \dagger \dagger}$ & $3.14 \pm 0.12 * * \dagger \dagger$ & $3.64 \pm 0.27 * * \dagger \dagger$ \\
\hline \multirow[t]{2}{*}{ Triglycerides (mg/dL) } & $0 \mathrm{ppm}$ & $98.8 \pm 6.1$ & $58.4 \pm 4.3 * *$ & $64.2 \pm 4.5^{* *}$ & $73.1 \pm 6.9$ \\
\hline & $300 \mathrm{ppm}$ & $93.3 \pm 7.9^{*}$ & $59.9 \pm 4.6^{* \dagger \dagger}$ & $67.5 \pm 7.0 \dagger \dagger$ & $62.2 \pm 5.0 * \dagger \dagger$ \\
\hline \multirow[t]{2}{*}{ Cholesterol (mg/dL) } & $0 \mathrm{ppm}$ & $132.4 \pm 5.4$ & $114.3 \pm 5.1$ & $117.9 \pm 4.9$ & $120.7 \pm 3.6$ \\
\hline & $300 \mathrm{ppm}$ & $132.6 \pm 4.6$ & $105.8 \pm 4.1 * *+\dagger$ & $118.9 \pm 4.1$ & $115.1 \pm 3.9 \dagger$ \\
\hline \multirow{2}{*}{$\begin{array}{l}\text { Alanine Aminotransferase } \\
\text { (IU/L) }\end{array}$} & $0 \mathrm{ppm}$ & $44.70 \pm 2.62 * *$ & $76.40 \pm 5.25^{* *}$ & $65.90 \pm 2.85^{* *}$ & $74.00 \pm 3.64 * *$ \\
\hline & $300 \mathrm{ppm}$ & $51.20 \pm 2.25^{* *}$ & $67.00 \pm 2.17 * *+\dagger$ & $68.50 \pm 7.95 * * \dagger \dagger$ & $70.00 \pm 4.49 * * \dagger \dagger$ \\
\hline \multirow[t]{2}{*}{ Alkaline Phosphatase (IU/L) } & $0 \mathrm{ppm}$ & $170.1 \pm 4.9^{* *}$ & $238.7 \pm 10.8^{* *}$ & $246.8 \pm 14.8^{* *}$ & $304.8 \pm 15.7^{* *}$ \\
\hline & $300 \mathrm{ppm}$ & $173.4 \pm 6.6^{* *}$ & $241.4 \pm 6.8^{* * \dagger \dagger}$ & $263.5 \pm 13.0 * * \dagger \dagger$ & $270.8 \pm 11.3 * * \dagger \dagger$ \\
\hline \multirow{2}{*}{$\begin{array}{l}\text { Sorbitol Dehydrogenase } \\
\text { (IU/L) }\end{array}$} & $0 \mathrm{ppm}$ & $9.4 \pm 0.8 * *$ & $15.3 \pm 1.3 * *$ & $12.7 \pm 1.2^{*}$ & $16.8 \pm 0.9 * *$ \\
\hline & $300 \mathrm{ppm}$ & $9.8 \pm 0.6^{* *}$ & $13.6 \pm 1.3^{*} \dagger$ & $18.3 \pm 3.5^{* \dagger}$ & $17.1 \pm 1.9^{* * \dagger \dagger}$ \\
\hline \multirow[t]{2}{*}{ Bile Salt/Acids $(\mu \mathrm{mol} / \mathrm{L})$} & $0 \mathrm{ppm}$ & $28.4 \pm 4.9$ & $29.6 \pm 4.2$ & $48.2 \pm 10.5$ & $32.6 \pm 4.3$ \\
\hline & $300 \mathrm{ppm}$ & $28.0 \pm 2.0^{*}$ & $44.4 \pm 6.3^{* \dagger}$ & $41.8 \pm 3.6^{* \dagger}$ & $40.6 \pm 4.5^{*}$ \\
\hline
\end{tabular}


Statistical significance for a treatment group indicates a significant pairwise test compared to the respective control group $(0 / 0$ or $300 / 0 \mathrm{ppm}$ ). Statistical significance for the $0 / 0$ or $300 / 0 \mathrm{ppm}$ control group indicates a significant trend test.

$*$ Statistically significant at $\mathrm{p} \leq 0.05 ; * \mathrm{p} \leq 0.01$.

$\dagger$ Statistically significant at $p \leq 0.05$ for pairwise comparisons of $0 / 0$ to $300 / 20,0 / 0$ to $300 / 40$, and $0 / 0$ to $300 / 80$ using a Wilcoxon rank-sum test with a Hommel $p$ value adjustment; $\dagger p \leq 0.01$.

\#Statistically significant at $p \leq 0.05$ for pairwise comparisons of $0 / 0$ to $300 / 0,0 / 20$ to $300 / 20,0 / 40$ to $300 / 40$, and $0 / 80$ to $300 / 80$ using a Wilcoxon rank-sum test with a Hommel $p$ value adjustment.

a Data presented as mean \pm SEM.

'Statistical analysis performed by Jonckheere's (trend) and Shirley's or Dunn's (pairwise) tests (unless otherwise noted).

cNumber of animals examined.

Liver: A spectrum of nonneoplastic hepatocellular lesions morphologically similar to those observed in the male and female 16-week interim evaluation of the first study also occurred in the male 16-week interim of the second study. The incidences of hepatocyte hypertrophy, hepatocyte cytoplasmic alteration, and hepatocyte single cell death were significantly increased in all exposed groups except $300 / 0 \mathrm{ppm}$, compared to the $0 / 0 \mathrm{ppm}$ control group (Table 37 ). The incidences of hepatocyte necrosis in the $0 / 40 \mathrm{ppm}$ group and pigment in the $0 / 40,0 / 80,300 / 40$, and 300/80 ppm groups were significantly increased.

Table 37. Incidences of Nonneoplastic Liver Lesions in Male Rats at the 16-week Interim of the Two-year Feed Study of Perfluorooctanoic Acid (Study 2)

\begin{tabular}{|c|c|c|c|c|c|}
\hline & \multirow[b]{2}{*}{$\begin{array}{l}\text { Perinatal } \\
\text { Exposure }\end{array}$} & \multicolumn{4}{|c|}{ Postweaning Exposure } \\
\hline & & 0 ppm & 20 ppm & 40 ppm & 80 ppm \\
\hline n & & $10^{\mathrm{a}}$ & 10 & 10 & 10 \\
\hline \multirow{2}{*}{$\begin{array}{l}\text { Hepatocyte, Cytoplasmic } \\
\text { Alteration }^{\text {b }}\end{array}$} & 0 ppm & $0 * *$ & $10 * *(1.0)^{\mathrm{c}}$ & $10 * *(1.8)$ & $10 * *(2.0)$ \\
\hline & $300 \mathrm{ppm}$ & $0 * *$ & $9 * *(1.2)$ & $10 * *(1.7)$ & $10 * *(1.9)$ \\
\hline \multirow[t]{2}{*}{ Hepatocyte, Hypertrophy } & 0 ppm & $0 * *$ & $10 * *(1.0)$ & $10 * *(1.0)$ & $10 * *(1.2)$ \\
\hline & $300 \mathrm{ppm}$ & $0 * *$ & $9 * *(1.1)$ & $10 * *(1.1)$ & $10 * *(1.2)$ \\
\hline \multirow[t]{2}{*}{ Hepatocyte, Single Cell Death } & 0 ppm & $0 * *$ & $7 * *(1.0)$ & $9 * *(1.0)$ & $10 * *(1.0)$ \\
\hline & $300 \mathrm{ppm}$ & $0 * *$ & $5 * *(1.0)$ & $8 * *(1.0)$ & $10 * *(1.0)$ \\
\hline \multirow[t]{2}{*}{ Necrosis } & 0 ppm & $1 *(1.0)$ & $1(1.0)$ & $6^{*}(1.0)$ & $4(1.5)$ \\
\hline & 300 ppm & 0 & $2(1.0)$ & $3(1.0)$ & $1(1.0)$ \\
\hline \multirow[t]{2}{*}{ Pigment } & 0 ppm & $0 * *$ & $2(1.0)$ & $8 * *(1.0)$ & $9 * *(1.0)$ \\
\hline & 300 ppm & $0 * *$ & $3(1.0)$ & $7 * *(1.0)$ & $10 * *(1.0)$ \\
\hline
\end{tabular}

Statistical significance for a treatment group indicates a significant pairwise test compared to the respective control group $(0 / 0$ or $300 / 0 \mathrm{ppm})$. Statistical significance for the $0 / 0$ or $300 / 0 \mathrm{ppm}$ control group indicates a significant trend test.

Pairwise comparisons across perinatal exposures ( $0 / 20$ vs. $300 / 20,0 / 40$ vs. $300 / 40$, and $0 / 80$ vs. $300 / 80$ ppm) did not show any statistically significant differences.

*Significantly different $(\mathrm{p} \leq 0.05)$ from the $0 / 0$ or $300 / 0$ ppm control by the Poly- 3 test; **p $\leq 0.01$.

${ }^{a}$ Number of animals with tissue examined microscopically.

${ }^{b}$ Number of animals with lesion.

${ }^{\mathrm{c}}$ Average severity grade of lesions in affected animals: $1=$ minimal, $2=$ mild, $3=$ moderate, $4=$ marked.

\section{Two-year Study in Males (Study 2)}

Survival in treated groups was similar to that of the control groups (Table 38, Table 39; Figure 7). There were no treatment-related clinical observations in any of the exposed groups (Appendix E). 
Table 38. Survival of Male Rats Following Postweaning-only Exposure in the Two-year Feed Study of Perfluorooctanoic Acid (Study 2)

\begin{tabular}{|c|c|c|c|c|}
\hline & 0/0 ppm & 0/20 ppm & 0/40 ppm & 0/80 ppm \\
\hline Animals Initially in Study & 50 & 50 & 50 & 50 \\
\hline Moribund & 7 & 6 & 8 & 3 \\
\hline Natural Deaths & 7 & 2 & 7 & 10 \\
\hline $\begin{array}{l}\text { Animals Surviving to } \\
\text { Study Termination }\end{array}$ & 36 & 42 & $35^{\mathrm{a}}$ & $37^{\mathrm{a}}$ \\
\hline $\begin{array}{l}\text { Percent Probability of } \\
\text { Survival at End of Study }\end{array}$ & 72.0 & 84.0 & 70.0 & 74.0 \\
\hline Mean Survival (days) ${ }^{\mathrm{c}}$ & 683.5 & 721.5 & 675.4 & 668.8 \\
\hline Survival Analysis ${ }^{\mathrm{d}}$ & $\mathrm{p}=0.733$ & $\mathrm{p}=0.160 \mathrm{~N}$ & $\mathrm{p}=0.856$ & $\mathrm{p}=0.882 \mathrm{~N}$ \\
\hline
\end{tabular}

ancludes one animal that died naturally during the last week of the study.

${ }^{b}$ Kaplan-Meier determinations.

${ }^{c}$ Mean of all deaths (uncensored, censored, and study termination).

${ }^{\mathrm{d}}$ The result of the life table trend test (Tarone) is in the $0 / 0 \mathrm{ppm}$ column, and the results of the life table pairwise comparisons (Cox) with the $0 / 0$ ppm control group are in the exposed group columns. A lower mortality in an exposure group is indicated by $\mathrm{N}$.

Table 39. Survival of Male Rats Following Perinatal and Postweaning Exposure in the Two-year Feed Study of Perfluorooctanoic Acid (Study 2)

\begin{tabular}{lcccc}
\hline & $\mathbf{3 0 0 / 0} \mathbf{~ p p m}$ & $\mathbf{3 0 0 / 2 0} \mathbf{~ p p m}$ & $\mathbf{3 0 0} / \mathbf{4 0} \mathbf{~ p p m}$ & $\mathbf{3 0 0 / 8 0} \mathbf{~ p p m}$ \\
\hline Animals Initially in Study & 50 & 50 & 50 & 50 \\
Moribund & 9 & 8 & 6 & 4 \\
Natural Deaths & 6 & 4 & 6 & 7 \\
Animals Surviving to & $35^{\mathrm{a}}$ & 38 & 38 & 39 \\
$\begin{array}{l}\text { Study Termination } \\
\begin{array}{l}\text { Percent Probability of } \\
\text { Survival at End of Study }\end{array}\end{array}$ & 70.0 & 76.0 & 76.0 & 78.0 \\
Mean Survival (days) $^{\mathrm{c}}$ & 692.2 & 700.8 & & \\
Survival Analysis $^{\mathrm{d}}$ & $\mathrm{p}=0.429 \mathrm{~N}$ & $\mathrm{p}=0.507 \mathrm{~N}$ & $\mathrm{p}=0.486 \mathrm{~N}$ & $\mathrm{p}=0.387 \mathrm{~N}$ \\
\hline
\end{tabular}

ancludes one animal that died naturally during the last week of the study.

${ }^{b}$ Kaplan-Meier determinations.

${ }^{\mathrm{c}}$ Mean of all deaths (uncensored, censored, and study termination).

${ }^{\mathrm{d}}$ The result of the life table trend test (Tarone) is in the $0 / 0 \mathrm{ppm}$ column, and the results of the life table pairwise comparisons (Cox) with the $0 / 0 \mathrm{ppm}$ control group are in the exposed group columns. A lower mortality in an exposure group is indicated by $\mathrm{N}$. 


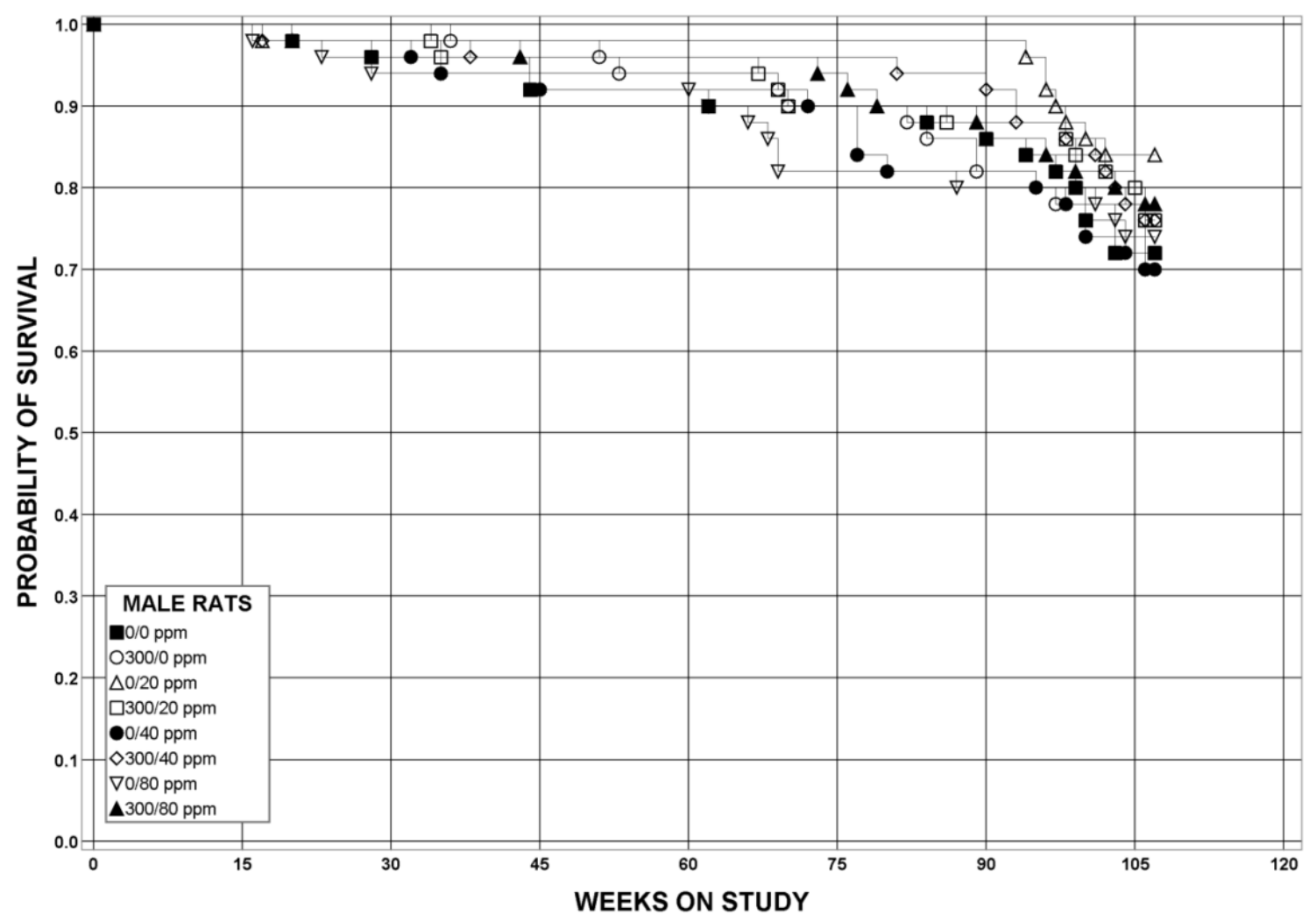

Figure 7. Kaplan-Meier Survival Curves for Male Rats Exposed to Perfluorooctanoic Acid in Feed for Two Years (Study 2)

At study termination, group mean body weights for the $0 / 20,0 / 40,0 / 80,300 / 0,300 / 20$, and $300 / 40$ ppm groups were within $10 \%$ of the $0 / 0 \mathrm{ppm}$ or $300 / 0 \mathrm{ppm}$ control group, respectively (Table 40, Table 41; Figure 8, Figure 9). The terminal mean body weight of the 300/80 ppm group was $13 \%$ less than that of the $0 / 0$ ppm control group. 
Perfluorooctanoic Acid, NTP TR 598

Table 40. Mean Body Weights and Survival of Male Rats Following Postweaning-only Exposure in the Two-year Feed Study of Perfluorooctanoic Acid (Study 2)

\begin{tabular}{|c|c|c|c|c|c|c|c|c|c|c|c|}
\hline \multirow[b]{2}{*}{ Day } & \multicolumn{2}{|c|}{ 0/0 ppm } & \multicolumn{3}{|c|}{ 0/20 ppm } & \multicolumn{3}{|c|}{ 0/40 ppm } & \multicolumn{3}{|c|}{ 0/80 ppm } \\
\hline & $\begin{array}{c}\text { Av. Wt. } \\
\text { (g) }\end{array}$ & $\begin{array}{c}\text { No. of } \\
\text { Litters }\end{array}$ & $\begin{array}{c}\text { Av. Wt. } \\
\text { (g) }\end{array}$ & $\begin{array}{l}\text { Wt. (\% of } \\
\text { Controls) }\end{array}$ & $\begin{array}{l}\text { No. of } \\
\text { Litters }\end{array}$ & $\begin{array}{c}\text { Av. Wt. } \\
\text { (g) }\end{array}$ & $\begin{array}{l}\text { Wt. (\% of } \\
\text { Controls) }\end{array}$ & $\begin{array}{l}\text { No. of } \\
\text { Litters }\end{array}$ & $\begin{array}{c}\text { Av. Wt. } \\
\text { (g) }\end{array}$ & $\begin{array}{l}\text { Wt. (\% of } \\
\text { Controls) }\end{array}$ & $\begin{array}{l}\text { No. of } \\
\text { Litters }\end{array}$ \\
\hline 1 & 51.9 & 25 & 53.6 & 103.3 & 25 & 54.4 & 104.7 & 25 & 53.7 & 103.5 & 25 \\
\hline 8 & 81.6 & 25 & 82.6 & 101.2 & 25 & 84.4 & 103.4 & 25 & 82.7 & 101.3 & 25 \\
\hline 15 & 124.5 & 25 & 123.6 & 99.2 & 25 & 126.7 & 101.7 & 25 & 124.6 & 100.1 & 25 \\
\hline 22 & 170.3 & 25 & 169.9 & 99.8 & 25 & 173.1 & 101.7 & 25 & 170.4 & 100.1 & 25 \\
\hline 29 & 217.1 & 25 & 215.0 & 99.0 & 25 & 214.7 & 98.9 & 25 & 210.2 & 96.8 & 25 \\
\hline 36 & 262.1 & 25 & 255.4 & 97.4 & 25 & 249.6 & 95.2 & 25 & 242.9 & 92.7 & 25 \\
\hline 43 & 296.4 & 25 & 284.2 & 95.9 & 25 & 273.7 & 92.3 & 25 & 266.5 & 89.9 & 25 \\
\hline 50 & 321.2 & 25 & 302.1 & 94.1 & 25 & 289.1 & 90.0 & 25 & 283.6 & 88.3 & 25 \\
\hline 57 & 341.3 & 25 & 316.8 & 92.8 & 25 & 307.7 & 90.2 & 25 & 293.3 & 85.9 & 25 \\
\hline 64 & 356.8 & 25 & 329.7 & 92.4 & 25 & 321.3 & 90.0 & 25 & 307.9 & 86.3 & 25 \\
\hline 71 & 374.3 & 25 & 342.7 & 91.5 & 25 & 332.0 & 88.7 & 25 & 318.8 & 85.2 & 25 \\
\hline 78 & 385.8 & 25 & 354.7 & 91.9 & 25 & 342.1 & 88.7 & 25 & 329.3 & 85.4 & 25 \\
\hline 85 & 395.6 & 25 & 360.0 & 91.0 & 25 & 343.5 & 86.8 & 25 & 337.8 & 85.4 & 25 \\
\hline 120 & 431.7 & 25 & 395.5 & 91.6 & 25 & 377.8 & 87.5 & 25 & 365.1 & 84.6 & 25 \\
\hline 141 & 447.3 & 25 & 408.2 & 91.3 & 25 & 391.0 & 87.4 & 25 & 376.9 & 84.3 & 25 \\
\hline 169 & 463.7 & 25 & 424.5 & 91.6 & 25 & 402.6 & 86.8 & 25 & 384.0 & 82.8 & 25 \\
\hline 197 & 484.5 & 25 & 436.2 & 90.0 & 25 & 414.7 & 85.6 & 25 & 400.7 & 82.7 & 25 \\
\hline 225 & 498.7 & 25 & 455.8 & 91.4 & 25 & 430.8 & 86.4 & 25 & 408.7 & 81.9 & 25 \\
\hline 253 & 508.7 & 25 & 464.6 & 91.3 & 25 & 440.0 & 86.5 & 25 & 419.3 & 82.4 & 25 \\
\hline 281 & 519.7 & 25 & 479.3 & 92.2 & 25 & 448.4 & 86.3 & 25 & 430.4 & 82.8 & 25 \\
\hline 309 & 528.1 & 25 & 490.1 & 92.8 & 25 & 463.0 & 87.7 & 25 & 437.9 & 82.9 & 25 \\
\hline 337 & 536.8 & 25 & 499.5 & 93.1 & 25 & 472.0 & 87.9 & 25 & 443.2 & 82.6 & 25 \\
\hline 365 & 549.0 & 25 & 510.4 & 93.0 & 25 & 481.8 & 87.8 & 25 & 454.8 & 82.8 & 25 \\
\hline 393 & 553.4 & 25 & 515.3 & 93.1 & 25 & 487.0 & 88.0 & 25 & 452.9 & 81.8 & 25 \\
\hline 421 & 555.0 & 25 & 517.0 & 93.2 & 25 & 490.2 & 88.3 & 25 & 459.9 & 82.9 & 25 \\
\hline 449 & 562.5 & 25 & 527.7 & 93.8 & 25 & 507.4 & 90.2 & 25 & 475.0 & 84.4 & 25 \\
\hline 477 & 572.0 & 25 & 542.9 & 94.9 & 25 & 517.7 & 90.5 & 25 & 486.1 & 85.0 & 25 \\
\hline 505 & 581.4 & 25 & 550.4 & 94.7 & 25 & 525.6 & 90.4 & 25 & 493.1 & 84.8 & 25 \\
\hline 533 & 586.5 & 25 & 555.6 & 94.7 & 25 & 528.6 & 90.1 & 25 & 501.4 & 85.5 & 25 \\
\hline 561 & 591.3 & 25 & 564.3 & 95.4 & 25 & 535.7 & 90.6 & 25 & 507.9 & 85.9 & 25 \\
\hline 589 & 591.7 & 25 & 570.1 & 96.3 & 25 & 544.8 & 92.1 & 25 & 515.0 & 87.0 & 25 \\
\hline 617 & 597.6 & 25 & 577.3 & 96.6 & 25 & 550.0 & 92.0 & 25 & 519.4 & 86.9 & 25 \\
\hline 645 & 598.5 & 24 & 577.5 & 96.5 & 25 & 545.6 & 91.2 & 25 & 527.6 & 88.2 & 25 \\
\hline 673 & 594.9 & 23 & 583.0 & 98.0 & 25 & 561.8 & 94.4 & 25 & 532.7 & 89.5 & 25 \\
\hline 701 & 605.6 & 23 & 582.7 & 96.2 & 24 & 565.7 & 93.4 & 24 & 535.5 & 88.4 & 24 \\
\hline 729 & 604.4 & 22 & 587.0 & 97.1 & 24 & 571.1 & 94.5 & 23 & 541.6 & 89.6 & 23 \\
\hline EOS & 598.3 & 22 & 588.1 & 98.3 & 24 & 578.7 & 96.7 & 21 & 541.3 & 90.5 & 23 \\
\hline
\end{tabular}

EOS $=$ end of study. 
Table 41. Mean Body Weights and Survival of Male Rats Following Perinatal and Postweaning Exposure in the Two-year Feed Study of Perfluorooctanoic Acid (Study 2)

\begin{tabular}{|c|c|c|c|c|c|c|c|c|c|c|c|}
\hline \multirow[b]{2}{*}{ Day } & \multicolumn{2}{|c|}{ 300/0 ppm } & \multicolumn{3}{|c|}{$300 / 20$ ppm } & \multicolumn{3}{|c|}{ 300/40 ppm } & \multicolumn{3}{|c|}{ 300/80 ppm } \\
\hline & $\begin{array}{c}\text { Av. Wt. } \\
\text { (g) }\end{array}$ & $\begin{array}{l}\text { No. of } \\
\text { Litters }\end{array}$ & $\begin{array}{c}\text { Av. Wt. } \\
\text { (g) }\end{array}$ & $\begin{array}{l}\text { Wt. (\% of } \\
\text { Controls) }\end{array}$ & $\begin{array}{l}\text { No. of } \\
\text { Litters }\end{array}$ & $\begin{array}{c}\text { Av. Wt. } \\
\text { (g) }\end{array}$ & $\begin{array}{l}\text { Wt. (\% of } \\
\text { Controls) }\end{array}$ & $\begin{array}{l}\text { No. of } \\
\text { Litters }\end{array}$ & $\begin{array}{c}\text { Av. Wt. } \\
\text { (g) }\end{array}$ & $\begin{array}{l}\text { Wt. (\% of } \\
\text { Controls) }\end{array}$ & $\begin{array}{l}\text { No. of } \\
\text { Litters }\end{array}$ \\
\hline 1 & 50.7 & 25 & 51.5 & 101.5 & 25 & 50.0 & 98.7 & 25 & 49.8 & 98.1 & 26 \\
\hline 8 & 80.0 & 25 & 80.7 & 100.8 & 25 & 78.6 & 98.2 & 25 & 76.9 & 96.1 & 26 \\
\hline 15 & 121.9 & 25 & 124.2 & 101.9 & 25 & 121.5 & 99.6 & 25 & 118.2 & 97.0 & 26 \\
\hline 22 & 168.8 & 25 & 172.2 & 102.0 & 25 & 169.4 & 100.4 & 25 & 165.4 & 98.0 & 26 \\
\hline 29 & 214.2 & 25 & 218.2 & 101.9 & 25 & 211.3 & 98.7 & 25 & 206.7 & 96.5 & 26 \\
\hline 36 & 258.1 & 25 & 259.3 & 100.5 & 25 & 249.2 & 96.5 & 25 & 242.5 & 94.0 & 26 \\
\hline 43 & 293.1 & 25 & 287.3 & 98.0 & 25 & 277.4 & 94.6 & 25 & 264.9 & 90.4 & 26 \\
\hline 50 & 318.1 & 25 & 304.6 & 95.7 & 25 & 295.5 & 92.9 & 25 & 284.5 & 89.4 & 26 \\
\hline 57 & 340.2 & 25 & 320.6 & 94.2 & 25 & 308.4 & 90.7 & 25 & 297.9 & 87.6 & 26 \\
\hline 64 & 356.3 & 25 & 335.1 & 94.1 & 25 & 320.4 & 89.9 & 25 & 309.8 & 87.0 & 26 \\
\hline 71 & 370.8 & 25 & 348.7 & 94.0 & 25 & 330.0 & 89.0 & 25 & 320.5 & 86.4 & 26 \\
\hline 78 & 382.0 & 25 & 357.4 & 93.6 & 25 & 342.1 & 89.6 & 25 & 331.3 & 86.7 & 26 \\
\hline 85 & 389.6 & 25 & 366.3 & 94.0 & 25 & 351.7 & 90.3 & 25 & 337.5 & 86.6 & 26 \\
\hline 120 & 428.9 & 25 & 399.3 & 93.1 & 25 & 383.4 & 89.4 & 25 & 364.7 & 85.0 & 26 \\
\hline 141 & 438.5 & 25 & 405.9 & 92.6 & 25 & 390.6 & 89.1 & 25 & 370.1 & 84.4 & 26 \\
\hline 169 & 456.8 & 25 & 429.1 & 93.9 & 25 & 410.4 & 89.9 & 25 & 385.9 & 84.5 & 26 \\
\hline 197 & 478.1 & 25 & 442.4 & 92.5 & 25 & 424.9 & 88.9 & 25 & 397.1 & 83.1 & 26 \\
\hline 225 & 492.1 & 25 & 462.5 & 94.0 & 25 & 442.5 & 89.9 & 25 & 409.8 & 83.3 & 26 \\
\hline 253 & 504.5 & 25 & 474.5 & 94.1 & 25 & 450.6 & 89.3 & 25 & 420.9 & 83.4 & 26 \\
\hline 281 & 518.9 & 25 & 487.9 & 94.0 & 25 & 463.8 & 89.4 & 25 & 428.1 & 82.5 & 26 \\
\hline 309 & 527.9 & 25 & 501.4 & 95.0 & 25 & 477.8 & 90.5 & 25 & 435.8 & 82.6 & 26 \\
\hline 337 & 536.5 & 25 & 507.2 & 94.5 & 25 & 484.1 & 90.2 & 25 & 445.4 & 83.0 & 26 \\
\hline 365 & 540.6 & 25 & 523.4 & 96.8 & 25 & 498.7 & 92.3 & 25 & 454.7 & 84.1 & 26 \\
\hline 393 & 545.1 & 25 & 524.7 & 96.3 & 25 & 502.0 & 92.1 & 25 & 454.0 & 83.3 & 26 \\
\hline 421 & 548.2 & 25 & 528.1 & 96.3 & 25 & 506.6 & 92.4 & 25 & 458.6 & 83.7 & 26 \\
\hline 449 & 558.7 & 25 & 539.7 & 96.6 & 25 & 525.6 & 94.1 & 25 & 470.1 & 84.1 & 26 \\
\hline 477 & 567.7 & 25 & 555.2 & 97.8 & 25 & 531.4 & 93.6 & 25 & 480.0 & 84.6 & 26 \\
\hline 505 & 575.4 & 25 & 563.6 & 97.9 & 25 & 541.7 & 94.1 & 25 & 484.1 & 84.1 & 26 \\
\hline 533 & 576.2 & 25 & 565.1 & 98.1 & 25 & 550.5 & 95.5 & 25 & 493.2 & 85.6 & 26 \\
\hline 561 & 577.2 & 25 & 576.9 & 99.9 & 25 & 560.0 & 97.0 & 25 & 501.2 & 86.8 & 26 \\
\hline 589 & 584.0 & 25 & 582.2 & 99.7 & 25 & 558.6 & 95.7 & 25 & 510.6 & 87.4 & 26 \\
\hline 617 & 588.5 & 25 & 578.0 & 98.2 & 25 & 570.3 & 96.9 & 25 & 517.2 & 87.9 & 25 \\
\hline 645 & 586.5 & 25 & 589.6 & 100.5 & 25 & 572.7 & 97.7 & 25 & 519.2 & 88.5 & 24 \\
\hline 673 & 580.6 & 25 & 599.7 & 103.3 & 25 & 572.7 & 98.6 & 25 & 524.8 & 90.4 & 24 \\
\hline 701 & 583.6 & 25 & 596.4 & 102.2 & 24 & 575.3 & 98.6 & 24 & 523.2 & 89.7 & 24 \\
\hline 729 & 575.6 & 25 & 593.4 & 103.1 & 24 & 575.3 & 99.9 & 24 & 527.6 & 91.7 & 23 \\
\hline EOS & 581.7 & 23 & 586.1 & 100.7 & 24 & 573.2 & 98.5 & 24 & 529.5 & 91.0 & 22 \\
\hline
\end{tabular}

EOS $=$ end of study. 


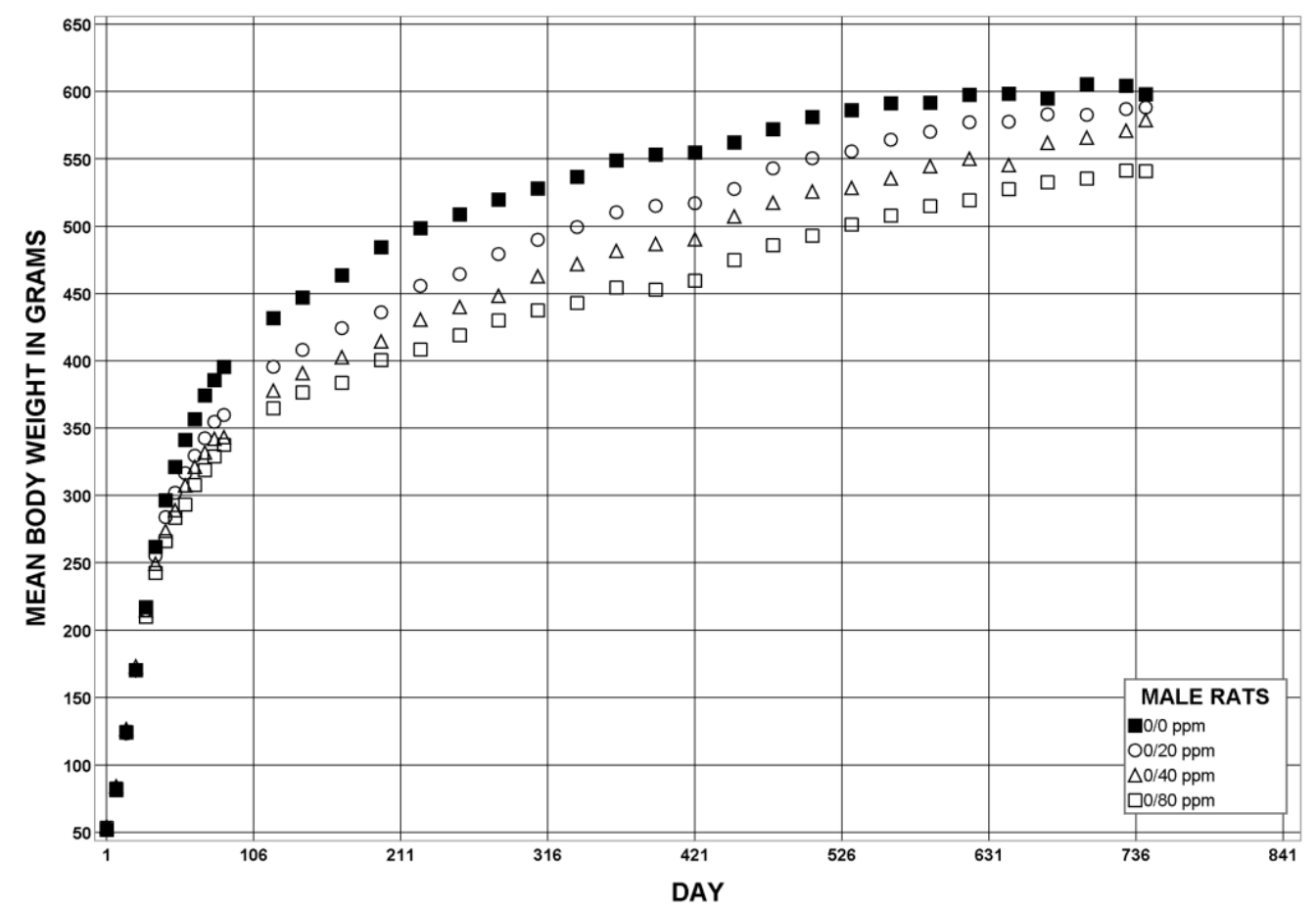

Figure 8. Growth Curves for Male Rats with Postweaning-only Exposure to 0/0, 0/20, 0/40, or 0/80 ppm Perfluorooctanoic Acid in Feed for Two Years (Study 2)

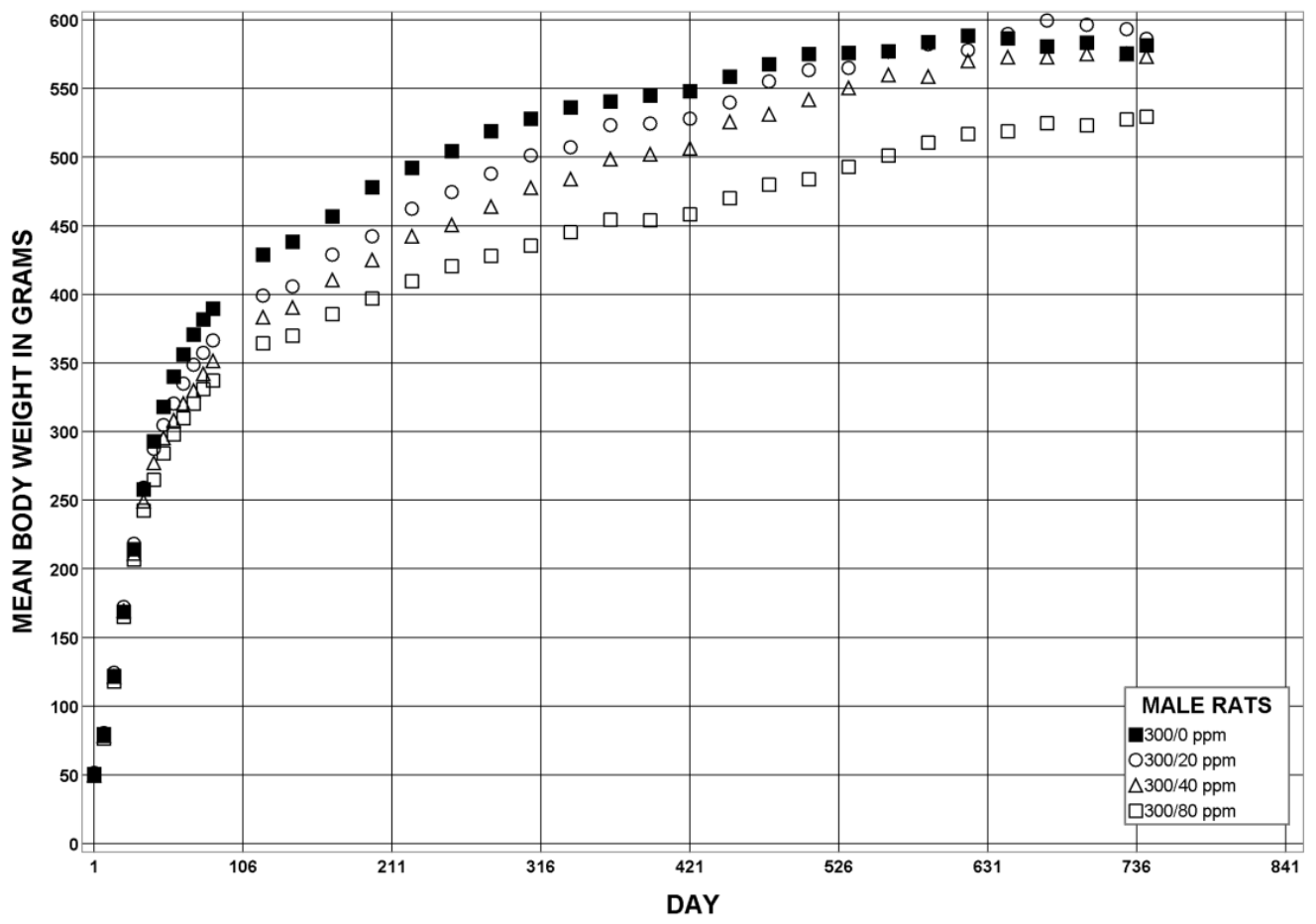

Figure 9. Growth Curves for Male Rats with Perinatal and Postweaning Exposure to 300/0, 300/20, 300/40, or 300/80 ppm Perfluorooctanoic Acid in Feed for Two Years (Study 2) 
Group mean feed consumption by exposed groups was within $10 \%$ of the $0 / 0 \mathrm{ppm}$ control group throughout the study (Appendix E). After weaning, PFOA consumption for rats in the $0 / 20,0 / 40$, and $0 / 80 \mathrm{ppm}$ groups and the $300 / 20,300 / 40$, and $300 / 80 \mathrm{ppm}$ groups averaged $1.1,2.2$, and $4.6 \mathrm{mg} / \mathrm{kg} / \mathrm{day}$ and $1.0,2.1$, and $4.6 \mathrm{mg} / \mathrm{kg} /$ day, respectively.

\section{Pathology and Statistical Analyses}

The morphologic features of the lesions discussed in this section are presented in the Histopathological Descriptions section following the Study 2 results.

Liver: Chronic exposure with and without perinatal exposure resulted in increases in the incidences of hepatocellular neoplasms (Table 42). Significant increases were observed in the incidences of hepatocellular adenoma (including multiple) in the $0 / 40$ and $0 / 80 \mathrm{ppm}$ groups compared to the $0 / 0 \mathrm{ppm}$ control group, and in the $300 / 80 \mathrm{ppm}$ group compared to the $300 / 0 \mathrm{ppm}$ group (Table 42). The incidence of hepatocellular carcinoma was increased in the $300 / 80 \mathrm{ppm}$ group; however, the increase was not statistically significant. Significant increases were observed in the incidences of hepatocellular adenoma or carcinoma (combined) in the $0 / 40,0 / 80$, and 300/80 ppm groups compared to their respective control group.

Chronic exposure with and without perinatal exposure resulted in increases in the incidences of a spectrum of nonneoplastic hepatocellular lesions that in general increased with increasing exposure concentration (Table 42; Appendix E). In general, the spectrum and the histological morphology of these lesions were similar to those that occurred in the female 2-year study.

The incidences of hepatocyte cytoplasmic alteration and hepatocyte hypertrophy were significantly increased in all groups of the chronic study, and in the 300/40 and 300/80 ppm groups of the perinatal and postweaning study. In general, the severity of these lesions tended to be minimum to moderate and were more severe in groups receiving the highest exposure concentrations. Hepatocyte hypertrophy and cytoplasmic alteration generally occurred in the same hepatocytes.

The incidences of hepatocyte single cell death were significantly increased in the $0 / 40$ and $0 / 80 \mathrm{ppm}$ groups compared to the $0 / 0 \mathrm{ppm}$ control group and in the $300 / 80 \mathrm{ppm}$ group compared to the $300 / 0 \mathrm{ppm}$ group (Table 42 ). The incidences of hepatocyte necrosis were significantly increased in all postweaning exposed groups compared to their respective controls (Table 42). The incidences of pigment were significantly increased in all exposure groups of the chronic study and in the 300/40 and 300/80 ppm groups of the perinatal and postweaning exposure study (Table 42).

Compared to the $0 / 0 \mathrm{ppm}$ control group, the incidences of mixed-cell foci of cellular alteration were increased in the $0 / 40$ and $0 / 80 \mathrm{ppm}$ groups of the postweaning exposure study and in the $300 / 80 \mathrm{ppm}$ group of the perinatal and postweaning exposure study (Table 42).

The incidences of focal inflammation were significantly increased in the $0 / 80$ and $300 / 80 \mathrm{ppm}$ groups compared to their respective controls (Table 42).

The incidences of cystic degeneration were significantly increased in the 300/80 ppm group of the perinatal and postweaning exposure study compared to the $300 / 0 \mathrm{ppm}$ control (Table 42). The incidences of bile duct hyperplasia were significantly less than those of the $0 / 0$ or $300 / 0 \mathrm{ppm}$ control group in all postweaning exposed groups (20, 40, and $80 \mathrm{ppm}$ ) (Table 42). 
Table 42. Incidences of Select Neoplastic and Nonneoplastic Liver Lesions in Male Rats in the Two-year Feed Study of Perfluorooctanoic Acid (Study 2)

\begin{tabular}{|c|c|c|c|c|c|}
\hline & \multirow[b]{2}{*}{$\begin{array}{l}\text { Perinatal } \\
\text { Exposure }\end{array}$} & \multicolumn{4}{|c|}{ Postweaning Exposure } \\
\hline & & O ppm & 20 ppm & $40 \mathrm{ppm}$ & 80 ppm \\
\hline $\mathbf{n}$ & & $50^{\mathrm{a}}$ & 50 & 50 & 50 \\
\hline \multirow[t]{2}{*}{ Hepatocyte, Cytoplasmic Alteration ${ }^{\mathrm{b}}$} & $0 \mathrm{ppm}$ & $0^{* *}$ & $12 * *(1.5)$ & $34 * *(1.6)$ & $46^{* *}(1.8)$ \\
\hline & $300 \mathrm{ppm}$ & $0 * *$ & $4(1.0)$ & $29 * *(1.4)$ & $41 * *(1.7)$ \\
\hline \multirow[t]{2}{*}{ Hepatocyte, Hypertrophy } & $0 \mathrm{ppm}$ & $0 * *$ & $13^{* *}(1.2)$ & $34 * *(1.2)$ & $43^{* *}(1.6)$ \\
\hline & $300 \mathrm{ppm}$ & $1^{* *}(4.0)^{\mathrm{c}}$ & $4(1.0)$ & $29 * *(1.4)$ & $42 * *(1.5)$ \\
\hline \multirow[t]{2}{*}{ Hepatocyte, Single Cell Death } & $0 \mathrm{ppm}$ & $1 * *(1.0)$ & $1(1.0)$ & $11 *(1.7)$ & $24 * *(1.3)$ \\
\hline & $300 \mathrm{ppm}$ & $1 * *(4.0)$ & $3(2.7)$ & $5(1.6)$ & $29 * *(1.3)$ \\
\hline \multirow[t]{2}{*}{ Necrosis } & $0 \mathrm{ppm}$ & $2 * *(1.5)$ & $17 * *(1.2)$ & $23^{* *}(1.4)$ & $20 * *(1.3)$ \\
\hline & $300 \mathrm{ppm}$ & $1 * *(1.0)$ & $11 * *(1.2)$ & $14 * *(1.1)$ & $21 * *(1.3)$ \\
\hline \multirow[t]{2}{*}{ Pigment } & $0 \mathrm{ppm}$ & $0 * *$ & $7 *(1.4)$ & $15^{* *}(1.1)$ & $30 * *(2.0)$ \\
\hline & $300 \mathrm{ppm}$ & $0^{* *}$ & $4(1.3)$ & $11 * *(1.4)$ & $26^{* *}(1.4)$ \\
\hline \multirow[t]{2}{*}{ Mixed-cell Focus } & $0 \mathrm{ppm}$ & $0^{*}$ & 4 & $9 * *$ & $6^{*}$ \\
\hline & $300 \mathrm{ppm}$ & $0^{* *}$ & 4 & 4 & $9 *$ \\
\hline \multirow[t]{2}{*}{ Eosinophilic Focus } & $0 \mathrm{ppm}$ & 3 & 6 & 5 & 9 \\
\hline & 300 ppm & 2 & 5 & 1 & 7 \\
\hline \multirow[t]{2}{*}{ Inflammation, Focal } & $0 \mathrm{ppm}$ & $15^{*}(1.0)$ & $19(1.0)$ & $18(1.1)$ & $24 *(1.0)$ \\
\hline & 300 ppm & $13 * *(1.0)$ & $11(1.0)$ & $19(1.1)$ & $24 *(1.0)$ \\
\hline \multirow[t]{2}{*}{ Degeneration, Cystic } & $0 \mathrm{ppm}$ & $2 *(1.0)$ & $5(1.2)$ & $7(1.0)$ & $8(1.1)$ \\
\hline & $300 \mathrm{ppm}$ & $0 * *$ & $3(1.0)$ & $3(1.0)$ & $11 * *(1.3)$ \\
\hline \multirow[t]{2}{*}{ Bile Duct, Hyperplasia } & $0 \mathrm{ppm}$ & $24 * *(1.1)$ & $3 * *(1.0)$ & $3 * *(1.0)$ & $1 * *(1.0)$ \\
\hline & 300 ppm & $25^{* *}(1.2)$ & $8 * *(1.0)$ & $2 * *(1.0)$ & $5 * *(1.0)$ \\
\hline \multirow[t]{2}{*}{ Hepatocellular Adenoma, Multiple } & $0 \mathrm{ppm}$ & 0 & 0 & 3 & 3 \\
\hline & 300 ppm & 0 & 0 & 0 & 5 \\
\hline \multicolumn{6}{|c|}{ Hepatocellular Adenoma (includes Multiple) ${ }^{\mathrm{d}}$} \\
\hline Overall Rate & $0 \mathrm{ppm}$ & $0 / 50(0 \%)$ & $0 / 50(0 \%)$ & $7 / 50(14 \%)$ & $11 / 50(22 \%)$ \\
\hline Litters Rate ${ }^{f}$ & & $0 / 25(0 \%)$ & $0 / 25(0 \%)$ & $6 / 25(24 \%)$ & $8 / 25(32 \%)$ \\
\hline Rao-Scott Adjusted Poly-3 Test ${ }^{\mathrm{g}}$ & & $\mathrm{p}<0.001$ & (e) & $\mathrm{p}=0.050$ & $\mathrm{p}=0.010$ \\
\hline Overall Rate & 300 ppm & $0 / 50(0 \%)$ & $1 / 50(2 \%)$ & $5 / 50(10 \%)$ & $10 / 50(20 \%)$ \\
\hline Litters Rate & & $0 / 25(0 \%)$ & $1 / 25(4 \%)$ & $5 / 25(20 \%)$ & $9 / 26(35 \%)$ \\
\hline Rao-Scott Adjusted Poly-3 Test & & $\mathrm{p}<0.001$ & $\mathrm{p}=0.564$ & $\mathrm{p}=0.070$ & $p=0.006$ \\
\hline
\end{tabular}




\begin{tabular}{|c|c|c|c|c|c|}
\hline & \multirow[b]{2}{*}{$\begin{array}{l}\text { Perinatal } \\
\text { Exposure }\end{array}$} & \multicolumn{4}{|c|}{ Postweaning Exposure } \\
\hline & & 0 ppm & $20 \mathrm{ppm}$ & 40 ppm & 80 ppm \\
\hline \multicolumn{6}{|l|}{ Hepatocellular Carcinoma $^{\mathrm{h}}$} \\
\hline $\begin{array}{l}\text { Overall Rate } \\
\text { Litters Rate } \\
\text { Rao-Scott Adiusted Poly-3 Test }\end{array}$ & $0 \mathrm{ppm}$ & $\begin{array}{l}0 / 50 \\
0 / 25 \\
i\end{array}$ & $\begin{array}{l}0 / 50 \\
0 / 25\end{array}$ & $\begin{array}{l}0 / 50 \\
0 / 25\end{array}$ & $\begin{array}{l}0 / 50 \\
0 / 25\end{array}$ \\
\hline $\begin{array}{l}\text { Overall Rate } \\
\text { Litters Rate } \\
\text { Rao-Scott Adjusted Poly-3 Test) }\end{array}$ & $300 \mathrm{ppm}$ & $\begin{array}{c}- \\
0 / 50(0 \%) \\
0 / 25(0 \%) \\
p=0.049\end{array}$ & $\begin{array}{c}- \\
0 / 50(0 \%) \\
0 / 25(0 \%) \\
\text { (e) }\end{array}$ & $\begin{array}{c}- \\
0 / 50(0 \%) \\
0 / 25(0 \%) \\
\text { (e) }\end{array}$ & $\begin{array}{c}- \\
4 / 50(8 \%) \\
3 / 26(12 \%) \\
p=0.236\end{array}$ \\
\hline \multicolumn{6}{|c|}{ Hepatocellular Adenoma or Carcinoma (Combined) $)^{j}$} \\
\hline $\begin{array}{l}\text { Overall Rate } \\
\text { Litters Rate } \\
\text { Rao-Scott Adjusted Poly-3 Test }\end{array}$ & $0 \mathrm{ppm}$ & $\begin{array}{l}0 / 50(0 \%) \\
0 / 25(0 \%) \\
\mathrm{p}<0.001\end{array}$ & $\begin{array}{l}0 / 50(0 \%) \\
0 / 25(0 \%) \\
\quad(\mathrm{e})\end{array}$ & $\begin{array}{c}7 / 50(14 \%) \\
6 / 25(24 \%) \\
p=0.050\end{array}$ & $\begin{array}{c}11 / 50(22 \%) \\
8 / 25(32 \%) \\
p=0.010\end{array}$ \\
\hline $\begin{array}{l}\text { Overall Rate } \\
\text { Litters Rate } \\
\text { Rao-Scott Adjusted Poly-3 Test }\end{array}$ & 300 ppm & $\begin{array}{l}0 / 50(0 \%) \\
0 / 25(0 \%) \\
p<0.001\end{array}$ & $\begin{array}{l}1 / 50(2 \%) \\
1 / 25(4 \%) \\
p=0.579\end{array}$ & $\begin{array}{l}5 / 50(10 \%) \\
5 / 25(20 \%) \\
p=0.077\end{array}$ & $\begin{array}{c}12 / 50(24 \%) \\
10 / 26(38 \%) \\
p=0.003\end{array}$ \\
\hline
\end{tabular}

Statistical significance for a treatment group indicates a significant pairwise test compared to the respective control group ( $0 / 0$ or $300 / 0 \mathrm{ppm})$. Statistical significance for the $0 / 0$ or $300 / 0 \mathrm{ppm}$ control group indicates a significant trend test.

*Significantly different $(\mathrm{p} \leq 0.05)$ from the $0 / 0$ or $300 / 0 \mathrm{ppm}$ control by the Rao-Scott test; **p $\leq 0.01$.

(e) = value of statistic could not be computed.

aNumber of animals with tissue examined microscopically.

${ }^{b}$ Number of animals with lesion.

${ }^{\mathrm{c}}$ Average severity grade of lesions in affected animals: $1=$ minimal, $2=$ mild, $3=$ moderate, $4=$ marked.

${ }^{\mathrm{d}}$ Historical control incidence for all routes of 2-year studies (mean \pm standard deviation): $2 / 340(0.67 \% \pm 1.03 \%)$; range: $0 \%$ to $2 \%$.

${ }^{\mathrm{e}}$ Number of animals with neoplasm per number of animals necropsied.

fNumber of litters with animals with neoplasm per number of litters necropsied.

gBeneath the control incidence is the $p$ value associated with the trend test. Beneath the exposed group incidence are the $p$ values corresponding to pairwise comparisons between the respective control and that exposed group. The Rao-Scott test adjusts the Poly-3 test for within-litter correlation. A negative trend or a lower incidence in an exposure group is indicated by $\mathrm{N}$.

hHistorical control incidence: $0 / 340$.

iNot applicable; no neoplasms in group.

${ }^{\mathrm{j} H i s t o r i c a l ~ c o n t r o l ~ i n c i d e n c e: ~} 2 / 340(0.67 \% \pm 1.03 \%)$; range: $0 \%$ to $2 \%$.

Pancreas: Chronic exposure with and without perinatal exposure resulted in increased incidences of pancreatic acinar cell neoplasms (Table 43). The incidences of acinar cell adenoma including multiple adenomas were significantly increased in all exposed groups. The incidences of acinar cell adenocarcinomas were increased in all groups; however, the increases were not statistically significant. The incidences of acinar cell adenoma or adenocarcinoma (combined) in all exposed groups of the postweaning studies with and without perinatal exposure were significantly greater than those of the respective control groups. No differences between groups with perinatal and without perinatal exposures were observed.

The incidences of acinus hyperplasia were also significantly increased in all postweaning-only exposure groups of the chronic study (Table 43), and in the 300/40 and 300/80 ppm groups of the perinatal and postweaning study, and this lesion is considered a potentially preneoplastic lesion. No differences between groups with perinatal and without perinatal exposures were observed. 
Table 43. Incidences of Select Neoplastic and Nonneoplastic Pancreas Lesions in Male Rats in the Two-year Feed Study of Perfluorooctanoic Acid (Study 2)

\begin{tabular}{|c|c|c|c|c|c|}
\hline & \multirow[b]{2}{*}{$\begin{array}{l}\text { Perinatal } \\
\text { Exposure }\end{array}$} & \multicolumn{4}{|c|}{ Postweaning Exposure } \\
\hline & & O ppm & $20 \mathrm{ppm}$ & 40 ppm & 80 ppm \\
\hline n & & $50^{\mathrm{a}}$ & 50 & 50 & 50 \\
\hline \multirow[t]{2}{*}{ Acinus, Hyperplasia ${ }^{\mathrm{b}}$} & $0 \mathrm{ppm}$ & $18^{* *}(2.7)$ & $32 *(3.7)$ & $37 * *(3.2)$ & $31 * *(3.2)$ \\
\hline & $300 \mathrm{ppm}$ & $23 *(2.7)$ & $27(3.2)$ & $38 * *(3.3)$ & $33(3.4)$ \\
\hline \multirow[t]{2}{*}{ Acinar Cell Adenoma, Multiple } & $0 \mathrm{ppm}$ & 2 & 20 & 22 & 26 \\
\hline & $300 \mathrm{ppm}$ & 4 & 18 & 22 & 27 \\
\hline \multicolumn{6}{|c|}{ Acinar Cell Adenoma (includes multiple) ${ }^{\mathrm{d}}$} \\
\hline $\begin{array}{l}\text { Overall Rate } \\
\text { Litters Rate } \\
\text { Rao-Scott Adjusted Poly-3 Test }{ }^{\mathrm{g}}\end{array}$ & $0 \mathrm{ppm}$ & $\begin{array}{l}3 / 50(6 \%) \\
3 / 25(12 \%) \\
\mathrm{p}<0.001\end{array}$ & $\begin{array}{c}28 / 50(56 \%) \\
21 / 25(84 \%) \\
p<0.001\end{array}$ & $\begin{array}{c}26 / 50(52 \%) \\
20 / 25(80 \%) \\
p<0.001\end{array}$ & $\begin{array}{c}32 / 50(64 \%) \\
22 / 25(88 \%) \\
\mathrm{p}<0.001\end{array}$ \\
\hline $\begin{array}{l}\text { Overall Rate } \\
\text { Litters Rate } \\
\text { Rao-Scott Adjusted Poly-3 Test }\end{array}$ & $300 \mathrm{ppm}$ & $\begin{array}{l}7 / 50(14 \%) \\
6 / 25(24 \%) \\
p<0.001\end{array}$ & $\begin{array}{l}18 / 50(36 \%) \\
12 / 25(48 \%) \\
p=0.016\end{array}$ & $\begin{array}{l}30 / 50(60 \%) \\
21 / 25(84 \%) \\
\mathrm{p}<0.001\end{array}$ & $\begin{array}{c}30 / 50(60 \%) \\
21 / 26(81 \%) \\
p<0.001\end{array}$ \\
\hline \multicolumn{6}{|c|}{ Acinar Cell Adenocarcinoma (includes multiple) ${ }^{\mathrm{h}}$} \\
\hline $\begin{array}{l}\text { Overall Rate } \\
\text { Litters Rate } \\
\text { Rao-Scott Adjusted Poly-3 Test }\end{array}$ & $0 \mathrm{ppm}$ & $\begin{array}{l}0 / 50(0 \%) \\
0 / 25(0 \%) \\
p=0.179\end{array}$ & $\begin{array}{c}3 / 50(6 \%) \\
3 / 25(12 \%) \\
p=0.188\end{array}$ & $\begin{array}{l}1 / 50(2 \%) \\
1 / 25(4 \%) \\
p=0.527\end{array}$ & $\begin{array}{c}3 / 50(6 \%) \\
3 / 25(12 \%) \\
p=0.154\end{array}$ \\
\hline $\begin{array}{l}\text { Overall Rate } \\
\text { Litters Rate } \\
\text { Rao-Scott Adjusted Poly-3 Test }\end{array}$ & $300 \mathrm{ppm}$ & $\begin{array}{l}0 / 50(0 \%) \\
0 / 25(0 \%) \\
p=0.144\end{array}$ & $\begin{array}{l}2 / 50(4 \%) \\
2 / 25(8 \%) \\
p=0.299\end{array}$ & $\begin{array}{l}1 / 50(2 \%) \\
1 / 25(4 \%) \\
p=0.559\end{array}$ & $\begin{array}{c}3 / 50(6 \%) \\
3 / 26(12 \%) \\
p=0.172\end{array}$ \\
\hline \multicolumn{6}{|c|}{ Acinar Cell Adenoma or Adenocarcinoma (Combined) ${ }^{\mathrm{i}}$} \\
\hline $\begin{array}{l}\text { Overall Rate } \\
\text { Litters Rate } \\
\text { Rao-Scott Adjusted Poly-3 Test }\end{array}$ & $0 \mathrm{ppm}$ & $\begin{array}{l}3 / 50(6 \%) \\
3 / 25(12 \%) \\
p<0.001\end{array}$ & $\begin{array}{l}29 / 50(58 \%) \\
21 / 25(84 \%) \\
p<0.001\end{array}$ & $\begin{array}{c}26 / 50(52 \%) \\
20 / 25(80 \%) \\
\mathrm{p}<0.001\end{array}$ & $\begin{array}{c}32 / 50(64 \%) \\
22 / 25(88 \%) \\
\mathrm{p}<0.001\end{array}$ \\
\hline $\begin{array}{l}\text { Overall Rate } \\
\text { Litters Rate } \\
\text { Rao-Scott Adjusted Poly-3 Test }\end{array}$ & $300 \mathrm{ppm}$ & $\begin{array}{l}7 / 50(14 \%) \\
6 / 25(24 \%) \\
p<0.001\end{array}$ & $\begin{array}{c}20 / 50(40 \%) \\
13 / 25(52 \%) \\
p=0.006\end{array}$ & $\begin{array}{l}30 / 50(60 \%) \\
21 / 25(84 \%) \\
p<0.001\end{array}$ & $\begin{array}{c}30 / 50(60 \%) \\
21 / 26(81 \%) \\
p<0.001\end{array}$ \\
\hline
\end{tabular}

Statistical significance for a treatment group indicates a significant pairwise test compared to the respective control group $(0 / 0$ or $300 / 0 \mathrm{ppm})$. Statistical significance for the $0 / 0$ or $300 / 0 \mathrm{ppm}$ control group indicates a significant trend test.

*Significantly different $(\mathrm{p} \leq 0.05)$ from the $0 / 0$ or $300 / 0 \mathrm{ppm}$ control by the Rao-Scott test; **p $\leq 0.01$.

${ }^{a}$ Number of animals with tissue examined microscopically.

${ }^{b}$ Number of animals with lesion.

${ }^{\mathrm{c} A v e r a g e ~ s e v e r i t y ~ g r a d e ~ o f ~ l e s i o n s ~ i n ~ a f f e c t e d ~ a n i m a l s: ~} 1=$ minimal, $2=$ mild, $3=$ moderate, $4=$ marked.

${ }^{\mathrm{d}}$ Historical control incidence for all routes of 2-year studies (mean \pm standard deviation): 45/340 (12.33\% $\left.\pm 10.07 \%\right)$; range: $0 \%$ to $28 \%$.

${ }^{\text {e}}$ Number of animals with neoplasm per number of animals necropsied.

fNumber of litters with animals with neoplasm per number of litters necropsied.

gBeneath the control incidence is the $p$ value associated with the trend test. Beneath the exposed group incidence are the $\mathrm{p}$ values corresponding to pairwise comparisons between the respective control and that exposed group. The Rao-Scott test adjusts the Poly-3 test (which accounts for differential mortality in animals that do not reach terminal euthanasia) for within-litter correlation. A negative trend or a lower incidence in an exposure group is indicated by $\mathrm{N}$.

hHistorical control incidence: $2 / 340(0.52 \% \pm 0.85 \%)$; range: $0 \%$ to $2 \%$.

${ }^{i}$ Historical control incidence: $45 / 340(12.33 \% \pm 10.07 \%)$; range: $0 \%$ to $28 \%$. 


\section{Histopathological Descriptions}

In general, the histopathological changes-when present in the liver, pancreas, uterus, kidney, stomach, forestomach, and thyroid gland — were morphologically similar across males and females in the first and second studies.

\section{Liver}

Hepatocellular adenomas were generally discrete, irregularly nodular masses that, at their margins, completely or partially compressed the surrounding normal hepatic parenchyma (Figure 10A). Adenomas were characterized by irregular cords of large, amphophilic to basophilic hepatocytes positioned tangentially to the surrounding normal hepatic parenchyma (Figure 10B). Portal areas were generally not present within adenomas.

A)

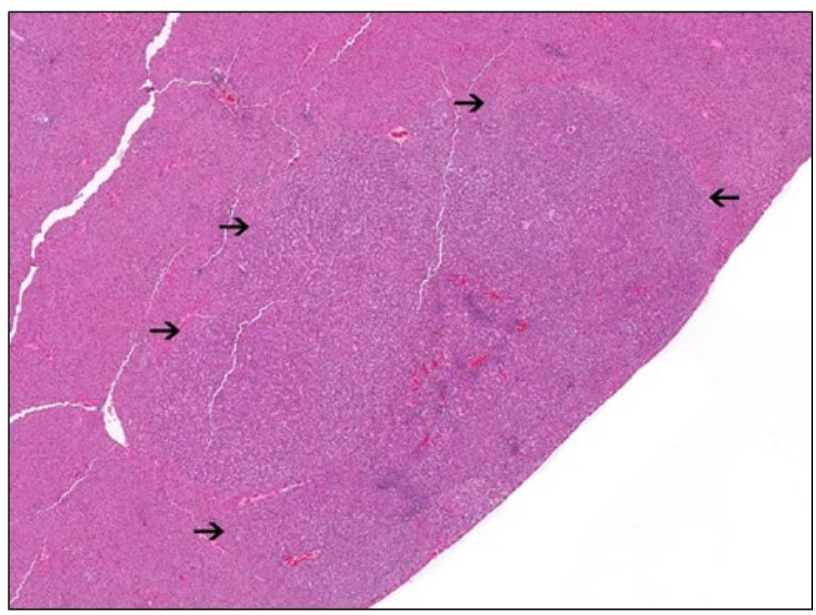

B)

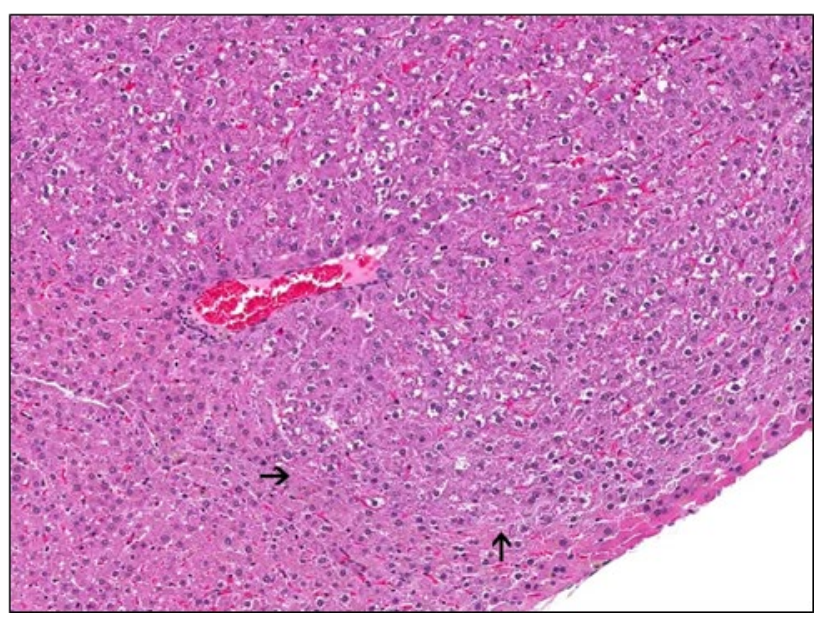

Figure 10. Hepatocellular Adenoma in a Male Sprague Dawley Rat Exposed to Perfluorooctanoic Acid in Feed for Two Years (Study 2)

A) The adenoma occurs as a discrete, irregularly nodular mass within the hepatic parenchyma (arrows). B) Higher magnification of panel A. The adenoma is characterized by irregular cords of amphophilic to basophilic hepatocytes positioned tangentially to the surrounding normal hepatic parenchyma. Note the partial compression of the adjacent hepatocytes at the margins (arrows). 
Hepatocellular carcinomas were large, irregularly nodular, invasive masses that in some cases lacked distinct borders (Figure 11A). The neoplastic hepatocytes were pleomorphic and generally arranged in irregular clusters and islands. However, in focal areas they formed irregular trabeculae or cords that varied from two to six cells thick; in these areas, the hepatic sinusoids were dilated (Figure 11B). Such patterns are hallmarks of hepatocellular carcinomas.

A)

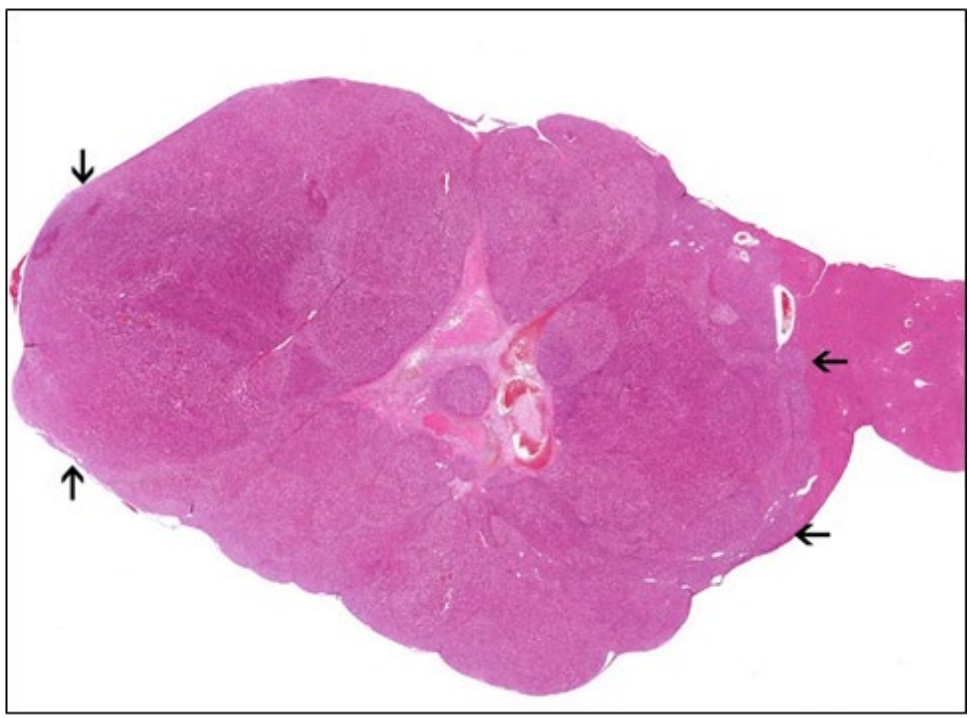

B)

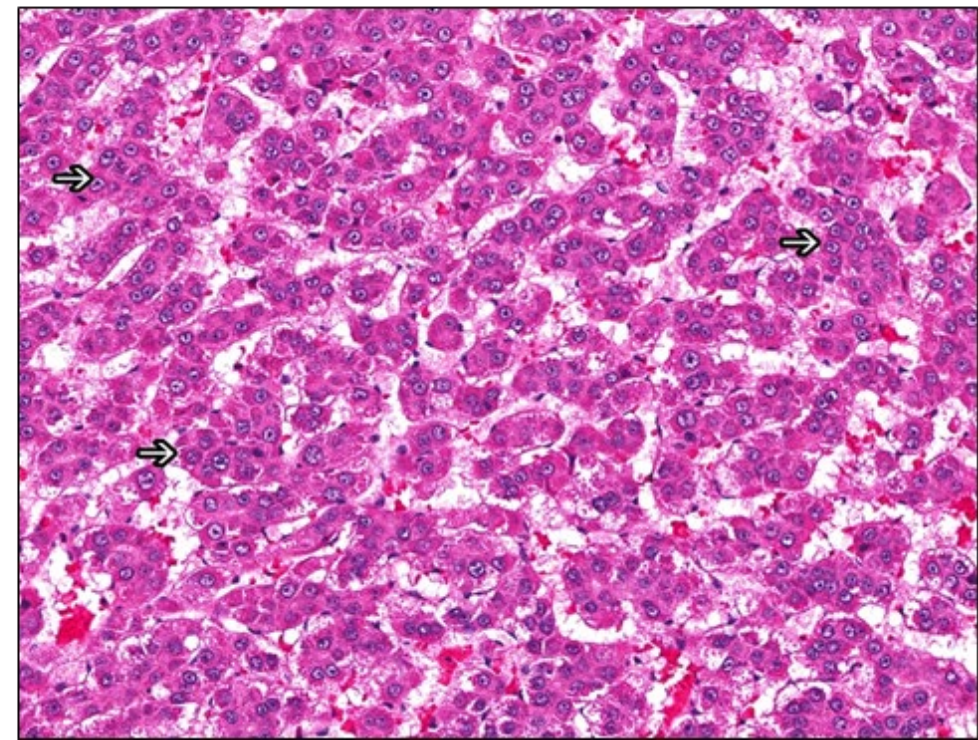

Figure 11. Hepatocellular Carcinoma in a Female Sprague Dawley Rat Exposed to Perfluorooctanoic Acid in Feed for Two Years (Study 1)

A) The carcinoma occurs as a large, irregularly discrete, pleomorphic, invasive mass that has effaced the hepatic parenchyma (arrows). B) Higher magnification of panel A. The neoplastic hepatocytes are pleomorphic and arranged in irregular clusters and islands with focal areas where they formed irregular trabeculae or cords that varied from two to six cells thick (arrows). 
In the male 2-year study, some adenomas (Figure 12) and carcinomas (Figure 13) were largely composed of neoplastic hepatocytes that contained prominent cytoplasmic microvesicular and macrovesicular cytoplasmic vacuoles.

A)

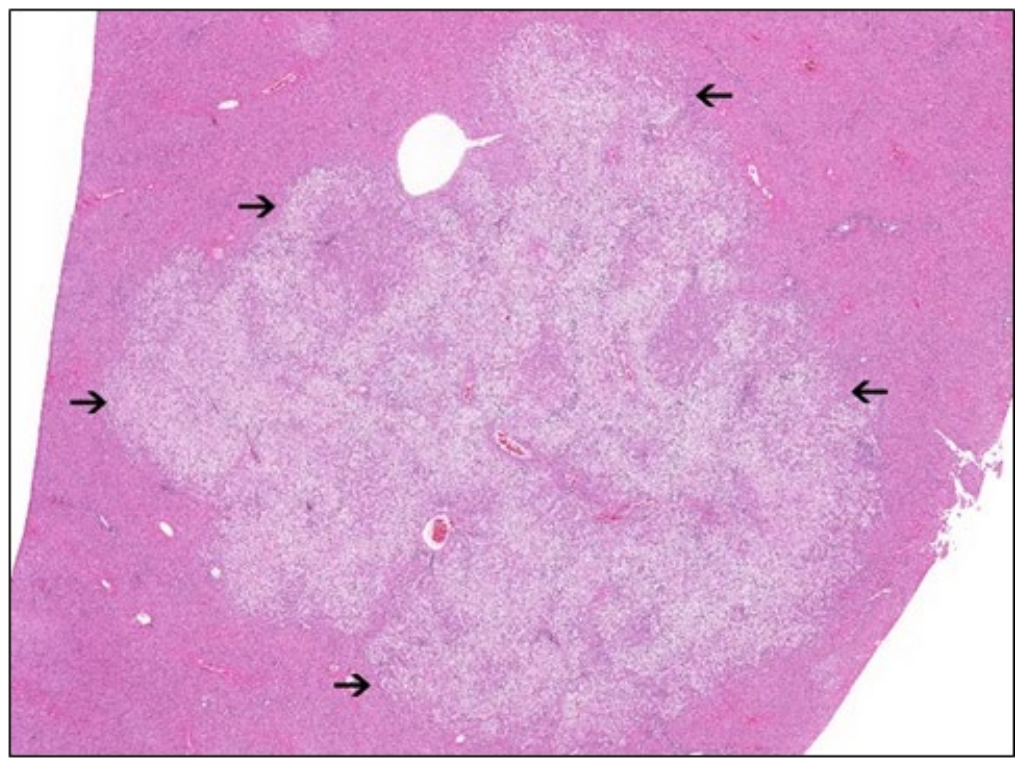

B)

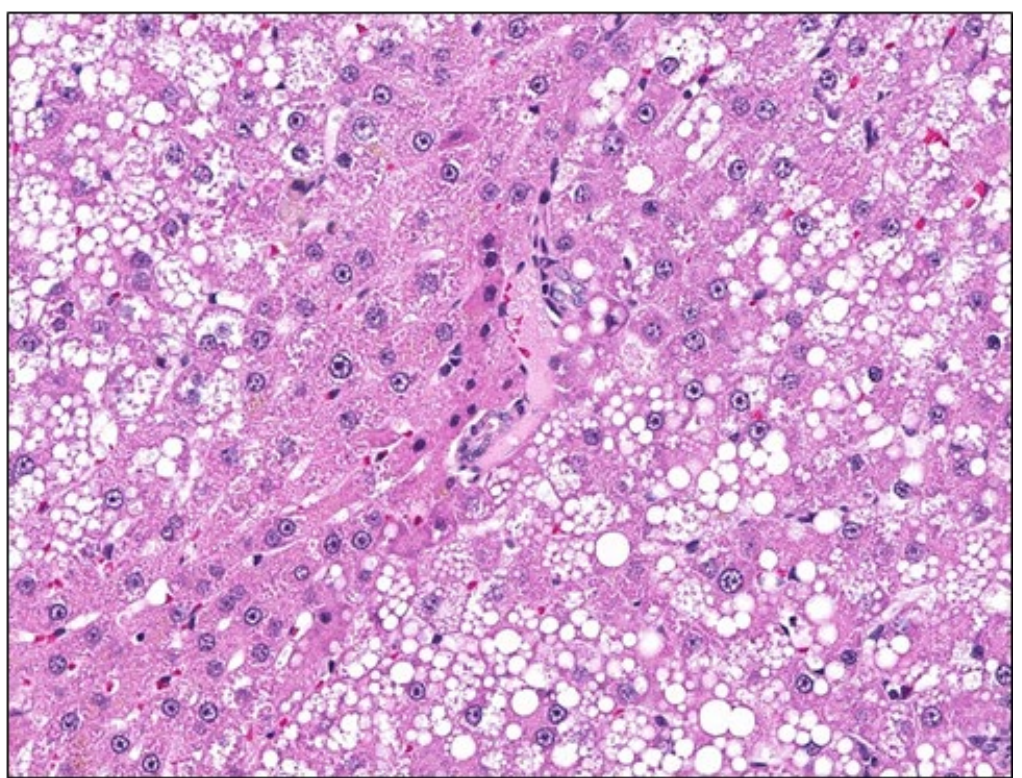

Figure 12. Hepatocellular Adenoma in a Male Sprague Dawley Rat Exposed to Perfluorooctanoic Acid in Feed for Two Years (Study 2)

A) The adenoma occurs as a discrete, irregularly nodular, vacuolated mass within the hepatic parenchyma. B) Higher magnification of panel A. The adenoma is composed of neoplastic hepatocytes that contain prominent cytoplasmic microvesicular and macrovesicular cytoplasmic vacuoles. 


\section{A)}

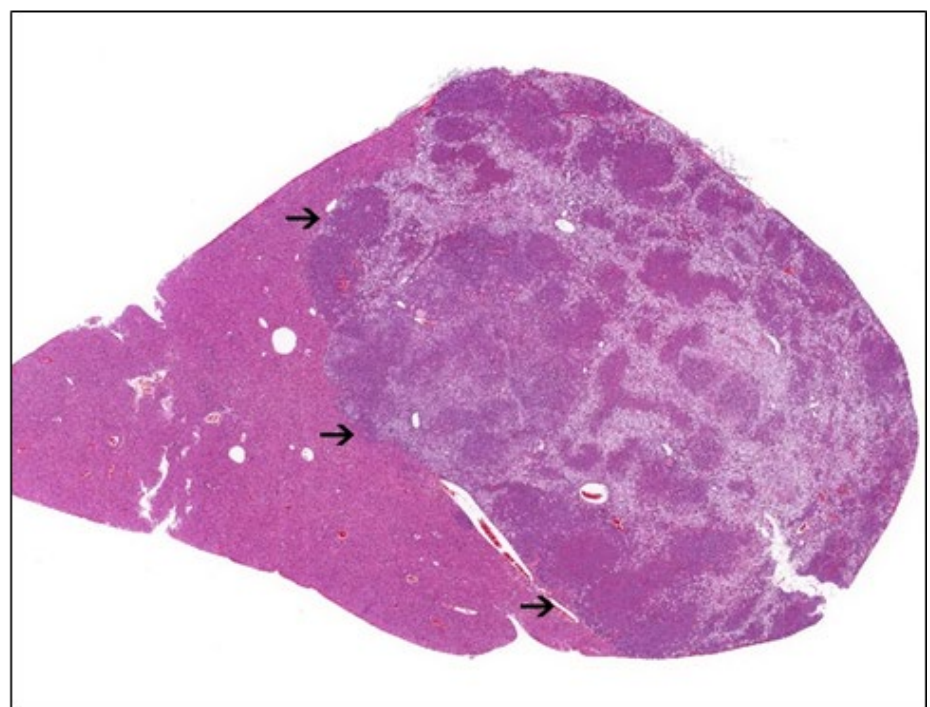

B)

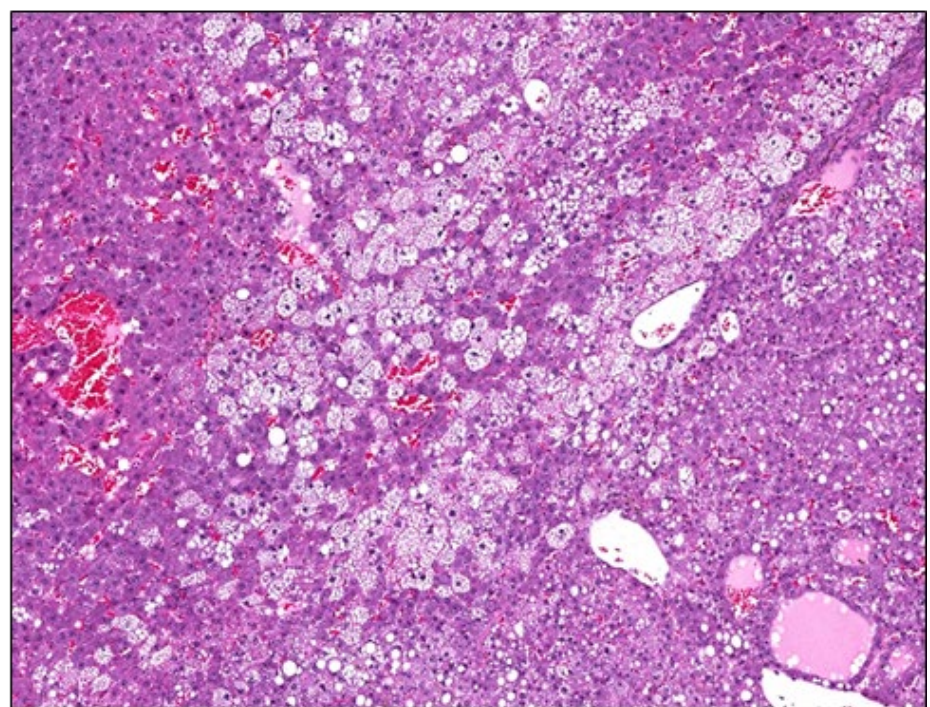

Figure 13. Hepatocellular Carcinoma in a Male Sprague Dawley Rat Exposed to Perfluorooctanoic Acid in Feed for Two Years (Study 2)

A) The carcinoma occurs as a large, irregularly nodular, pleomorphic, invasive mass that has effaced the hepatic parenchyma (arrows). B) Higher magnification of panel A. Similar to the adenoma in Figure 12, the carcinoma is composed largely of neoplastic hepatocytes that contain prominent cytoplasmic microvesicular and macrovesicular cytoplasmic vacuoles.

Mixed-cell foci were focal proliferations of hepatocytes that tended to blend with the surrounding normal hepatic parenchyma at their margins (Figure 14A). They were composed of a mixture of eosinophilic to amphophilic hepatocytes mixed with hepatocytes that contained prominent cytoplasmic microvesicular and macrovesicular cytoplasmic vacuoles similar to those that occurred in hepatocellular adenomas (Figure 14B). At times, the distinction between hepatocellular adenoma and mixed-cell focus was not clear-cut and could only be based on lack of compression of the surrounding hepatic parenchyma along the margins of mixed-cell foci. Mixed-cell foci are considered potentially preneoplastic. 


\section{A)}

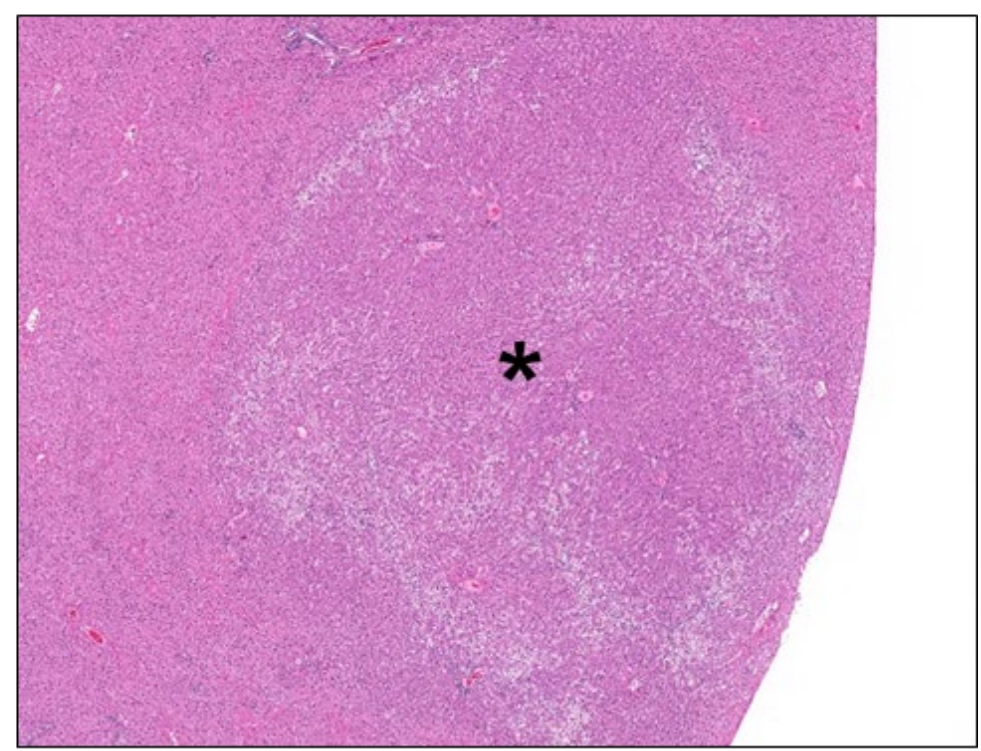

B)

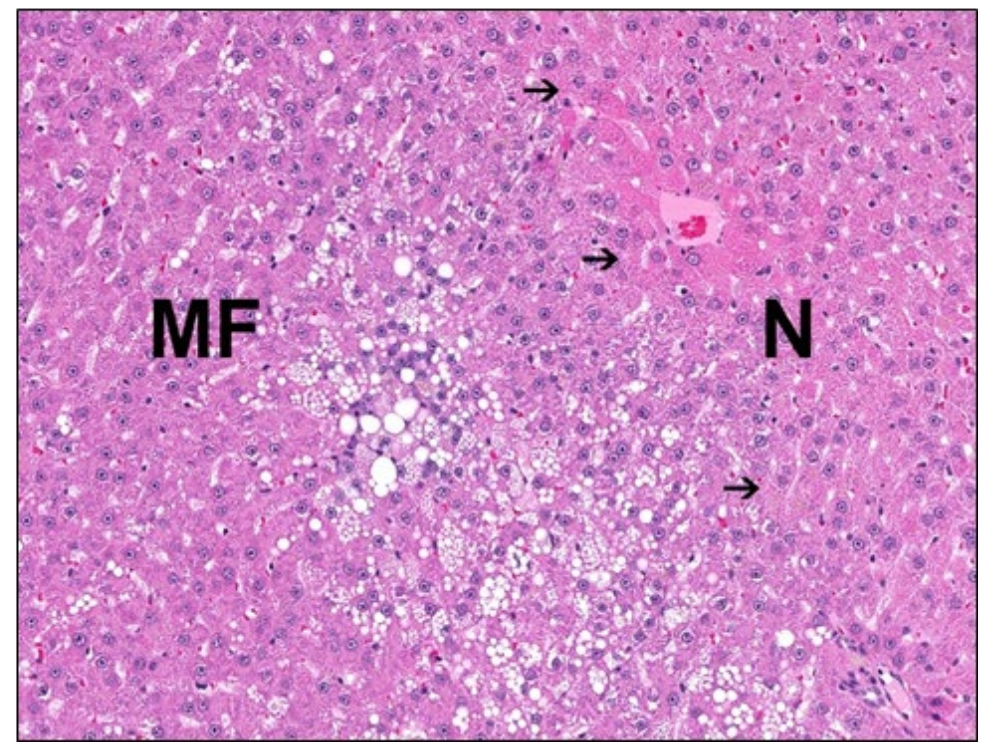

Figure 14. Mixed-cell Focus of Hepatocytes from the Liver of a Male Sprague Dawley Rat Exposed to Perfluorooctanoic Acid in Feed for Two Years (Study 2)

A) Mixed-cell focus (MF), characterized by a focal, proliferation of hepatocytes that blends with the surrounding normal hepatic parenchyma at the margins (asterisk). B) Higher magnification of panel A. The MF is composed of a mixture of eosinophilic to amphophilic hepatocytes and hepatocytes that contain prominent microvesicular and macrovesicular cytoplasmic vacuoles similar to the cells that were present in hepatocellular adenomas. Also note how the hepatocytes in the foci blend with the normal hepatocytes (arrows).

Hepatocyte cytoplasmic alteration and hepatocyte hypertrophy were generally colocalized within hepatocytes and were generally of mild to moderate severity. These hepatocyte changes were observed throughout the liver sections but were often most prominent in centrilobular hepatocytes (Figure 15A). Hepatocyte with cytoplasmic alteration appeared granular and 
hypereosinophilic due to accumulations of eosinophilic granules in the cytoplasm (Figure 15B). Hepatocellular hypertrophy was characterized by hepatocyte enlargement due to either accumulation of eosinophilic granules (when associated with cytoplasmic alteration) or homogenous eosinophilic cytoplasm, in the absence of cytoplasmic alteration.

\section{A)}

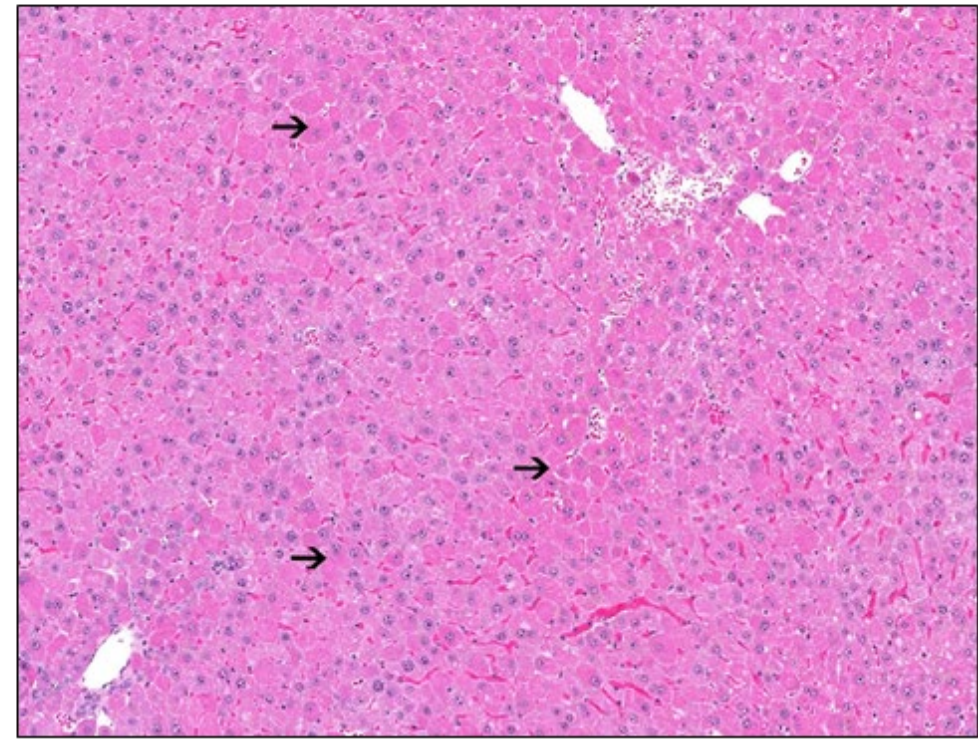

B)

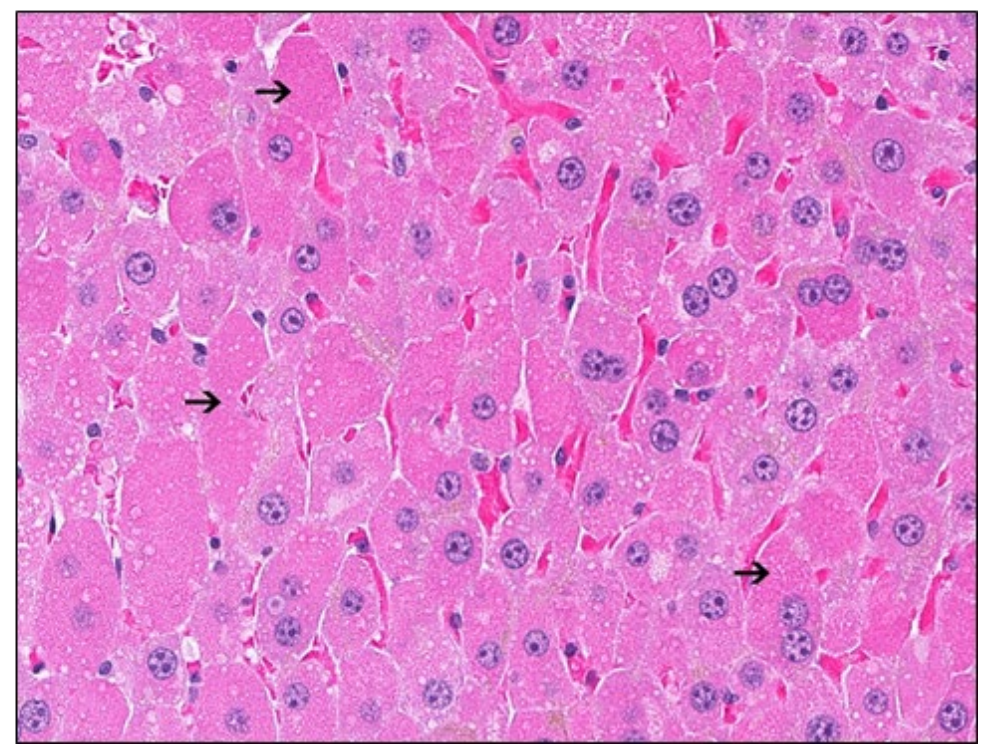

Figure 15. Hepatocyte Cytoplasmic Alteration and Hypertrophy in a Male Sprague Dawley Rat Exposed to Perfluorooctanoic Acid in Feed for Two Years (Study 2)

A) Affected hepatocytes are enlarged and brightly eosinophilic (arrows). B) Higher magnification of panel A. Note enlarged hepatocytes that have brightly eosinophilic granules (arrows). 
Hepatocyte single cell death consisted of randomly distributed, individual, irregularly round hepatocytes that were shrunken and had hypereosinophilic cytoplasm, and pyknotic nuclei with condensed, tortuous chromatin (Figure 16). Some cells were surrounded by a clear space or halo.

A)

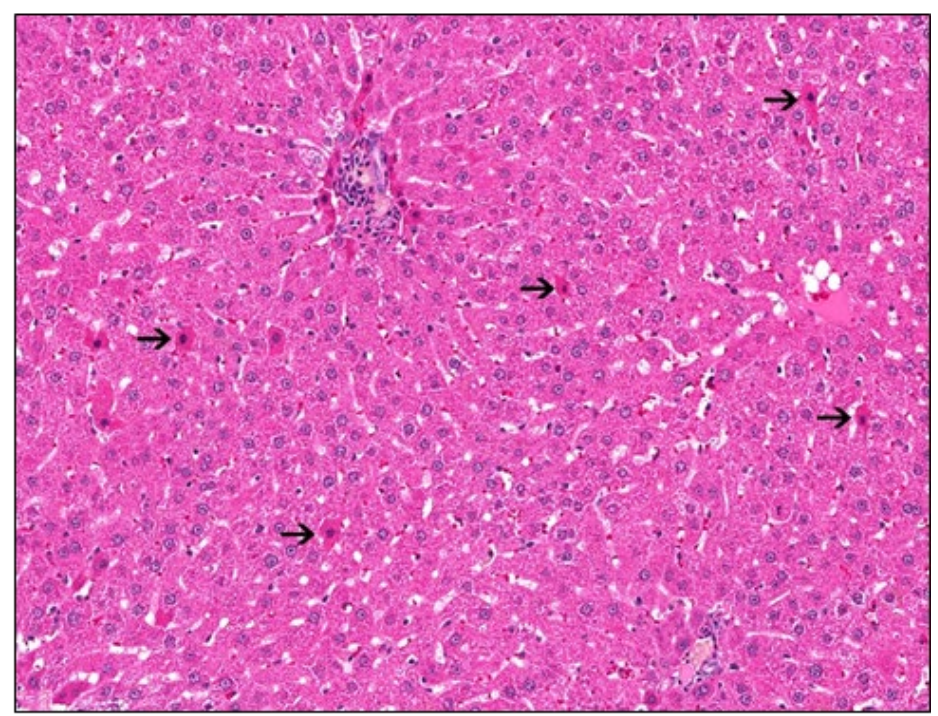

B)

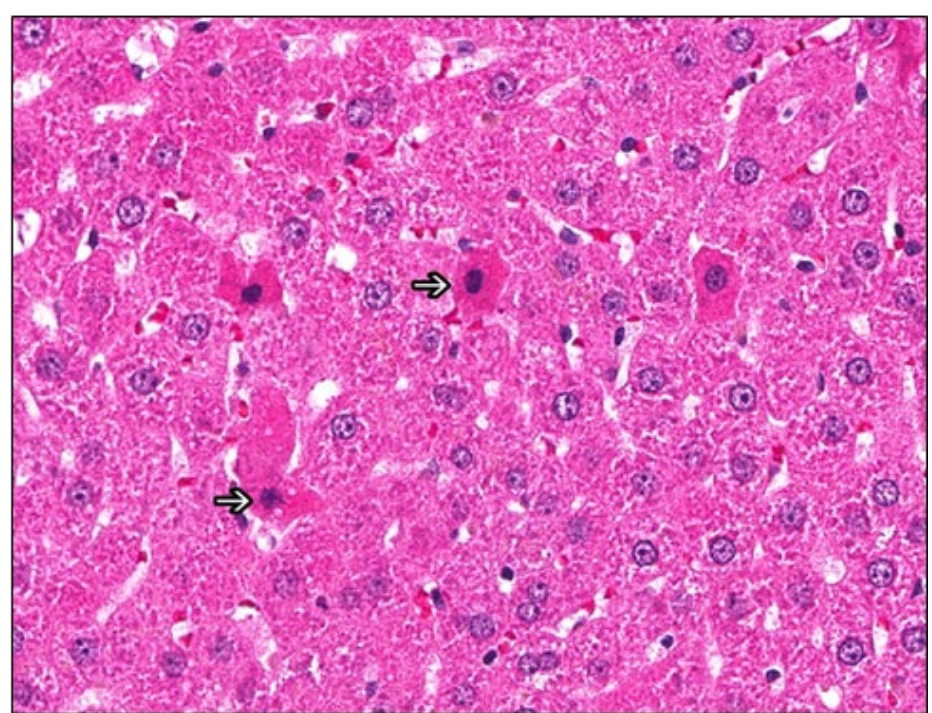

Figure 16. Hepatocyte Single Cell Death in a Female Sprague Dawley Rat Exposed to Perfluorooctanoic Acid in Feed for Two Years (Study 1)

A) Affected hepatocytes are randomly distributed, individual, hypereosinophilic hepatocytes (arrows). B) Higher magnification of panel A. Affected hepatocytes are shrunken and have hypereosinophilic cytoplasm and pyknotic nuclei with condensed chromatin (arrows).

Necrosis occurred as variably distributed, (focal, multifocal, diffuse), variably sized, irregular zones of coagulative necrosis in the parenchyma that were often prominent in the centribobular zones (Figure 17). In areas of necrosis, necrotic hepatocytes were swollen, pale, and had lost all cellular detail. Bridging between adjacent centrilobular zones of necrosis was sometimes evident. 


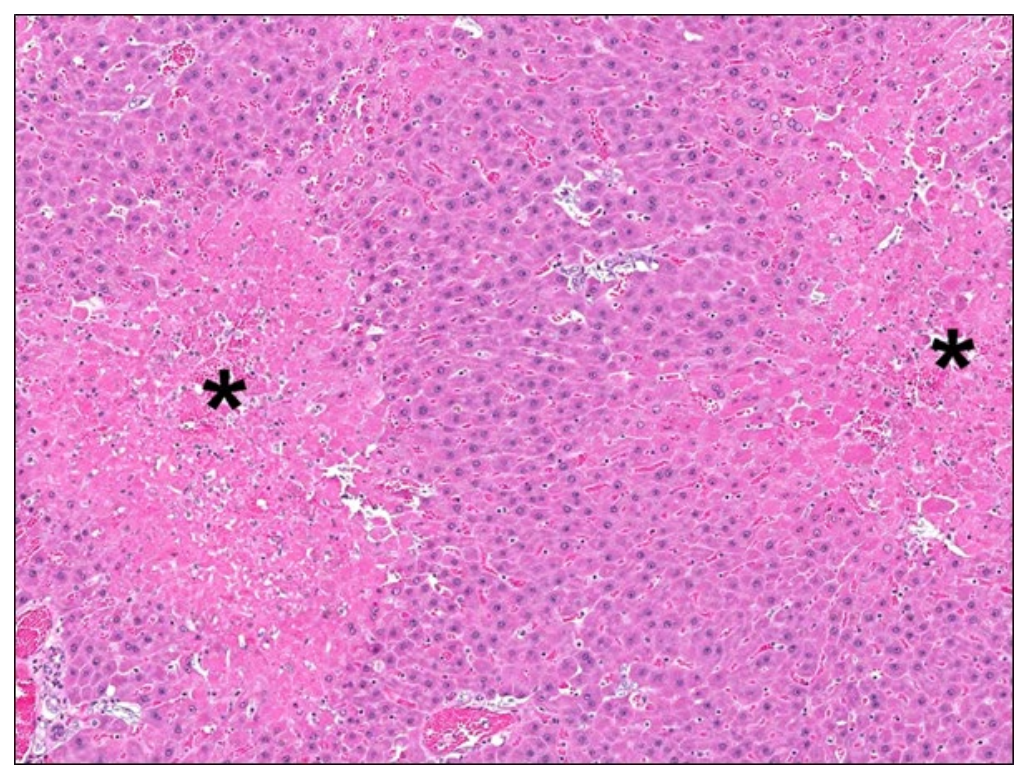

Figure 17. Hepatocyte Necrosis in a Female Sprague Dawley Rat Exposed to Perfluorooctanoic Acid in Feed for Two Years (Study 1)

Necrosis consisted of prominent, variably sized, irregular zones of coagulative necrosis (asterisks) that are sharply demarcated from the surrounding unaffected hepatic parenchyma. Compared with the surrounding hepatic parenchyma, in affected areas, the necrotic hepatocytes are swollen, lightly eosinophilic and lack cellular detail.

Hepatocyte pigment was characterized by the presence of fine golden-brown material in both hepatocytes and Kupffer cells (Figure 18). The pigment was considered likely to be lipofuscin due to the lack of staining with the histochemical stains for iron (Perl's Prussian blue stain) or for bilirubin (Hall's bilirubin stain).

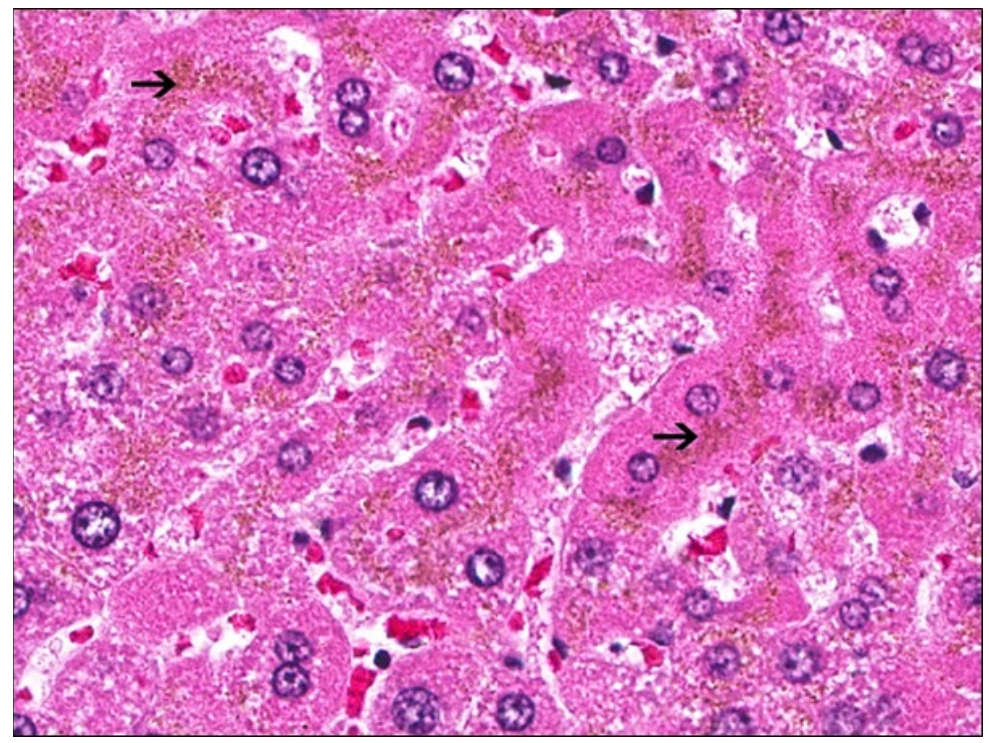

Figure 18. Hepatocyte Pigment in a Female Sprague Dawley Rat Exposed to Perfluorooctanoic Acid in Feed for Two Years (Study 1)

Hepatocyte pigment is characterized by the presence of fine golden-brown material in both hepatocytes and Kupffer cells (arrows). 
Bile duct hyperplasia was multifocal in distribution and consisted of increased numbers of bile duct profiles within the portal areas (Figure 19). The hyperplastic ducts were sometimes surrounded by dense collagen.

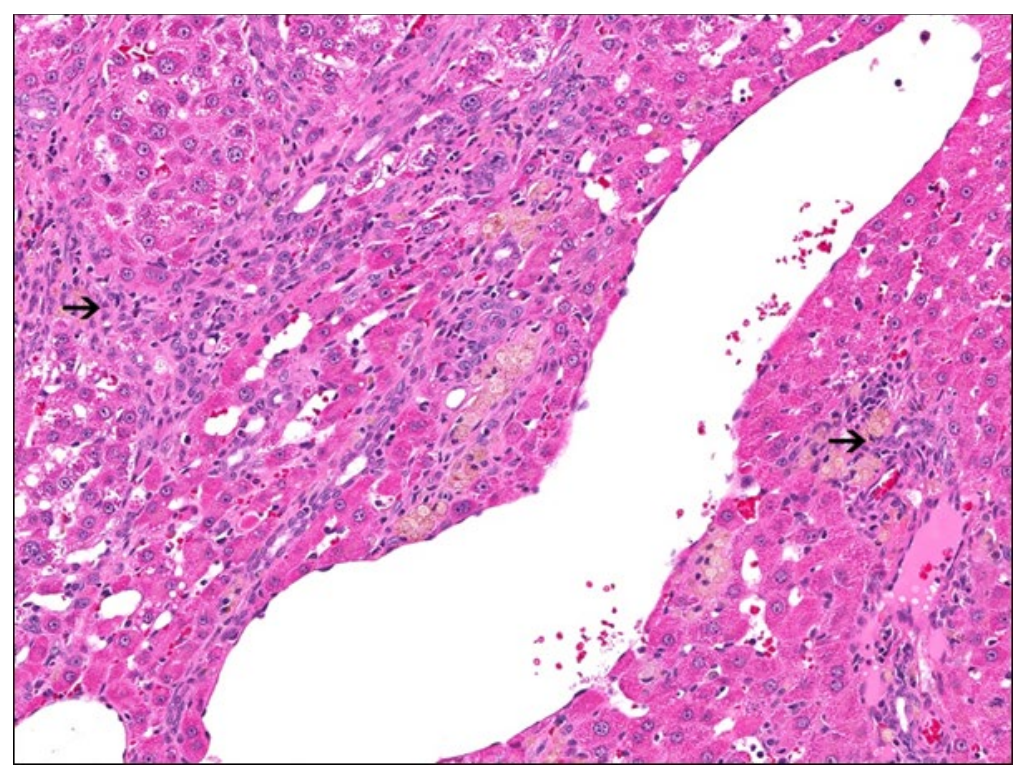

Figure 19. Bile Duct Hyperplasia in a Female Sprague Dawley Rat Exposed to Perfluorooctanoic Acid in Feed for Two Years (Study 1)

Bile duct hyperplasia is characterized by increased numbers of bile duct profiles within a portal area (arrows).

Hepatocyte mitoses consisted of increased numbers of hepatocytes in which the nuclei were undergoing mitoses (Figure 20).

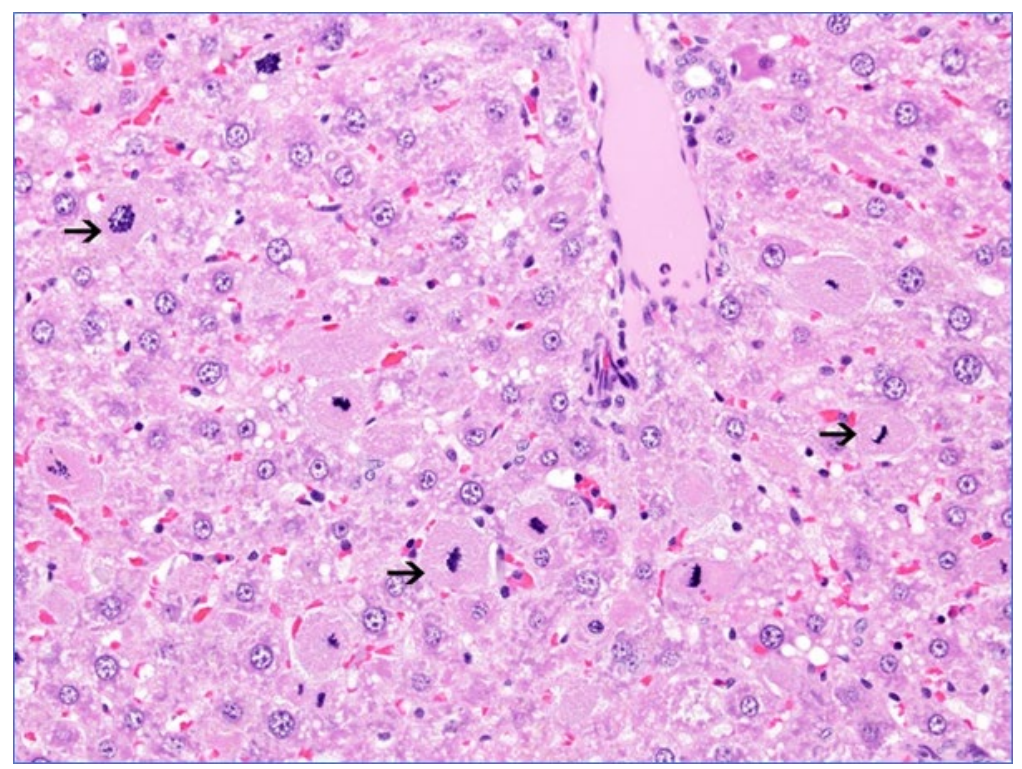

Figure 20. Hepatocyte Mitoses in a Female Sprague Dawley Rat Exposed to Perfluorooctanoic Acid in Feed for Two Years (Study 1)

Hepatocyte mitoses are characterized by increased numbers of hepatocytes in which the nuclei were undergoing mitosis (arrows). 


\section{Pancreas}

Acinar cell hyperplasias often coexisted in tissue sections with adenomas but were also present in tissue sections that did not have adenomas (Figure 21A). Hyperplasia was morphologically similar to adenomas, which suggested a continuum from hyperplasia to adenoma. The distinction between acinar cell hyperplasia and adenoma was based largely upon size, with acinar cell hyperplasia diagnosed when they were less than $3 \mathrm{~mm}$ in the widest diameter. ${ }^{121}$ Acinar cell hyperplasia was characterized by nodular proliferations of rounded clusters of normal-appearing pancreatic acinar cells, and relative normal-appearing acinar architecture (Figure 21B).

Acinar cell adenomas occurred as single or multiple discrete, irregularly nodular masses that were more than $3 \mathrm{~mm}$ in diameter, and sometimes compressed the adjacent pancreatic parenchyma (Figure 21A). Neoplasm cells were well differentiated and formed small, irregular acini (Figure 21).

A)

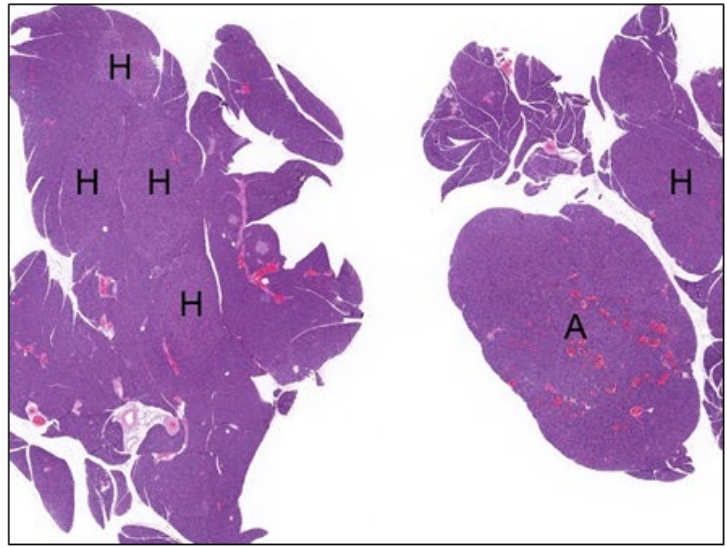

C)

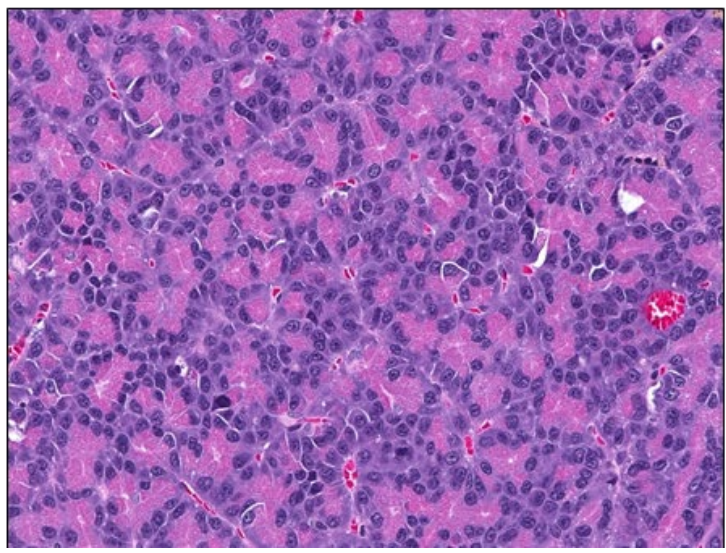

B)

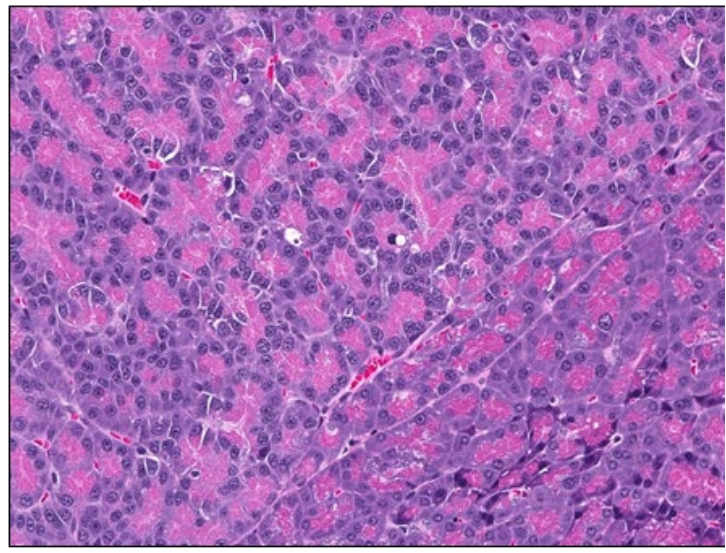

Figure 21. Acinar Cell Hyperplasia and Adenoma of the Pancreas in a Male Sprague Dawley Rat Exposed to Perfluorooctanoic Acid for Two Years (Study 2)

A) Acinus hyperplasia (H) and acinus adenoma (A) were nodular lesions that often occurred in the same histological section and were distinguishable only by size. B) Higher magnification of the hyperplasia in panel A. Acinar hyperplasia was characterized by proliferation of normal-appearing pancreatic acinar cells with retention of the normal-appearing acinar architecture. C) Higher magnification of the adenoma in panel A. Acinar cell adenomas were morphologically similar to that of acinar hyperplasia but sometimes compressed the adjacent pancreatic parenchyma. 
Acinar cell adenocarcinomas occurred as invasive, irregular multinodular masses separated by bands of fibrous or connective tissue (scirrhous response) (Figure 22A). The growth patterns within adenocarcinomas were pleomorphic with well to poorly differentiated neoplastic acinar cells that formed sheets, small acini, gland-like structures, and trabeculae (Figure 22B). Islets of Langerhans were absent within the acinar cell neoplasms.

A)

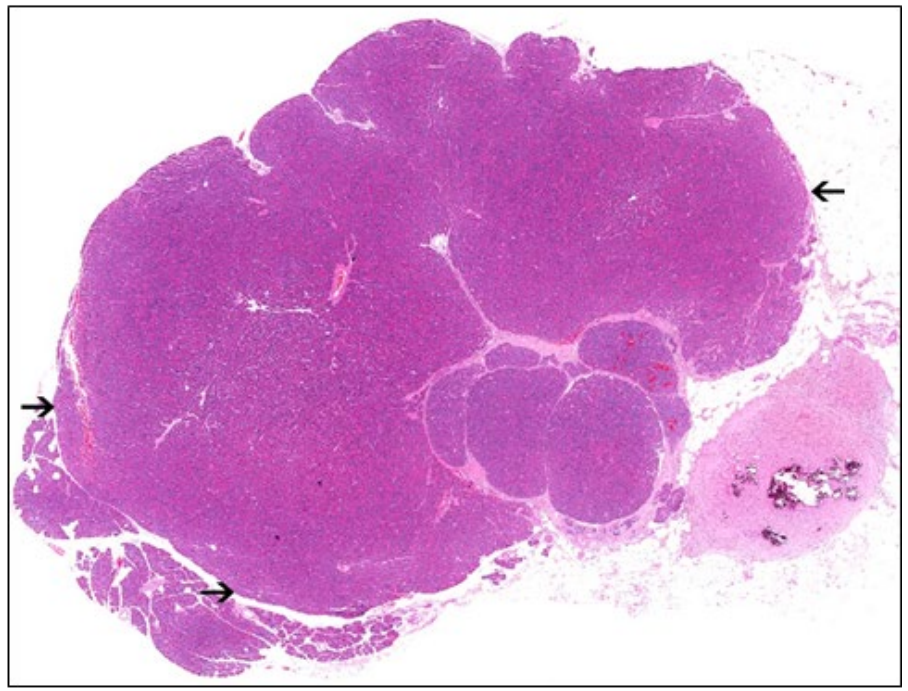

B)

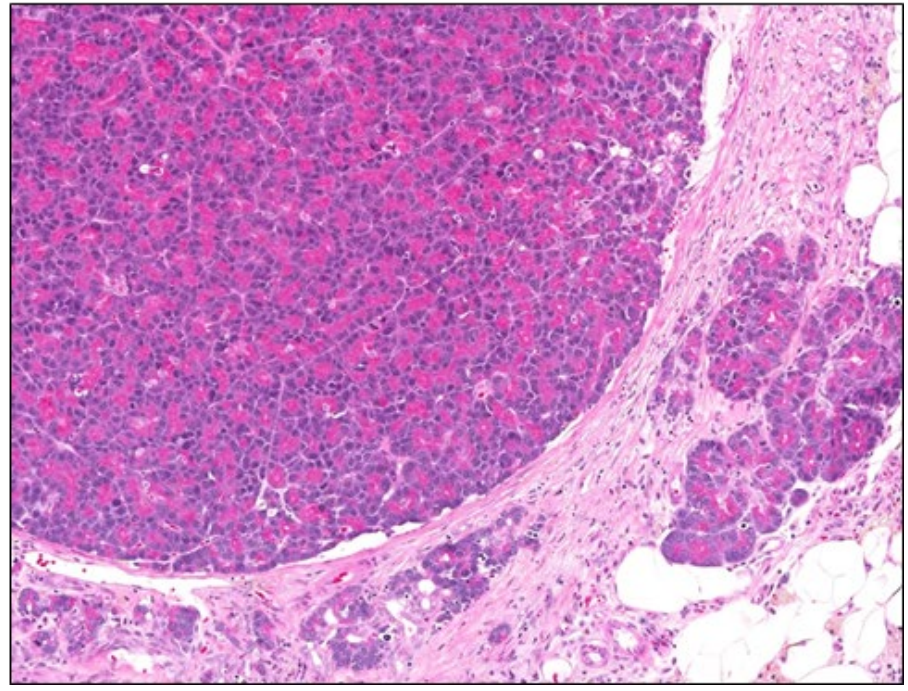

Figure 22. Adenocarcinoma of the Pancreas in a Male Sprague Dawley Rat Exposed to Perfluorooctanoic Acid in Feed for Two Years (Study 2)

A) The pancreas adenocarcinoma occurs as a multinodular masse that has replaced most of the pancreatic parenchyma (arrows).

B) Higher magnification of panel A. The pancreas adenocarcinoma is composed of relatively well differentiated acinar cells with retention of the normal-appearing acinar architecture. 


\section{Uterus}

Uterine adenocarcinomas were poorly circumscribed, invasive masses that varied in size from small focal lesions to some larger lesions that effaced the entire endometrium and extended into or sometimes through the myometrium (Figure 23A). The neoplastic epithelial cells had multiple morphologies that included solid nests, cords, and papillary or acinar structures (Figure 23B). Typically, the neoplastic epithelial cells had at least some degree of pleomorphism or atypia and mitotic figures were common.

A)

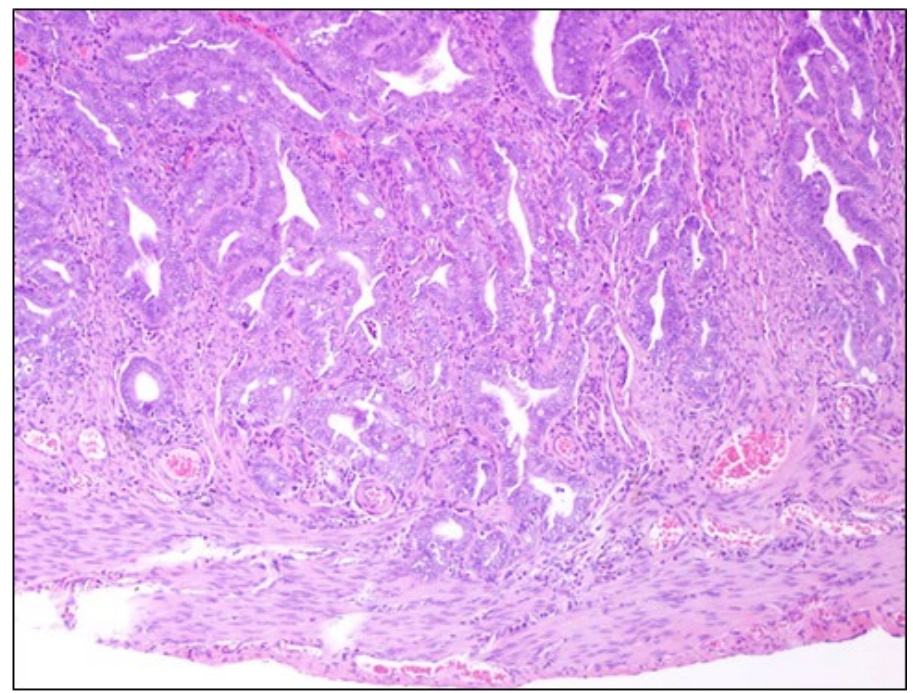

B)

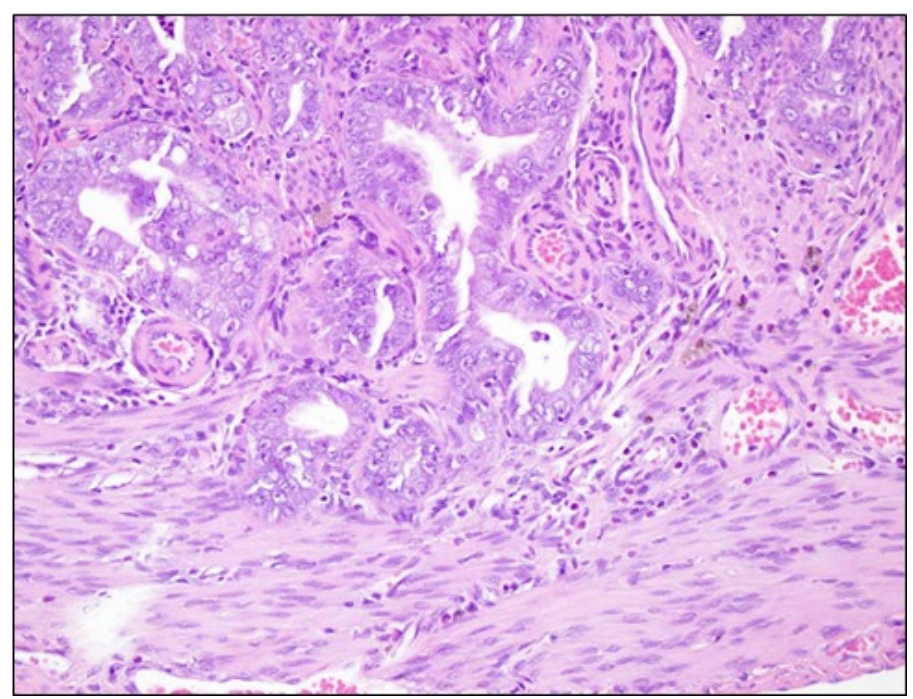

Figure 23. Adenocarcinoma of the Uterus in a Female Sprague Dawley Rat Exposed to Perfluorooctanoic Acid in Feed for Two Years (Study 1)

A) The uterus adenocarcinoma occurs as a highly invasive mass that has completely effaced the architecture of the uterus. B) Higher magnification of panel A. 


\section{Kidney}

Kidney papillary urothelial hyperplasia was characterized by minimal to moderate proliferative thickening of the urothelium lining the renal papilla (Figure 24A), which formed variably sized, irregular, papillary protuberances that extended into the lumen of the renal pelvis (Figure 24B). In some cases, the proliferative urothelium extended into the interstitium of the renal papilla itself, forming variably sized, irregular gland-like structures (Figure 24C).

A)

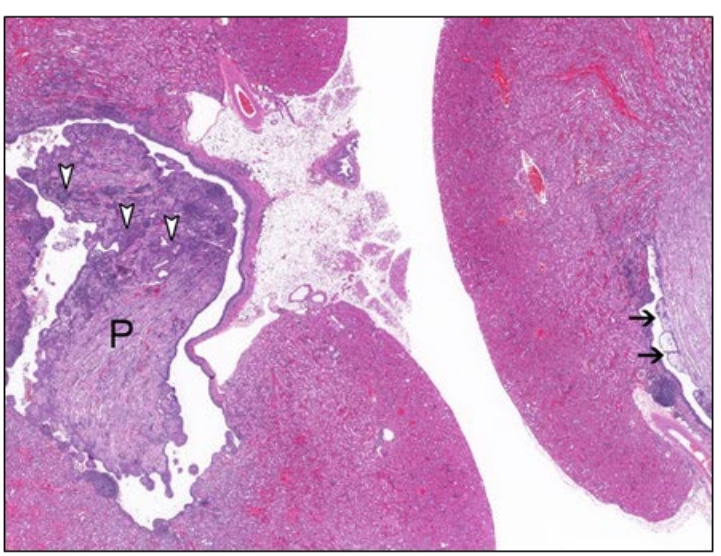

C)

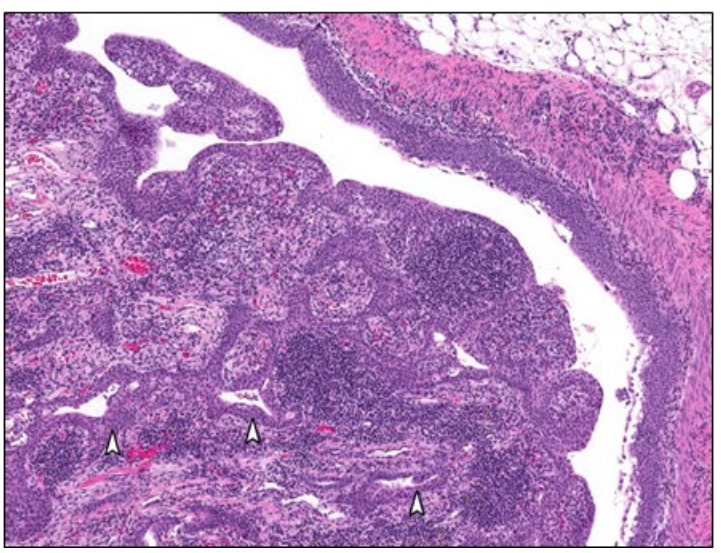

B)

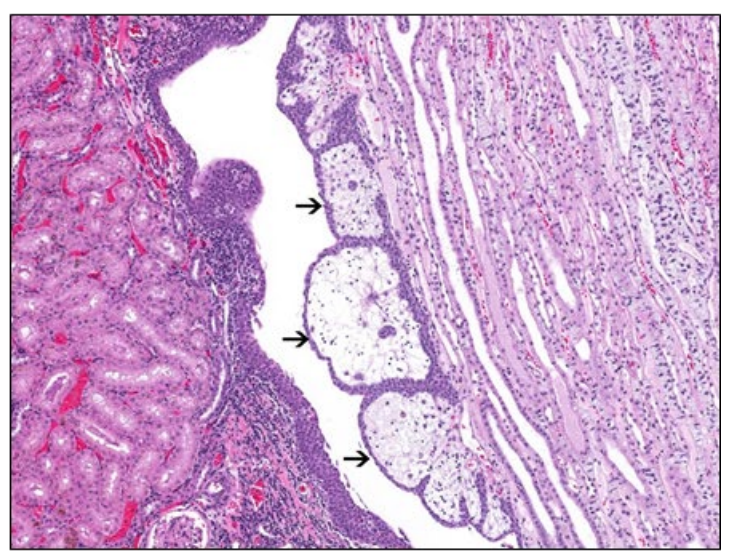

Figure 24. Papilla Urothelial Hyperplasia in the Kidney of a Female Sprague Dawley Rat Exposed to Perfluorooctanoic Acid in Feed for Two Years (Study 1)

A) Papilla urothelial hyperplasia of the kidney is characterized by hyperplasia of the epithelium of the renal papilla in the form of papillary projections into the lumen of the renal pelvis (arrows), or within the interstitium (arrows) of the renal papilla (P). B) Higher magnification of panel A. The hyperplastic epithelium forms papillary projections that protrude into the lumen of the renal pelvis (arrows). C) Higher magnification of panel A. The hyperplastic epithelium forms irregular anastomosing tubule-like structures within the interstitium of the renal papilla (arrows). 
Kidney papillary necrosis was characterized by coagulative necrosis of the distal one-third to one-half of the papilla with complete loss of architecture (Figure 25).

A)

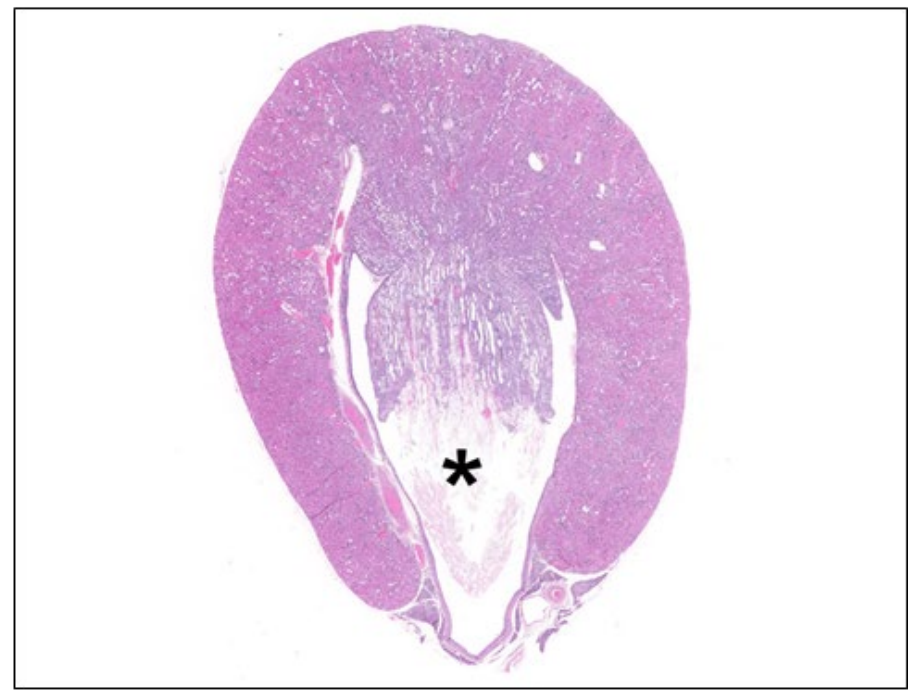

B)

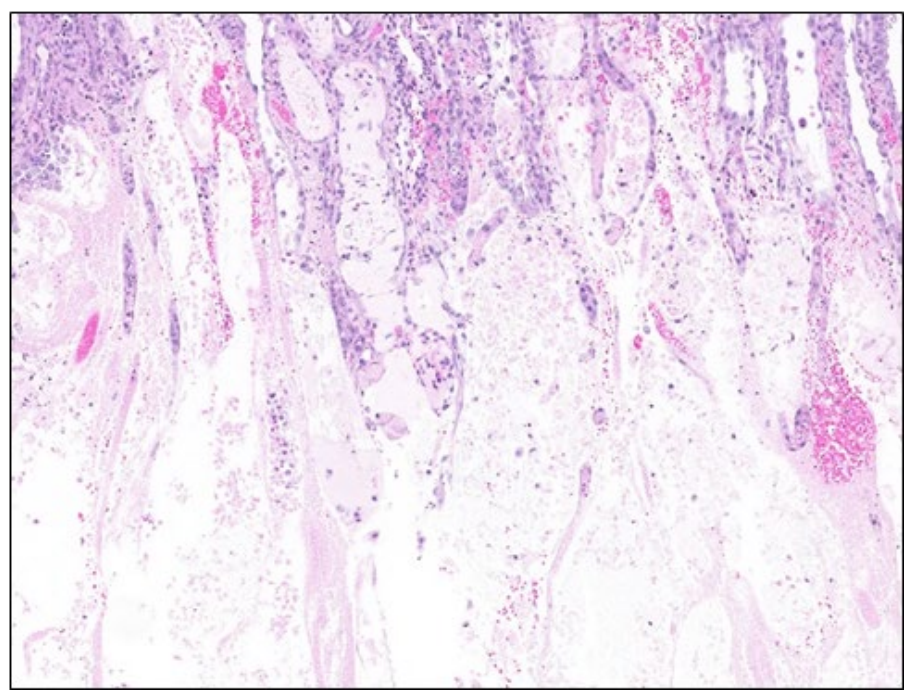

Figure 25. Papillary Necrosis in the Kidney of a Female Rat Exposed to Perfluorooctanoic Acid in Feed for Two Years (Study 1)

A) Papillary necrosis of the kidney is characterized by necrosis of the distal one-half of the renal papilla (asterisk). B) Higher magnification of the necrotic area in panel A (asterisk) demonstrating coagulative necrosis with complete loss of the architecture of renal papilla.

Tubular mineral was of minimal severity and characterized by the presence of randomly distributed basophilic mineral deposits in the epithelial cells lining the cortical and medullary tubules. 


\section{Forestomach}

Forestomach ulceration, epithelial hyperplasia, and inflammation were associated lesions (Figure 26). Ulcers were focal lesions characterized by full-thickness loss of the lining mucosal squamous epithelium and accompanied by variable thickening (up to 6 to 10 cell layers) of the adjacent squamous epithelium (hyperplasia) that extended from the margins, and the presence of a mixed inflammatory cell infiltrates (inflammation, chronic active) within the underlying submucosa, that sometimes extended into the muscularis mucosa below (Figure 26).

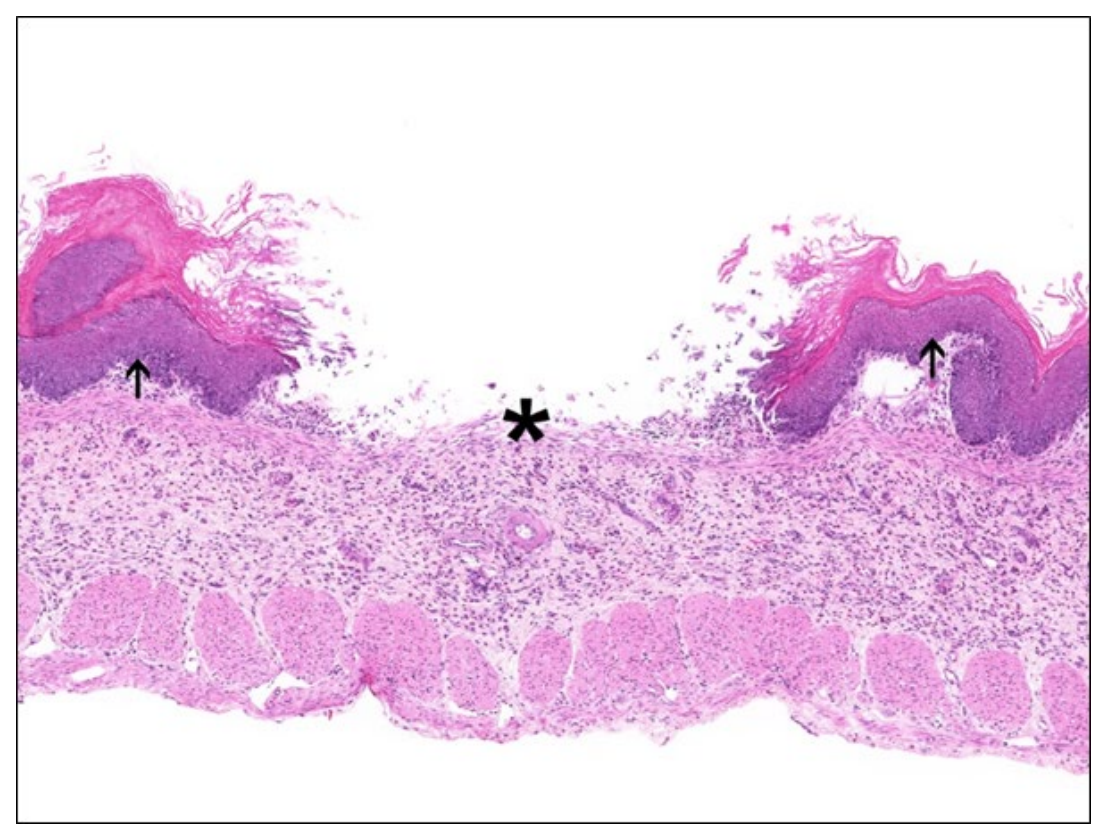

Figure 26. Forestomach Ulcer in the Stomach of a Female Sprague Dawley Rat Exposed to Perfluorooctanoic Acid in Feed for Two Years (Study 1)

Forestomach ulcer (asterisk) accompanied by epithelial hyperplasia (arrows) and submucosal inflammation.

\section{Thyroid Gland}

Follicular cell hypertrophy was of minimal to mild severity and diagnosed when the thyroid gland was composed predominantly of small follicles that had minimal amounts of lightly basophilic colloid. Affected follicles were lined by cuboidal rather than flattened epithelial cells. Such small follicles are typically present in the centers of normal thyroid glands and constituted less than $30 \%$ of the area of thyroid gland sections among control animals. 


\section{Discussion}

Perfluorooctanoic acid (PFOA) is a widespread contaminant and the second most prevalent per/polyfluoroalkyl substance (PFAS) measured in human plasma to date; second only to perfluorooctane sulfonic acid (PFOS). Its stability in the environment and long half-life in humans have led to decades of exposure, which is declining, but is still present despite removal from use. Exposure likely occurs throughout development, starting in utero. Previous studies in rats have identified the carcinogenic activity of PFOA, but in these studies exposures were started in young adult animals after critical periods of development. ${ }^{74 ; 72}$ Due to the concern of widespread exposure occurring through multiple life stages, the National Toxicology Program (NTP) tested the hypothesis that additional exposure during the perinatal period (in utero and during lactation up to weaning) would increase the incidence of neoplasms or lead to the appearance of different neoplasm types. To test the hypothesis, groups of rats exposed during the perinatal period and after weaning were compared to groups with postweaning exposure only. Because female rats are known to have higher PFOA elimination rates than male rats, higher postweaning feed exposures of up to 1,000 ppm were provided to females. Exposure groups were analyzed by pairwise comparison to assess potential differences

In the current studies, exposure during the perinatal period was up to $300 \mathrm{ppm}$, which led to plasma concentrations of $74-75 \mu \mathrm{M}$ in the dam on gestation day (GD) 18 and postnatal day (PND) 4. The concentrations were similar at different time periods (GD 18 versus PND 4), although feed consumption was higher during lactation compared to gestation. This could be due, in part, to lactational transfer from dams to pups. At 19 weeks of age, plasma concentrations were approximately $50 \mu \mathrm{M}$ in the $\mathrm{F}_{1}$ females at a similar exposure concentration (i.e., $300 \mathrm{ppm}$ ). The lower concentrations are likely due to the differences in $\mathrm{F}_{0}$ feed consumption during gestation and lactation versus $\mathrm{F}_{1}$ nonpregnant females.

$\mathrm{F}_{1}$ exposure evaluations occurred on GD 18, PND 4, and at 19 weeks of age, and showed maternal transfer early in development and continued exposure at the later time periods. Fetuses pooled by litter had concentrations about a third of maternal plasma concentrations on GD 18, indicating some maternal transfer. Pooled whole pups had consistent concentrations between male and female pups indicating lactational transfer to the offspring early during postnatal development. No apparent sex differences were observed in the pups, which is consistent with previous reports that sex differences arise during puberty with increases in testosterone. ${ }^{26}$ At 19 weeks of age, male and female adult plasma and liver concentrations were consistent between groups that were and were not perinatally exposed. As expected, plasma concentrations were about 12 -fold lower in females compared to males with a similar exposure $(0 / 300 \mathrm{ppm})$.

Exposure-adjusted ( $\mathrm{mg} / \mathrm{kg} /$ day) plasma concentrations decreased in males as exposure increased from $20 \mathrm{ppm}$ up to $300 \mathrm{ppm}$. This is consistent with the hypothesized saturation of a kidney reabsorption pathway. ${ }^{26 ; 122}$ Exposure-adjusted plasma concentrations in females at 19 weeks of age did not appear to change with exposure concentration.

In general, the rat plasma PFOA concentrations were considerably higher than those attained in the general human population, for which 2015-2016 NHANES data yield a geometric mean of $4 \mathrm{nM}$ (95th percentile $=10 \mathrm{nM}$ ) in human sera. ${ }^{5}$ Human sera:plasma and sera: whole blood ratios are estimated to be $1: 1$ and $2: 1$, respectively. ${ }^{123}$ The rat plasma concentrations were marginally 
higher than concentrations measured in the NTP 28 -day toxicity studies $(57 \mu \mathrm{M})$ with administered doses of $100 \mathrm{mg} / \mathrm{kg} /$ day via gavage route of exposure. ${ }^{88}$

In the current studies, exposure during gestation and lactation up to $300 \mathrm{ppm}$ (approximately 22 and approximately $46 \mathrm{mg} / \mathrm{kg} /$ day, respectively) resulted in minimal to no changes in body weight of the $\mathrm{F}_{0}$ dams and no effect on litter size or survival. Pup weights were at most $8 \%$ lower compared to the $0 / 0 \mathrm{ppm}$ control group. These data are consistent with published feed studies in SD rats, which observed effects at $30 \mathrm{mg} / \mathrm{kg} /$ day in rats. ${ }^{49}$ However, with continued exposure, body weights of exposed groups were significantly lower compared to the $0 / 0 \mathrm{ppm}$ control group.

At the interim evaluation, liver toxicity was observed in the PFOA-exposed male rats with no difference between groups with and without perinatal exposure; similar liver effects were observed in the PFOA-exposed female rats, but to a much lesser degree. In males, liver weights were increased and hepatocyte pigment (most likely lipofuscin), hepatocyte cytoplasmic alteration, hepatocyte hypertrophy, and hepatocyte necrosis were observed in the PFOA-exposed animals. The male portion of Study 1 was stopped because of reduced body weight and liver necrosis in males exposed to 150 or 300 ppm PFOA either perinatally and postweaning or postweaning alone. In female rats, liver weights were also increased, but the incidences of hepatocyte necrosis and hepatocyte hypertrophy were much lower compared to the males. These sex differences are likely in part due to the lower plasma concentrations in females compared to males.

In the NTP 28-day toxicity studies, PFOA activated PPAR $\alpha$ and constitutive androstane receptor (CAR) in this animal model (Hsd:Sprague Dawley ${ }^{\circledR} \mathrm{SD}^{\circledR}$ rats) as evident by increased expression of associated genes. ${ }^{88}$ At the 16 -week interim necropsy in this 2-year study, liver acyl-CoA oxidase enzyme activities were elevated in male and female rats. The hepatocellular hypertrophy and cytoplasmic alteration are likely due to peroxisome proliferation, but may also be mediated through CAR activation or possibly other mechanisms. ${ }^{45 ; 124-127}$ Mild increases (less than twofold) in the biomarkers of hepatocellular injury, ALT and SDH activity, correlated with the liver histopathology (necrosis and single cell death). In male rats, bile acid concentrations were increased in the higher dosed groups with a greater than twofold increase compared to the 0/0 ppm control group. Greater than twofold increases in bile acid concentrations are consistent with cholestasis, the causes of which include physical disruption of bile flow through the biliary system or perturbation of bile acid formation and excretion at the cellular level. ${ }^{128 ;} 129$ ALP was mildly increased (less than twofold) in male and female rats. These increases may be due to cholestasis; however, mild increases in ALP activity (and ALT activity) are also associated with the administration of hepatic microsomal enzyme inducer compounds, including PPAR $\alpha$ agonist, when the only histological finding is centrilobular hypertrophy. ${ }^{128 ; 130 ; 131}$ Additionally, these effects corresponded with large increases in the acyl-CoA oxidase activity in males compared to females. Similar to the observed liver toxicity, there were no differences in acyl-CoA oxidase activity between animals exposed perinatally and postweaning versus those only exposed after weaning.

Liver aromatase activity was not affected by PFOA exposure in females and males of Study 1, but there was a consistent twofold increase across postweaning exposure groups $(20,40$, and $80 \mathrm{ppm}$ ) in males exposed to the lower concentrations in Study 2. This occurred in animals with and without perinatal exposure, with no obvious explanation for why this occurred in males of 
Study 2 and not in Study 1. Aromatase activity was measured to potentially understand the mechanism of Leydig cell neoplasms of the testis and other potentially endocrine-related effects; however, there was no increase in the incidence of Leydig cell neoplasms observed in this study. This may be due to differences in exposure concentrations among studies, as Leydig cell neoplasms were observed at a higher exposure of $300 \mathrm{ppm},{ }^{74 ; 72}$ or due to differences among rat stocks (Crl:COBS CD(SD)BR/Crl:CD BR (CD) versus Hsd:Sprague Dawley ${ }^{\circledR}$ SD $^{\circledR}$ ).

Other clinical chemistry changes included increases in total protein (female only) and albumin concentrations, and decreases in total protein (male only), globulin, cholesterol (male only), and triglyceride concentrations. In general, these clinical chemistry changes were similar with and without perinatal exposure, but in females were of lesser magnitude or absent compared to the male rats. Albumin concentrations may have been elevated due to decreased water intake (supported by the increases in blood urea nitrogen) or as an acute phase protein in response to (liver) inflammation. Globulins are produced by the liver or lymphocytes (immunoglobulins), and it is not clear if PFOA caused a perturbation of hepatic or lymphocytic production or metabolism of these proteins. The decreases in lipid concentrations (cholesterol, triglycerides) are consistent with the known effects of PPAR $\alpha$ activation on lipid metabolism, which includes increases in peroxisomal fatty acid $\beta$-oxidation and effects on lipid transport. ${ }^{132-134} \mathrm{CAR}$ is also an important regulator of cholesterol homeostasis, and its activation may also be related to the observed lipid alterations. ${ }^{135}$ The various clinical chemistry changes at the 16-week interim are similar to those observed in the NTP 28-day PFOA study. ${ }^{88}$

In addition to the liver, increased incidences of thyroid gland hypertrophy were observed at the 16-week interim (male and female) and terminal evaluation (female) in the higher exposure groups compared to the control animals. This may be a compensatory effect related to decreased circulating total thyroxine and triiodothyronine hormone concentrations, which were observed in the NTP 28-day toxicity study. ${ }^{88}$ Increased submucosa inflammation of the glandular stomach was observed in the male postweaning exposure groups of 150 and $300 \mathrm{ppm}$ at the 16-week interim, but not at lower exposure groups in the second study. This lesion was increased in the female 1,000 ppm postweaning exposure groups at the terminal evaluation, but an exposurerelated increase was not observed at the 16-week interim.

The following discussion on carcinogenic activity is based on a weight of evidence of several factors described in the preface of this report and on the consistent findings in animals exposed either perinatally and postweaning or postweaning alone. A few differences between exposure paradigms are noted, but in general, the additional effect of including perinatal exposure on the chronic toxicity or carcinogenic response of PFOA appeared to be minimal.

At the end of the 2-year study, several neoplastic and nonneoplastic liver lesions were observed. In males, the incidences of hepatocellular adenomas were increased in the 40 and 80 ppm groups with and without perinatal exposure and exceeded the historical control range. In addition, hepatocellular carcinomas, a rare neoplasm (0/340 historical control), occurred in the 300/80 group. Increased incidences of liver necrosis were observed in all exposure groups with and without perinatal exposure, as were incidences of hepatocyte pigment, cytoplasmic alteration, and hypertrophy. Hepatocyte single cell death occurred in the mid- and high-postweaning exposure groups of $0 / 40,300 / 40$, and $0 / 80,300 / 80 \mathrm{ppm}$. The increase in the incidences of hepatocellular adenomas or carcinomas (combined) was related to exposure. The incidence of hepatocellular carcinoma in animals exposed perinatally $(300 / 80 \mathrm{ppm})$ was higher compared to 
those that were not $(0 / 80 \mathrm{ppm})$. Although this increase was not statistically significant, it is uncertain if this was an effect of the additional perinatal exposure. The rarity of the lesion based on historical control data suggests this effect may be due to perinatal exposure; however, there were no other indications in the liver that demonstrated a difference between animals with the perinatal exposure versus animals without this exposure. The increase in incidence of hepatocellular neoplasms is similar to that seen in a previous PFOA rat study with $300 \mathrm{ppm}$ exposure $^{74}$ and could be related at least in part to the PPAR $\alpha$ activity ${ }^{74}$, which reviews of studies suggest that the human liver is not as sensitive to PPAR $\alpha$ activity as rodents. ${ }^{136 ; 137}$

In female rats, there were higher incidences of hepatocellular carcinomas, which are rare (1/340 historical control), in the $0 / 1,000$ and 300/1,000 ppm groups, compared to the $0 / 0 \mathrm{ppm}$ controls. Similar to males, this was accompanied by higher incidences of necrosis, pigment, cytoplasmic alteration, hypertrophy, increased mitosis, and hepatocyte single cell death. The magnitude of these findings was less than those in the males, which again might in part be due to the lower plasma concentrations of PFOA in females than in males. The marginally higher incidence of carcinomas compared to the controls may be related to exposure given the liver response in males, and that females had consistently lower incidences. No differences were observed between groups exposed perinatally and those that were not.

Increased incidences of pancreatic acinar cell adenomas and adenocarcinomas were observed in exposed males, as was the combined incidence of these neoplasms. Significantly increased incidences of adenomas in all postweaning exposed groups (36-64\%) were higher than the historical control range for adenomas in males (45/340 historical control; range 0-28\%) and the occurrence of rare adenocarcinomas (2/340 historical control; range 0-2\%) were observed in all postweaning exposure groups $(20,40$, and $80 \mathrm{ppm})$. The combined incidence of these neoplasms was statistically significant at all postweaning exposure concentrations with and without perinatal exposure. In addition, there was an increase in the incidence of pancreatic acinus hyperplasia with and without perinatal exposure. Taken together, the increase in the incidences of pancreatic acinar cell adenoma or adenocarcinoma (combined) neoplasms (predominately adenomas) was related to PFOA exposure. There was no difference in response between groups with combined perinatal and postweaning exposure compared to groups with postweaning exposure only. These findings are consistent with a previous PFOA chronic exposure study, ${ }^{74}$ and although not considered to be related to exposure in the earlier study, ${ }^{72}$ a reevaluation of tissue from the first PFOA chronic study indicated increased incidences of pancreatic acinar cell hyperplasia. ${ }^{75}$ The female pancreatic response was considered to be stronger than the liver response because pancreatic adenomas and adenocarcinomas were present, which were not observed in other studies ( $0 / 340$ historical control), and because the exposure response was strengthened in both exposure paradigms when these two neoplasms were combined. This response differed from the observed response in the liver, where hepatocellular adenomas did not increase but there was a marginal increase in hepatocellular carcinomas.

There were higher incidences of pancreatic acinar cell neoplasms in the current study that also occurred at lower exposure concentrations compared to previous studies, ${ }^{74 ; 7}$ for which several explanations are possible. In this study, the criterion used for diagnosis of pancreatic acinar cell neoplasms was larger than $3 \mathrm{~mm}$ at their widest diameter, whereas previous studies used a diameter of $5 \mathrm{~mm}$ for their criterion. ${ }^{75}$ Additionally, the Hsd:Sprague Dawley ${ }^{\circledR} \mathrm{SD}^{\circledR}$ rat appears to have a higher background incidence of pancreatic acinar neoplasms, up to $28 \%$, historically, in control animals; thus, they may be more sensitive to these neoplasms compared to the other rat 
stocks used previously. For example, NTP studies with the Wistar Han and F344/N rats appear to have a lower background incidence for pancreatic acinar cell neoplasms ${ }^{138 ; 139}$ and Crl:CD (SD) Sprague Dawley rats are reported to have a background incidence of $<1 \%$. ${ }^{140}$

In females, low incidences of pancreatic acinar cell adenomas and adenocarcinomas were observed in the highest exposure groups of $0 / 1,000$ and 300/1,000. These neoplasms are rare in females (adenomas $=0 / 340$; carcinomas $=0 / 340$ historical control). There were low occurrences of acinus hyperplasia in the exposed female groups, but these occurrences were not increased as they were in the male exposed groups. Although the occurrences of these neoplasms were low and not statistically significant, observations of increased incidences of pancreatic acinar cell neoplasms in males increased confidence that the occurrence of these rare neoplasms in PFOAtreated female animals also was due to exposure and hence was considered to be some evidence of carcinogenic activity. Perinatal and postweaning exposure groups did not differ from the postweaning-only exposure groups. These neoplasms were not observed in females in the first PFOA chronic study, ${ }^{72}$ which may be due to a lower exposure level compared to this study (300 versus $1,000 \mathrm{ppm}$ ) or other study design differences noted previously.

Within the uterus, there was a higher incidence of adenocarcinomas in PFOA-exposed females. This occurred in groups that had perinatal and postweaning or postweaning-only exposure, although the increase in most of the groups was not statistically significant. Historical control data for adenocarcinomas for similarly sectioned uterine tissue is very limited, with the concurrent control having a $2 \%$ incidence and two other studies having a $10 \%$ background incidence, suggesting that this is not a rare neoplasm. The incidences of nonneoplastic lesions of the uterus (e.g., atypical hyperplasia of the endometrium) were not increased in response to exposure. The increase in the incidence of adenocarcinomas of the uterus may have been related to exposure, as incidences in exposed females were higher than those in the $0 / 0 \mathrm{ppm}$ control group, but the strength of the response was marginal and there was a low concurrent control incidence that lowered confidence in the response.

Treatment-related increased incidences of hyperplasia of the urothelium that lines the renal papilla, renal papilla necrosis, and renal tubule mineralization occurred in the female rats. Renal tubule mineralization and hyperplasia of the urothelium were present at the 16-week interim and terminal 2-year evaluation, whereas renal papilla necrosis was only observed at the 2-year evaluation and likely arose due to continued exposure. These lesions primarily occurred in the $1,000 \mathrm{ppm}$ postweaning exposure groups. Organic anion transporters play a major role in predominant excretion of PFOA in urine, and the excretion is significantly faster in females than males. ${ }^{26}$ As a result, female rats have higher PFOA concentrations in the urine compared to males. ${ }^{26}$ Although the mechanisms of injury were not explored, direct cytotoxicity from the high concentration of PFOA in the urine is a possibility. ${ }^{141}$ A positive association between higher serum concentrations of perfluoroalkyl chemical and chronic kidney disease has been reported in humans ${ }^{142}$; however, it is not clear if the disease was due to increased PFAS exposure or if the disease itself increased PFAS exposure due to poor kidney function. ${ }^{143}$

The lack of differences between exposure paradigms is consistent with the similar plasma concentrations measured at the interim evaluation between PFOA-exposed animals with and without perinatal exposure. A review of perinatal carcinogenic risks suggests that non-genotoxic chemicals or chemicals that require activation generally are less potent perinatal carcinogens during this time of development compared to genotoxic chemicals or direct-acting chemicals, 
which can lead to new neoplasm types and/or a greater response. ${ }^{144}$ Previous NTP studies examined the contribution of perinatal exposure to carcinogenic activity and found some differences between groups with and without perinatal exposure. ${ }^{89-91}$ These differences were marginal in some cases and it was unclear if the length of exposure, and not developmental exposure per se, contributed to these differences. There was a general consistency in response between male and female rats in this study, but it varied in degree. Female rats generally had a lower response compared to males, which is consistent with the lower internal dose measured in females than in males at 16 weeks and supports the hypothesis that female response differences are due to pharmacokinetic differences. 


\section{Conclusions}

Under the conditions of these 2-year feed studies, there was clear evidence of carcinogenic activity $^{\mathrm{b}}$ of PFOA in male Hsd:Sprague Dawley ${ }^{\circledR} \mathrm{SD}^{\circledR}$ rats based on the increased incidence of hepatocellular neoplasms (predominately hepatocellular adenomas) and increased incidence of acinar cell neoplasms (predominately acinar cell adenomas) of the pancreas. The additional effect of perinatal exposure in combination with postnatal exposure was uncertain and limited to the observation of hepatocellular carcinomas..

There was some evidence of carcinogenic activity of PFOA in female Hsd:Sprague Dawley ${ }^{\circledR}$ $\mathrm{SD}^{\circledR}$ rats based on the increased incidences of pancreatic acinar cell adenoma or adenocarcinoma (combined) neoplasms. The higher incidence of hepatocellular carcinomas and adenocarcinomas of the uterus may have been related to exposure. The combined perinatal and postweaning exposure was not observed to change the neoplastic or nonneoplastic response compared to the postweaning exposure alone in female rats.

Exposure to PFOA resulted in increased incidences of nonneoplastic lesions in the liver and pancreas of male rats and the liver, kidney, forestomach, and thyroid gland of female rats.

${ }^{\mathrm{b}}$ See Explanation of Levels of Evidence of Carcinogenic Activity. 


\section{References}

1. United States Environmental Protection Agency (USEPA). Technical fact sheet Perfluorooctane sulfonate (PFOS) and perfluorooctanoic acid (PFOA). Washington, DC: U.S. EPA, Office of Land and Emergency Management; 2017. EPA/505/F-17/001. https://www.epa.gov/sites/production/files/201712/documents/ffrrofactsheet contaminants pfos_pfoa 11-20-17 508 0.pdf

2. PubChem. PubChem Compound Database Summary: Perfluorooctanoic acid. Bethesda, MD: National Library of Medicine, National Center for Biotechnology Information; 2019. https://pubchem.ncbi.nlm.nih.gov/compound/9554 [Accessed: March 16, 2019]

3. Begley TH, White K, Honigfort P, Twaroski ML, Neches R, Walker RA. Perfluorochemicals: Potential sources of and migration from food packaging. Food Addit Contam. 2005; 22(10):1023-1031. 10.1080/02652030500183474

4. Butt CM, Muir DC, Mabury SA. Biotransformation pathways of fluorotelomer-based polyfluoroalkyl substances: A review. Environ Toxicol Chem. 2014; 33(2):243-267. $10.1002 /$ etc. 2407

5. National Health and Nutrition Examination Survey (NHANES). Fourth national report on human exposure to environmental chemicals. Volume 1. Atlanta, GA: U.S. Department of Health and Human Services, Centers for Disease Control and Prevention; 2019. https://www.cdc.gov/exposurereport/pdf/FourthReport UpdatedTables Volume1 Jan2019$\underline{508 . p d f}$

6. Steenland K, Tinker S, Frisbee S, Ducatman A, Vaccarino V. Association of perfluorooctanoic acid and perfluorooctane sulfonate with serum lipids among adults living near a chemical plant. Am J Epidemiol. 2009; 170(10):1268-1278. 10.1093/aje/kwp279

7. Olsen GW, Burris JM, Burlew MM, Mandel JH. Epidemiologic assessment of worker serum perfluorooctanesulfonate (PFOS) and perfluorooctanoate (PFOA) concentrations and medical surveillance examinations. J Occup Environ Med. 2003; 45(3):260-270.

8. United States Environmental Protection Agency (USEPA). Drinking water health advisory for perfluorooctanoic acid (PFOA). Washington, DC: U.S. EPA, Office of Water; 2016. EPA/822/R16/005. https://www.epa.gov/sites/production/files/201605/documents/pfoa_health_advisory_final_508.pdf

9. Lau C, Thibodeaux JR, Hanson RG, Narotsky MG, Rogers JM, Lindstrom AB, Strynar MJ. Effects of perfluorooctanoic acid exposure during pregnancy in the mouse. Toxicol Sci. 2006; 90(2):510-518. 10.1093/toxsci/kfj105

10. Agency for Toxic Substances and Disease Registry (ATSDR). ATSDR's Minimal Risk Levels (MRLs) and Environmental Media Evaluation Guides (EMEGs) for PFAS. Atlanta, GA: Centers for Disease Control and Prevention; 2018. https://www.atsdr.cdc.gov/pfas/mrl_pfas.html 
11. Onishchenko N, Fischer C, Wan Ibrahim WN, Negri S, Spulber S, Cottica D, Ceccatelli S. Prenatal exposure to PFOS or PFOA alters motor function in mice in a sex-related manner. Neurotox Res. 2011; 19(3):452-461. 10.1007/s12640-010-9200-4

12. Koskela A, Finnila MA, Korkalainen M, Spulber S, Koponen J, Hakansson H, Tuukkanen J, Viluksela M. Effects of developmental exposure to perfluorooctanoic acid (PFOA) on long bone morphology and bone cell differentiation. Toxicol Appl Pharmacol. 2016; 301:14-21. 10.1016/j.taap.2016.04.002

13. Minnesota Department of Health (MNDP). Toxicological summary for perfluorooctanoate. Health Risk Assessment Unit, Environmental Health Division; 2018. https://www.health.state.mn.us/communities/environment/risk/docs/guidance/gw/pfoa.pdf

14. New Jersey Department of Environmental Protection (NJDEP). Contaminants of emerging concern: Per- and polyfluoroalkyl substances. Trenton, NJ: Site Remediation Program; 2018. https://www.nj.gov/dep/srp/emerging-contaminants/

15. European Food Safety Authority (EFSA). Risk to human health related to the presence of perfluorooctane sulfonic acid and perfluorooctanoic acid in food. EFSA J. 2018; 16(12):e05194. https://dx.doi.org/10.2903/j.efsa.2018.5194

16. Kudo N, Kawashima Y. Toxicity and toxicokinetics of perfluorooctanoic acid in humans and animals. J Toxicol Sci. 2003; 28(2):49-57.

17. Dzierlenga A, Robinson V, Waidyanatha S, DeVito M, Eifrid M, Gibbs S, Granville C, Blystone C. Toxicokinetics of perfluorohexanoic acid (PFHxA), perfluorooctanoic acid (PFOA), and perfluorodecanoic acid (PFDA) in male and female Hsd:Sprague Dawley SD rats following intravenous or gavage administration. Submitted to Toxicology Reports. 2019.

18. Benskin JP, De Silva AO, Martin LJ, Arsenault G, McCrindle R, Riddell N, Mabury SA, Martin JW. Disposition of perfluorinated acid isomers in Sprague-Dawley rats; part 1: Single dose. Environ Toxicol Chem. 2009; 28(3):542-554. 10.1897/08-239.1

19. Johnson J, Gibson S, Ober R. Extent and route of excretion and tissue distribution of total carbon-14 in rats after a single IV dose of FC-95- ${ }^{14}$ C. U.S. EPA docket AR-226-0006.

Washington, DC: U.S. Environmental Protection Agency; 1979.

20. Kemper R. Perfluorooctanoic acid: Toxicokinetics in the rat. Laboratory Project ID: Dupont7473. U.S. EPA docket AR-226-1350. Washington, DC: U.S. Environmental Protection Agency; 2003.

21. Kim SJ, Heo SH, Lee DS, Hwang IG, Lee YB, Cho HY. Gender differences in pharmacokinetics and tissue distribution of 3 perfluoroalkyl and polyfluoroalkyl substances in rats. Food Chem Toxicol. 2016; 97:243-255. 10.1016/j.fct.2016.09.017

22. Ohmori K, Kudo N, Katayama K, Kawashima Y. Comparison of the toxicokinetics between perfluorocarboxylic acids with different carbon chain length. Toxicology. 2003; 184(2-3):135140. 
23. Vanden Heuvel JP, Kuslikis BI, Shrago E, Peterson RE. Inhibition of long-chain acyl-CoA synthetase by the peroxisome proliferator perfluorodecanoic acid in rat hepatocytes. Biochem Pharmacol. 1991; 42(2):295-302.

24. Lou I, Wambaugh JF, Lau C, Hanson RG, Lindstrom AB, Strynar MJ, Zehr RD, Setzer RW, Barton HA. Modeling single and repeated dose pharmacokinetics of PFOA in mice. Toxicol Sci. 2009; 107(2):331-341. 10.1093/toxsci/kfn234

25. Butenhoff JL, Kennedy GL, Jr., Hinderliter PM, Lieder PH, Jung R, Hansen KJ, Gorman GS, Noker PE, Thomford PJ. Pharmacokinetics of perfluorooctanoate in cynomolgus monkeys. Toxicol Sci. 2004; 82(2):394-406. 10.1093/toxsci/kfh302

26. Kudo N, Katakura M, Sato Y, Kawashima Y. Sex hormone-regulated renal transport of perfluorooctanoic acid. Chem Biol Interact. 2002; 139(3):301-316.

27. Andersen ME, Clewell HJ, 3rd, Tan YM, Butenhoff JL, Olsen GW. Pharmacokinetic modeling of saturable, renal resorption of perfluoroalkylacids in monkeys--probing the determinants of long plasma half-lives. Toxicology. 2006; 227(1-2):156-164. 10.1016/j.tox.2006.08.004

28. Loccisano AE, Campbell JL, Jr., Andersen ME, Clewell HJ, 3rd. Evaluation and prediction of pharmacokinetics of PFOA and PFOS in the monkey and human using a PBPK model. Regul Toxicol Pharmacol. 2011; 59(1):157-175. 10.1016/j.yrtph.2010.12.004

29. Loccisano AE, Campbell JL, Jr., Butenhoff JL, Andersen ME, Clewell HJ, 3rd. Comparison and evaluation of pharmacokinetics of PFOA and PFOS in the adult rat using a physiologically based pharmacokinetic model. Reprod Toxicol. 2012; 33(4):452-467.

10.1016/j.reprotox.2011.04.006

30. Loccisano AE, Campbell JL, Jr., Butenhoff JL, Andersen ME, Clewell HJ, 3rd. Evaluation of placental and lactational pharmacokinetics of PFOA and PFOS in the pregnant, lactating, fetal and neonatal rat using a physiologically based pharmacokinetic model. Reprod Toxicol. 2012; 33(4):468-490. 10.1016/j.reprotox.2011.07.003

31. Loccisano AE, Longnecker MP, Campbell JL, Jr., Andersen ME, Clewell HJ, 3rd. Development of PBPK models for PFOA and PFOS for human pregnancy and lactation life stages. J Toxicol Environ Health A. 2013; 76(1):25-57. 10.1080/15287394.2012.722523

32. Olsen GW, Burris JM, Ehresman DJ, Froehlich JW, Seacat AM, Butenhoff JL, Zobel LR. Half-life of serum elimination of perfluorooctanesulfonate, perfluorohexanesulfonate, and perfluorooctanoate in retired fluorochemical production workers. Environ Health Perspect. 2007; 115(9):1298-1305. 10.1289/ehp.10009

33. Li Y, Fletcher T, Mucs D, Scott K, Lindh CH, Tallving P, Jakobsson K. Half-lives of PFOS, PFHxS and PFOA after end of exposure to contaminated drinking water. Occup Environ Med. 2018; 75(1):46-51. 10.1136/oemed-2017-104651

34. Gomis MI, Vestergren R, Nilsson H, Cousins IT. Contribution of direct and indirect exposure to human serum concentrations of perfluorooctanoic acid in an occupationally exposed group of ski waxers. Environ Sci Technol. 2016; 50(13):7037-7046. 10.1021/acs.est.6b01477 
35. Kudo N, Suzuki-Nakajima E, Mitsumoto A, Kawashima Y. Responses of the liver to perfluorinated fatty acids with different carbon chain length in male and female mice: In relation to induction of hepatomegaly, peroxisomal beta-oxidation and microsomal 1acylglycerophosphocholine acyltransferase. Biol Pharm Bull. 2006; 29(9):1952-1957.

36. Kudo N, Yamazaki T, Sakamoto T, Sunaga K, Tsuda T, Mitsumoto A, Kawashima Y. Effects of perfluorinated fatty acids with different carbon chain length on fatty acid profiles of hepatic lipids in mice. Biol Pharm Bull. 2011; 34(6):856-864.

37. Permadi H, Lundgren B, Andersson K, DePierre JW. Effects of perfluoro fatty acids on xenobiotic-metabolizing enzymes, enzymes which detoxify reactive forms of oxygen and lipid peroxidation in mouse liver. Biochem Pharmacol. 1992; 44(6):1183-1191.

38. Vanden Heuvel JP, Kuslikis BI, Van Rafelghem MJ, Peterson RE. Tissue distribution, metabolism, and elimination of perfluorooctanoic acid in male and female rats. J Biochem Toxicol. 1991; 6(2):83-92.

39. Vanden Heuvel JP, Thompson JT, Frame SR, Gillies PJ. Differential activation of nuclear receptors by perfluorinated fatty acid analogs and natural fatty acids: A comparison of human, mouse, and rat peroxisome proliferator-activated receptor- $\alpha,-\beta$, and $-\gamma$, liver $\mathrm{X}$ receptor- $\beta$, and retinoid X receptor- $\alpha$. Toxicol Sci. 2006; 92(2):476-489. 10.1093/toxsci/kfl014

40. Wolf CJ, Takacs ML, Schmid JE, Lau C, Abbott BD. Activation of mouse and human peroxisome proliferator-activated receptor alpha by perfluoroalkyl acids of different functional groups and chain lengths. Toxicol Sci. 2008; 106(1):162-171. 10.1093/toxsci/kfn166

41. Cheng X, Klaassen CD. Perfluorocarboxylic acids induce cytochrome P450 enzymes in mouse liver through activation of PPAR-alpha and CAR transcription factors. Toxicol Sci. 2008; 106(1):29-36. 10.1093/toxsci/kfn147

42. Rosen MB, Lee JS, Ren H, Vallanat B, Liu J, Waalkes MP, Abbott BD, Lau C, Corton JC. Toxicogenomic dissection of the perfluorooctanoic acid transcript profile in mouse liver: Evidence for the involvement of nuclear receptors PPAR alpha and CAR. Toxicol Sci. 2008; 103(1):46-56. 10.1093/toxsci/kfn025

43. Elcombe CR, Elcombe BM, Foster JR, Farrar DG, Jung R, Chang SC, Kennedy GL, Butenhoff JL. Hepatocellular hypertrophy and cell proliferation in Sprague-Dawley rats following dietary exposure to ammonium perfluorooctanoate occurs through increased activation of the xenosensor nuclear receptors PPARalpha and CAR/PXR. Arch Toxicol. 2010; 84(10):787798. 10.1007/s00204-010-0572-2

44. Perkins RG, Butenhoff JL, Kennedy GL, Jr., Palazzolo MJ. 13-week dietary toxicity study of ammonium perfluorooctanoate (APFO) in male rats. Drug Chem Toxicol. 2004; 27(4):361-378. $10.1081 /$ dct-200039773

45. Butenhoff J, Costa G, Elcombe C, Farrar D, Hansen K, Iwai H, Jung R, Kennedy G, Jr., Lieder $\mathrm{P}$, Olsen $\mathrm{G}$ et al. Toxicity of ammonium perfluorooctanoate in male cynomolgus monkeys after oral dosing for 6 months. Toxicol Sci. 2002; 69(1):244-257. 
46. C8 Science Panel. C8 probable link reports: 2011-2012. 2012. http://www.c8sciencepanel.org/prob link.html

47. Agency for Toxic Substances and Disease Registry (ATSDR). Toxicological profile for perfluoroalkyls: Draft for public comment. Atlanta, GA: Centers for Disease Control and Prevention; 2018. https://www.atsdr.cdc.gov/toxprofiles/TP.asp?id=1117\&tid=237

48. Fenton SE, Reiner JL, Nakayama SF, Delinsky AD, Stanko JP, Hines EP, White SS, Lindstrom AB, Strynar MJ, Petropoulou SE. Analysis of PFOA in dosed CD-1 mice. Part 2. Disposition of PFOA in tissues and fluids from pregnant and lactating mice and their pups. Reprod Toxicol. 2009; 27(3-4):365-372. 10.1016/j.reprotox.2009.02.012

49. Butenhoff JL, Kennedy GL, Jr., Frame SR, O'Connor JC, York RG. The reproductive toxicology of ammonium perfluorooctanoate (APFO) in the rat. Toxicology. 2004; 196(1-2):95116. 10.1016/j.tox.2003.11.005

50. Johnson PI, Sutton P, Atchley DS, Koustas E, Lam J, Sen S, Robinson KA, Axelrad DA, Woodruff TJ. The Navigation Guide-Evidence-based medicine meets environmental health: Systematic review of human evidence for PFOA effects on fetal growth. Environ Health Perspect. 2014; 122(10):1028-1039.

51. Negri E, Metruccio F, Guercio V, Tosti L, Benfenati E, Bonzi R, La Vecchia C, Moretto A. Exposure to PFOA and PFOS and fetal growth: A critical merging of toxicological and epidemiological data. Crit Rev Toxicol. 2017; 47(6):482-508. 10.1080/10408444.2016.1271972

52. Verner M-A, Loccisano AE, Morken N-H, Yoon M, Wu H, McDougall R, Maisonet M, Marcus M, Kishi R, Miyashita C et al. Associations of Perfluoroalkyl Substances (PFAS) with lower birth weight: An evaluation of potential confounding by glomerular filtration rate using a Physiologically Based Pharmacokinetic Model (PBPK). Environ Health Perspect. 2015; 123(12):1317-1324. 10.1289/ehp.1408837

53. Steenland K, Barry V, Savitz D. Serum perfluorooctanoic acid and birthweight: An updated meta-analysis with bias analysis. Epidemiology. 2018; 29(6):765-776.

10.1097/ede.0000000000000903

54. Rappazzo KM, Coffman E, Hines EP. Exposure to perfluorinated alkyl substances and health outcomes in children: A systematic review of the epidemiologic literature. Int J Env Res Public Health. 2017; 14(7). 10.3390/ijerph14070691

55. Loveless SE, Hoban D, Sykes G, Frame SR, Everds NE. Evaluation of the immune system in rats and mice administered linear ammonium perfluorooctanoate. Toxicol Sci. 2008; 105(1):8696. $10.1093 /$ toxsci/kfn1 13

56. Yang Q, Abedi-Valugerdi M, Xie Y, Zhao XY, Moller G, Nelson BD, DePierre JW. Potent suppression of the adaptive immune response in mice upon dietary exposure to the potent peroxisome proliferator, perfluorooctanoic acid. Int Immunopharmacol. 2002; 2(2-3):389-397.

57. Yang Q, Xie Y, Alexson SE, Nelson BD, DePierre JW. Involvement of the peroxisome proliferator-activated receptor alpha in the immunomodulation caused by peroxisome proliferators in mice. Biochem Pharmacol. 2002; 63(10):1893-1900. 
58. Yang Q, Xie Y, Depierre JW. Effects of peroxisome proliferators on the thymus and spleen of mice. Clin Exp Immunol. 2000; 122(2):219-226. 10.1046/j.1365-2249.2000.01367.x

59. Dewitt JC, Copeland CB, Strynar MJ, Luebke RW. Perfluorooctanoic acid-induced immunomodulation in adult C57BL/6J or C57BL/6N female mice. Environ Health Perspect. 2008; 116(5):644-650. 10.1289/ehp.10896

60. DeWitt JC, Williams WC, Creech NJ, Luebke RW. Suppression of antigen-specific antibody responses in mice exposed to perfluorooctanoic acid: Role of PPARalpha and T- and B-cell targeting. J Immunotoxicol. 2016; 13(1):38-45. 10.3109/1547691x.2014.996682

61. Fairley KJ, Purdy R, Kearns S, Anderson SE, Meade B. Exposure to the immunosuppressant, perfluorooctanoic acid, enhances the murine $\mathrm{IgE}$ and airway hyperreactivity response to ovalbumin. Toxicol Sci. 2007; 97(2):375-383. 10.1093/toxsci/kfm053

62. Ryu MH, Jha A, Ojo OO, Mahood TH, Basu S, Detillieux KA, Nikoobakht N, Wong CS, Loewen M, Becker AB et al. Chronic exposure to perfluorinated compounds: Impact on airway hyperresponsiveness and inflammation. Am J Physiol. 2014; 307(10):L765-774.

10.1152/ajplung.00100.2014

63. Grandjean P, Andersen EW, Budtz-Jørgensen E, Nielsen F, Mølbak K, Weihe P, Heilmann C. Serum vaccine antibody concentrations in children exposed to perfluorinated compounds. JAMA. 2012; 307(4):391-397. 10.1001/jama.2011.2034

64. Grandjean P, Heilmann C, Weihe P, Nielsen F, Mogensen UB, Timmermann A, BudtzJørgensen E. Estimated exposures to perfluorinated compounds in infancy predict attenuated vaccine antibody concentrations at age 5-years. J Immunotoxicol. 2017; 14(1):188-195. 10.1080/1547691X.2017.1360968

65. Grandjean P, Heilmann C, Weihe P, Nielsen F, Mogensen Ulla B, Budtz-Jørgensen E. Serum vaccine antibody concentrations in adolescents exposed to perfluorinated compounds. Environ Health Perspect. 2017; 125(7):077018. 10.1289/EHP275

66. Granum B, Haug LS, Namork E, Stolevik SB, Thomsen C, Aaberge IS, van Loveren H, Lovik M, Nygaard UC. Pre-natal exposure to perfluoroalkyl substances may be associated with altered vaccine antibody levels and immune-related health outcomes in early childhood. J Immunotoxicol. 2013; 10(4):373-379. 10.3109/1547691x.2012.755580

67. Kielsen K, Shamim Z, Ryder LP, Nielsen F, Grandjean P, Budtz-Jørgensen E, Heilmann C. Antibody response to booster vaccination with tetanus and diphtheria in adults exposed to perfluorinated alkylates. J Immunotoxicol. 2016; 13(2):270-273.

10.3109/1547691X.2015.1067259

68. Mogensen UB, Grandjean P, Heilmann C, Nielsen F, Weihe P, Budtz-Jorgensen E. Structural equation modeling of immunotoxicity associated with exposure to perfluorinated alkylates. Environ Health. 2015; 14:47. 10.1186/s12940-015-0032-9

69. Stein CR, McGovern KJ, Pajak AM, Maglione PJ, Wolff MS. Perfluoroalkyl and polyfluoroalkyl substances and indicators of immune function in children aged 12-19 y: National 
Health and Nutrition Examination Survey. Pediatr Res. 2016; 79(2):348-357. $10.1038 /$ pr.2015.213

70. Looker C, Luster MI, Calafat AM, Johnson VJ, Burleson GR, Burleson FG, Fletcher T. Influenza vaccine response in adults exposed to perfluorooctanoate and perfluorooctanesulfonate. Toxicol Sci. 2014; 138(1):76-88. 10.1093/toxsci/kft269

71. National Toxicology Program (NTP). Monograph on immunotoxicity associated with exposure to perfluorooctanoic acid (PFOA) and perfluorooctane sulfonate (PFOS). Research Triangle Park, NC: U.S. Department of Health and Human Services, National Institutes of Health, Office of Health Assessment and Translation; 2016. https://ntp.niehs.nih.gov/ntp/ohat/pfoa_pfos/pfoa_pfosmonograph_508.pdf

72. Butenhoff JL, Kennedy GL, Jr., Chang SC, Olsen GW. Chronic dietary toxicity and carcinogenicity study with ammonium perfluorooctanoate in Sprague-Dawley rats. Toxicology. 2012; 298(1-3):1-13. 10.1016/j.tox.2012.04.001

73. Hardisty JF, Willson GA, Brown WR, McConnell EE, Frame SR, Gaylor DW, Kennedy GL, Butenhoff JL. Pathology Working Group review and evaluation of proliferative lesions of mammary gland tissues in female rats fed ammonium perfluorooctanoate (APFO) in the diet for 2 years. Drug Chem Toxicol. 2010; 33(2):131-137. 10.3109/01480541003667610

74. Biegel LB, Hurtt ME, Frame SR, O'Connor JC, Cook JC. Mechanisms of extrahepatic tumor induction by peroxisome proliferators in male CD rats. Toxicol Sci. 2001; 60(1):44-55.

75. Caverly Rae JM, Frame SR, Kennedy GL, Butenhoff JL, Chang S-C. Pathology review of proliferative lesions of the exocrine pancreas in two chronic feeding studies in rats with ammonium perfluorooctanoate. Toxicol Rep. 2014; 1:85-91.

https://doi.org/10.1016/j.toxrep.2014.04.005

76. Tilton SC, Orner GA, Benninghoff AD, Carpenter HM, Hendricks JD, Pereira CB, Williams DE. Genomic profiling reveals an alternate mechanism for hepatic tumor promotion by perfluorooctanoic acid in rainbow trout. Environ Health Perspect. 2008; 116(8):1047-1055. 10.1289/ehp. 11190

77. International Agency for Research on Cancer (IARC). IARC monographs on the evaluation of carcinogenic risks to humans. Some chemicals used as solvents and in polymer manufacture. Lyon, France: International Agency for Research on Cancer; 2017. https://monographs.iarc.fr/wp-content/uploads/2018/06/mono110.pdf

78. Takagi A, Sai K, Umemura T, Hasegawa R, Kurokawa Y. Short-term exposure to the peroxisome proliferators, perfluorooctanoic acid and perfluorodecanoic acid, causes significant increase of 8-hydroxydeoxyguanosine in liver DNA of rats. Cancer Lett. 1991; 57(1):55-60.

79. Buhrke T, Kibellus A, Lampen A. In vitro toxicological characterization of perfluorinated carboxylic acids with different carbon chain lengths. Toxicol Lett. 2013; 218(2):97-104. 10.1016/j.toxlet.2013.01.025 
80. Fernandez Freire P, Perez Martin JM, Herrero O, Peropadre A, de la Pena E, Hazen MJ. In vitro assessment of the cytotoxic and mutagenic potential of perfluorooctanoic acid. Toxicol In Vitro. 2008; 22(5):1228-1233. 10.1016/j.tiv.2008.04.004

81. Yahia D, Haruka I, Kagashi Y, Tsuda S. 8-Hydroxy-2'-deoxyguanosine as a biomarker of oxidative DNA damage induced by perfluorinated compounds in TK6 cells. Environ Toxicol. 2016; 31(2):192-200. 10.1002/tox.22034

82. Yao X, Zhong L. Genotoxic risk and oxidative DNA damage in HepG2 cells exposed to perfluorooctanoic acid. Mutat Res. 2005; 587(1-2):38-44. 10.1016/j.mrgentox.2005.07.010

83. Wielsoe M, Long M, Ghisari M, Bonefeld-Jorgensen EC. Perfluoroalkylated substances (PFAS) affect oxidative stress biomarkers in vitro. Chemosphere. 2015; 129:239-245. 10.1016/j.chemosphere.2014.10.014

84. Florentin A, Deblonde T, Diguio N, Hautemaniere A, Hartemann P. Impacts of two perfluorinated compounds (PFOS and PFOA) on human hepatoma cells: Cytotoxicity but no genotoxicity? Int J Hyg Environ Health. 2011; 214(6):493-499. 10.1016/j.ijheh.2011.05.010

85. Jacquet N, Maire MA, Rast C, Bonnard M, Vasseur P. Perfluorooctanoic acid (PFOA) acts as a tumor promoter on Syrian hamster embryo (SHE) cells. Environ Sci Pollut Res Int. 2011; 19(7):2537-2549. 10.1007/s11356-012-0968-Z

86. Lindeman B, Maass C, Duale N, Gutzkow KB, Brunborg G, Andreassen A. Effects of perand polyfluorinated compounds on adult rat testicular cells following in vitro exposure. Reprod Toxicol. 2012; 33(4):531-537. 10.1016/j.reprotox.2011.04.001

87. Butenhoff JL, Kennedy GL, Jung R, Chang SC. Evaluation of perfluorooctanoate for potential genotoxicity. Toxicol Rep. 2014; 1:252-270. 10.1016/j.toxrep.2014.05.012

88. National Toxicology Program (NTP). Toxicity studies of perfluorinated carboxylic acids (perfluorohexanoic acid, perfluorooctanoic acid, perfluorononanoic acid, and perfluorodecanoic acid) administered by gavage to Sprague Dawley (Hsd:Sprague Dawley SD) rats. Research Triangle Park, NC: U.S. Department of Health and Human Services, Public Health Service, National Institutes of Health; 2019. Toxicity Study Report No. 97 (in preparation).

89. Chhabra RS, Bucher JR, Haseman JK, Elwell MR, Kurtz PJ, Carlton BD. Comparative carcinogenicity of 5,5-diphenylhydantoin with or without perinatal exposure in rats and mice. Fundam Appl Toxicol. 1993; 21(2):174-186.

90. Chhabra RS, Bucher JR, Haseman JK, Elwell MR, Kurtz PJ, Carlton BD. Comparative carcinogenicity of polybrominated biphenyls with or without perinatal exposure in rats and mice. Fundam Appl Toxicol. 1993; 21(4):451-460.

91. Chhabra RS, Eustis S, Haseman JK, Kurtz PJ, Carlton BD. Comparative carcinogenicity of ethylene thiourea with or without perinatal exposure in rats and mice. Fundam Appl Toxicol. 1992; 18(3):405-417.

92. Maronpot RR, Boorman GA. Interpretation of rodent hepatocellular proliferative alterations and hepatocellular tumors in chemical safety assessment. Toxicol Pathol. 1982; 10(2):71-78. $10.1177 / 019262338201000210$ 
93. Boorman G, Montgomery C, Jr., Eustis S, Wolfe M, McConnell E, Hardisty J. Quality assurance in pathology for rodent carcinogenicity studies In: Milman H, Weisburger E, editors. Handbook of Carcinogen Testing. Park Ridge, NJ: Noyes Publications; 1985. p. 345-357.

94. McConnell EE, Solleveld HA, Swenberg JA, Boorman GA. Guidelines for combining neoplasms for evaluation of rodent carcinogenesis studies. J Natl Cancer Inst. 1986; 76(2):283289.

95. Kaplan EL, Meier P. Nonparametric estimation from incomplete observations. J Am Stat Assoc. 1958; 53(282):457-481. 10.2307/2281868

96. Cox DR. Regression models and life-tables. J R Stat Soc Ser B. 1972; 34(2):187-202.

97. Bailer AJ, Portier CJ. Effects of treatment-induced mortality and tumor-induced mortality on tests for carcinogenicity in small samples. Biometrics. 1988; 44(2):417-431.

98. Piegorsch W, Bailer A. Statistics for environmental biology and toxicology: Section 6.3.2. London, UK: Chapman and Hall; 1997.

99. Portier CJ, Bailer AJ. Testing for increased carcinogenicity using a survival-adjusted quantal response test. Fundam Appl Toxicol. 1989; 12(4):731-737.

100. Portier CJ, Hedges JC, Hoel DG. Age-specific models of mortality and tumor onset for historical control animals in the National Toxicology Program's carcinogenicity experiments. Cancer Res. 1986; 46(9):4372-4378.

101. Bieler GS, Williams RL. Ratio estimates, the delta method, and quantal response tests for increased carcinogenicity. Biometrics. 1993; 49(3):793-801.

102. Nam JM. A simple approximation for calculating sample sizes for detecting linear trend in proportions. Biometrics. 1987; 43(3):701-705.

103. Rao JN, Scott AJ. A simple method for the analysis of clustered binary data. Biometrics. 1992; 48(2):577-585.

104. Fung KY, Krewski D, Rao JN, Scott AJ. Tests for trend in developmental toxicity experiments with correlated binary data. Risk Anal. 1994; 14(4):639-648.

105. Gart JJ, Chu KC, Tarone RE. Statistical issues in interpretation of chronic bioassay tests for carcinogenicity. J Natl Cancer Inst. 1979; 62(4):957-974.

106. Dixon W, Massey FJ J. Introduction to statistical analysis. New York: McGraw Hill Book Company, Inc.; 1957.

107. Tukey J. Easy summaries - numerical and graphical. In: Exploratory Data Analysis. Reading, MA: Addison-Wesley; 1977. p. 43-44.

108. Dunnett CW. A multiple comparison procedure for comparing several treatments with a control. J Am Stat Assoc. 1955; 50(272):1096-1121.

109. Williams DA. A test for differences between treatment means when several dose levels are compared with a zero dose control. Biometrics. 1971; 27(1):103-117. 
110. Williams DA. The comparison of several dose levels with a zero dose control. Biometrics. 1972; 28(2):519-531.

111. Hommel G. A stagewise rejective multiple test procedure based on a modified Bonferroni test. Biometrika. 1988; 75(2):383-386.

112. Shirley E. A non-parametric equivalent of Williams' test for contrasting increasing dose levels of a treatment. Biometrics. 1977; 33(2):386-389.

113. Williams DA. A note on Shirley's nonparametric test for comparing several dose levels with a zero-dose control. Biometrics. 1986; 42(1):183-186.

114. Dunn OJ. Multiple comparisons using rank sums. Technometrics. 1964; 6(3):241-252.

115. Jonckheere AR. A distribution-free $k$-sample test against ordered alternatives. Biometrika. 1954; 41(1/2):133-145. 10.2307/2333011

116. Hsu JC. The factor analytic approach to simultaneous inference in the general linear model. J Comput Graph Stat. 1992; 1(2):151-168. 10.1080/10618600.1992.10477011

117. Haseman JK. Value of historical controls in the interpretation of rodent tumor data. Drug Inf J. 1992; 26(2):191-200. 10.1177/009286159202600210

118. Haseman JK. Data analysis: Statistical analysis and use of historical control data. Regul Toxicol Pharmacol. 1995; 21(1):52-59; discussion 81-56. 10.1006/rtph.1995.1009

119. Haseman JK, Rao GN. Effects of corn oil, time-related changes, and inter-laboratory variability on tumor occurrence in control Fischer 344 (F344/N) rats. Toxicol Pathol. 1992; 20(1):52-60. 10.1177/019262339202000107

120. Code of Federal Regulations (CFR). 21:Part 58.

121. Suttie A, Masson R, Schutten M. Chapter 10 - Endocrine pancreas In: Suttie A, editor. Boorman's Pathology of the Rat. 2nd ed. Boston, MA: Academic Press; 2018. p. 107-122.

122. Weaver YM, Ehresman DJ, Butenhoff JL, Hagenbuch B. Roles of rat renal organic anion transporters in transporting perfluorinated carboxylates with different chain lengths. Toxicol Sci. 2010; 113(2):305-314. 10.1093/toxsci/kfp275

123. Ehresman DJ, Froehlich JW, Olsen GW, Chang S-C, Butenhoff JL. Comparison of human whole blood, plasma, and serum matrices for the determination of perfluorooctanesulfonate (PFOS), perfluorooctanoate (PFOA), and other fluorochemicals. Environ Res. 2007; 103(2):176184.

124. Lilienthal H, Dieter HH, Holzer J, Wilhelm M. Recent experimental results of effects of perfluoroalkyl substances in laboratory animals - Relation to current regulations and guidance values. Int J Hyg Environ Health. 2017; 220(4):766-775. 10.1016/j.ijheh.2017.03.001

125. Post GB, Cohn PD, Cooper KR. Perfluorooctanoic acid (PFOA), an emerging drinking water contaminant: A critical review of recent literature. Environ Res. 2012; 116:93-117. 10.1016/j.envres.2012.03.007 
126. Rosen MB, Das KP, Rooney J, Abbott B, Lau C, Corton JC. PPARalpha-independent transcriptional targets of perfluoroalkyl acids revealed by transcript profiling. Toxicology. 2017; 387:95-107. 10.1016/j.tox.2017.05.013

127. Seacat AM, Thomford PJ, Hansen KJ, Olsen GW, Case MT, Butenhoff JL. Subchronic toxicity studies on perfluorooctanesulfonate potassium salt in cynomolgus monkeys. Toxicol Sci. 2002; 68(1):249-264. 10.1093/toxsci/68.1.249

128. Ennulat D, Magid-Slav M, Rehm S, Tatsuoka KS. Diagnostic performance of traditional hepatobiliary biomarkers of drug-induced liver injury in the rat. Toxicol Sci. 2010; 116(2):397412. $10.1093 /$ toxsci/kfq144

129. Thompson MB. Bile acids in the assessment of hepatocellular function. Toxicol Pathol. 1996; 24(1):62-71. 10.1177/019262339602400109

130. Ennulat D, Walker D, Clemo F, Magid-Slav M, Ledieu D, Graham M, Botts S, Boone L. Effects of hepatic drug-metabolizing enzyme induction on clinical pathology parameters in animals and man. Toxicol Pathol. 2010; 38(5):810-828. 10.1177/0192623310374332

131. Hall A, Elcombe C, Foster J, Harada T, Kaufmann W, Knippel A, Küttler K, Malarkey D, Maronpot R, Nishikawa A. Liver hypertrophy: A review of adaptive (adverse and non-adverse) changes - Conclusions from the 3rd International ESTP Expert Workshop. Toxicol Pathol. 2012; 40(7):971-994.

132. Chen X, Matthews J, Zhou L, Pelton P, Liang Y, Xu J, Yang M, Cryan E, Rybczynski P, Demarest K. Improvement of dyslipidemia, insulin sensitivity, and energy balance by a peroxisome proliferator-activated receptor alpha agonist. Metabolism. 2008; 57(11):1516-1525. 10.1016/j.metabol.2008.06.005

133. Konig B, Koch A, Spielmann J, Hilgenfeld C, Stangl GI, Eder K. Activation of PPARalpha lowers synthesis and concentration of cholesterol by reduction of nuclear SREBP-2. Biochem Pharmacol. 2007; 73(4):574-585. 10.1016/j.bcp.2006.10.027

134. Walker D, Tomlinson L. Lipids In: Kurtz DM, Travlos GS, editors. The Clinical Chemistry of Laboratory Animals. Boca Raton, FL: CRC Press; 2018. p. 777-871.

135. Yan J, Chen B, Lu J, Xie W. Deciphering the roles of the constitutive androstane receptor in energy metabolism. Acta Pharmacol Sin. 2015; 36(1):62-70. 10.1038/aps.2014.102

136. Corton JC, Peters JM, Klaunig JE. The PPAR $\alpha$-dependent rodent liver tumor response is not relevant to humans: addressing misconceptions. Arch Toxicol. 2018; 92(1):83-119. 10.1007/s00204-017-2094-7

137. Felter SP, Foreman JE, Boobis A, Corton JC, Doi AM, Flowers L, Goodman J, Haber LT, Jacobs A, Klaunig JE et al. Human relevance of rodent liver tumors: key insights from a Toxicology Forum workshop on nongenotoxic modes of action. Regul Toxicol Pharmacol. 2018; 92:1-7. 10.1016/j.yrtph.2017.11.003

138. National Toxicology Program (NTP). NTP historical controls report: All routes and vehicles - F344/N rats. Research Triangle Park, NC: U.S. Department of Health and Human Services, Public Health Service, National Toxicology Program; 2013. 
https://ntp.niehs.nih.gov/ntp/historical controls/ntp2000 2013/histcont2013 ratsf344 allroutes $\underline{508 . p d f}$

139. National Toxicology Program (NTP). NTP historical controls report: All routes and vehicles - Wistar-Han rats. Research Triangle Park, NC: U.S. Department of Health and Human Services, Public Health Service, National Toxicology Program; 2016. https://ntp.niehs.nih.gov/ntp/historical_controls/ntp2000 2016/aug-2016-hc-report-wh-rats-allroutes.pdf

140. Charles River Laboratories. Compilation of spontaneous neoplastic lesions and survival in Crl:CD (SD) rats from control groups. Wilmington, MA: Charles River Laboratories; 2013. https://www.criver.com/sites/default/files/Technical\%20Resources/Compilation\%20of\%20Spont aneous\%20Neoplastic\%20Lesions\%20and\%20Survival $\% 20 \mathrm{in} \% 20 \mathrm{Crl}-$ CD_SD_\%20Rats\%20From\%20Control\%20Groups\%20-\%20March\%202013.pdf

141. Giménez-Bastida JA, Surma M, Zieliński H. In vitro evaluation of the cytotoxicity and modulation of mechanisms associated with inflammation induced by perfluorooctanesulfonate and perfluorooctanoic acid in human colon myofibroblasts CCD-18Co. Toxicol In Vitro. 2015; 29(7):1683-1691.

142. Shankar A, Xiao J, Ducatman A. Perfluoroalkyl chemicals and chronic kidney disease in US adults. Am J Epidemiol. 2011; 174(8):893-900.

143. Dhingra R, Winquist A, Darrow LA, Klein M, Steenland K. A study of reverse causation: Examining the associations of perfluorooctanoic acid serum levels with two outcomes. Environ Health Perspect. 2017; 125(3):416-421. 10.1289/EHP273

144. Anderson LM. Predictive values of traditional animal bioassay studies for human perinatal carcinogenesis risk determination. Toxicol Appl Pharmacol. 2004; 199(2):162-174.

10.1016/j.taap.2004.02.008 


\section{Appendix A. Chemical Characterization and Dose Formulation Studies}

\section{Table of Contents}

A.1. Procurement and Characterization of Perfluorooctanoic Acid ...................................... A-2

A.2. Preparation and Analysis of Dose Formulations........................................................... A-3

\section{Tables}

Table A-1. Preparation and Storage of Dose Formulations in the 21-week and Two-year Feed Study of Perfluorooctanoic Acid ....................................................... A-4

Table A-2. Chromatography Systems Used in the 21-week and Two-year Feed Study of Perfluorooctanoic Acid

Table A-3. Results of Analyses of Dose Formulations Administered to Rats in the 21-week Feed Study of Perfluorooctanoic Acid.

Table A-4. Results of Analyses of Dose Formulations Administered to Rats in the Two-year Feed Study of Perfluorooctanoic Acid A-5

\section{Figures}

Figure A-1. Reference Infrared Absorption Spectrum of Perfluorooctanoic Acid................... A-8 Figure A-2. ${ }^{19}$ F-NMR Spectrum of Sample of Lot 03427TH of Perfluorooctanoic Acid......... A-8 Figure A-3. ${ }^{13} \mathrm{C}$ NMR Spectrum of Sample of Lot 03427TH of Perfluorooctanoic Acid......... A-9 


\section{A.1. Procurement and Characterization of Perfluorooctanoic Acid}

PFOA was obtained from Sigma-Aldrich (St Louis, MO) in a single lot (lot 03427TH). Identity, purity, and stability analyses were conducted under the analytical chemistry laboratory and study laboratory at Battelle (Columbus, $\mathrm{OH}$ ). Reports on analyses performed in support of the PFOA studies are on file at the National Institute of Environmental Health Sciences (NIEHS).

PFOA is a white crystalline solid. The lot was identified using infrared (IR) spectroscopy. In addition, the lot was analyzed using ${ }^{19} \mathrm{~F}$ (including fluorine-fluorine correlation spectroscopy, $\mathrm{COSY}$ ) and ${ }^{13} \mathrm{C}$ nuclear magnetic resonance (NMR) spectroscopy and gas chromatography (GC) with mass spectrometry (MS) detection. The IR spectrum (Figure A-1) was in good agreement with the structure of PFOA and with the reference spectrum of PFOA from the National Institute of Advanced Industrial Science and Technology Spectral Database (No. 6075). Due to extensive coupling, the peak shapes in the ${ }^{19} \mathrm{~F}$ spectrum were broad and poorly resolved, but consistent with the structure of PFOA. The ${ }^{13} \mathrm{C}$ spectrum was consistent with the structure of PFOA and also with the prediction from the Advanced Chemistry Development spectral prediction program (Version 10.02, Toronto, Ontario, Canada) for PFOA. The ${ }^{19} \mathrm{~F}$ and ${ }^{13} \mathrm{C}$ spectra are provided in Figure A-2 and Figure A-3, respectively. GC/MS analysis, following conversion to its methyl ester, identified the major peak as PFOA using fragmentation pattern and comparison with the National Institute of Standards and Technology standard for methyl perfluorooctanoate.

The moisture content of lot $03427 \mathrm{TH}$ was determined by Karl Fisher titration performed at Prevalere Life Sciences, Inc. (Whitesboro, NY). The purity of lot $03427 \mathrm{TH}$ was evaluated using $\mathrm{GC}$ with electron capture detection (ECD), following conversion of PFOA to its methyl ester, and using ion chromatography (IC) with conductivity detection and by differential scanning calorimetry (DSC).

Karl Fisher titration yielded a water content of $0.24 \%$. Purity by DSC was $98.96 \%$ with a melting point of approximately $55^{\circ} \mathrm{C}$. GC-FID analysis detected one major peak with an area of $98.3 \%$ of the total peak area, with four reportable impurities that had areas greater than or equal to $0.1 \%$ of the total peak area. IC detected one major peak with $98.8 \%$ of the total peak area, with three impurities that had areas greater than $0.1 \%$ of the total peak area. The overall purity of lot $03427 \mathrm{TH}$ was determined to be greater than $98 \%$. GC with electron capture detection (ECD) showed that the impurities are likely fluorinated compounds. GC-MS analysis showed that two of the impurities representing approximately $1 \%$ were isomers of PFOA; the remaining impurities were perfluorooctenoic acid $(0.51 \%)$ and a structurally dissimilar fluorinated compound $(0.11 \%)$.

Accelerated stability studies of PFOA were conducted by the analytical chemistry laboratory using lot 027022E from Sigma-Aldrich (St Louis, MO) using GC-FID. Stability of PFOA was confirmed for at least 2 weeks when stored in sealed glass vials at temperatures up to $60^{\circ} \mathrm{C}$. To ensure stability, PFOA lot $03427 \mathrm{TH}$ was stored in amber glass bottles at room temperature $\left(25^{\circ} \mathrm{C}\right)$. Periodic analyses of lot $03427 \mathrm{TH}$ of the test chemical were performed prior to and during the animal studies by the study laboratory using GC-ECD; no degradation of the test chemical was detected. 


\section{A.2. Preparation and Analysis of Dose Formulations}

The base diet was meal feed purchased from Zeigler Brothers, Inc. (Gardners, PA). The 21-week study utilized NIH-07 (single lot, milled July 2008) and NTP-2000 (four lots, milled September through December 2008). The 2-year study utilized NIH-07 (two lots milled May and April 2009) and NTP-2000 (24 lots milled June 2009 through June 2011).

Dose formulations were prepared monthly by mixing PFOA with feed (Table A-1). For the 21-week study, formulations of 0, 150, and $300 \mathrm{ppm}$ were prepared in NIH-07 meal feed in September 2008, and in NTP-2000 meal feed twice (October 2008 and January 2009). For the 2-year study, formulations of 0 and 300 ppm PFOA in NIH-07 meal feed were prepared in June 2009. Formulations of 0, 20, 40, and 80 ppm PFOA in NTP-2000 meal feed were also prepared monthly for the 2-year study (28 formulations, July 2009-July 2011).

The analytical chemistry laboratory at Battelle (Columbus, $\mathrm{OH}$ ) confirmed the homogeneity of NIH-07 and NTP-2000 dosed feed at formulations of 150 and 300 ppm PFOA with GC-FID prior to conducting studies. The homogeneity of dosed feed was also assessed by the study laboratory for NIH-07 (150 and 300 ppm PFOA) and NTP-2000 (20, 80, 150, 300, and 1,000 ppm PFOA) formulations with GC-ECD. After mixing, each formulation was sampled from three distinct locations and analysis of PFOA content was conducted using the protocols described in the above chemical procurement and characterization section and detailed in Table A-2. Formulations were determined to be homogenous and of appropriate concentration.

Remaining control and treated formulations were stored in plastic bag-lined buckets. Formulations of NIH- 07 were refrigerated (approximately $5^{\circ} \mathrm{C}$ ), whereas formulations of NTP-2000 were stored at room temperature (approximately $25^{\circ} \mathrm{C}$ ). Stability was confirmed for these conditions up to 42 days.

Analysis of preadministration and postadministration (animal room) dose formulations of PFOA were each conducted every 1-3 months over the course of the study to determine purity (Table A-3, Table A-4). All preadministration formulations in both the 21-week and 2-year studies were within $10 \%$ of the target concentration. In the 21 -week study, the $300 \mathrm{ppm}$ formulation prepared in October 2008 was $12.7 \%$ below the target concentration when evaluated from feeders 6 weeks later, but only $6.5 \%$ below target when sampled from the remainder in the bucket at that same time. Postadministration formulation samples were analyzed five times over the course of the 2-year study. With the exception of the July 2009 formulation evaluated in September 2009 from residual feed in feeders, the postadministration formulations were within $10 \%$ of the target concentrations. These analyses provide confidence that the administered formulations were reflective of the target concentrations throughout the studies. 
Table A-1. Preparation and Storage of Dose Formulations in the 21-week and Two-year Feed Study of Perfluorooctanoic Acid

\section{Preparation}

Stock solutions of PFOA were created by weighing an appropriate amount of lot $03427 \mathrm{TH}$ and adding it to a volumetric flask. Acetone was used to clean the weighing container until clear (at least three times) and bring the solution to volume. Flasks of stocks solution were sealed and shaken until lot $03427 \mathrm{TH}$ was dissolved (at least 10 inversions). An initial formulation premix was created by weighing an appropriate amount of feed (NIH-07 or NTP-2000) into a mixing bowl. The stock PFOA solution was slowly poured onto the feed while the mixture was stirred using a Hobart mixer. The formulations were mixed for approximately one hour and acetone was used twice to rinse the sides of the bowl and incorporate any residuals. The entire procedure was conducted under a nitrogen stream to encourage cyclonic flow and ensure acetone fully evaporated. In a twin shell blender, half of the remaining untreated feed was evenly covered with the premix. The sides were "rinsed" with the remaining untreated feed in two increments. The final formulation was mixed in the blender for 15 minutes. Dose formulations were prepared monthly throughout the experiments for a total of four formulations in the 21-week study and 30 formulations in the 2-year study.

\section{Chemical Lot Number}

$03427 \mathrm{TH}$

\section{Maximum Storage Time}

42 days

\section{Storage Conditions}

Stored in sealed plastic bag-lined buckets at $\sim 5^{\circ} \mathrm{C}$ (NIH-07) or $\sim 25^{\circ} \mathrm{C}$ (NTP-2000)

\section{Study Laboratory}

Battelle (Columbus, OH)

Table A-2. Chromatography Systems Used in the 21-week and Two-year Feed Study of Perfluorooctanoic Acid

\begin{tabular}{|c|c|c|c|}
\hline Chromatography & Detection System & Column & Mobile Phase \\
\hline \multicolumn{4}{|l|}{ System A } \\
\hline Gas Chromatography & $\begin{array}{l}\text { Flame ionization } \\
\text { detection }\end{array}$ & $\begin{array}{l}\text { Restek RTX-5, } 1.0 \mu \mathrm{m} \text { film } \\
\text { thickness, } 30 \mathrm{~m} \times 0.32 \mathrm{~mm} \text { (ID) }\end{array}$ & Helium, flow rate $\sim 1 \mathrm{~mL} / \mathrm{min}$ \\
\hline \multicolumn{4}{|l|}{ System B } \\
\hline Gas Chromatography & $\begin{array}{l}\text { Electron capture } \\
\text { detection }\end{array}$ & $\begin{array}{l}\text { Restek RTX-5, } 1.0 \mu \mathrm{m} \text { film } \\
\text { thickness, } 30 \mathrm{~m} \times 0.32 \mathrm{~mm} \text { (ID) }\end{array}$ & Helium, flow rate $\sim 1 \mathrm{~mL} / \mathrm{min}$ \\
\hline \multicolumn{4}{|l|}{ System C } \\
\hline Gas Chromatography & Mass selective detector & $\begin{array}{l}\text { Restek RTX-5, } 1.0 \mu \mathrm{m} \text { film } \\
\text { thickness, } 30 \mathrm{~m} \times 0.32 \mathrm{~mm} \text { (ID) }\end{array}$ & Helium, flow rate $\sim 1 \mathrm{~mL} / \mathrm{min}$ \\
\hline \multicolumn{4}{|l|}{ System D } \\
\hline Ion Chromatography & $\begin{array}{l}\text { Suppressed } \\
\text { conductivity } / 40^{\circ} \mathrm{C}\end{array}$ & $\begin{array}{l}\text { Dionex (Sunnyvale, CA) IonPac } \\
\text { NG1-5 uM, } 150 \times 4 \mathrm{~mm} \text { (ID) }\end{array}$ & $\begin{array}{l}\text { A: } 0.1 \mathrm{M} \mathrm{NaOH} \text { in water } \\
\text { B: } 70 \% \text { isopropanol in water } \\
\text { C: water } \\
\text { Flow rate: } 0.6 \mathrm{~mL} / \mathrm{min}\end{array}$ \\
\hline
\end{tabular}

$\mathrm{ID}=$ internal diameter. 
Table A-3. Results of Analyses of Dose Formulations Administered to Rats in the 21-week Feed Study of Perfluorooctanoic Acid

\begin{tabular}{|c|c|c|c|c|}
\hline Date Prepared & Date Analyzed & $\begin{array}{l}\text { Target } \\
\text { Concentration } \\
(\mathbf{p p m})\end{array}$ & $\begin{array}{c}\text { Determined } \\
\text { Concentration } \\
(\mathbf{p p m})^{\mathrm{a}}\end{array}$ & $\begin{array}{l}\text { Difference from } \\
\text { Target }(\%)\end{array}$ \\
\hline \multirow[t]{3}{*}{ September 3, 2008} & September 5, 2008 & 0 & BLOQ & NA \\
\hline & & 150 & 149.5 & -0.3 \\
\hline & & 300 & 296.5 & -1.2 \\
\hline \multirow[t]{3}{*}{ October 14, 2008} & October 17, 2008 & 0 & BLOQ & NA \\
\hline & & 150 & 148.7 & -0.9 \\
\hline & & 300 & 296.5 & -1.2 \\
\hline \multirow[t]{3}{*}{ January 7, 2009} & January 9, 2009 & 0 & BLOQ & NA \\
\hline & & 150 & 148.0 & -1.3 \\
\hline & & 300 & 302.3 & 0.8 \\
\hline \multicolumn{5}{|c|}{ Animal Room Samples ${ }^{b}$} \\
\hline \multirow[t]{3}{*}{ September 3, 2008} & October 17, 2008 & 0 & BLOQ & NA \\
\hline & & 150 & $148 / 149$ & $-1.6 /-0.9$ \\
\hline & & 300 & $310 / 301$ & $3.5 / 0.3$ \\
\hline \multirow[t]{3}{*}{ October 14, 2008} & December 2, 2008 & 0 & BLOQ & NA \\
\hline & & 150 & $140 / 144$ & $-6.9 /-4.0$ \\
\hline & & 300 & $262 / 281$ & $-12.7 /-6.5$ \\
\hline \multicolumn{5}{|c|}{$\begin{array}{l}\text { BLOQ = below the limit of quantification; NA = not applicable. } \\
\text { aAverage of triplicate analysis. } \\
\text { bValue to left of slash mark is a composite sample from formulation left in feeders. Value to the right of the slash mark is for } \\
\text { sample collected from bucket. }\end{array}$} \\
\hline \multicolumn{5}{|c|}{$\begin{array}{l}\text { Table A-4. Results of Analyses of Dose Formulations Administered to Rats in the Two-year Feed } \\
\text { Study of Perfluorooctanoic Acid }\end{array}$} \\
\hline Date Prepared & Date Analyzed & $\begin{array}{l}\text { Target } \\
\text { Concentration } \\
(\text { ppm })\end{array}$ & $\begin{array}{l}\text { Determined } \\
\text { Concentration } \\
(\text { ppm })^{\mathrm{a}}\end{array}$ & $\begin{array}{c}\text { Difference from } \\
\text { Target }(\%)\end{array}$ \\
\hline \multirow[t]{2}{*}{ June 3, 2009} & June 5, 2009 & 0 & BLOQ & NA \\
\hline & & 300 & 297.2 & -0.9 \\
\hline \multirow[t]{4}{*}{ July 16, 2009} & July 21, 2009 & 0 & BLOQ & NA \\
\hline & & 20 & 19.1 & -4.8 \\
\hline & & 40 & 39.0 & -2.6 \\
\hline & & 80 & 75.1 & -6.2 \\
\hline \multirow[t]{3}{*}{ October 6, 2009} & October 9, 2009 & 0 & BLOQ & NA \\
\hline & & 20 & 19.7 & -1.5 \\
\hline & & 40 & 40.1 & 0.2 \\
\hline
\end{tabular}


Perfluorooctanoic Acid, NTP TR 598

\begin{tabular}{|c|c|c|c|c|}
\hline Date Prepared & Date Analyzed & $\begin{array}{c}\text { Target } \\
\text { Concentration } \\
(\mathbf{p p m})\end{array}$ & $\begin{array}{c}\text { Determined } \\
\text { Concentration } \\
(\mathbf{p p m})^{\mathrm{a}}\end{array}$ & $\begin{array}{c}\text { Difference from } \\
\text { Target (\%) }\end{array}$ \\
\hline & & 80 & 79.4 & -0.7 \\
\hline \multirow[t]{4}{*}{ December 29, 2009} & December 30, 2009 & 0 & BLOQ & NA \\
\hline & & 20 & 19.7 & -1.8 \\
\hline & & 40 & 40.8 & 2.0 \\
\hline & & 80 & 80.8 & 1.0 \\
\hline \multirow[t]{4}{*}{ March 23, 2010} & March 24, 2010 & 0 & BLOQ & NA \\
\hline & & 20 & 19.9 & -0.5 \\
\hline & & 40 & 40.1 & 0.1 \\
\hline & & 80 & 83.1 & 3.9 \\
\hline \multirow[t]{4}{*}{ June 15, 2010} & June 16, 2010 & 0 & BLOQ & NA \\
\hline & & 20 & 20.2 & 0.7 \\
\hline & & 40 & 41.8 & 4.4 \\
\hline & & 80 & 81.9 & 2.3 \\
\hline \multirow[t]{4}{*}{ September 7, 2010} & September 10, 2010 & 0 & BLOQ & NA \\
\hline & & 20 & 20.9 & 4.5 \\
\hline & & 40 & 41.3 & 3.2 \\
\hline & & 80 & 82.7 & 3.3 \\
\hline \multirow[t]{4}{*}{ November 30, 2010} & December 1, 2010 & 0 & BLOQ & NA \\
\hline & & 20 & 20.6 & 2.7 \\
\hline & & 40 & 42.3 & 5.7 \\
\hline & & 80 & 81.4 & 1.8 \\
\hline \multirow[t]{4}{*}{ February 23, 2011} & February 24, 2011 & 0 & BLOQ & NA \\
\hline & & 20 & 21.4 & 7.0 \\
\hline & & 40 & 41.7 & 4.3 \\
\hline & & 80 & 85.2 & 6.5 \\
\hline \multirow[t]{4}{*}{ May 23, 2011} & May 24, 2011 & 0 & BLOQ & NA \\
\hline & & 20 & 20.0 & 0.0 \\
\hline & & 40 & 39.2 & -2.0 \\
\hline & & 80 & 77.3 & -3.4 \\
\hline
\end{tabular}


Perfluorooctanoic Acid, NTP TR 598

\begin{tabular}{|c|c|c|c|c|}
\hline Date Prepared & Date Analyzed & $\begin{array}{c}\text { Target } \\
\text { Concentration } \\
(\mathbf{p p m})\end{array}$ & $\begin{array}{c}\text { Determined } \\
\text { Concentration } \\
(\mathbf{p p m})^{\mathrm{a}}\end{array}$ & $\begin{array}{c}\text { Difference from } \\
\text { Target }(\%)\end{array}$ \\
\hline \multirow[t]{4}{*}{ July 18, 2011} & July 19, 2011 & 0 & BLOQ & NA \\
\hline & & 20 & 20.5 & 2.3 \\
\hline & & 40 & 40.1 & 0.1 \\
\hline & & 80 & 81.3 & 1.6 \\
\hline \multicolumn{5}{|c|}{ Animal Room Samples ${ }^{b}$} \\
\hline \multirow[t]{2}{*}{ June 3, 2009} & July 10, 2009 & 0 & BLOQ & NA \\
\hline & & 300 & $280 / 294$ & $-6.7 /-1.9$ \\
\hline \multirow[t]{4}{*}{ July 16, 2009} & September 9, 2009 & 0 & BLOQ & NA \\
\hline & & 20 & $17.7 / 18.3$ & $-11.5 /-8.3$ \\
\hline & & 40 & $35.3 / 37.4$ & $-11.9 /-6.5$ \\
\hline & & 80 & $69.3 / 73.5$ & $-13.4 /-8.1$ \\
\hline \multirow[t]{4}{*}{ March 23, 2010} & May 5, 2010 & 0 & BLOQ & NA \\
\hline & & 20 & $19.3 / 19.8$ & $-3.7 /-1.2$ \\
\hline & & 40 & $39.2 / 39.7$ & $-2.1 /-0.8$ \\
\hline & & 80 & $78.2 / 77.9$ & $-2.3 /-2.7$ \\
\hline \multirow[t]{4}{*}{ November 30, 2010} & January 12, 2011 & 0 & BLOQ & NA \\
\hline & & 20 & $19.3 / 19.8$ & $-3.7 /-0.8$ \\
\hline & & 40 & $40.1 / 41.5$ & $0.2 / 3.8$ \\
\hline & & 80 & $78.8 / 82.1$ & $-1.4 / 2.7$ \\
\hline \multirow[t]{4}{*}{ July 18, 2011} & August 31, 2011 & 0 & BLOQ & NA \\
\hline & & 20 & 19.6/19.2 & $-2.2 /-4.2$ \\
\hline & & 40 & $39.7 / 40.3$ & $-0.7 / 0.8$ \\
\hline & & 80 & 79.0/79.9 & $-1.2 /-0.2$ \\
\hline
\end{tabular}

$\mathrm{BLOQ}=$ below the limit of quantification; $\mathrm{NA}=$ not applicable.

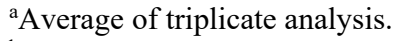

${ }^{b}$ Value to left of slash mark is a composite sample from formulation left in feeders. Value to the right of the slash mark is for sample collected from bucket. 


\section{Perfluorooctanoic Acid, NTP TR 598}

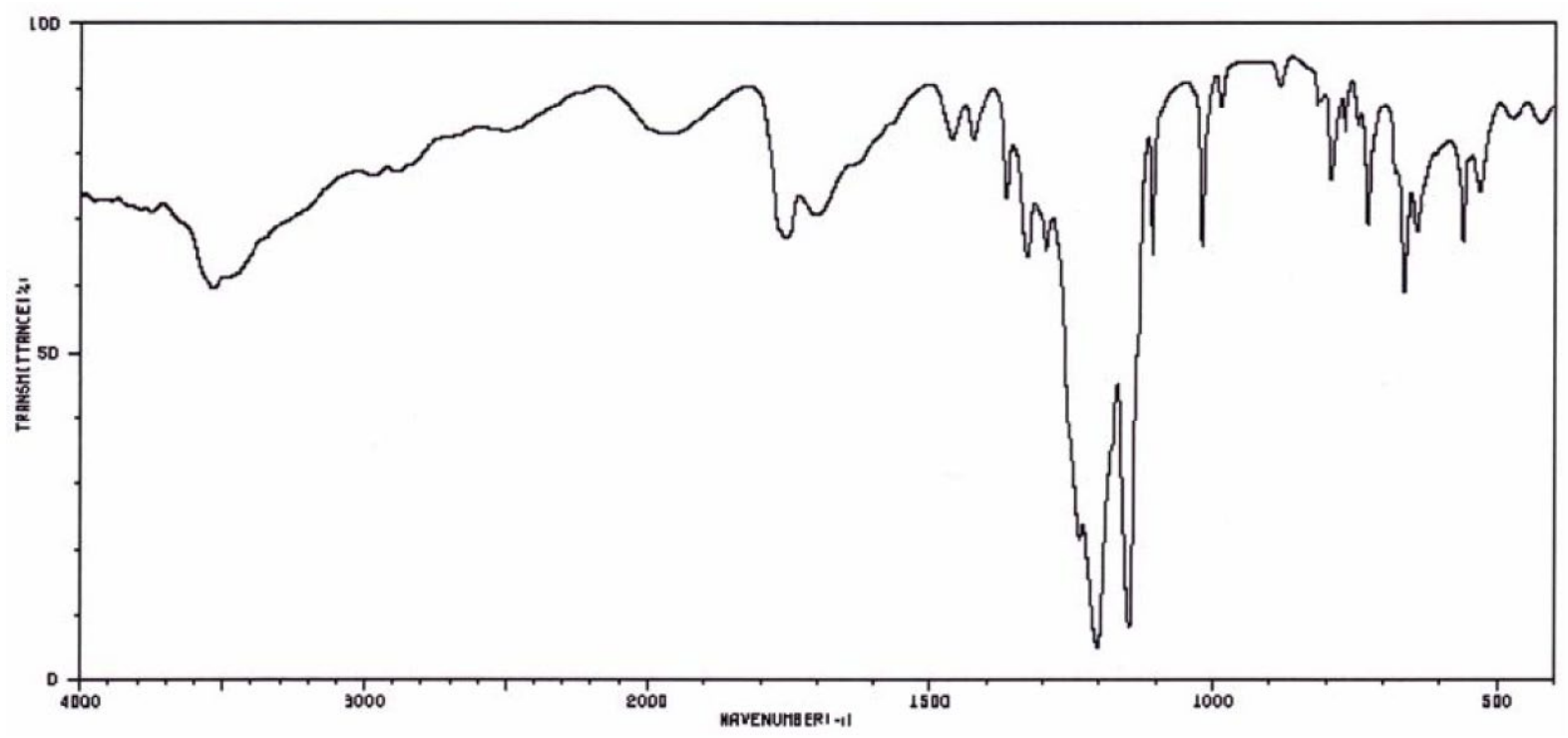

Figure A-1. Reference Infrared Absorption Spectrum of Perfluorooctanoic Acid

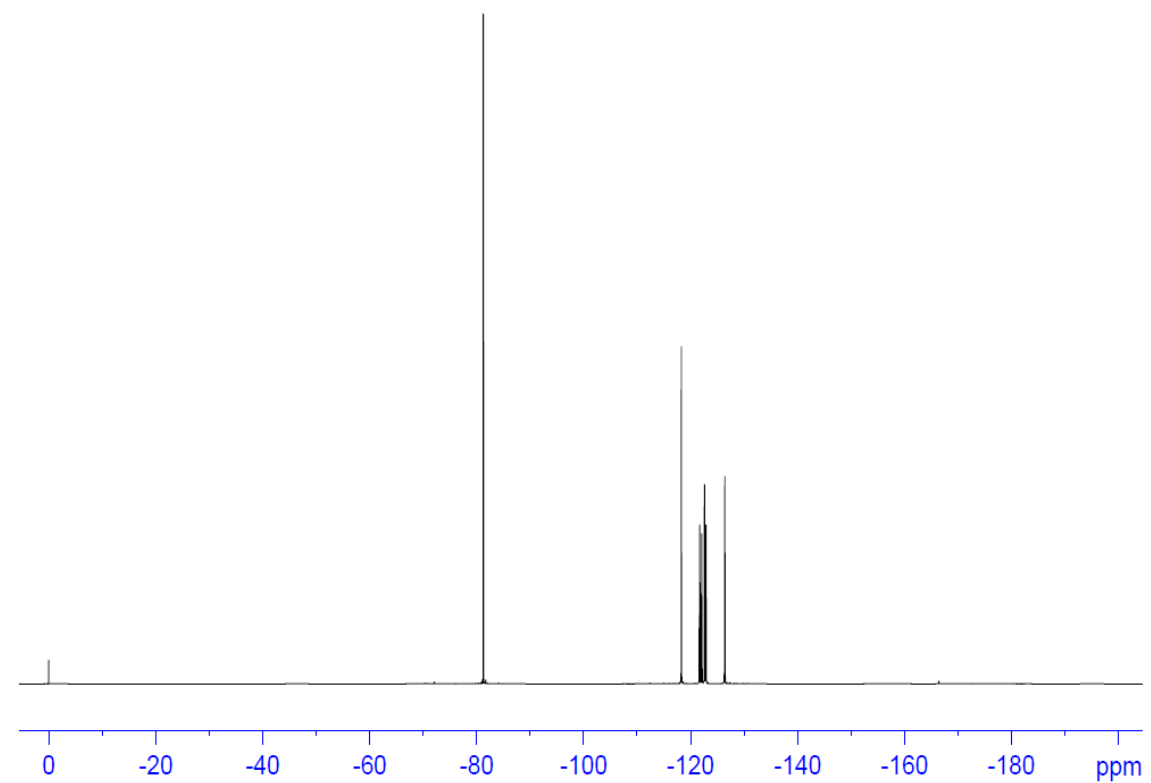

Figure A-2. ${ }^{19}$ F-NMR Spectrum of Sample of Lot 03427TH of Perfluorooctanoic Acid 
Perfluorooctanoic Acid, NTP TR 598

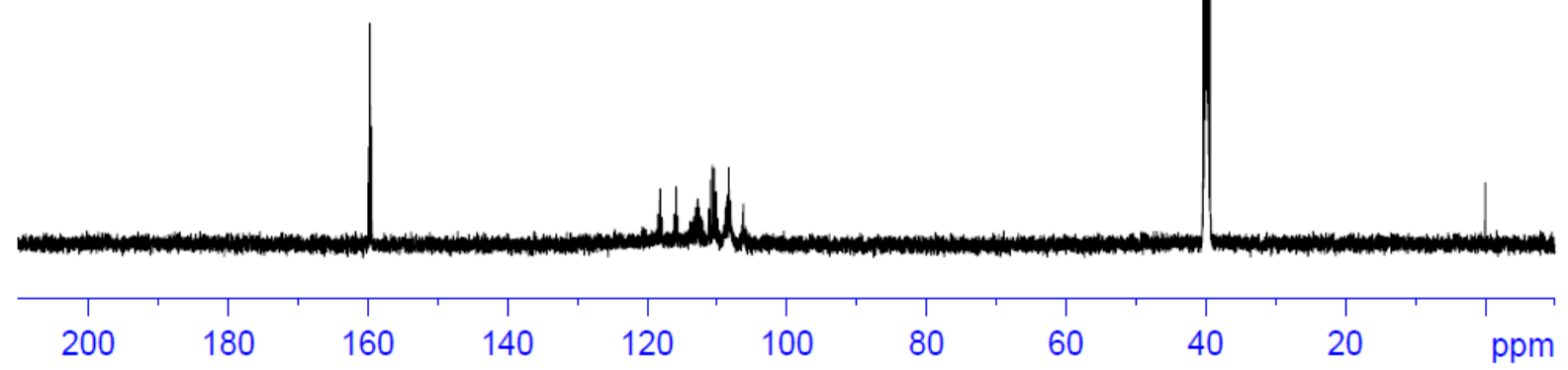

Figure A-3. ${ }^{13}$ C NMR Spectrum of Sample of Lot 03427TH of Perfluorooctanoic Acid 


\section{Appendix B. Ingredients, Nutrient Composition, and Contaminant Levels in NTP-2000 Rat and Mouse Ration}

\section{Tables}

Table B-1. Ingredients of NTP-2000 Rat Ration....

Table B-2. Vitamins and Minerals Added to NTP-2000 Rat Ration ...........................................

Table B-3. Nutrient Composition of NTP-2000 Rat Ration ......................................................

Table B-4. Contaminant Levels in NTP-2000 Rat Ration 
Table B-1. Ingredients of NTP-2000 Rat Ration

\begin{tabular}{|c|c|c|c|c|c|}
\hline \multicolumn{3}{|c|}{ Ingredient } & \multicolumn{2}{|c|}{ Percent by Weight (Study 1) } & Percent by Weight (Study 2) \\
\hline \multicolumn{3}{|c|}{ Ground Hard Winter Wheat } & 22.26 & & 22.26 \\
\hline \multicolumn{3}{|c|}{ Ground \#2 Yellow Shelled Corn } & 22.18 & & 22.18 \\
\hline \multicolumn{3}{|l|}{ Wheat Middlings } & 15.0 & & 15.0 \\
\hline \multicolumn{3}{|l|}{ Oat Hulls } & 8.5 & & 8.5 \\
\hline \multicolumn{3}{|c|}{ Alfalfa Meal (Dehydrated, 17\% Protein) } & 7.5 & & 7.5 \\
\hline \multicolumn{3}{|l|}{ Purified Cellulose } & 5.5 & & 5.5 \\
\hline \multicolumn{3}{|c|}{ Soybean Meal (49\% Protein) } & 5.0 & & 5.0 \\
\hline \multicolumn{3}{|c|}{ Fish Meal (60\% Protein) } & 4.0 & & 4.0 \\
\hline \multicolumn{3}{|c|}{ Corn Oil (without Preservatives) } & 3.0 & & 3.0 \\
\hline \multicolumn{3}{|c|}{ Soy Oil (without Preservatives) } & 3.0 & & 3.0 \\
\hline \multicolumn{3}{|l|}{ Dried Brewer's Yeast } & 1.0 & & 1.0 \\
\hline \multicolumn{3}{|c|}{ Calcium Carbonate (USP) } & 0.9 & & 0.9 \\
\hline \multicolumn{3}{|l|}{ Vitamin Premix $1^{\mathrm{a}}$} & 0.5 & & 0.5 \\
\hline \multicolumn{3}{|l|}{ Mineral Premix $2^{b}$} & 0.5 & & 0.5 \\
\hline \multicolumn{3}{|c|}{ Calcium Phosphate, Dibasic (USP) } & 0.4 & & 0.4 \\
\hline \multicolumn{3}{|l|}{ Sodium Chloride } & 0.3 & & 0.3 \\
\hline \multicolumn{3}{|c|}{ Choline Chloride (70\% Choline) } & 0.26 & & 0.26 \\
\hline \multicolumn{3}{|l|}{ Methionine } & 0.2 & & 0.2 \\
\hline \multicolumn{6}{|c|}{$\begin{array}{l}\text { USP }=\text { United States Pharmacopeia. } \\
\text { aWheat middlings as a carrier. } \\
\text { bCalcium carbonate as a carrier. }\end{array}$} \\
\hline & \multicolumn{3}{|c|}{ Study 1} & \multicolumn{2}{|r|}{ Study 2} \\
\hline & Amount & & Source & Amount & Source \\
\hline \multicolumn{6}{|l|}{ Vitamins } \\
\hline $\mathrm{A}$ & $4,000 \mathrm{IU}$ & $\begin{array}{l}\text { Stab } \\
\text { paln }\end{array}$ & $\begin{array}{l}\text { zed vitamin } \mathrm{A} \\
\text { ate or acetate }\end{array}$ & $4,000 \mathrm{IU}$ & $\begin{array}{l}\text { Stabilized vitamin A palmitate } \\
\text { or acetate }\end{array}$ \\
\hline $\mathrm{D}$ & $1,000 \mathrm{IU}$ & $\mathrm{D}-\mathrm{a}$ & vated animal sterol & $1,000 \mathrm{IU}$ & D-activated animal sterol \\
\hline K & $1.0 \mathrm{mg}$ & Men & lione (MSBC) & $1.0 \mathrm{mg}$ & Menadione (MSBC) \\
\hline$\alpha$-Tocopheryl Acetate & $100 \mathrm{IU}$ & - & & $100 \mathrm{IU}$ & - \\
\hline Niacin & $23 \mathrm{mg}$ & - & & $23 \mathrm{mg}$ & - \\
\hline Folic Acid & $1.1 \mathrm{mg}$ & $\alpha-\mathrm{C}$ & ium pantothenate & $1.1 \mathrm{mg}$ & $\alpha$-Calcium pantothenate \\
\hline$\alpha$-Pantothenic Acid & $10 \mathrm{mg}$ & - & & $10 \mathrm{mg}$ & - \\
\hline Riboflavin & $3.3 \mathrm{mg}$ & This & ine mononitrate & $3.3 \mathrm{mg}$ & Thiamine mononitrate \\
\hline Thiamin & $4 \mathrm{mg}$ & - & & $4 \mathrm{mg}$ & - \\
\hline $\mathrm{B}_{12}$ & $52 \mu \mathrm{g}$ & - & & $52 \mu \mathrm{g}$ & - \\
\hline
\end{tabular}


Perfluorooctanoic Acid, NTP TR 598

\begin{tabular}{lclcl}
\hline & \multicolumn{2}{c}{ Study 1 } & \multicolumn{1}{c}{ Study 2 } \\
\cline { 2 - 5 } & Amount & \multicolumn{1}{c}{ Source } & Amount & \multicolumn{1}{c}{ Source } \\
\hline Pyridoxine & $6.3 \mathrm{mg}$ & Pyridozine hydrochloride & $6.3 \mathrm{mg}$ & Pyridozine hydrochloride \\
Biotin & $0.2 \mathrm{mg}$ & $\alpha$-Biotin & $0.2 \mathrm{mg}$ & $\alpha$-Biotin \\
Minerals & & & & \\
Magnesium & $514 \mathrm{mg}$ & Magnesium oxide & $514 \mathrm{mg}$ & Magnesium oxide \\
Iron & $35 \mathrm{mg}$ & Iron sulfate & $35 \mathrm{mg}$ & Iron sulfate \\
Zinc & $12 \mathrm{mg}$ & Zinc oxide & $12 \mathrm{mg}$ & Zinc oxide \\
Manganese & $10 \mathrm{mg}$ & Manganese oxide & $10 \mathrm{mg}$ & Manganese oxide \\
Copper & $2.0 \mathrm{mg}$ & Copper sulfate & $2.0 \mathrm{mg}$ & Copper sulfate \\
Iodine & $0.2 \mathrm{mg}$ & Calcium iodate & $0.2 \mathrm{mg}$ & Calcium iodate \\
Chromium & $0.2 \mathrm{mg}$ & Chromium acetate & $0.2 \mathrm{mg}$ & Chromium acetate \\
\hline
\end{tabular}

$\mathrm{MSBC}=$ menadione sodium bisulfite complex.

aper kg of finished product.

Table B-3. Nutrient Composition of NTP-2000 Rat Ration

\begin{tabular}{|c|c|c|c|c|c|c|}
\hline \multirow[b]{2}{*}{ Nutrient } & \multicolumn{3}{|c|}{ Study 1} & \multicolumn{3}{|c|}{ Study 2} \\
\hline & Mean \pm SD & Range & $\begin{array}{c}\text { Number } \\
\text { of } \\
\text { Samples }\end{array}$ & Mean \pm SD & Range & $\begin{array}{c}\text { Number } \\
\text { of } \\
\text { Samples }\end{array}$ \\
\hline Protein ( $\%$ by Weight) & $14.57 \pm 0.389$ & $13.9-15.8$ & 23 & $14.6 \pm 0.239$ & $14.1-15.0$ & 24 \\
\hline Crude Fat ( $\%$ by Weight) & $8.46 \pm 0.257$ & $8.1-9.0$ & 23 & $8.55 \pm 0.289$ & $8.1-9.1$ & 24 \\
\hline Crude Fiber ( $\%$ by Weight) & $9.3 \pm 0.987$ & $7.5-11.6$ & 23 & $9.5 \pm 0.952$ & $7.5-11.6$ & 24 \\
\hline Ash (\% by weight) & $5.11 \pm 0.133$ & $4.82-5.3$ & 23 & $4.99 \pm 0.184$ & $4.61-5.22$ & 24 \\
\hline \multicolumn{7}{|c|}{ Amino Acids (\% of Total Diet) } \\
\hline Arginine & $0.802 \pm 0.075$ & $0.67-0.97$ & 28 & $0.802 \pm 0.075$ & $0.67-0.97$ & 28 \\
\hline Cystine & $0.220 \pm 0.022$ & $0.15-0.25$ & 28 & $0.220 \pm 0.022$ & $0.15-0.25$ & 28 \\
\hline Glycine & $0.703 \pm 0.038$ & $0.62-0.80$ & 28 & $0.703 \pm 0.038$ & $0.62-0.80$ & 28 \\
\hline Histidine & $0.342 \pm 0.071$ & $0.27-0.68$ & 28 & $0.342 \pm 0.071$ & $0.27-0.68$ & 28 \\
\hline Isoleucine & $0.549 \pm 0.041$ & $0.43-0.66$ & 28 & $0.549 \pm 0.041$ & $0.43-0.66$ & 28 \\
\hline Leucine & $1.097 \pm 0.064$ & $0.96-1.24$ & 28 & $1.097 \pm 0.064$ & $0.96-1.24$ & 28 \\
\hline Lysine & $0.700 \pm 0.106$ & $0.31-0.86$ & 28 & $0.700 \pm 0.106$ & $0.31-0.86$ & 28 \\
\hline Methionine & $0.410 \pm 0.042$ & $0.26-0.49$ & 28 & $0.410 \pm 0.042$ & $0.26-0.49$ & 28 \\
\hline Phenylalanine & $0.623 \pm 0.047$ & $0.47-0.72$ & 28 & $0.623 \pm 0.047$ & $0.47-0.72$ & 28 \\
\hline Threonine & $0.512 \pm 0.042$ & $0.43-0.61$ & 28 & $0.512 \pm 0.042$ & $0.43-0.61$ & 28 \\
\hline Tryptophan & $0.155 \pm 0.027$ & $0.11-0.20$ & 28 & $0.155 \pm 0.027$ & $0.11-0.20$ & 28 \\
\hline Tyrosine & $0.420 \pm 0.066$ & $0.28-0.54$ & 28 & $0.420 \pm 0.066$ & $0.28-0.54$ & 28 \\
\hline Valine & $0.666 \pm 0.040$ & $0.55-0.73$ & 28 & $0.666 \pm 0.040$ & $0.55-0.73$ & 28 \\
\hline Essential Fatty Acids (\%o & Total Diet) & & & & & \\
\hline
\end{tabular}


Perfluorooctanoic Acid, NTP TR 598

\begin{tabular}{|c|c|c|c|c|c|c|}
\hline \multirow[b]{2}{*}{ Nutrient } & \multicolumn{3}{|c|}{ Study 1} & \multicolumn{3}{|c|}{ Study 2} \\
\hline & Mean \pm SD & Range & $\begin{array}{c}\text { Number } \\
\text { of } \\
\text { Samples }\end{array}$ & Mean \pm SD & Range & $\begin{array}{c}\text { Number } \\
\text { of } \\
\text { Samples }\end{array}$ \\
\hline Linoleic & $3.88 \pm 0.455$ & $1.89-4.55$ & 28 & $3.88 \pm 0.455$ & $1.89-4.55$ & 28 \\
\hline Linolenic & $0.30 \pm 0.065$ & $0.007-0.368$ & 28 & $0.30 \pm 0.065$ & $0.007-0.368$ & 28 \\
\hline \multicolumn{7}{|l|}{ Vitamins } \\
\hline Vitamin A (IU/kg) & $3,731 \pm 85$ & $2,360-5,280$ & 23 & $3,842 \pm 77$ & $2,360-5,290$ & 24 \\
\hline Vitamin D (IU/kg) & $1,000^{\mathrm{a}}$ & - & & $1,000^{\mathrm{a}}$ & - & \\
\hline$\alpha$-Tocopherol (ppm) & $2,543 \pm 13,044$ & $27.0-69,100$ & 28 & $2,543 \pm 13,044$ & $27.0-69,100$ & 28 \\
\hline Thiamine $(\mathrm{ppm})^{\mathrm{b}}$ & $7.45 \pm 1.24$ & $6.1-12.4$ & 23 & $8.14 \pm 1.87$ & $3.9-12.5$ & 24 \\
\hline Riboflavin (ppm) & $8.06 \pm 2.83$ & $4.20-17.50$ & 28 & $8.06 \pm 2.83$ & $4.20-17.50$ & 28 \\
\hline Niacin (ppm) & $78.6 \pm 8.26$ & $66.4-98.2$ & 28 & $78.6 \pm 8.26$ & $66.4-98.2$ & 28 \\
\hline Pantothenic Acid (ppm) & $26.6 \pm 11.22$ & $17.4-81.0$ & 28 & $26.6 \pm 11.22$ & $17.4-81.0$ & 28 \\
\hline Pyridoxine (ppm) ${ }^{b}$ & $9.78 \pm 2.08$ & $6.44-14.3$ & 28 & $9.78 \pm 2.08$ & $6.44-14.3$ & 28 \\
\hline Folic Acid (ppm) & $1.58 \pm 0.44$ & $1.15-3.27$ & 28 & $1.58 \pm 0.44$ & $1.15-3.27$ & 28 \\
\hline Biotin (ppm) & $0.32 \pm 0.09$ & $0.20-0.704$ & 28 & $0.32 \pm 0.09$ & $0.20-0.704$ & 28 \\
\hline Vitamin B12 (ppb) & $50.6 \pm 35.5$ & $18.3-174.0$ & 28 & $50.6 \pm 35.5$ & $18.3-174.0$ & 28 \\
\hline Choline (as Chloride) (ppm) & $2,615 \pm 635$ & $1,160-3,790$ & 28 & $2,615 \pm 635$ & $1,160-3,790$ & 28 \\
\hline \multicolumn{7}{|l|}{ Minerals } \\
\hline Calcium (\%) & $0.915 \pm 0.046$ & $0.797-0.99$ & 23 & $0.896 \pm 0.046$ & $0.797-0.99$ & 24 \\
\hline Phosphorus (\%) & $0.553 \pm 0.031$ & $0.487-0.613$ & 23 & $0.563 \pm 0.025$ & $0.487-0.613$ & 24 \\
\hline Potassium (\%) & $0.667 \pm 0.030$ & $0.626-0.733$ & 28 & $0.667 \pm 0.030$ & $0.626-0.733$ & 28 \\
\hline Chloride (\%) & $0.393 \pm 0.045$ & $0.300-0.517$ & 28 & $0.393 \pm 0.045$ & $0.300-0.517$ & 28 \\
\hline Sodium (\%) & $0.197 \pm 0.026$ & $0.160-0.283$ & 28 & $0.197 \pm 0.026$ & $0.160-0.283$ & 28 \\
\hline Magnesium (\%) & $0.217 \pm 0.055$ & $0.185-0.490$ & 28 & $0.217 \pm 0.055$ & $0.185-0.490$ & 28 \\
\hline Sulfur (\%) & $0.170 \pm 0.029$ & $0.116-0.209$ & 14 & $0.170 \pm 0.029$ & $0.116-0.209$ & 14 \\
\hline Iron (ppm) & $191.6 \pm 36.8$ & $135-311$ & 28 & $191.6 \pm 36.8$ & $135-311$ & 28 \\
\hline Manganese (ppm) & $50.1 \pm 9.59$ & $21.0-73.1$ & 28 & $50.1 \pm 9.59$ & $21.0-73.1$ & 28 \\
\hline Zinc (ppm) & $57.4 \pm 26.0$ & $43.3-184.0$ & 28 & $57.4 \pm 26.0$ & $43.3-184.0$ & 28 \\
\hline Copper (ppm) & $7.53 \pm 2.53$ & $3.21-16.3$ & 28 & $7.53 \pm 2.53$ & $3.21-16.3$ & 28 \\
\hline Iodine (ppm) & $0.531 \pm 0.201$ & $0.158-0.972$ & 28 & $0.531 \pm 0.201$ & $0.158-0.972$ & 28 \\
\hline Chromium (ppm) & $0.684 \pm 0.258$ & $0.330-1.380$ & 27 & $0.684 \pm 0.258$ & $0.330-1.380$ & 27 \\
\hline Cobalt (ppm) & $0.225 \pm 0.154$ & $0.086-0.864$ & 26 & $0.225 \pm 0.154$ & $0.086-0.864$ & 26 \\
\hline
\end{tabular}

$\mathrm{SD}=$ standard deviation .

${ }^{a}$ From formulation.

${ }^{\mathrm{b}}$ As hydrochloride. 
Perfluorooctanoic Acid, NTP TR 598

Table B-4. Contaminant Levels in NTP-2000 Rat Ration ${ }^{\text {a }}$

\begin{tabular}{|c|c|c|c|c|c|c|}
\hline & \multicolumn{3}{|c|}{ Study 1} & \multicolumn{3}{|c|}{ Study 2} \\
\hline & $\operatorname{Mean} \pm \mathbf{S D}^{\mathbf{b}}$ & Range & $\begin{array}{c}\text { Number } \\
\text { of } \\
\text { Samples }\end{array}$ & $\operatorname{Mean} \pm \mathbf{S D}^{\mathbf{b}}$ & Range & $\begin{array}{c}\text { Number } \\
\text { of } \\
\text { Samples }\end{array}$ \\
\hline \multicolumn{7}{|l|}{ Contaminants } \\
\hline Arsenic (ppm) & $0.25 \pm 0.046$ & $0.159-0.341$ & 23 & $0.257 \pm 0.059$ & $0.172-0.385$ & 24 \\
\hline Cadmium (ppm) & $0.059 \pm 0.007$ & $0.042-0.069$ & 23 & $0.059 \pm 0.011$ & $0.042-0.094$ & 24 \\
\hline Lead (ppm) & $0.086 \pm 0.016$ & $0.06-0.119$ & 23 & $0.091 \pm 0.033$ & $0.06-0.194$ & 24 \\
\hline Mercury (ppm) & $0.019 \pm 0.004$ & $0.019-0.004$ & 23 & $0.017 \pm 0.008$ & $0.01-0.049$ & 24 \\
\hline Selenium (ppm) & $0.211 \pm 0.051$ & $0.16-0.333$ & 23 & $0.191 \pm 0.049$ & $0.145-0.333$ & 24 \\
\hline Aflatoxins (ppm) & $<5.00$ & - & 23 & $<5.00$ & - & 24 \\
\hline Nitrate Nitrogen $(\mathrm{ppm})^{\mathrm{c}}$ & $16.64 \pm 7.97$ & $0.61-34.6$ & 23 & $16.33 \pm 6.09$ & $10.0-29.6$ & 24 \\
\hline Nitrite Nitrogen $(\mathrm{ppm})^{\mathrm{c}}$ & 0.61 & - & 23 & 0.61 & - & 24 \\
\hline BHA $(\mathrm{ppm})^{\mathrm{d}}$ & $<1.0$ & - & 23 & $<1.0$ & - & 24 \\
\hline BHT $(p p m)^{d}$ & $1.09 \pm 0.446$ & $1.0-3.14$ & 23 & $1.09 \pm 0.437$ & $1.0-3.14$ & 24 \\
\hline Aerobic Plate Count (CFU/g) & $<10.0$ & - & 23 & $<10.0$ & - & 24 \\
\hline Coliform (MPN/g) & 3.0 & - & 23 & 3.0 & - & 24 \\
\hline Escherichia coli (MPN/g) & $<10.0$ & - & 23 & $<10.0$ & - & 24 \\
\hline Salmonella (MPN/g) & Negative & - & 23 & Negative & - & 24 \\
\hline Total Nitrosamines (ppb) ${ }^{\mathrm{e}}$ & $10.0 \pm 4.5$ & $3.2-21.7$ & 23 & $9.8 \pm 4.5$ & $3.2-18.9$ & 24 \\
\hline N-Ndimethylamine $(\mathrm{ppb})^{\mathrm{e}}$ & $2.5 \pm 2.6$ & $0-11.8$ & 23 & $2.8 \pm 2.0$ & $0-6.8$ & 24 \\
\hline N-Npyrrolidine $(\mathrm{ppb})^{\mathrm{e}}$ & $7.5 \pm 2.4$ & $3.2-11.6$ & 23 & $7.0 \pm 3.1$ & $2.1-15.15$ & 24 \\
\hline \multicolumn{7}{|l|}{ Pesticides (ppm) } \\
\hline$\alpha-\mathrm{BHC}$ & $<0.01$ & - & 23 & $<0.01$ & - & 24 \\
\hline$\beta$-BHC & $<0.02$ & - & 23 & $<0.02$ & - & 24 \\
\hline$\gamma-\mathrm{BHC}$ & $<0.01$ & - & 23 & $<0.01$ & - & 24 \\
\hline$\delta$-BHC & $<0.01$ & - & 23 & $<0.01$ & - & 24 \\
\hline Heptachlor & $<0.01$ & - & 23 & $<0.01$ & - & 24 \\
\hline Aldrin & $<0.01$ & - & 23 & $<0.01$ & - & 24 \\
\hline Heptachlor Epoxide & $<0.01$ & - & 23 & $<0.01$ & - & 24 \\
\hline DDE & $<0.01$ & - & 23 & $<0.01$ & - & 24 \\
\hline DDD & $<0.01$ & - & 23 & $<0.01$ & - & 24 \\
\hline DDT & $<0.01$ & - & 23 & $<0.01$ & - & 24 \\
\hline $\mathrm{HCB}$ & $<0.01$ & - & 23 & $<0.01$ & - & 24 \\
\hline Mirex & $<0.01$ & - & 23 & $<0.01$ & - & 24 \\
\hline Methoxychlor & $<0.05$ & - & 23 & $<0.05$ & - & 24 \\
\hline Dieldrin & $<0.01$ & - & 23 & $<0.01$ & - & 24 \\
\hline
\end{tabular}


Perfluorooctanoic Acid, NTP TR 598

\begin{tabular}{|c|c|c|c|c|c|c|}
\hline & \multicolumn{3}{|c|}{ Study 1} & \multicolumn{3}{|c|}{ Study 2} \\
\hline & $\operatorname{Mean} \pm \mathbf{S D}^{\mathbf{b}}$ & Range & $\begin{array}{c}\text { Number } \\
\text { of } \\
\text { Samples }\end{array}$ & $\operatorname{Mean} \pm \mathbf{S D}^{\mathbf{b}}$ & Range & $\begin{array}{c}\text { Number } \\
\text { of } \\
\text { Samples }\end{array}$ \\
\hline Endrin & $<0.01$ & - & 23 & $<0.01$ & - & 24 \\
\hline Telodrin & $<0.01$ & - & 23 & $<0.01$ & - & 24 \\
\hline Chlordane & $<0.05$ & - & 23 & $<0.05$ & - & 24 \\
\hline Toxaphene & $<0.10$ & - & 23 & $<0.10$ & - & 24 \\
\hline Estimated PCBs & $<0.20$ & - & 23 & $<0.20$ & - & 24 \\
\hline Ronnel & $<0.01$ & - & 23 & $<0.01$ & - & 24 \\
\hline Ethion & $<0.02$ & - & 23 & $<0.02$ & - & 24 \\
\hline Trithion & $<0.05$ & - & 23 & $<0.05$ & - & 24 \\
\hline Diazinon & $<0.10$ & - & 23 & $<0.10$ & - & 24 \\
\hline Methyl Chlorpyrifos & $0.138 \pm 0.126$ & $0.02-0.567$ & 23 & $0.13 \pm 0.129$ & $0.02-0.567$ & 24 \\
\hline Methyl Parathion & $<0.02$ & - & 23 & $<0.02$ & - & 24 \\
\hline Ethyl Parathion & $<0.02$ & - & 23 & $<0.02$ & - & 24 \\
\hline Malathion & $0.122 \pm 0.102$ & $0.02-0.385$ & 23 & $0.142 \pm 0.101$ & $0.02-0.385$ & 24 \\
\hline Endosulfan I & $<0.01$ & - & 23 & $<0.01$ & - & 24 \\
\hline Endosulfan II & $<0.01$ & - & 23 & $<0.01$ & - & 24 \\
\hline Endosulfan Sulfate & $<0.03$ & - & 23 & $<0.03$ & - & 24 \\
\hline
\end{tabular}

$\mathrm{CFU}=$ colony-forming units; $\mathrm{MPN}=$ most probable number; $\mathrm{BHC}=$ hexachlorocyclohexane or benzene hexachloride;

$\mathrm{PCB}=$ polychlorinated biphenyl.

${ }^{\text {a} A l l ~ s a m p l e s ~ w e r e ~ i r r a d i a t e d . ~}$

${ }^{b}$ For values less than the limit of detection, the detection limit is given as the mean.

'Sources of contamination: alfalfa, grains, and fish meal.

${ }^{\mathrm{d}}$ Sources of contamination: soy oil and fish meal.

${ }^{\mathrm{e}}$ All values were corrected for percent recovery. 


\section{Appendix C. Sentinel Animal Program \\ Table of Contents}

C.1. Methods

C-2

C.2. Results

\section{Tables}

Table C-1. Methods and Results for Sentinel Animal Testing (Study 1) ..................................2

Table C-2. Methods and Results for Sentinel Animal Testing (Study 2) 


\section{C.1. Methods}

Rodents used in the National Toxicology Program are produced in optimally clean facilities to eliminate potential pathogens that may affect study results. The Sentinel Animal Program is part of the periodic monitoring of animal health that occurs during the toxicological evaluation of test compounds. Under this program, the disease state of the rodents is monitored via sera or feces from extra (sentinel) or dosed animals in the study rooms. The sentinel animals and the study animals are subject to identical environmental conditions. Furthermore, the sentinel animals are from the same production source and weanling groups as the animals used for the studies of test compounds.

For these toxicology and carcinogenesis studies of perfluorooctanoic acid, blood samples were collected from the rodents and allowed to clot, and the serum was separated. All samples were processed appropriately with serology testing sent to IDEXX BioResearch (formerly Rodent Animal Diagnostic Laboratory [RADIL], University of Missouri), Columbia, MO for determination of the presence of pathogens. The laboratory methods and agents for which testing was performed are tabulated below; the times at which samples were collected during the studies are also listed. Blood was collected per the following methods and as shown in Table $\mathrm{C}-1$ and Table C-2.

Study 1: 10 females at arrival; 5 females, 4 weeks postarrival; 5 animals per sex at 6, 12, and 18 months; 10 females at study termination.

Study 2: 10 females at arrival; 5 females, 4 weeks postarrival; 5 males at 6,12 , and 18 months, and study termination.

Table C-1. Methods and Results for Sentinel Animal Testing (Study 1)

\begin{tabular}{|c|c|}
\hline Method and Test & Time of Collection \\
\hline \multicolumn{2}{|l|}{ Multiplex Fluorescent Immunoassay } \\
\hline Kilham's Rat Virus & Arrival $^{\text {a }} ; 4$ weeks postarrival ${ }^{\text {b }} ; 6,12$, and 18 months; study termination \\
\hline Mycoplasma pulmonis & Arrival; 4 weeks postarrival; 6,12 , and 18 months; study termination \\
\hline Parvo NS-1 & Arrival; 4 weeks postarrival; 6 and 12 months \\
\hline Pneumonia Virus of Mice & Arrival; 4 weeks postarrival; 6,12 , and 18 months; study termination \\
\hline Rat Coronavirus/Sialodacryoadenitis Virus & Arrival; 4 weeks postarrival; 6,12 , and 18 months; study termination \\
\hline Rat Minute Virus & Arrival; 4 weeks postarrival; 6,12 , and 18 months; study termination \\
\hline Rat Parvovirus & Arrival; 4 weeks postarrival; 6,12 , and 18 months; study termination \\
\hline Rat Theilovirus & Arrival; 4 weeks postarrival; 6,12 , and 18 months; study termination \\
\hline Sendai & Arrival; 4 weeks postarrival; 6,12 , and 18 months; study termination \\
\hline $\begin{array}{l}\text { Theiler's Murine Encephalomyelitis Virus } \\
\text { Strain GDVII }\end{array}$ & Arrival; 4 weeks postarrival; 6 and 12 months \\
\hline Toolan's H-1 & Arrival; 4 weeks postarrival; 6,12 , and 18 months; study termination \\
\hline
\end{tabular}


Table C-2. Methods and Results for Sentinel Animal Testing (Study 2)

Method and Test

Time of Collection

\section{Multiplex Fluorescent Immunoassay}

Kilham's Rat Virus

Mycoplasma pulmonis

Parvo NS-1

Pneumonia Virus of Mice

Rat Coronavirus/Sialodacryoadenitis Virus

Rat Minute Virus

Rat Parvovirus

Rat Theilovirus

Sendai

Theiler's Murine Encephalomyelitis Virus Strain GDVII

Toolan's H-1

Immunofluorescence Assay

Mycoplasma pulmonis

Pneumocystis carinii

${ }^{a}$ Age-matched nonpregnant females.

${ }^{\text {b}}$ Time-mated females that did not have a litter.

\section{C.2. Results}

All test results were negative.
Arrival $^{\text {a }} ; 4$ weeks postarrival ${ }^{\mathrm{b}} ; 6,12$, and 18 months; study termination

Arrival; 4 weeks postarrival; 6, 12, and 18 months; study termination Arrival; 4 weeks postarrival; 6 months

Arrival; 4 weeks postarrival; 6, 12, and 18 months; study termination Arrival; 4 weeks postarrival; 6,12 , and 18 months; study termination Arrival; 4 weeks postarrival; 6, 12, and 18 months; study termination Arrival; 4 weeks postarrival; 6, 12, and 18 months; study termination Arrival; 4 weeks postarrival; 6, 12, and 18 months; study termination Arrival; 4 weeks postarrival; 6, 12, and 18 months; study termination Arrival; 4 weeks postarrival; 6 months

Arrival; 4 weeks postarrival; 6,12 , and 18 months; study termination

Study termination

Study termination 


\section{Appendix D. Summary of Peer Review Panel Comments}

\section{Table of Contents}

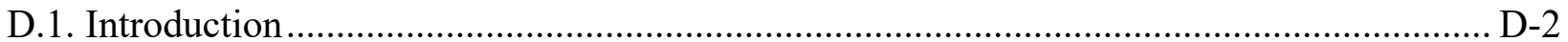

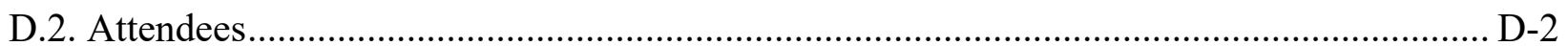

D.3. Peer Review of the Draft NTP Technical Reports on the Toxicology and

Carcinogenesis Studies of 2-Hydroxy-4-methoxybenzone and Perfluorooctanoic Acid ... D-3 


\section{D.1. Introduction}

The National Toxicology Program (NTP) convened the NTP Technical Reports Peer Review Panel via webcast on December 12, 2019, to peer review the draft NTP Technical Reports on the Toxicology and Carcinogenesis Studies of 2-Hydroxy-4-methoxybenzophenone and Perfluorooctanoic Acid. Meeting information, including the draft reports, actions, and presentations is currently archived under NTP's "Past Events."

The panel peer reviewed the draft reports and provided its opinion on NTP's preliminary conclusions regarding the level of evidence of carcinogenic activity of 2-hydroxy-4methoxybenzophenone and perfluorooctanoic acid. The panel's comments for the draft NTP Technical Report on the Toxicology and Carcinogenesis Studies of Perfluorooctanoic Acid begin at Section D.3.4. The panel's recommendations do not necessarily represent the opinion of NTP.

\section{D.2. Attendees}

\section{Peer Review Panel Chair}

Russell Cattley, Auburn University

Peer Review Panel

Michael Elwell, APEX TOXPATH, LLC

Wendy Halpern, Genentech, Inc.

Gabriele Ludewig, University of Iowa

Kristini Miles, Venture Chemical Consulting, LLC

Karen Regan, Regan Pathology/Toxicology Services, Inc. (2-hydroxy-4-methoxybenzophenone only)

\section{National Institute of Environmental Health Sciences Staff}

Brian Berridge

Chad Blystone

Michelle Cora

Stephen Ferguson

Shawn Harris

Angela King-Herbert

Ron Herbert

Dave Malarkey

Elizabeth Maull, Designated Federal Official

Barry McIntyre

Georgia Roberts

Sheena Scruggs

Keith Shockley

Robert Sills

Matthew Stout

Suramya Waidyanatha

Nigel Walker

AtLee Watson

Kristine Witt

Mary Wolfe 
Other Federal Agency Staff

Gonçalo Gamboa, FDA (by WebEx)

Contract Support Staff

Amy Brix, EPL, Inc.

Canden Byrd, ICF

Josh Cleland, ICF

Katherine Duke, ICF

Sophie Hearn, ICF

Ernie Hood, Bridport Services

Kyathanahalli Janardhan, ILS

Kelly Shipkowski, ICF

Samantha Snow, ICF

Jessica Wignall, ICF

\section{D.3. Peer Review of the Draft NTP Technical Reports on the Toxicology and Carcinogenesis Studies of 2-Hydroxy-4- methoxybenzone and Perfluorooctanoic Acid}

\section{D.3.1. Introductions and Welcome}

The National Toxicology Program (NTP) convened a peer-review panel for the Draft NTP Technical Reports on the Toxicology and Carcinogenesis Studies of 2-Hydroxy4-methoxybenzophenone and Perfluorooctanoic Acid on December 12, 2019 via webcast.

- Dr. Russell Cattley, panel chair, called the meeting to order at 10:00 a.m., welcomed everyone to the meeting, asked all attendees to introduce themselves, and reviewed the peer-review meeting format for the panel and audience.

- Dr. Brian Berridge, NTP Associate Director, welcomed all participants to the meeting.

- Dr. Elizabeth Maull read the conflict of interest policy statement and briefed the attendees on meeting logistics.

\section{D.3.2. Background and Charge to the Panel}

Dr. Chad Blystone gave a brief presentation on NTP draft technical reports, including information about the levels of evidence for the potential carcinogenic activity of the chemicals tested. He also described the NTP's historical controls, which are categorized by route of exposure and rodent strains. He then gave the charge to the panel for the individual peer reviews:

- Review and evaluate the scientific and technical elements of the study and its presentation.

- Determine whether the study's experimental design, conduct, and findings support NTP's conclusions regarding the hypothesis under the conditions of this study. The peer-review meeting materials can be found on the NTP website. 


\section{D.3.3. Toxicology and Carcinogenesis Studies of 2-Hydroxy- 4-methoxybenzophenone}

\section{D.3.3.1. Presentation and Clarifying Questions}

Dr. Barry McIntyre summarized the studies and conclusions reported in the Draft NTP Technical Report on the Toxicology and Carcinogenesis Studies of 2-Hydroxy-4-methoxybenzophenone (CAS No. 131-57-7) Administered in Feed to Sprague Dawley (Hsd:Sprague Dawley ${ }^{\circledR} S D^{\circledR}$ ) Rats and B6C3F1/N Mice.

2-Hydroxy-4-methoxybenzophenone is an ultraviolet (UV) filter used in sunscreens and cosmetics to protect the wearer from solar erythema. 2-Hydroxy-4-methoxybenzophenone is also an indirect food additive as it is added to acrylic and modified acrylic plastics that encounter food to prevent UV-mediated degradation. NTP chose to study 2-hydroxy4-methoxybenzophenone due to widespread human exposure and lack of carcinogenicity data.

Dr. McIntyre first presented a summary of results from the 2-hydroxy-4-methoxybenzophenone Endocrine Disruptor Screening Panel studies reported in Appendix F of the technical report.

Genetic toxicology studies conducted in Salmonella typhimurium strains TA98 and TA100 as well as Escherichia coli strain $u v r \mathrm{~A}$ pKM101 with and without S9 were negative.

NTP conducted a perinatal toxicity/carcinogenicity study in time-mated female Hsd:Sprague Dawley ${ }^{\circledR} \mathrm{SD}^{\circledR}$ rats, with exposure concentrations of $0,1,000,3,000$, and $10,000 \mathrm{ppm}$ in the diet. Exposure began on gestation day (GD) 6 through lactation in the dams. In the offspring, exposure continued after weaning on postnatal day (PND) $21(n=50 /$ dose) for 2 years. In addition, there was a 14-week interim necropsy for the 0 and 10,000 ppm groups $(n=10 /$ sex/dose). Dr. McIntyre presented a summary of results from the 2-hydroxy4-methoxybenzophenone perinatal toxicity/carcinogenicity study.

NTP also conducted a standard chronic bioassay in male and female B6C3F1/N mice, with exposure concentrations of $0,1,000,3,000$, and 10,000 ppm in the diet for 2 years. Dr. McIntyre presented a summary of findings from the standard chronic bioassay.

Under the conditions of these 2-year studies, NTP's draft conclusions were:

- Equivocal evidence of carcinogenic activity of 2-hydroxy-4-methoxybenzophenone exposure in male Hsd:Sprague Dawley ${ }^{\circledR} \mathrm{SD}^{\circledR}$ rats based on the occurrence of brain and spinal cord malignant meningiomas.

- Exposure to 2-hydroxy-4-methoxybenzophenone resulted in increased incidences of nonneoplastic lesions of the testis and pancreas in male rats.

- Equivocal evidence of carcinogenic activity of 2-hydroxy-4-methoxybenzophenone exposure in female Hsd:Sprague Dawley ${ }^{\circledR} \mathrm{SD}^{\circledR}$ rats based on the increased incidence of thyroid C-cell adenomas and the increased incidence of uterine stromal polyps.

- Exposure to 2-hydroxy-4-methoxybenzophenone resulted in increased incidences of nonneoplastic lesions of the uterus and adrenal cortex in female rats.

- No evidence of carcinogenic activity in male or female $\mathrm{B} 6 \mathrm{C} 3 \mathrm{~F} 1 / \mathrm{N}$ mice at exposure concentrations of 1,000, 3,000, and 10,000 ppm 2-hydroxy-4-methoxybenzophenone. 
- Exposure to 2-hydroxy-4-methoxybenzophenone resulted in increased incidences of nonneoplastic lesions of the bone marrow, spleen, and kidney in male and female mice, and liver in male mice.

There were no clarifying questions or comments about the presentation.

\section{D.3.3.2. Public Comments}

Dr. Cattley acknowledged the receipt of written public comments from private citizen Mr. Joe DiNardo. He noted that the panel did not receive requests for oral public comments on the draft technical report.

\section{D.3.3.3. Peer-Review Comments and Panel Discussion}

\section{D.3.3.3.1. First Reviewer-Dr. Karen Regan}

Dr. Karen Regan said that the studies were well-written and well-conducted. She requested clarification on how the dose used in the studies compared to human exposure. She asked for more information on the historical control data used for this study and whether there were any data available from the same strain of rat exposed from GD 6. Dr. Regan questioned why NTP did not evaluate spinal cords for all animals in the study. Dr. Regan asked whether there were any tables that showed the overall incidence of multiplicity for thyroid tumors in female rats, and whether there were any animals with multiple tumors.

- Dr. McIntyre indicated that the plasma levels found in the rodents following exposure were comparable to levels recently reported in human blood (JAMA 2019).

- Dr. Blystone reported that the historical controls used in this study include all exposure start times with most of these studies starting at GD 6.

- Dr. Amy Brix stated that only animals with clinical neuropathological signs had their spinal cords examined and indicated that NTP would consider adding a sentence to the report to clarify this point. She noted that it is possible that they did not observe additional occurrences of malignant meningiomas in the spinal cords. Dr. Brix noted that there were no occurrences of these type of tumors in the historical controls or control group. Even without the single occurrence in the spinal cord, NTP considered the occurrence of malignant meningioma in the brain of adult rats to be equivocal evidence of carcinogenicity.

- Dr. Brix noted that only one female in the highest dose group had bilateral C-cell adenomas in the thyroid, with the rest of the adenomas being unilateral. She remarked that NTP only counted an animal once if it had both a thyroid adenoma and carcinoma, which occurred in only one rat. She stated that they will explain these methods further in the report.

\section{D.3.3.3.2. Second Reviewer - Dr. Kristini Miles}

Dr. Kristini Miles stated that the study was well-designed and executed. She noted that NTP chose sufficient doses for the rats and mice as they were based on previously conducted studies. Dr. Miles noted that 2-hydroxy-4-methoxybenzophenone has been reported in the literature to be a persistent environmental contaminant, specifically in water sources, and there are reports that traditional wastewater treatment processes may not eliminate the contaminant. She asked whether NTP tested 2-hydroxy-4-methoxybenzophenone in the municipal tap water used in the 
study. Dr. Miles inquired whether there was any information available on 2-hydroxy-4methoxybenzophenone concentrations in synthetic resins and plastics, and how it might leach out of such containers. She asked that NTP include the information in the report. Regarding Table 8 in the report, Dr. Miles asked whether the trend test referred to historical controls or something else.

- Dr. McIntyre stated that they did not examine the municipal water used for the presence of 2-hydroxy-4-methoxybenzophenone; however, all rodents received the same water supply.

- Dr. McIntyre indicated that NTP provided information on leachates in plastics, and they would consider adding this information to the report.

- Dr. Keith Shockley noted that they based the trend test on experimental data, not historical controls.

\section{D.3.3.3.3. Third Reviewer - Dr. Michael Elwell}

Dr. Michael Elwell indicated that he had no comments on the study design or dose selection and the results and figures were clearly presented by the NTP. He concurred with the neoplastic and nonneoplastic findings listed in the draft report for the male rats. Regarding the data and discussions of the meningioma and interstitial cell hyperplasia, Dr. Elwell requested confirmation that NTP examined spinal cords from only one or two animals per group. He asked whether it was correct to combine the spinal cord and brain data as the study staff did in Table 11 to perform statistical analysis on the occurrence of these tumors. Dr. Elwell noted that there was one meningioma present in the spinal cord but three in the brain in male rats exposed to $1,000 \mathrm{ppm}$. He remarked that one of these animals (Animal 151) also had a meningioma recorded in the trigeminal nerve. He asked whether NTP should report that meningioma separately and include it in the discussion. He questioned whether NTP should mention the occurrence of granular cell tumors in the meninges in the report as part of the assessment of the meningiomas since NTP Technical Report 573 discussed the relationship between granular cell tumors and meningiomas, with an indication that they had similar morphologies and a common progenitor cell type. Dr. Elwell recommended that the NTP report the increased incidence of interstitial cell hyperplasia of the testes in the discussion section since they included it in the abstract and results section. Dr. Elwell agreed in principle with the conclusion of no evidence of carcinogenicity in the male mice. He suggested clarifying the wording that described the cytoplasmic alteration of the kidneys that occurred. Dr. Elwell stated that the incidence of lymphocyte infiltrates and nephropathy in the kidney listed in the abstract appeared to be very minor given the minimal severity and common background occurrence of these findings.

Dr. Elwell remarked that prior studies with ethylbenzene reported no association of syncytial cell alterations in the liver with hepatocellular neoplasia. He suggested this would be worth mentioning in the discussion since ethylbenzene has a similar structure to 2-hydroxy4-methoxybenzophenone.

In response to Dr. Elwell's comments, Dr. Brix indicated that:

- While NTP examined the brains of all animals, only animals with clinical neurological signs had their spinal cords examined. NTP will update the table to reflect this. NTP will also consider removing the spinal cord data from this analysis. 
- There was an error in the table reporting two meningiomas in Animal 151 (one should have been recorded as a metastasis of the other) and they would update the table to reflect this. NTP will also consider adding language to the discussion section regarding malignant meningiomas.

- NTP will consider adding to the discussion section that meningiomas and granular cell tumors may have a common progenitor.

- NTP will consider adding text to the report that there was no effect on interstitial cell adenomas reported in male rats. NTP will also consider adding text to the discussion regarding interstitial cell hyperplasia.

- There was an error in describing the cytoplasmic alteration in the kidneys in male mice. NTP will update the report to reflect this.

- NTP will consider adding language to the results section downplaying the importance of the chronic progressive nephropathy and lymphocytic infiltrates in the kidneys of male mice and will remove mentions of these findings from the discussion.

- NTP would consider adding language to the report regarding the lack of association between syncytial cell alteration in the liver and exposure to ethylbenzene.

In a follow-up question, Dr. Elwell described his confusion regarding the statistical approaches for the non-neoplastic kidney findings in this report, which seemed to take severity into account.

Dr. Shockley replied that the statistical analysis did not take severity into account but was instead based on incidence. However, this method did account for differential survival.

\section{D.3.3.4. Panel Discussion}

Dr. Gabriele Ludewig stated that the report was clear and well-written. She wondered whether the number of incidences of meningiomas indicated a relationship to exposure and whether NTP should report this as clear evidence instead of equivocal. Dr. Ludewig asked for comment on why they used rats and not hamsters since they metabolize this compound differently, which may make it genotoxic. Dr. Ludewig noted that ER and AR binding is only one way a compound can be an endocrine disruptor. She noticed in the report that NTP reported findings in the adrenal gland which could lead to serotonin disruption and suggested adding that point to the report. Dr. Ludewig observed that only the highest exposure group had female rats that were not pregnant and suggested adding a statement regarding this point.

- Dr. Brix stated that it is always challenging to make a call on uncommon tumors without statistical support, dose response, a change in latency, or supporting evidence from other sex, species, or preneoplastic lesions. Therefore, NTP decided there was equivocal evidence based on the presence of meningiomas.

- Dr. McIntyre noted that NTP no longer used the hamster S9 assay under Organisation for Economic Co-operation and Development (OECD) guidance and that performing those tests would be outside the scope of this report.

- Dr. McIntyre indicated that NTP has done extensive work in relation to testing for hormonal activity and is in the process of reporting on reproductive performance as well as markers of altered endocrine action in another technical report. 
- Dr. McIntyre noted that they examined the animals that did not deliver for implantation sites and they were not pregnant. Since exposure began after implantation, they were not concerned that this was an exposure-related effect.

In a follow-up statement, Dr. Ludewig concluded that she was between some and equivocal evidence regarding the presence of meningiomas.

Dr. Wendy Halpern noted that other reviewers addressed most of her comments. She asked the panel to comment on whether it was a common observation that there were fewer potentially exposure-related tumors identified at the highest dose where the animals had lower body weight.

Dr. Blystone reported that the influence of lower body weight on the cancer response has been characterized for only a few tumor types (e.g., mammary gland tumors) and that we do not have the information for the other tumor types to include in the report.

Dr. Cattley questioned why there had been a separate peer review conducted on the uterus in the rats.

- Dr. Brix reported that over the past several years, NTP had changed its procedure from doing cross-sectional evaluations to more comprehensive analyses of the uterus.

- Dr. Brix reported that NTP would consider adding language to the report to clarify this point.

\section{D.3.3.5. Vote on NTP Conclusions}

\section{D.3.3.5.1. Male Hsd:Sprague Dawley ${ }^{\circledR} S D^{\circledR}$ rats}

Dr. Cattley called for a motion from the panel to approve the conclusions as written. The panel did not offer a motion. Dr. Regan moved that NTP delete the reference to spinal cord malignant meningiomas from the conclusion. Dr. Ludewig seconded the motion. The panel voted unanimously ( 5 yes, 0 no, 0 abstentions) to approve the new conclusion.

\section{D.3.3.5.2. Female Hsd:Sprague Dawley ${ }^{\circledR} S D^{\circledR}$ rats}

Dr. Cattley called for a motion from the panel to approve the conclusions as written. Dr. Regan so moved, and Dr. Elwell seconded the motion. The panel voted unanimously ( 5 yes, 0 no, 0 abstentions) to approve the conclusions as written.

\section{D.3.3.5.3. Male B6C3F1/N mice}

Dr. Cattley called for a motion from the panel to approve the conclusions as written. Dr. Regan so moved and Dr. Ludewig seconded the motion. The panel voted unanimously (5 yes, 0 no, 0 abstentions) to approve the conclusions as written.

\section{D.3.3.5.4. Female B6C3F1/N mice}

Dr. Cattley called for a motion from the panel to approve the conclusions as written. Dr. Regan so moved, and Dr. Ludewig seconded the motion. The panel voted unanimously ( 5 yes, 0 no, 0 abstentions) to approve the conclusions as written.

Following the voting, Dr. Cattley noted that Dr. Regan would sign off from the session. 


\section{D.3.4. Toxicology and Carcinogenesis Studies of Perfluorooctanoic Acid}

\section{D.3.4.1. Presentation and Clarifying Questions}

Dr. Blystone summarized the studies and conclusions reported in the Draft NTP Technical Report on the Toxicology and Carcinogenesis Studies of Perfluorooctanoic Acid (CAS No. 335-67-1) Administered in Feed to Sprague Dawley (Hsd:Sprague Dawley ${ }^{\circledR} S D^{\circledR}$ ) Rats.

Perfluorooctanoic acid is a perfluoroalkyl substance (PFAS) used for decades in creating nonstick properties in a variety of products. Manufacturers agreed to discontinue use due to widespread exposure and health concerns. Due to a long half-life measured in years and resistance to environmental degradation, exposure has continued but declined. Perfluorooctanoic acid is the second most abundant PFAS measured in the human population, including children and pregnant women.

Human exposure to perfluorooctanoic acid can occur during early development. It is unknown whether exposure during gestation and lactation alters the carcinogenic response induced by perfluorooctanoic acid. NTP tested the hypothesis that including perinatal exposure with postweaning exposure would quantitatively or qualitatively alter the perfluorooctanoic acid response compared to postweaning exposure only.

NTP conducted a perinatal and postweaning toxicity/carcinogenicity study in Hsd:Sprague Dawley ${ }^{\circledR} \mathrm{SD}^{\circledR}$ rats. In Study \#1, they exposed time-mated female rats to 0,150 , or $300 \mathrm{ppm}$ perfluorooctanoic acid during the perinatal period. NTP provided $\mathrm{F}_{1}$ female rats with 0,300 , or $1,000 \mathrm{ppm}$ perfluorooctanoic acid during the postweaning period (i.e., perinatal/postweaning exposures of $0 / 0,0 / 300,0 / 1,000,150 / 300$, or $300 / 1,000 \mathrm{ppm}$ ) while they provided $\mathrm{F}_{1}$ male rats with 0,150 , or $300 \mathrm{ppm}$ perfluorooctanoic acid during the postweaning period (i.e., perinatal/postweaning exposures of $0 / 0,0 / 150,0 / 300,150 / 150$, or 300/300 ppm) $(\mathrm{n}=50 / \mathrm{sex} /$ dose $)$. Female rats have a lower systemic exposure than males due to a faster perfluorooctanoic acid elimination rate, so NTP provided a higher feed exposure concentration to female rats postweaning. In addition, they conducted a 16-week (19 weeks of age) interim necropsy $(n=10 /$ sex/dose $)$.

Due to observed unanticipated toxicity in males during the interim necropsy, NTP removed males from Study \#1 at week 21. In Study \#2, they exposed time-mated female rats to 0 or $300 \mathrm{ppm}$ perfluorooctanoic acid during the perinatal period. They provided $\mathrm{F}_{1}$ male rats 0,20 , 40 , or $80 \mathrm{ppm}$ perfluorooctanoic acid during the postweaning period (i.e., perinatal/postweaning exposures of $0 / 0,0 / 20,0 / 40,0 / 80,300 / 0,300 / 20,300 / 40$, or 300/80 ppm) (n=50/sex/dose).

Dr. Blystone presented a summary of results from the perinatal and postweaning toxicity/carcinogenicity study.

Under the conditions of these 2-year studies, NTP's draft conclusions were:

- Clear evidence of carcinogenic activity of perfluorooctanoic acid in male Hsd:Sprague Dawley ${ }^{\circledR} \mathrm{SD}^{\circledR}$ rats based on the increased incidences of hepatocellular neoplasms (predominately hepatocellular adenomas) and increased incidences of acinar cell neoplasms (predominantly acinar cell adenomas) of the pancreas.

- Exposure to perfluorooctanoic acid resulted in increased incidences of nonneoplastic lesions in the liver and pancreas of male rats. The additional effect of combined 
perinatal and postweaning exposure was limited to a higher incidence of hepatocellular carcinomas compared to postweaning exposure alone.

- Some evidence of carcinogenic activity of perfluorooctanoic acid in female Hsd:Sprague Dawley ${ }^{\circledR} \mathrm{SD}^{\circledR}$ rats based on the increased incidences of pancreatic acinar cell adenoma or adenocarcinoma (combined) neoplasms.

- The higher incidence of hepatocellular carcinomas and higher incidence of adenocarcinomas of the uterus may have been related to perfluorooctanoic acid exposure.

- Exposure to perfluorooctanoic acid resulted in increased incidences of nonneoplastic lesions in the liver, kidney, forestomach, and thyroid gland.

- The combined perinatal and postweaning exposure was not observed to change the neoplastic or nonneoplastic response compared to postweaning exposure alone.

There were no clarifying questions or comments about the presentation.

\section{D.3.4.2. Public Comments}

Dr. Cattley acknowledged the receipt of three written public comments from Dr. Oyebode A. Taiwo on behalf of the 3M Company, Dr. Alexis Temkin on behalf of the Environmental Working Group, and Mr. Jason Dadakis from the Orange County Water District. Dr. Cattley noted that there was one oral public comment from Mr. Steve Risotto on behalf of the American Chemistry Council (ACC).

Mr. Risotto said the ACC believed the peer-review committee should carefully consider NTP's conclusion that there is "some evidence of carcinogenic activity" in female rats, requested additional analysis of the pancreatic tumor data for male rats, and asked whether a conclusion could be reached about the sensitivity of fetal rats to perfluorooctanoic acid exposure. Regarding the evidence for carcinogenicity in female rats, Mr. Risotto observed that there was a nonsignificant increase of combined acinar cell adenomas and adenocarcinomas at 1,000 ppm. He noted that while the increased incidence of acinar cell neoplasms in males increased NTP's confidence that neoplasms in females were related to perfluorooctanoic acid exposure, NTP did not observe acinus hyperplasia in the female rats, which was significantly increased in the male rats. If this hyperplasia is a potentially preneoplastic lesion as NTP suggests, Mr. Risotto stated that this finding should also have been observed in the female rats. Mr. Risotto also noted that the survival rate in the female rats was quite low, which might raise concerns about the general animal husbandry practices of the study since survival was depressed in both the control and exposed animals. Regarding the incidence of acinar cell neoplasms in the male rats, Mr. Risotto noted that the control group had significantly elevated acinus hyperplasia, a possible preneoplastic lesion, affecting nearly $40 \%$ of the control animals. The high background rate observed in the study confirmed the higher sensitivity of the Hsd:Sprague Dawley ${ }^{\circledR} \mathrm{SD}^{\circledR}$ rats compared to other rat strains, and more significantly, to humans. Mr. Risotto also observed that NTP used a smaller size criterion for classifying pancreatic acinar cell neoplasms than previous perfluorooctanoic acid studies. He stated that the draft report does not provide an explanation for why NTP reduced the lesion criteria, or the potential impact such a reduction may have on the findings. Mr. Risotto stated that given the flat dose response for acinar cell neoplasms and high rate of preneoplastic hyperplasia in the control group, NTP should further consider the pancreatic results in the male rats, particularly given the likely contribution of peroxisome proliferator- 
activated receptor alpha (PPAR $\alpha$ ) to tumor formation. Mr. Risotto questioned the relevance of the male rat findings to human risk assessment. He said that ACC was unable to find additional information in the draft report on the nature of the toxicity that caused NTP to restart the male portion of the study. He added that it is critically important that the committee understand the nature of the unanticipated toxicity and consider its potential significance to the findings in the draft report. Regarding the conclusion about fetal sensitivity to perfluorooctanoic acid exposure, Mr. Risotto observed that the draft report indicates that there were very few significant differences between the groups of animals exposed postweaning-only versus groups with perinatal and postweaning exposure. He noted that the differences observed were sporadic and that the report does not prove a conclusion regarding the potential impact of perinatal exposure yet that is the stated hypothesis for conducting the study. Given that NTP rarely conducts combined perinatal and postweaning chronic studies, Mr. Risotto said that ACC believes the committee should evaluate whether the study results support NTP's central hypothesis. He stated that the report summary suggests NTP does not support the hypothesis.

\section{D.3.4.3. Peer-Review Comments and Panel Discussion}

\section{D.3.4.3.1. First Reviewer - Dr. Michael Elwell}

Dr. Elwell said that both studies were well-designed, nicely presented, and NTP clearly stated the results. Dr. Elwell requested further discussion of why the proposed level of carcinogenic activity for pancreatic neoplasms in females does not also apply to the liver carcinoma findings. He said the rationale for the pancreas acinar neoplasm increases as "some evidence" in females appears to be based on the current and historical control data, and association with the finding of "clear evidence" in males. He felt that the rationale could apply to the female liver neoplasm conclusion as well. Dr. Elwell requested discussion of why NTP did not consider the uterine carcinomas "equivocal." Dr. Elwell asked about the relationship of the extended and standard evaluations on the incidence of adenoma and adenocarcinoma in the uterus.

In response to Dr. Elwell's comments, Dr. Blystone indicated that:

- NTP applied a call of some evidence of carcinogenic activity to the adenomas and adenocarcinomas in the pancreas in females since they were present in the highest dose group and considered a rare lesion. However, in the liver, there was only a marginal increase in the incidence of hepatocellular carcinomas in females and no change in the incidence of adenomas.

- NTP used a weight of evidence approach to determine that uterine adenocarcinomas might have been related to exposure.

- NTP found most of the uterine adenocarcinomas after the new sectioning and extended evaluation.

\section{D.3.4.3.2. Second Reviewer-Dr. Gabriele Ludewig}

Dr. Ludewig agreed that NTP executed and described the studies very well. She noted that due to the interest in the results for human risk assessment, the introduction should be perfectly clear as to the limitations of the study. Dr. Ludewig suggested that NTP should clearly state the reference to the perfluorooctanoic acid half-life in female rats, which is measured in hours, versus the halflife in humans, which is measured in years, in the introduction to prevent a false assumption of safety from the high dose that was used. Dr. Ludewig recommended clarifying what type of 
"overt toxicity" NTP observed in males in Study \#1. Dr. Ludewig suggested they add a statement to the discussion as to whether they considered/analyzed ossification and changes in bone morphology since regulatory values in the United States are based on these findings. Dr. Ludewig recommended emphasizing in the report that the PPAR $\alpha$ pathway, which NTP mentions in the report, is not relevant to humans. The CAR pathway and any observation of its activation should be discussed. Dr. Ludewig said NTP should clearly state that the adult exposure included some developmental exposure during sexual maturation since the rats do not fully develop until PND 90. She noted this is important since the hypothesis was to test whether there was an influence of developmental exposure. Dr. Ludewig pointed out that NTP did not mention fecal excretion. Dr. Ludewig stressed that they clearly state the study limitations, especially since the short half-life in rodents is thought to be due to specific transporters present in the kidneys and other organs which may have influenced organ-specific concentrations of PFOA. Dr. Ludewig reported that NTP should cite recently published studies on perfluorooctanoic acid, glucose levels, and liver toxicity to support the findings that there is some liver toxicity.

- Dr. Blystone indicated that NTP would consider clarifying some of the language and adding statements to the report based on her suggestions. This may include additional information on the differences in perfluorooctanoic acid elimination between rodents and humans, a statement about bone morphology findings, and highlighting the point that exposure occurred during sexual maturation.

\section{D.3.4.3.3. Third Reviewer-Dr. Wendy Halpern}

Dr. Halpern indicated that NTP clearly presented and described the findings in the draft report. Dr. Halpern suggested adding more information to the discussion section, in a similar manner to the introduction, that highlights the potential mechanisms of these findings. For instance, the discussion could address the fact that previous carcinogenicity studies identified interstitial cell tumors in male rats as potentially related to perfluorooctanoic acid exposure, which NTP did not identify in this study. Dr. Halpern requested more discussion on the potential immunomodulatory activity as indicated by the decreased spleen and thymus weights. Dr. Halpern suggested expansion of the interim necropsy results, particularly the effect on liver weights. She noted that the biggest challenge in interpreting the study results is the exposure differences, both between rats and humans and between male and female rats. For instance, if testosterone is the driver for exposure differences in males, it is hard to interpret the exposure relationship during development when testosterone is still low in male pups and where female pups were given a higher dose based on exposure differences in adult rats. Dr. Halpern agreed that the decreased body weight and hepatic findings in the males in the initial 16-week necropsy warranted a change in dose administration. However, it is difficult to distinguish the sex-related from potential study-related differences in hepatocellular carcinoma incidence, especially with a small absolute magnitude of difference. Dr. Halpern noted that in almost every parameter evaluated, perinatal exposure seemed to have minimal or no effect, with the singular exception of a numerical increase in hepatocellular carcinomas in male rats exposed to 300/80 ppm in Study \#2. She did not think the overall data supports that perinatal exposure drives this finding since there was a numerically similar incidence of hepatocellular carcinomas in the female rats and because of the potential linkage of these neoplasms to PPAR $\alpha$. She noted that she did not see a difference with perinatal exposure in either liver weights, acyl-CoA activation, or any other parameter that would suggest that PPAR $\alpha$ induction was different. She did not think this finding was clearly 
related or dependent on perinatal exposure, which goes back to the hypothesis presented. Dr. Halpern indicated that her main question was whether this was a developmentally sensitive effect given that male rats had the same exposure as female rats based on the kinetic data and these findings were not present in female rats.

In response to Dr. Halpern's comments, Dr. Blystone indicated that:

- NTP phrased the conclusion statements as they were because they limited the response to that one finding and, since perinatal exposure may by an influence, it was not an outright rejection of the hypothesis.

- NTP did not observe differences in liver weights or acyl-CoA oxidase activity. He noted that there might be other mechanisms at play besides increased PPAR $\alpha$ via acyl-CoA activation, such as the constitutive androstane receptor (CAR) pathway. While CAR activity has been shown in other studies, NTP did not evaluate it in this study.

- NTP would consider clarifying various points in the report based on Dr. Halpern's suggestions such as the exposure concentration differences between this study and concentrations used previously, the role sexual maturation may play in the exposure differences, and details regarding spleen and thyroid weights.

In a follow-up statement, Dr. Halpern said it was her impression from reading the report that NTP did not expect that male and female perinatal exposures would have differed, yet they only saw hepatocellular carcinomas in the males, not the females.

- Dr. Blystone confirmed Dr. Halpern's statement.

\section{D.3.4.4. Panel Discussion}

Dr. Cattley expressed concern that there was not sufficient evidence to conclude that there was an influence of perinatal exposure. For instance, the hepatocellular carcinoma response was so weak that there was not much of a window to detect any increase that might occur without any perinatal exposure. In addition, there was no effect on the incidence of hepatocellular adenomas with perinatal exposure. He noted that the report appropriately combined the incidence of hepatocellular adenomas and hepatocellular carcinomas since NTP considered adenomas to be the precursor lesion and can potentially progress to carcinomas. He indicated that he was struggling with the hypothesis about the impact of perinatal exposure on the incidence of hepatocellular neoplasia in the study.

- Dr. Blystone confirmed that the incidence of adenomas did not appear different between animals with and without perinatal exposure. He remarked that although the strength of response was not strong, the rarity of the lesion and the fact that the liver responded to the chemical led NTP to make this conclusion.

In a follow-up statement, Dr. Cattley indicated that he was still hesitant to conclude that there was a perinatal effect in this study. 


\section{D.3.4.5. Vote on NTP Conclusions}

\section{D.3.4.5.1. Male Hsd:Sprague Dawley ${ }^{\circledR} S D^{\circledR}$ rats}

Dr. Cattley called for a motion from the panel to approve the conclusions as written.

Dr. Ludewig so moved, but there was no second to the motion. Dr. Cattley called for a motion from the panel to approve the first two bullets as written and delete the third bullet, and the panel would consider adding a replacement third bullet. Dr. Halpern so moved and Dr. Ludewig seconded the motion. The panel voted unanimously (4 yes, 0 no, 0 abstentions) to approve the first two bullets of the conclusion. Dr. Cattley called for a motion to add a third bullet. Following an extensive discussion, the panel proposed the third bullet read, "The additional effect of perinatal exposure in combination with postnatal exposure was uncertain and limited to the observation of hepatocellular carcinomas." Dr. Halpern moved for the approval of the third bullet. Dr. Ludewig seconded the motion. The panel voted unanimously (4 yes, 0 no, 0 abstentions) to approve the proposed third bullet.

\section{D.3.4.5.2. Female Hsd:Sprague Dawley ${ }^{\circledR} S D^{\circledR}$ rats}

Dr. Cattley called for a motion from the panel to approve the conclusions as written. Dr. Elwell so moved and Dr. Ludewig seconded the motion. The panel voted unanimously (4 yes, 0 no, 0 abstentions) to approve the conclusions as written.

\section{D.3.5. Closing Remarks on the Draft Reports}

Dr. Cattley welcomed additional panel comments on the draft reports. There were no additional comments.

Closing the meeting, Dr. Maull thanked all the peer-review panelists.

Dr. Cattley added his thanks to the NTP staff and the panel members for their efforts.

Dr. Cattley adjourned the meeting at 1:15 p.m. EDT on December 12, 2019. 


\section{Appendix E. Supplemental Data}

Tables with supplemental data can be found here: https://doi.org/10.22427/NTP-DATA-TR598.

\section{E.1. Study 1: Two-year Study in Females and 16-week Interim Evaluation in Males and Females}

\section{E.1.1. Sixteen-week Interim Evaluation in Males and Females}

E01 - Animal Removal Summary by Treatment Group

E02 - Animals Removed from Experiment

E05 - Clinical Observations Summary

E08 - Feed Water and Compound Consumption Table

P03 - Incidence Rates of Non-Neoplastic Lesions by Anatomic Site

P04 - Neoplasms by Individual Animal

P05 - Incidence Rates of Neoplasms by Anatomic Site (Systemic Lesions Abridged)

P09 - Non-Neoplastic Lesions by Individual Animal

P10 - Statistical Analysis of Non-Neoplastic Lesions - Females 0-0, 0-300, 0-1000

P10 - Statistical Analysis of Non-Neoplastic Lesions - Females 0-0, 150-300, 300-1000

P10 - Statistical Analysis of Non-Neoplastic Lesions - Females 0-1000, 300-1000

P10 - Statistical Analysis of Non-Neoplastic Lesions - Females 0-300, 150-300

P10 - Statistical Analysis of Non-Neoplastic Lesions - Males 0-0, 0-150, 0-300

P10 - Statistical Analysis of Non-Neoplastic Lesions - Males 0-0, 150-150, 300-300

P10 - Statistical Analysis of Non-Neoplastic Lesions - Males 0-150, 150-150

P10 - Statistical Analysis of Non-Neoplastic Lesions - Males 0-300, 300-300

P14 - Individual Animal Pathology Data

P17 - Neoplasms by Individual Animal (Systemic Lesions Abridged)

P18 - Incidence Rates of Non-Neoplastic Lesions by Anatomic Site with Average Severity Grades

PA06 - Organ Weights Summary

PA41 - Clinical Chemistry Summary

PA45 - Liver Special Studies Summary 
PA48 - Tissue Concentration Summary

R02 - Reproductive Performance Summary

\section{E.1.2. Two-year Study in Females}

E01 - Animal Removal Summary by Treatment Group

E02 - Animals Removed from Experiment

E03 - Growth Curves - litter (0-0, 0-150, 0-300) male

E03 - Growth Curves - litter (0-0, 0-300, 0-1000) female

E03 - Growth Curves - litter (0-0, 150-150, 300-300) male

E03 - Growth Curves - litter (0-0, 150-300, 300-1000) female

E03 - Growth Curves - litter (0-1000, 300-1000) female

E03 - Growth Curves - litter (0-150, 150-150) male

E03 - Growth Curves - litter (0-300, 150-300) female

E03 - Growth Curves - litter (0-300, 300-300) male

E04 - Mean Body Weights and Survival Table litter (0-0, 0-300, 0-1000) female

E04 - Mean Body Weights and Survival Table litter (0-0, 150-300, 300-1000) female

E04 - Mean Body Weights and Survival Table litter (0-0, 0-150, 0-300) male

E04 - Mean Body Weights and Survival Table litter (0-0, 150-150, 300-300) male

E04 - Mean Body Weights and Survival Table litter (0-1000, 300-1000) female

E04 - Mean Body Weights and Survival Table litter (0-150, 150-150) male

E04 - Mean Body Weights and Survival Table litter (0-300, 150-300) female

E04 - Mean Body Weights and Survival Table litter (0-300, 300-300) male

E05 - Clinical Observations Summary

E08 - Feed Water and Compound Consumption Table

F0 Female Harlan Sprague Dawley Rats Post-Cull Pup Body Weights

F0 Female Harlan Sprague Dawley Rats Gestational Body and Body Weight Gains

F0 Female Harlan Sprague Dawley Rats Gestational and Lactational Chemical Consumption

F0 Female Harlan Sprague Dawley Rats Gestational and Lactational Food Consumption

F0 Female Harlan Sprague Dawley Rats Lactational Body and Body Weight Gains 
F0 Litter Data Analysis in Female Harlan Sprague Dawley Rats: Live Litter Size and Survival F0 Litter Data Analysis in Female Harlan Sprague Dawley Rats: PND 1 Data P03 - Incidence Rates of Non-Neoplastic Lesions by Anatomic Site P04 - Neoplasms by Individual Animal P05 - Incidence Rates of Neoplasms by Anatomic Site (Systemic Lesions Abridged) P08 - Statistical Analysis of Primary Tumors - Uterine 0-0 0-300 0-1000 P08 - Statistical Analysis of Primary Tumors - Uterine 0-0 150-300 300-1000 P08 - Statistical Analysis of Primary Tumors - Uterine 0-1000 300-1000 P08 - Statistical Analysis of Primary Tumors - Uterine 0-300 150-300 P08 - Statistical Analysis of Primary Tumors - litter (0-0, 0-300, 0-1000) P08 - Statistical Analysis of Primary Tumors - litter (0-0, 150-300, 300-1000) P08 - Statistical Analysis of Primary Tumors - litter (0-1000, 300-1000)

P08 - Statistical Analysis of Primary Tumors - litter (0-300, 150-300)

P09 - Non-Neoplastic Lesions by Individual Animal

P10 - Statistical Analysis of Non-Neoplastic Lesions - Uterine 0-0 0-300 0-1000

P10 - Statistical Analysis of Non-Neoplastic Lesions - Uterine 0-0 150-300 300-1000

P10 - Statistical Analysis of Non-Neoplastic Lesions - Uterine 0-1000 300-1000

P10 - Statistical Analysis of Non-Neoplastic Lesions - Uterine 0-300 150-300

P10 - Statistical Analysis of Non-Neoplastic Lesions - litter (0-0, 0-300, 0-1000)

P10 - Statistical Analysis of Non-Neoplastic Lesions - litter (0-0, 150-300, 300-1000)

P10 - Statistical Analysis of Non-Neoplastic Lesions - litter (0-1000, 300-1000)

P10 - Statistical Analysis of Non-Neoplastic Lesions - litter (0-300, 150-300)

P11 - Statistical Analysis of Survival Data - litter (0-0, 0-300, 0-1000)

P11 - Statistical Analysis of Survival Data - litter (0-0, 150-300, 300-1000)

P11 - Statistical Analysis of Survival Data - litter (0-1000, 300-1000)

P11 - Statistical Analysis of Survival Data - litter (0-300, 150-300)

P14 - Individual Animal Pathology Data

P17 - Neoplasms by Individual Animal (Systemic Lesions Abridged) 
P18 - Incidence Rates of Non-Neoplastic Lesions by Anatomic Site with Average Severity Grades

P18 - Incidence Rates of Non-Neoplastic Lesions by Anatomic Site with Average Severity Grades - Uterine Hyperplasia

P40 - Survival Curves - 0-0, 0-300, 0-1000

P40 - Survival Curves - 0-0, 150-300, 300-1000

P40 - Survival Curves - 0-1000, 300-1000

P40 - Survival Curves - 0-300, 150-300

P40 - Survival Curves - All Treatments

\section{E.2. Study 2: Two-year Study in Males with 16-week Interim Evaluation}

\section{E.2.1. Sixteen-week Interim Evaluation in Males}

E01 - Animal Removal Summary by Treatment Group

E02 - Animals Removed from Experiment

E05 - Clinical Observations Summary

E08 - Feed Water and Compound Consumption Table

P03 - Incidence Rates of Non-Neoplastic Lesions by Anatomic Site

P04 - Neoplasms by Individual Animal

P05 - Incidence Rates of Neoplasms by Anatomic Site (Systemic Lesions Abridged)

P09 - Non-Neoplastic Lesions by Individual Animal

P10 - Statistical Analysis of Non-Neoplastic Lesions - Males 0-0, 0-20, 0-40, 0-80

P10 - Statistical Analysis of Non-Neoplastic Lesions - Males 0-0, 300-0

P10 - Statistical Analysis of Non-Neoplastic Lesions - Males 0-20, 300-20

P10 - Statistical Analysis of Non-Neoplastic Lesions - Males 0-40, 300-40

P10 - Statistical Analysis of Non-Neoplastic Lesions - Males 0-80, 300-80

P10 - Statistical Analysis of Non-Neoplastic Lesions - Males 300-0, 300-20, 300-40, 300-80

P14 - Individual Animal Pathology Data

P17 - Neoplasms by Individual Animal (Systemic Lesions Abridged)

P18 - Incidence Rates of Non-Neoplastic Lesions by Anatomic Site with Average Severity Grades 
PA06 - Organ Weights Summary

PA41 - Clinical Chemistry Summary

PA45 - Liver Special Studies Summary

PA48 - Tissue Concentration Summary

R02 - Reproductive Performance Summary

\section{E.2.2. Two-year Study in Males}

E01 - Animal Removal Summary by Treatment Group

E02 - Animals Removed from Experiment

E03 - Growth Curves - litter (0-0, 0-20, 0-40, 0-80)

E03 - Growth Curves - litter (0-0, 300-0)

E03 - Growth Curves - litter (0-20, 300-20)

E03 - Growth Curves - litter (0-40, 300-40)

E03 - Growth Curves - litter (0-80, 300-80)

E03 - Growth Curves - litter (300-0, 300-20, 300-40, 300-80)

E04 - Mean Body Weights and Survival Table litter (0-0, 0-20, 0-40, 0-80)

E04 - Mean Body Weights and Survival Table litter (0-0, 300-0)

E04 - Mean Body Weights and Survival Table litter (0-20, 300-20)

E04 - Mean Body Weights and Survival Table litter (0-40, 300-40)

E04 - Mean Body Weights and Survival Table litter (0-80, 300-80)

E04 - Mean Body Weights and Survival Table litter (300-0, 300-20, 300-40, 300-80)

E05 - Clinical Observations Summary

E08 - Feed Water and Compound Consumption Table

F0 Female Harlan Sprague Dawley Rats Gestational Body and Body Weight Gains

F0 Female Harlan Sprague Dawley Rats Gestational and Lactational Chemical Consumption

F0 Female Harlan Sprague Dawley Rats Gestational and Lactational Food Consumption

F0 Female Harlan Sprague Dawley Rats Lactational Body and Body Weight Gains

F0 Litter Data Analysis in Female Harlan Sprague Dawley Rats: Male Pup Body Weight F0 Litter Data Analysis in Female Harlan Sprague Dawley Rats: PND 1 Data 
F0 Litter Data Analysis in Female Harlan Sprague Dawley Rats: PND 4 Data P03 - Incidence Rates of Non-Neoplastic Lesions by Anatomic Site P04 - Neoplasms by Individual Animal

P05 - Incidence Rates of Neoplasms by Anatomic Site (Systemic Lesions Abridged)

P08 - Statistical Analysis of Primary Tumors - litter (0-0, 0-20, 0-40, 0-80

P08 - Statistical Analysis of Primary Tumors - litter (0-0, 300-0)

P08 - Statistical Analysis of Primary Tumors - litter (0-20, 300-20)

P08 - Statistical Analysis of Primary Tumors - litter (0-40, 300-40)

P08 - Statistical Analysis of Primary Tumors - litter (0-80, 300-80)

P08 - Statistical Analysis of Primary Tumors - litter (300-0, 300-40, 300-60, 300-80)

P09 - Non-Neoplastic Lesions by Individual Animal

P10 - Statistical Analysis of Non-Neoplastic Lesions - litter (0-0, 0-20, 0-40, 0-80)

P10 - Statistical Analysis of Non-Neoplastic Lesions - litter (0-0, 300-0)

P10 - Statistical Analysis of Non-Neoplastic Lesions - litter (0-20, 300-20)

P10 - Statistical Analysis of Non-Neoplastic Lesions - litter (0-40, 300-40)

P10 - Statistical Analysis of Non-Neoplastic Lesions - litter (0-80, 300-80)

P10 - Statistical Analysis of Non-Neoplastic Lesions - litter (300-0, 300-20, 300-40, 300-80)

P11 - Statistical Analysis of Survival Data - litter (0-0, 0-20, 0-40, 0-80)

P11 - Statistical Analysis of Survival Data - litter (0-0, 300-0)

P11 - Statistical Analysis of Survival Data - litter (0-20, 300-20)

P11 - Statistical Analysis of Survival Data - litter (0-40, 300-40)

P11 - Statistical Analysis of Survival Data - litter (0-80, 300-80)

P11 - Statistical Analysis of Survival Data - litter (300-0, 300-20, 300-40, 300-80)

P14 - Individual Animal Pathology Data

P17 - Neoplasms by Individual Animal (Systemic Lesions Abridged)

P18 - Incidence Rates of Non-Neoplastic Lesions by Anatomic Site with Average Severity Grades

P40 - Survival Curves 0-0, 0-20, 0-40, 0-80

P40 - Survival Curves 0-0, 300-0 
Perfluorooctanoic Acid, NTP TR 598

P40 - Survival Curves 0-20, 300-20

P40 - Survival Curves 0-40, 300-40

P40 - Survival Curves 0-80, 300-80

P40 - Survival Curves 300-0, 300-20, 300-40, 300-80

P40 - Survival Curves All Treatment Groups 


\section{Appendix F. Revision Listing}

\section{F.1. 2020 Erratum}

An error was identified in the NTP Technical Report on the Toxicology and Carcinogenesis Studies of Perfluorooctanoic Acid (CASRN 335-67-1) Administered in Feed to Sprague Dawley (Hsd:Sprague Dawley ${ }^{\circledR} S D^{\circledR}$ ) Rats (Technical Report 598). The survival rates of female rats reported in the summary table were changed to reflect those in the corresponding results tables. [May 22, 2020]

The corrections made as part of the 2020 erratum, including the page numbers, are specified below.

\section{Summary Table, page $\mathrm{xx}$}

Survival rates were corrected as outlined below:

\begin{tabular}{|c|c|c|}
\hline $\begin{array}{l}\text { Summary of the Two-ye } \\
\text { and without Perinatal E }\end{array}$ & $\begin{array}{l}\text { r Toxicology and Carcinogenesi } \\
\text { posure }\end{array}$ & lies of Perfluorooctanoic Acid \\
\hline & $\begin{array}{c}\text { Male } \\
\text { Sprague Dawley Rats }\end{array}$ & $\begin{array}{c}\text { Female } \\
\text { Sprague Dawley Rats }\end{array}$ \\
\hline Concentrations in Feed & & \\
\hline Postweaning & $0 / 0,0 / 20,0 / 40,0 / 80 \mathrm{ppm}$ & $0 / 0,0 / 300,0 / 1,000 \mathrm{ppm}$ \\
\hline Perinatal + Postweaning & $300 / 0,300 / 20,300 / 40,300 / 80 \mathrm{ppm}$ & $0 / 0,150 / 300,300 / 1,000 \mathrm{ppm}$ \\
\hline Survival Rates & & \\
\hline Postweaning & $36 / 50,42 / 50, \underline{35} 34 / 50, \underline{37} 36 / 50$ & $23 / 50, \underline{28} 26 / 50,23 / 50$ \\
\hline Perinatal + Postweaning & $\underline{35} 34 / 50,38 / 50,38 / 50,39 / 50$ & $23 / 50,32 / 50, \underline{23} z 22 / 50$ \\
\hline
\end{tabular}

\section{F.2. 2022 Revisions}

Errors were identified in the NTP Technical Report on the Toxicology and Carcinogenesis Studies of Perfluorooctanoic Acid (CASRN 335-67-1) Administered in Feed to Sprague Dawley (Hsd:Sprague Dawley ${ }^{\circledR} S D^{\circledR}$ ) Rats (Technical Report 598). For the uterine findings, changes were made to the number of animals in the $0 / 1,000 \mathrm{ppm}$ group with a neoplasm (overall rates) and the number of litters with animals with a neoplasm (litter rates). One animal with a squamous cell carcinoma in the $0 / 1,000$ ppm group was inadvertently combined in the adenocarcinoma analysis of the extended evaluation. The number of animals examined during the standard, extended, and standard or extended (combined) evaluations was also corrected in the $0 / 300,0 / 1,000$, and 300/1,000 ppm groups. Due to these corrections in the incidence data, statistical analysis was rerun, and the Rao-Scott-adjusted Poly-3 test $\mathrm{p}$ values were updated for all exposure groups. As a result, the trend tests for uterine adenocarcinoma are no longer statistically significant $(\mathrm{p}>0.05)$ for the extended and the standard or extended (combined) evaluations. In addition, the pairwise comparisons of adenocarcinoma incidence between the control and the $0 / 1,000$ ppm groups are now $p=0.05$ for the extended and the standard or extended (combined) evaluations. The original conclusion that the higher incidence of uterine 
adenocarcinoma may have been related to PFOA exposure (equivocal evidence) is not changed. The corrections made are specified below. [February 1, 2023]

\section{Summary Table, page xxi}

The numbers of rats examined and the overall rates of uterine adenocarcinoma were corrected as outlined below:

\begin{tabular}{|c|c|c|}
\hline \multicolumn{3}{|c|}{ Equivocal Findings } \\
\hline Liver & None & $\begin{array}{l}\text { Postweaning: hepatocellular carcinoma } \\
(1 / 50,1 / 50,3 / 49)\end{array}$ \\
\hline \multirow{3}{*}{ Uterus } & \multirow{3}{*}{ None } & $\begin{array}{l}\text { Perinatal + Postweaning: hepatocellular } \\
\text { carcinoma }(1 / 50,0 / 50,4 / 50)\end{array}$ \\
\hline & & $\begin{array}{l}\text { Postweaning: adenocarcinoma }(1 / 50, \\
5 / \underline{9} 50,8 \underline{8} \text {, } \underline{4} 50)\end{array}$ \\
\hline & & $\frac{\text { Perinatal + Postweaning: adenocarcinoma }}{(1 / 50,3 / 50,5 / 50)}$ \\
\hline
\end{tabular}

\section{Page 48}

The results text was updated as follows to reflect the correct table:

Uterus: In the standard evaluation of the perinatal and/or postweaning exposures, increased incidences of adenocarcinomas of the uterus, compared to the $0 / 0 \mathrm{ppm}$ control group, occurred in the $0 / 300,0 / 1,000,150 / 300$, and 300/1,000 ppm groups (Table 25) (Appendix E).

In the extended evaluation, additional adenocarcinomas were diagnosed in the uteri of exposed groups (Table 25) (Appendix E). The incidences of adenocarcinoma were increased in the $0 / 300$ and $0 / 1,000 \mathrm{ppm}$ groups; the increase in the $0 / 1,000 \mathrm{ppm}$ group was significant. 


\section{Table 25, pages $48-50$}

Tables for the statistical analysis of primary neoplasms in the uterus and statistical analysis of nonneoplastic lesions in the uterus were rerun on March 9, 2022, and March 10, 2022, respectively, to correct for the number of rats examined in the $0 / 300,0 / 1,000$, and $300 / 1,000$ ppm groups. The resulting changes in overall rates, litter rates, and Rao-Scott-adjusted Poly-3 test $\mathrm{p}$ values were made as outlined below:

Table 25. Incidences of Neoplastic and Nonneoplastic Lesions in the Standard and Extended Evaluations of the Uterus in the Two-year Feed Study of Perfluorooctanoic Acid in Female Rats (Study 1)

\begin{tabular}{|c|c|c|c|c|}
\hline & \multirow[b]{2}{*}{$\begin{array}{l}\text { Perinatal } \\
\text { Exposure }\end{array}$} & \multicolumn{3}{|c|}{ Postweaning Exposure } \\
\hline & & $0 \mathrm{ppm}$ & $300 \mathrm{ppm}$ & $1,000 \mathrm{ppm}$ \\
\hline \# & & $50^{a}$ & 50 & $50^{6}$ \\
\hline \multicolumn{5}{|l|}{ Standard Evaluation } \\
\hline \multirow[t]{3}{*}{ Hyperplasia, Atypicals } & 0 ppm & $0 / \underline{50}$ & $0 / 49$ & $0 / 49$ \\
\hline & $150 \mathrm{ppm}$ & - & $0 / 50$ & - \\
\hline & $300 \mathrm{ppm}$ & - & - & $\underline{0 / 50}$ \\
\hline \multicolumn{5}{|l|}{ Adenomab } \\
\hline 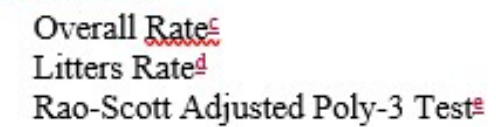 & $0 \mathrm{ppm}$ & $\begin{array}{c}0 / 50(0 \%) \\
0 / 32(0 \%) \\
\mathrm{p}=0.7173 \mathrm{~N} \text { ef }\end{array}$ & $\begin{array}{c}1 / 4950(2 \%) \\
1 / 29(3 \%) \\
p=0.5913\end{array}$ & $\begin{array}{c}0 / 4950(0 \%) \\
0 / 31(0 \%) \\
(\mathrm{e})\end{array}$ \\
\hline $\begin{array}{l}\text { Overall Rate } \\
\text { Litters Rate } \\
\text { Rao-Scott Adjusted Poly-3 Test }\end{array}$ & $150 \mathrm{ppm}$ & - & $\begin{array}{c}0 / 50 \\
0 / 29 \\
\text { fg } \\
-5\end{array}$ & - \\
\hline $\begin{array}{l}\text { Overall Rate } \\
\text { Litters Rate } \\
\text { Rao-Scott Adjusted Poly-3 Test }\end{array}$ & $300 \mathrm{ppm}$ & - & - & $\begin{array}{l}0 / 50 \\
0 / 30\end{array}$ \\
\hline \multicolumn{5}{|l|}{ Adenosarcinomah } \\
\hline $\begin{array}{l}\text { Overall Rate } \\
\text { Litters Rate } \\
\text { Rao-Scott Adjusted Poly-3 Test }\end{array}$ & $0 \mathrm{ppm}$ & $\begin{aligned} & 0 / 50(0 \%) \\
& 0 / 32(0 \%) \\
\mathrm{p}= & 0.0498 / 0.512^{\text {is }}\end{aligned}$ & 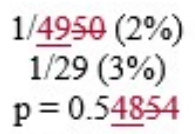 & $\begin{array}{c}4 / 4950(8 \%) \\
4 / 31(13 \%) \\
p=0.102\end{array}$ \\
\hline $\begin{array}{l}\text { Overall Rate } \\
\text { Litters Rate } \\
\text { Rao-Scott Adjusted Poly-3 Test }\end{array}$ & $150 \mathrm{ppm}$ & - & $\begin{array}{l}2 / 50(4 \%) \\
2 / 29(7 \%) \\
\mathrm{p}=0.285\end{array}$ & - \\
\hline $\begin{array}{l}\text { Overall Rate } \\
\text { Litters Rate } \\
\text { Rao-Scott Adjusted Poly-3 Test }\end{array}$ & $300 \mathrm{ppm}$ & - & - & $\begin{array}{l}1 / 50(2 \%) \\
1 / 30(3 \%) \\
p=0.477\end{array}$ \\
\hline \multicolumn{5}{|c|}{ Adenoma or Adenocarcinoma, (Combined)i } \\
\hline $\begin{array}{l}\text { Overall Rate } \\
\text { Litters Rate } \\
\text { Rao-Scott Adjusted Poly-3 Test }\end{array}$ & $0 \mathrm{ppm}$ & $\begin{array}{c}0 / 50(0 \%) \\
0 / 32(0 \%) \\
p=0.0686 / 0.512\end{array}$ & $\begin{array}{l}2 / 4950(4 \%) \\
2 / 29(7 \%) \\
p=0.28592\end{array}$ & $\begin{array}{c}4 / 4950(8 \%) \\
4 / 31(13 \%) \\
p=0.086\end{array}$ \\
\hline $\begin{array}{l}\text { Overall Rate } \\
\text { Litters Rate } \\
\text { Rao-Scott Adjusted Poly-3 Test }\end{array}$ & $150 \mathrm{ppm}$ & - & $\begin{array}{l}2 / 50(4 \%) \\
2 / 29(7 \%) \\
p=0.285\end{array}$ & - \\
\hline $\begin{array}{l}\text { Overall Rate } \\
\text { Litters Rate } \\
\text { Rao-Scott Adjusted Poly-3 Test }\end{array}$ & $300 \mathrm{ppm}$ & - & - & $\begin{array}{l}1 / 50(2 \%) \\
1 / 30(3 \%) \\
p=0.477\end{array}$ \\
\hline
\end{tabular}


Perfluorooctanoic Acid, NTP TR 598

\begin{tabular}{|c|c|c|c|c|}
\hline & \multirow[b]{2}{*}{$\begin{array}{l}\text { Perinatal } \\
\text { Exposure } \\
\end{array}$} & \multicolumn{3}{|c|}{ Postweaning Exposure } \\
\hline & & $0 \mathrm{ppm}$ & $300 \mathrm{ppm}$ & $1,000 \mathrm{ppm}$ \\
\hline \multicolumn{5}{|l|}{ Extended Evaluation } \\
\hline \multirow[t]{3}{*}{ Hyperplasia, Atypical } & 0 ppm & $3 / 50$ & $4 / 49$ & $3 / 48$ \\
\hline & $150 \mathrm{ppm}$ & - & $7 / 50$ & - \\
\hline & $300 \mathrm{ppm}$ & - & - & $3 / 48$ \\
\hline \multicolumn{5}{|l|}{ Adenoma } \\
\hline Overall Rate & $0 \mathrm{ppm}$ & $1 / 50(2 \%)$ & $0 / \underline{49} 50(0 \%)$ & $0 / 4850(0 \%)$ \\
\hline Litters Rate & & $1 / 32(3 \%)$ & $\overline{0 / 29}(0 \%)$ & $0 / 301(0 \%)$ \\
\hline Rao-Scott Adjusted Poly-3 Test & & $\mathrm{p}=\frac{0.52112 \mathrm{~N}}{\mathrm{~N}} / 0.51 \underline{8} 3$ & $\mathrm{p}=0.57 \underline{8} 6 \mathrm{~N}$ & $\mathrm{p}=0.57 \underline{9} 3 \mathrm{~N}$ \\
\hline Overall Rate & $150 \mathrm{ppm}$ & - & $0 / 50(0 \%)$ & - \\
\hline Litters Rate & & & $0 / 29(0 \%)$ & \\
\hline Rao-Scott Adjusted Poly-3 Test & & & $\mathrm{p}=0.576 \underline{4} \mathrm{~N}$ & \\
\hline $\begin{array}{l}\text { Overall Rate } \\
\text { Litters Rate } \\
\text { Rao-Scott Adjusted Poly-3 Test }\end{array}$ & $300 \mathrm{ppm}$ & - & - & $\begin{array}{c}0 / 4850(0 \%) \\
0 / 30(0 \%) \\
p=0.57 \underline{8} 3 \mathrm{~N}\end{array}$ \\
\hline \multicolumn{5}{|l|}{ Adenocarcinoma } \\
\hline $\begin{array}{l}\text { Overall Rate } \\
\text { Litters Rate } \\
\text { Rao-Scott Adjusted Poly-3 Test }\end{array}$ & $0 \mathrm{ppm}$ & $\begin{array}{c}1 / 50(2 \%) \\
1 / 32(3 \%) \\
\mathrm{p}=0.028055 / 0.0894\end{array}$ & $\begin{array}{c}5 / 4950(10 \%) \\
5 / 29(17 \%) \\
p=0.164159\end{array}$ & $\begin{array}{c}8 \underline{8} / 4850(156 \%) \\
\underline{67} / 3100(230 \%) \\
p=0.031050\end{array}$ \\
\hline $\begin{array}{l}\text { Overall Rate } \\
\text { Litters Rate } \\
\text { Rao-Scott Adjusted Poly-3 Test }\end{array}$ & $150 \mathrm{ppm}$ & - & $\begin{array}{l}3 / 50(6 \%) \\
3 / 29(10 \%) \\
p=0.34 \underline{6} 5\end{array}$ & - \\
\hline $\begin{array}{l}\text { Overall Rate } \\
\text { Litters Rate } \\
\text { Rao-Scott Adjusted Poly-3 Test }\end{array}$ & $300 \mathrm{ppm}$ & - & - & $\begin{array}{c}5 / 4850(10 \%) \\
5 / 30(17 \%) \\
p=0.1105\end{array}$ \\
\hline \multicolumn{5}{|c|}{ Adenoma or Adenocarcinoma, (Combined) } \\
\hline $\begin{array}{l}\text { Overall Rate } \\
\text { Litters Rate } \\
\text { Rao-Scott Adjusted Poly-3 Test }\end{array}$ & $0 \mathrm{ppm}$ & $\begin{array}{c}2 / 50(4 \%) \\
2 / 32(6 \%) \\
p=0.052094 / 0.1609\end{array}$ & $\begin{array}{c}5 / 4950(10 \%) \\
5 / 29(17 \%) \\
p=0.2890\end{array}$ & $\begin{array}{c}8 \underline{7 / 4850}(156 \%) \\
\underline{67 / 3} \underline{10}(2 \underline{0} 3 \%) \\
p=0.065102\end{array}$ \\
\hline $\begin{array}{l}\text { Overall Rate } \\
\text { Litters Rate } \\
\text { Rao-Scott Adjusted Poly-3 Test }\end{array}$ & $150 \mathrm{ppm}$ & - & $\begin{array}{c}3 / 50(6 \%) \\
3 / 29(10 \%) \\
p=0.535\end{array}$ & - \\
\hline $\begin{array}{l}\text { Overall Rate } \\
\text { Litters Rate } \\
\text { Rao-Scott Adjusted Poly-3 Test }\end{array}$ & $300 \mathrm{ppm}$ & - & - & $\begin{array}{l}5 / 4850(10 \%) \\
5 / 30(17 \%) \\
p=0.212 \theta\end{array}$ \\
\hline
\end{tabular}


Perfluorooctanoic Acid, NTP TR 598

\begin{tabular}{|c|c|c|c|c|}
\hline & \multirow[b]{2}{*}{$\begin{array}{l}\text { Perinatal } \\
\text { Exposure }\end{array}$} & \multicolumn{3}{|c|}{ Postweaning Exposure } \\
\hline & & 0 ppm & $300 \mathrm{ppm}$ & $1,000 \mathrm{ppm}$ \\
\hline \multicolumn{5}{|c|}{ Standard or Extended Evaluation (Combined) } \\
\hline \multirow{3}{*}{ Hyperplasia, Atypical } & $0 \mathrm{ppm}$ & $3 / 50(2.0)^{\text {ak }}$ & $4 / 49(2.0)$ & $3 / 48 \underline{49}(2.7)$ \\
\hline & $150 \mathrm{ppm}$ & - & $7 / 50(2.1)$ & - \\
\hline & $300 \mathrm{ppm}$ & - & - & $3 / 48 \underline{50}(4.0)$ \\
\hline \multicolumn{5}{|l|}{ Adenoma $^{i}$} \\
\hline $\begin{array}{l}\text { Overall Rate } \\
\text { Litters Rate } \\
\text { Rao-Scott Adjusted Poly-3 Test }{ }^{j}\end{array}$ & $0 \mathrm{ppm}$ & $\begin{array}{c}1 / 50(2 \%) \\
1 / 32(3 \%) \\
\mathrm{p}=0.37 \underline{6} \underline{\mathrm{N}} / 0.513 \mathrm{~N}\end{array}$ & $\begin{array}{l}1 / \underline{49} 50(2 \%) \\
1 / 29(3 \%) \\
\mathrm{p}=0.71 \underline{72} \mathrm{~N}\end{array}$ & $\begin{array}{c}0 / 4950(0 \%) \\
0 / 31(0 \%) \\
p=0.4895 \mathrm{~N}\end{array}$ \\
\hline $\begin{array}{l}\text { Overall Rate } \\
\text { Litters Rate } \\
\text { Rao-Scott Adjusted Poly-3 Test }\end{array}$ & $150 \mathrm{ppm}$ & - & $\begin{array}{l}0 / 50(0 \%) \\
0 / 29(0 \%) \\
\mathrm{p}=0.576 \mathrm{~N}\end{array}$ & - \\
\hline $\begin{array}{l}\text { Overall Rate } \\
\text { Litters Rate } \\
\text { Rao-Scott Adjusted Poly-3 Test }\end{array}$ & $300 \mathrm{ppm}$ & - & - & $\begin{array}{l}0 / 50(0 \%) \\
0 / 30(0 \%) \\
p=0.573 \mathrm{~N}\end{array}$ \\
\hline \multicolumn{5}{|l|}{ Adenocarcinoma ${ }^{\mathrm{m}}$} \\
\hline $\begin{array}{l}\text { Overall Rate } \\
\text { Litters Rate } \\
\text { Rao-Scott Adjusted Poly- } 3 \text { Test }\end{array}$ & $0 \mathrm{ppm}$ & $\begin{array}{c}1 / 50(2 \%) \\
1 / 32(3 \%) \\
\mathrm{p}=0.028054 / 0.094\end{array}$ & $\begin{array}{c}5 / 4950(10 \%) \\
5 / 29(17 \%) \\
p=0.164 \underline{159}\end{array}$ & $\begin{array}{l}8 \underline{87} \underline{49} 50(146 \%) \\
\underline{67 / 31}(\underline{1923} \%) \\
\mathrm{p}=0.031 \underline{050}\end{array}$ \\
\hline $\begin{array}{l}\text { Overall Rate } \\
\text { Litters Rate } \\
\text { Rao-Scott Adjusted Poly-3 Test }\end{array}$ & $150 \mathrm{ppm}$ & - & $\begin{array}{c}3 / 50(6 \%) \\
3 / 29(10 \%) \\
p=0.345\end{array}$ & - \\
\hline $\begin{array}{l}\text { Overall Rate } \\
\text { Litters Rate } \\
\text { Rao-Scott Adjusted Poly-3 Test }\end{array}$ & $300 \mathrm{ppm}$ & - & - & $\begin{array}{l}5 / 50(10 \%) \\
5 / 30(17 \%) \\
p=0.115\end{array}$ \\
\hline \multicolumn{5}{|c|}{ Adenoma or Adenocarcinoma, (Combined) $)^{n}$} \\
\hline $\begin{array}{l}\text { Overall Rate } \\
\text { Litters Rate } \\
\text { Rao-Scott Adjusted Poly-3 Test }\end{array}$ & $0 \mathrm{ppm}$ & $\begin{array}{c}2 / 50(4 \%) \\
2 / 32(6 \%) \\
\mathrm{p}=0.052094 / 0.169\end{array}$ & $\begin{array}{c}5 / 4950(10 \%) \\
5 / 29(17 \%) \\
p=0.2809\end{array}$ & $\begin{array}{l}8 \underline{8} / 4950(146 \%) \\
\underline{67 / 31}(1923 \%) \\
p=0.065101\end{array}$ \\
\hline $\begin{array}{l}\text { Overall Rate } \\
\text { Litters Rate } \\
\text { Rao-Scott Adjusted Poly-3 Test }\end{array}$ & $150 \mathrm{ppm}$ & - & $\begin{array}{c}3 / 50(6 \%) \\
3 / 29(10 \%) \\
p=0.535\end{array}$ & - \\
\hline $\begin{array}{l}\text { Overall Rate } \\
\text { Litters Rate } \\
\text { Rao-Scott Adjusted Poly-3 Test }\end{array}$ & $300 \mathrm{ppm}$ & - & - & $\begin{array}{l}5 / 50(10 \%) \\
5 / 30(17 \%) \\
p=0.220\end{array}$ \\
\hline
\end{tabular}




\section{Table 25, page 50}

Footnotes that were no longer applicable were removed from the table, and the remaining footnotes were edited for clarity and reordered as outlined below:

Pairwise comparisons across perinatal exposures ( $0 / 300$ vs. $150 / 300 \mathrm{ppm}$ and $0 / 1,000 \mathrm{vs} .300 / 1,000 \mathrm{ppm})$ did not show any statistically significant differences.

(e) = value of statistic could not be computed.

anumber of animals with lesion/number of animals with tissue examined microscopically.

${ }^{b} \mathrm{~N}-49$ for the $0 / 1,000 \mathrm{ppm}$ group. $\mathrm{b}$ Historical control incidence for all routes of 2 -vear studies (mean \pm standard deviation): $1 / 150(0.67 \% \pm 1.15 \%)$; range: $0 \%$ to $2 \%$ eNumber of animals with lesion.

dN -49 for the $0 / 300$ ppm group; $N-48$ for the $0 / 1,000$ and $300 / 1,000$ ppm groups.

sumber of animals with neoplasm per number of animals necropsied.

lidumber of litters with animals with neoplasm per number of litters necropsied.

IeBeneath the control incidence is the $p$ value associated with the trend test. Beneath the exposed group incidences are the $p$ values corresponding to pairwise comparisons between the respective control and that exposed group. The Rao-Scott test adjusts the Polv-3 test for within-litter correlation. A negative trend or a lower incidence in an exposure group is indicated by $\mathrm{N}$.

fep value represents the trend for the $0 / 0,0 / 300$, and $0 / 1,000$ ppm groups.

gtNot applicable; no neoplasms in group.

hm=Historical control incidence: $11 / 150(7.33 \% \pm 4.62 \%)$; range: $2 \%$ to $10 \%$.

ifRag-Scott trend values presented as: $\mathrm{p}$ value (postweaning-only exposure groups)/p value (perinatal and postweaning exposure groups).

im Historical control incidence: $12 / 150(8 \% \pm 3.46 \%)$; range: $4 \%$ to $10 \%$.

kh Average severity grade of lesions in affected animals: $1=$ minimal, $2=$ mild, $3=$ moderate, $4=$ marked.

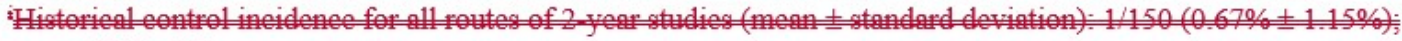

20. $0 \%$ to

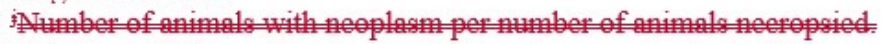

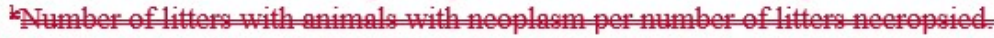

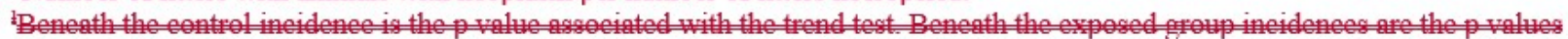

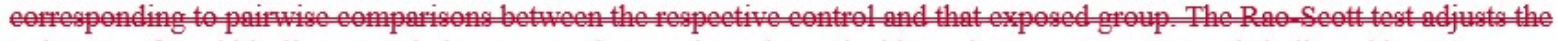

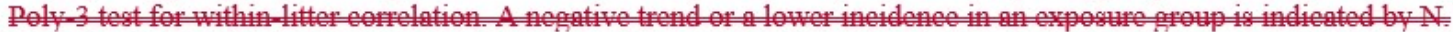

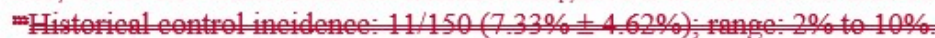

"Hitoried ontrol ineideneo: $12150(8 \% \pm 3.46 \%)$; range: $4 \%$ to $10 \%$ 


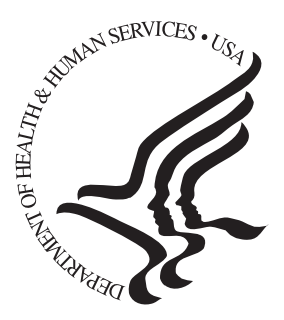

\section{National Toxicology Program}

NTP Central Data Management, MD EC-03

National Institute of Environmental Health Sciences

P.O. Box 12233

Research Triangle Park, NC 27709

http://ntp.niehs.nih.gov 